Fabricio Vasconcelos Branco

\title{
AS MUDANÇAS CLIMÁTICAS E O CLIMA DE ONDAS NO ATLÂNTICO SUL
}

Tese apresentada ao Instituto Oceanográfico da Universidade de São Paulo como parte dos requesitos para obtenção do título de Doutor em Ciências, Programa de Oceanografia, Área de Oceanografia Física.

Orientadora: Prof ${ }^{\mathrm{a}}$. Dr ${ }^{\mathrm{a}}$ Ilana Wainer 

Fabricio Vasconcelos Branco

\section{AS MUDANÇAS CLIMÁTICAS E O CLIMA DE ONDAS NO ATLÂNTICO SUL}

Tese apresentada ao Instituto Oceanográfico da Universidade de São Paulo como parte dos requesitos para obtenção do título de Doutor em Ciências, Programa de Oceanografia, Área de Oceanografia Física.

Orientadora: Prof ${ }^{\mathrm{a}}$. Dr ${ }^{\mathrm{a}}$ Ilana Wainer 
Universidade de São Paulo

Intituto Oceanográfico

\section{AS MUDANÇAS CLIMÁTICAS E O CLIMA DE ONDAS NO ATLÂNTICO SUL}

Fabricio Vasconcelos Branco

Tese apresentada ao Instituto Oceanográfico da Universidade de São Paulo como parte dos requesitos para obtenção do título de Doutor em Ciências, Programa de Oceanografia, Área de Oceanografia Física.

Julgada em 


\section{AGRADECIMENTOS}

Como não esquecer as diversas pessoas e instituições envolvidas direta e indiretamente com este trabalho, ou até mesmo, pessoas que estiveram, estão e estarão presentes em minha vida antes, durante e depois da finalização desta etapa da minha vida profissional? Aqui está um desafio enorme para não ser injusto em esquecer de citar todos os nomes. Este trabalho não se realizaria sem os incentivos do CENPES-PETROBRAS e CAPES. Agradeço as pessoas diretamente envolvidas com este projeto: IlanaWainer, Edmo Campos, Ricardo de Camargo, José Edson Pereira, Bruno Biazeto, Bruno Ferrero, Daniel Moita, Pedro Lopes e Tiago Nicolosi. Aos amigos e sócios Bruno Biazeto e Enzo Todesco que tanto me ajudaram pessoalmente e profissionalmente. Aos professores, também amigos, que sempre me apoiaram em diversas fases da minha vida profissional: Ricardo de Camargo, llana Wainer (minha orientadora), Pedro Dias, Maria Assunção e Edimilson Freitas. Do lado da minha vida pessoal como não agradecer a toda minha família e meus pais Getulio e Nelma. Jamais esquecerei meu grande companheiro de todas as horas José Maurício, minha grande amiga Veruscka Girio, Roberta Cassaniga, Penelope Manetti, Maira Onaga, Maria Carolina, Mariana Duarte, Tiago Santos, Gil Riquerme, Gabiru, Quick, Sica Orthi, Priscila, Gabriel Brito e Gibi. 
Quanto tempo temos antes de voltarem aquelas ondas Que vieram feito gotas em silêncio tão furioso Derrubando homens entre outros animais

Devastando a sede desses matagais Devorando árvores, pensamentos, seguindo a linha do que foi escrito pelo mesmo lábio tão furioso.

E se teu amigo vento não te procurar É porque multidões ele foi arrastar. 


\section{RESUMO}

Modificações nas posições médias dos centros de tempestades intensas assim como nos seus sentidos de propagação estão sendo sugeridas por diversos estudos sobre mudanças climáticas. Este fato pode ser determinante para a geração de ondas sobre os oceanos, e consequentemente para o conhecimento das climatologias de ondas. Na costa brasileira a falta de observações diretas em escala climática justifica o uso de técnicas de modelagem numérica para representação do fenômeno. Este trabalho apresenta resultados de simulações numéricas para caracterizar a climatologia das ondas de superfície e suas correspondentes perspectivas de mudanças para um futuro próximo sobre a região do Atlântico Sudoeste. Uma estratégia complexa de modelagem de ondas global, para assegurar a propagação de swell, e uma grade regional forçada por um ventos superficiais obtidos com um modelo de meso-escala atmosférico foi desenvolvida neste estudo. Os modelos utilizados foram o WAVEWATCH-III e o BRAMS. O período de 1982-1999 foi escolhido para representação do século XX com campos atmosféricos provenientes da REANÁLISE-I do NCEP, os quais são utilizados como controle do experimento. O período de 2030-2049 é investigado com base em dois cenários de projeções futuras CCSM3. Os valores médios de altura significativa para a porção Sudoeste do Atlântico Sul são superestimados no conjunto de simulação histórica do CCSM3; ao se considerar dois pontos de localização sobre a Bacia de Campos e Bacia de Santos, valores máximos do ciclo anual são encontrados durante os meses de outono enquanto que o conjunto referência apresenta valores máximos durante os meses de inverno. $O$ estabelecimento de probabilidades de ocorrência de swell e wind sea revelam que o conjunto CCSM3 superestima a influência de swell gerados remotamente. Em termos das projeções climáticas para as bacias de Campos e Santos, pequenas diferenças nos valores médios de altura significativas aparecem de Maio a Dezembro, quando os resultados sugerem um leve aumento das alturas de ondas para as duas bacias quando comparadas com as respectivas médias do século XX. Por outro lado, a obtenção de séries de tendências durante os anos de 2030-2049 demonstram um padrão variável mas um fato comum aparece nos dois cenários de projeções climáticas: diminuição das alturas de ondas na área de oceano aberto e numa porção da região costeira próxima aos 20S, enquanto a porção sudoeste da região de estudo apresenta um pequeno aumento. Isto não é um desenvolvimento monotônico pois variabilidades interanuais de decadais estão evidentes para os dois cenários com diferentes amplitudes e fases entre elas.

Palavras-chave: Modelagem de Ondas, Climatologia, projeções climáticas, swell . 


\section{ABSTRACT}

Modifications in the mean position of the storm tracks as well as in the direction of propagation of severe storms have been suggested by many studies about climate change. This fact can be determined for the wind-wave generation over the oceans, and consequently for the wave climatology knowledge. In the coast of Brazil, the lack of long term direct observations of wave characteristics leads to the use of numerical modeling techniques to represent the phenomena. This study presents analysis of numerical simulations to characterize the climatology of surface gravity waves and the determined perspectives of changing in the near future for the Western South Atlantic region, with focus on its southern portion, off the southern Brazil coast. A complex strategy of global wave modeling to represent swell propagation associated with regional wave modeling forced by mesoscale winds is adopted; the models employed are WAVEWATCH-III and BRAMS. The period 1982-1999 is used to represent the 20th century with atmospheric fields from NCEP/Reanalysis-I, which results are used as reference. The period 2030-2049 is investigated based on two projected scenarios of the coupled climate model CCSM3. The average significant wave height for the Western South Atlantic is overestimated by the historical run of CCSM3; when considering two locations of interest, Campos and Santos Basins, the maximum values of the annual cycle are found during the autumn, while the reference field presents maximum values during the late winter. The evaluation of probabilities of occurrences of swell and wind sea revealed that CCSM3 overestimated the influence of remotely generated swell for the Western South Atlantic region. In terms of projected scenarios for Campos Basin and Santos Basin, some small differences in the average significant wave height appear from May to December, when the results suggest a small increase of wave height in both locations compared to the correspondent 20th century results. On the other hand, the obtained spatial distribution of trends during the period 2030-2049 shows a variable pattern, but a common feature appears in both projected scenarios of CCSM3: decrease of the wave heights in the open ocean area and part of the shelf around $20^{\circ} \mathrm{S}$, while the southwestern portion of the study region presents a small increase. This is not a monotonic behavior, because interannual and decadal variability are evident in both scenarios, with different amplitudes and phases between them.

Keywords: Wave modeling, climatology, climate projections, swell 


\section{LISTA DE ILUSTRAÇÕES}

\begin{tabular}{l} 
Figura 1 \\
\begin{tabular}{|c|}
\hline Figura esquemática dos resultados de anomalia da temperatura média \\
\hline global, em relação à temperatura média de 1990 a 2009, para dife- \\
\hline rentes cenários, resultados do modelo CCSM3.0. O cenário A2 (ver- \\
\hline melho) representa um futuro pessimista em termos de emissões de \\
\hline gases estufa, enquanto que o cenário B1 (azul) apresentam um fu- \\
\hline turo otimista. http://www.gisclimatechange.org/runSetsHelp.html. \\
\hline
\end{tabular} \\
\hline
\end{tabular}

Figura 2 Figura esquemática dos domínios regionais. O retângulo menor em preto representa o domínio do oceano Atlântico Sudoeste e o retângulo maior o oceano Atlântico Sul. . . . . . . . . . . . . . . . . . . 34

Figura 3 Diagrama de Taylor para as variáveis atmosféricas incluindo tempera-

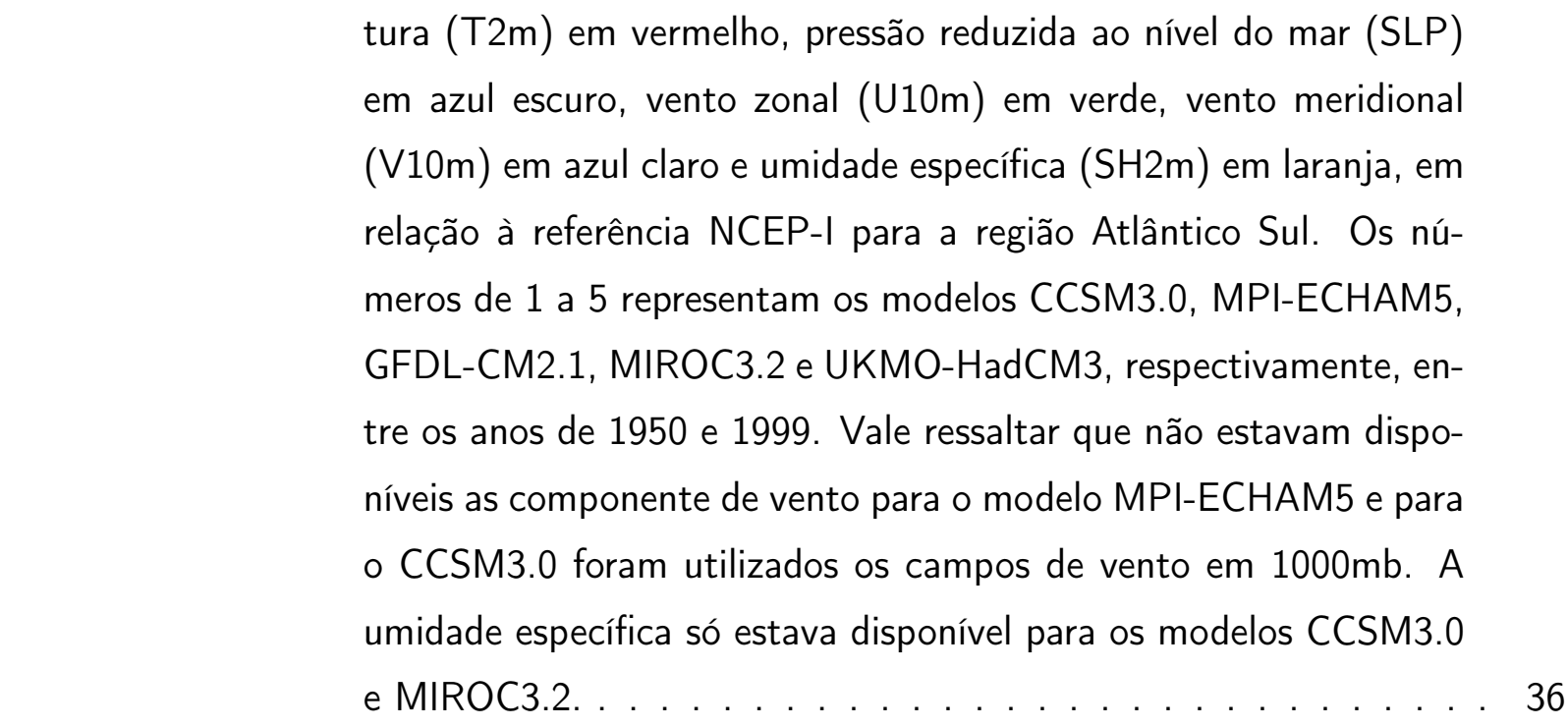

Figura 4 Diagrama de Taylor para as variáveis atmosféricas incluindo tempera-

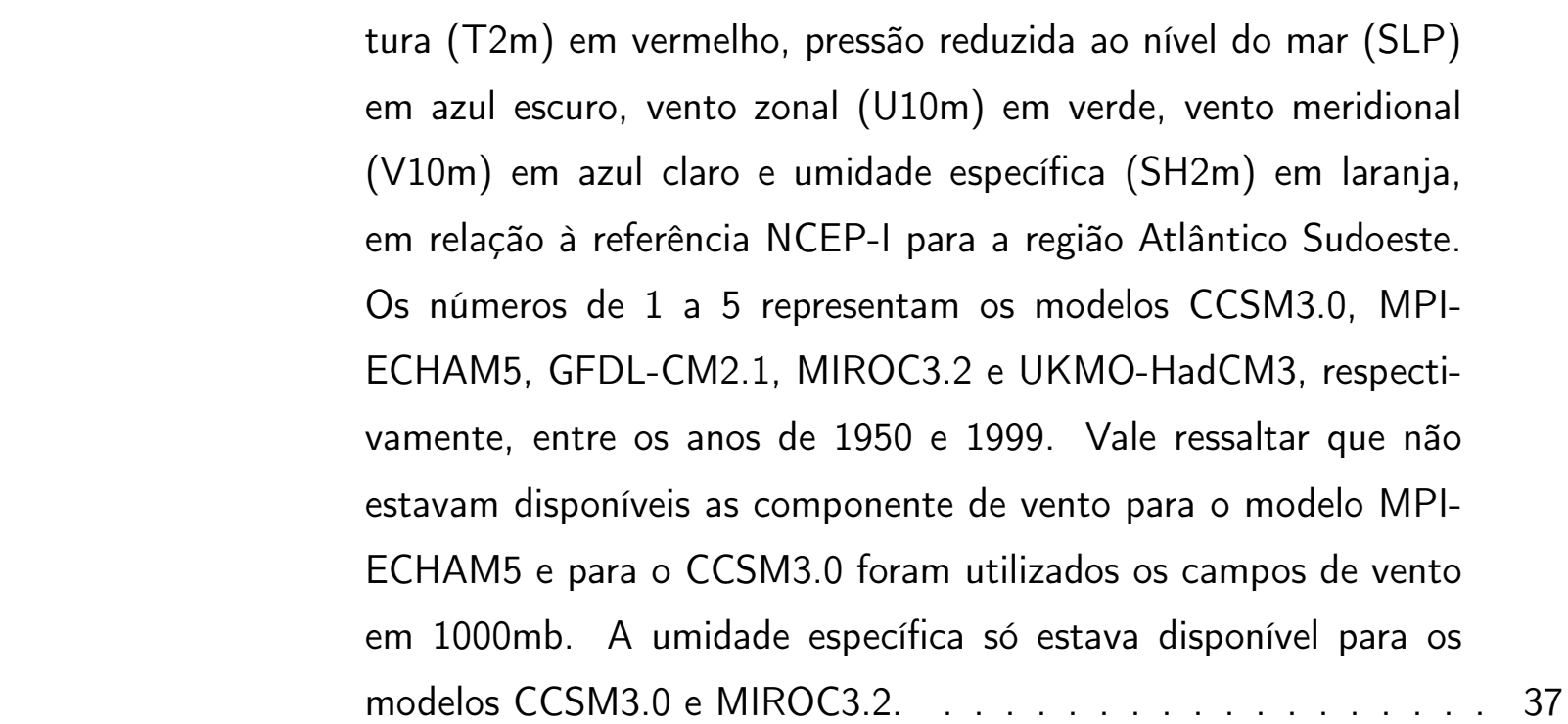


Figura $5 \quad$ Grades utilizadas para o downscaling atmosférico . . . . . . . . . 43

Figura $6 \quad$ Grade global utilizada para simulação dos campos de agitação global. 48

Figura $7 \quad$ Grade regional utilizada para simulação dos campos de agitação. . . . . 49

Figura $8 \quad$ Função de definição das aplicadas nas simulações de agitação. . . . . . 49

Figura $9 \quad$ Esquema gráfico da grade espectral aplicada nas simulações. . . . . . 50

Figura $10 \quad$ Média da Altura Significativa [m] ao longo de 20 anos forçados com o downscaling BRAMS/NCEP. . . . . . . . . . . . . . 56

Figura $11 \quad$ Médias sazonais de Altura Significativa [m] ao longo de 20 anos força-

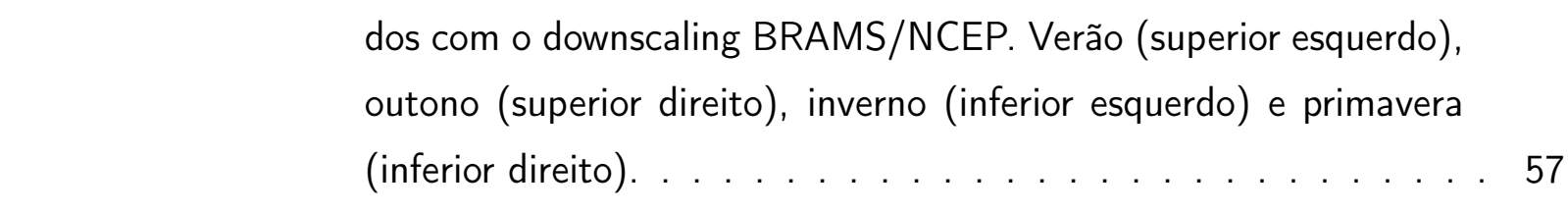

Figura 12 Variância da Altura Significativa ao longo de 20 anos forçados com o downscaling BRAMS/NCEP. . . . . . . . . . . . . . . . . 58

Figura 13 Médias de Período Médio [s] e Direção média ao longo de 20 anos forçados com o downscaling BRAMS/NCEP. . . . . . . . . . . . 59

Figura 14 Médias sazonais de Período Médio [s] e Direção Média ao longo de 20

anos forçados com o downscaling BRAMS/NCEP. Verão (superior

esquerdo), outono (superior direito), inverno (inferior esquerdo) e
primavera (inferior direito). . . . . . . . . . . . . . . . . . 60

Figura $15 \quad$ Variância de Período Médio ao longo de 20 anos forçados com o downscaling BRAMS/NCEP. . . . . . . . . . . . . . . 61

Figura $16 \quad$ Histogramas bivariados de $\mathrm{Hs}$ X Dm (superior a esquerda), Hs X Dp

(superior a direita), Tm X Dm (inferior a esquerda) e Tp X Dp

(inferior a direita) para o ponto BC. . . . . . . . . . . . . . 63

Figura $17 \quad$ Histogramas bivariados de $\mathrm{Hs}$ X Dm (superior a esquerda), Hs X Dp (superior a direita), Tm X Dm (inferior a esquerda) e Tp X Dp (inferior a direita) para o ponto BSO. . . . . . . . . . . . . . . . . 64

Figura $18 \quad$ Média da Altura Significativa [m] ao longo de 20 anos forçados com o downscaling BRAMS/CCSM3. . . . . . . . . . . . . . . 65

Figura 19 Médias sazonais da Altura Significativa [m] ao longo de 20 anos for-

\begin{tabular}{|l|}
\hline çados com o downscaling BRAMS/CCSM3. Verão (superior es- \\
\hline querdo), outono (superior direito), inverno (inferior esquerdo) e \\
\hline primavera (inferior direito). . . . . . . . . . . . . . . . 66
\end{tabular}


Figura $20 \quad$ Variância da Altura Significativa ao longo de 20 anos forçados com o downscaling BRAMS/CCSM3. . . . . . . . . . . . . . 67

Figura $21 \quad$ Médias de Período Médio [s] e Direção Média ao longo de 20 anos forçados com o downscaling BRAMS/CCSM3. . . . . . . . . . . 68

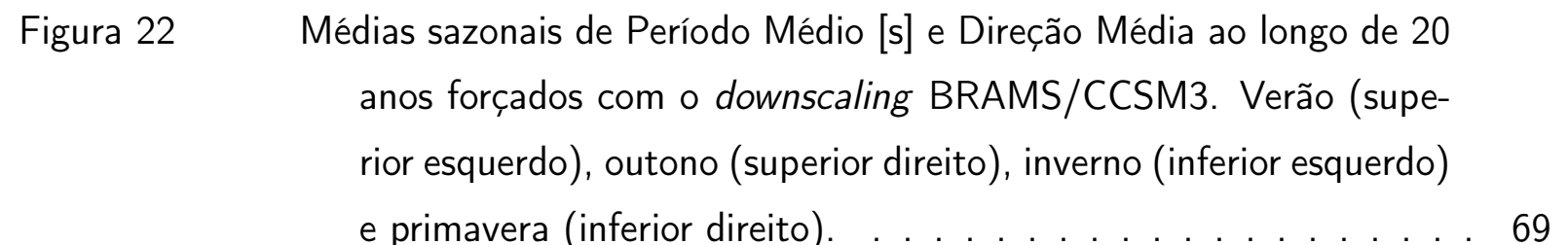

Figura $23 \quad$ Variância do Período Médio ao longo de 20 anos forçados com o downscaling BRAMS/CCSM3. . . . . . . . . . . . . . 70

Figura $24 \quad$ Histogramas bivariados de Hs X Dm (superior a esquerda), Hs X Dp

(superior a direita) , Tm X Dm (inferior a esquerda) e Tp X Dp
(inferior a direita) para o ponto BC. . . . . . . . . . . . . . 71

Figura $25 \quad$ Histogramas bivariados de $\mathrm{Hs}$ X Dm (superior a esquerda), Hs X Dp

(superior a direita), Tm X Dm (inferior a esquerda) e Tp X Dp
(inferior a direita) para o ponto BSO. . . . . . . . . . . . 72

Figura $26 \quad$ Viés da Altura Significativa (esquerda) e Período Médio (direita) de 1982 a 1999. . . . . . . . . . . . . . . . . . . . . 73

Figura $27 \quad$ RMS para Altura Significativa (esquerda) e Período Médio (direita) de 1982 a 1999. . . . . . . . . . . . . . . . . . . . . 74

Figura $28 \quad$ Correlação para Altura Significativa (esquerda) e Período Médio (direita) de 1982 a 1999. . . . . . . . . . . . . . . . . 75

Figura 29 Tendência da Altura Significativa [m/ano] ao longo de 20 anos forçados com o downscaling BRAMS/CCSM3 (a) e BRAMS/NCEP (b). . 76

Figura $30 \quad$ Variação temporal dos valores médios anuais de altura significativa [m] nos pontos BC e BSO (de cima para baixo) para as simulações forçadas com o downscaling BRAMS/NCEP (gráficos a esquerda) e BRAMS/CCSM3 (gráficos a direita) . . . . . . . . . . . . 77

Figura $31 \quad$ Média da Altura Significativa [m] ao longo de 20 anos forçados com o downscaling BRAMS/RESA2. . . . . . . . . . . . . . 78

Figura $32 \quad$ Médias sazonais da Altura Significativa [m] ao longo de 20 anos forçados com o downscaling BRAMS/RESA2. Verão (superior esquerdo), outono (superior direito), inverno (inferior esquerdo) e primavera (inferior direito). . . . . . . . . . . . . . . . . . . . . . 79 


\begin{tabular}{|c|c|}
\hline igura 33 & Variância da Altura Significativa [m] ao longo de 20 anos forçados com \\
\hline & o downscaling BRAMS/RESA2. \\
\hline Figura 34 & Média de Período Médio [s] e Direção Média ao longo de 20 anos \\
\hline & forçados com o downscaling BRAMS/RESA2. \\
\hline Figura 35 & Médias sazonais de Período Médio [s] e Direção Média ao longo de 20 \\
\hline & anos forçados com o downscaling BRAMS/RESA2. Verão (superior \\
\hline & esquerdo), outono (superior direito), inverno (inferior esquerdo) e \\
\hline & primavera (inferior direito). \\
\hline
\end{tabular}

Figura $36 \quad$ Variância do Período Médio [s] ao longo de 20 anos forçados com o downscaling BRAMS/RESA2.

Figura $37 \quad$ Histogramas bivariados de Hs X Dm (superior a esquerda), Hs X Dp (superior a direita), Tm X Dm (inferior a esquerda) e Tp X Dp (inferior a direita) para o ponto BC. .

Figura $38 \quad$ Histogramas bivariados de Hs X Dm (superior a esquerda), Hs X Dp

(superior a direita), Tm X Dm (inferior a esquerda) e Tp X Dp
(inferior a direita) para o ponto BSO.

Figura 39 Média da Altura Significativa [m] ao longo de 20 anos forçados com o downscaling BRAMS/RESB1. . . . . . . . . . . . . 85

Figura $40 \quad$ Média sazonal da Altura Significativa [m] ao longo de 20 anos forçados

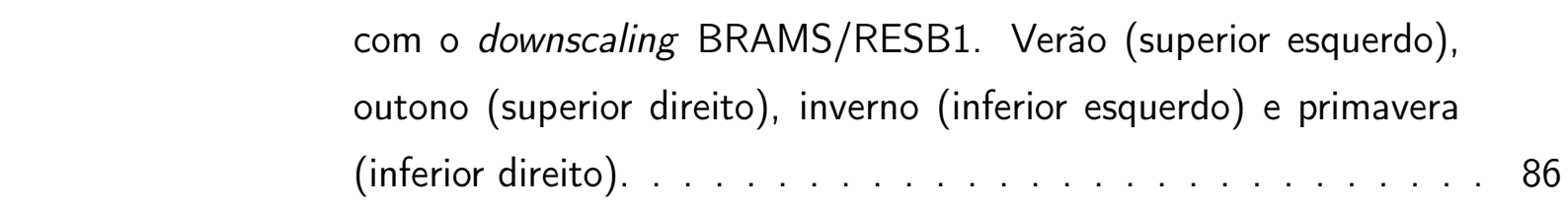

Figura 41 Variância da Altura Significativa ao longo de 20 anos forçados com o downscaling BRAMS/RESB1. . . . . . . . . . . . . . 887

Figura 42 Média de Período Médio [s] e Direção Média ao longo de 20 anos forçados com o downscaling BRAMS/RESB1. . . . . . . . . . . . 88

Figura 43 Médias sazonais de Período Médio [s] e Direção Média ao longo de 20

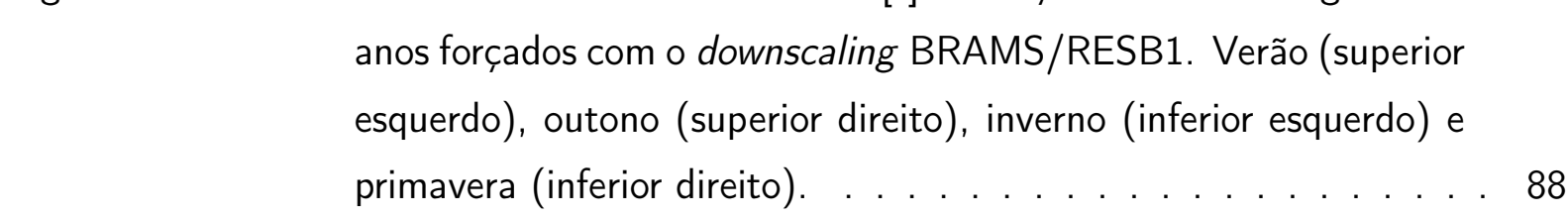

Figura $44 \quad$ Variância do Período Médio [s] ao longo de 20 anos forçados com o downscaling BRAMS/RESB1.

Figura $45 \quad$ Histogramas bivariados de $\mathrm{Hs}$ X Dm (superior a esquerda), Hs X Dp (superior a direita) , Tm X Dm (inferior a esquerda) e Tp X Dp (inferior a direita) para o ponto $\mathrm{BC}$. . 
Figura $46 \quad$ Histogramas bivariados de $\mathrm{Hs}$ X Dm (superior a esquerda), Hs X Dp (superior a direita) , Tm X Dm (inferior a esquerda) e Tp X Dp (inferior a direita) para o ponto BSO. . . . . . . . . . . . . . . . . 91

Figura $47 \quad$ Tendência de altura significativa [m/ano] ao longo de 20 anos forçados com o downscaling BRAMS/RESA2 (a) e BRAMS/RESB1 (b). . . 92

Figura $48 \quad$ Variação temporal dos valores médios anuais de altura significativa [m] nos pontos BC e BSO (de cima para baixo) para as simulações forçadas com o downscaling BRAMS/RESB1 (gráficos a esquerda) e BRAMS/RESA2 (gráficos a direita) . . . . . . . . . . . . . . 93

Figura $49 \quad$ Série temporal de Hs em um ponto arbitrário para o conjunto de simulações representativas do séc. XX forçadas com o downscaling BRAMS/NCEP. . . . . . . . . . . . . . . . . . 94

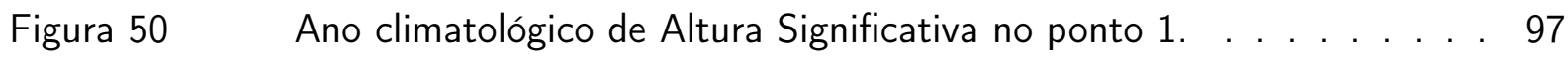

Figura 51 Diagrama de espalhamento de vento de superfície e altura de onda.

\begin{tabular}{|l|}
\hline Os ventos correspondem a reanálise do NCEP e as alturas de onda \\
\hline são obtidas com a simulação do modelo WW3. A linha em preto \\
\hline corresponde as alturas teóricas obtidas com a relação descritas nas \\
\hline equações 11.1 e 11.2. Casos de swell são considerados acima da \\
\hline linha teórica de desenvolvimento completo, casos de wind sea estão \\
\hline abaixo desta linha. Neste exemplo são utilizados ventos e alturas \\
\hline para o ano de 1999. . . . . . . . . . . . . . . . . . . . . . . . . 99
\end{tabular}

Figura $52 \quad$ Probabilidade de ocorrência de swell para a simulação global a partir da reanálise do NCEP entre os anos de 1982 a 1999.

Figura 53 Variação Sazonal da probabilidade de ocorrência de swell para a simulação global a partir da reanálise do NCEP entre os anos de 1982 a 1999. . . . . . . . . . . . . . . . . . . . . . . 101

Figura 54 Diferença da probabilidade de ocorrência de swell entre os conjuntos CCSM3 e NCEP entre os anos de 1982 a 1999. . . . . . . . . . . 101

Figura 55 Variação Sazonal das diferenças de probabilidade de ocorrência de swell entre os conjuntos CCSM3 e NCEP para os anos de 1982 a 1999.102

Figura $56 \quad$ Histogramas bivariados de Hs X Dm para verão (superior a esquerda), outono (superior a direita), inverno (inferior a esquerda) e primavera (inferior a direita) no ponto BC. . . . . . . . . . . . . . . . 111 
Figura $57 \quad$ Histogramas bivariados de Hs X Dm para verão (superior a esquerda),

\begin{tabular}{|c|c|}
\hline & outono (superior a direita), inverno (inferior a esquerda) e primavera \\
\hline & (inferior a direita) no ponto BC. . \\
\hline Figura 58 & Histogramas bivariados de Hs X Dm para verão (superior a esquerda), \\
\hline & outono (superior a direita), inverno (inferior a esquerda) e primavera \\
\hline & (inferior a direita) no ponto BC. . \\
\hline Figura 59 & Histogramas bivariados de Hs X Dm para verão (superior a esquerda), \\
\hline & outono (superior a direita), inverno (inferior a esquerda) e primavera \\
\hline & (inferior a direita) no ponto BC. . \\
\hline Figura 60 & Histogramas bivariados de Hs X Dm para verão (superior a esquerda), \\
\hline & outono (superior a direita), inverno (inferior a esquerda) e primavera \\
\hline & (inferior a direita) no ponto BSO. \\
\hline Figura 61 & Histogramas bivariados de Hs X Dm para verão (superior a esquerda), \\
\hline & outono (superior a direita), inverno (inferior a esquerda) e primavera \\
\hline
\end{tabular}
(inferior a direita) no ponto BSO. . . . . . . . . . . . . . . . . . . . 116

Figura 62 Histogramas bivariados de Hs X Dm para verão (superior a esquerda),

\begin{tabular}{|c|}
\hline outono (superior a direita), inverno (inferior a esquerda) e primavera \\
\hline (inferio a direita) no ponto BSO
\end{tabular}

Figura 63 Histogramas bivariados de Hs X Dm para verão (superior a esquerda),

outono (superior a direita), inverno (inferior a esquerda) e primavera
(inferior a direita) no ponto BSO. . . . . . . . . . . . . . . . . . . . 118

Figura $64 \quad$ Histogramas bivariados de Hs X Dp para verão (superior a esquerda),

outono (superior a direita), inverno (inferior a esquerda) e primavera
(inferior a direita) no ponto BC. . . . . . . . . . . . . . . . . . . . 119

Figura $65 \quad$ Histogramas bivariados de Hs X Dp para verão (superior a esquerda), outono (superior a direita), inverno (inferior a esquerda) e primavera (inferior a direita) no ponto BC. . . . . . . . . . . . . . . 120 Figura $66 \quad$ Histogramas bivariados de Hs X Dp para verão (superior a esquerda), \begin{tabular}{|c|c|c|}
\hline outono (superior a direita), inverno (inferior a esquerda) e primavera \\
\hline (inferior a direita) no ponto BC. . . . . . . . . . . . . . 121
\end{tabular} Figura 67 Histogramas bivariados de Hs X Dp para verão (superior a esquerda), outono (superior a direita), inverno (inferior a esquerda) e primavera (inferior a direita) no ponto BC. . . . . . . . . . . . . . . 122 Figura 68 Histogramas bivariados de Hs X Dp para verão (superior a esquerda), outono (superior a direita), inverno (inferior a esquerda) e primavera (inferior a direita) no ponto BSO. . . . . . . . . . . . . . . 123 
Figura 69 Histogramas bivariados de Hs X Dp para verão (superior a esquerda),

\begin{tabular}{|c|c|}
\hline & outono (superior a direita), inverno (inferior a esquerda) e primavera \\
\hline & (inferior a direita) no ponto BSO. . . \\
\hline Figura 70 & Histogramas bivariados de Hs X Dp para verão (superior a esquerda), \\
\hline & outono (superior a direita), inverno (inferior a esquerda) e primavera \\
\hline & (inferior a direita) no ponto BSO. \\
\hline Figura 71 & Histogramas bivariados de Hs X Dp para verão (superior a esquerda), \\
\hline & outono (superior a direita), inverno (inferior a esquerda) e primavera \\
\hline & (inferior a direita) no ponto BSO. . . . \\
\hline Figura 72 & Histogramas bivariados de Tm X Dm para verão (superior a esquerda), \\
\hline & outono (superior a direita), inverno (inferior a esquerda) e primavera \\
\hline & (inferior a direita) no ponto BC. \\
\hline Figura 73 & Histogramas bivariados de Tm X Dm para verão (superior a esquerda), \\
\hline
\end{tabular}

(inferior a direita) no ponto BC. . . . . . . . . . . . . . 128

\begin{tabular}{|c|c|}
\hline Figura 74 & Histogramas bivariados de Tm X Dm para verão (superior a esquerda), \\
\hline & outono (superior a direita), inverno (inferior a esquerda) e primavera \\
\hline
\end{tabular}

\begin{tabular}{|c|c|}
\hline Figura 75 & Histogramas bivariados de Tm X Dm para verão (superior a esquerda), \\
\hline & outono (superior a direita), inverno (inferior a esquerda) e primavera \\
\hline & (inferior a direita) no ponto BC. . \\
\hline
\end{tabular}

Figura $76 \quad$ Histogramas bivariados de Tm X Dm para verão (superior a esquerda),

\begin{tabular}{|l|l|}
\hline \multicolumn{4}{|c|}{ outono (superior a direita), inverno (inferior a esquerda) e primavera } \\
\hline (inferior a direita) no ponto BSO. . . . . . . . . . . . . . . . 131 \\
\hline
\end{tabular}

Figura 77 Histogramas bivariados de Tm X Dm para verão (superior a esquerda),

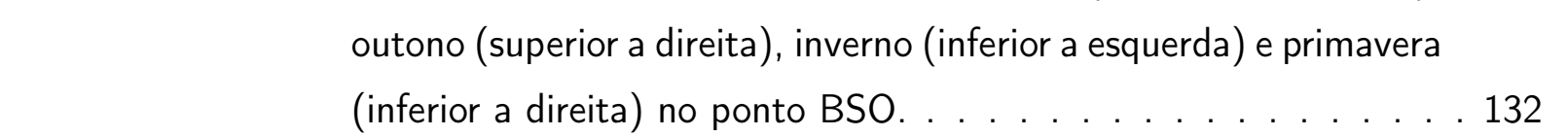

Figura $78 \quad$ Histogramas bivariados de Tm X Dm para verão (superior a esquerda),

\begin{tabular}{|l|l|}
\hline outono (superior a direita), inverno (inferior a esquerda) e primavera \\
\hline (inferior a direita) no ponto BSO. . . . . . . . . . . . . . 133
\end{tabular}

Figura $79 \quad$ Histogramas bivariados de Tm X Dm para verão (superior a esquerda),

outono (superior a direita), inverno (inferior a esquerda) e primavera

(inferior a direita) no ponto BSO. . . . . . . . . . . . . . . . . . 134

Figura $80 \quad$ Histogramas bivariados de Tp X Dp para verão (superior a esquerda),

outono (superior a direita), inverno (inferior a esquerda) e primavera

(inferior a direita) no ponto BC. . . . . . . . . . . . . 135 
Figura $81 \quad$ Histogramas bivariados de Tp X Dp para verão (superior a esquerda), outono (superior a direita), inverno (inferior a esquerda) e primavera (inferior a direita) no ponto BC. . . . . . . . . . . . . . . 136

(inferior a direita) no ponto BC. . . . . . . . . 136

Figura $82 \quad$ Histogramas bivariados de Tp X Dp para verão (superior a esquerda),

\begin{tabular}{|l}
\hline outono (superior a direita), inverno (inferior a esquerda) e primavera \\
\hline (inferior a direita) no ponto BC. . . . . . . . . . . . . . . . 137
\end{tabular}

Figura $83 \quad$ Histogramas bivariados de Tp X Dp para verão (superior a esquerda),

outono (superior a direita), inverno (inferior a esquerda) e primavera

(inferior a direita) no ponto BC. . . . . . . . . . . . . . 138

Figura $84 \quad$ Histogramas bivariados de Tp X Dp para verão (superior a esquerda)

\begin{tabular}{|c|c|}
\hline & outono (superior a direita), inverno (inferior a esquerda) e primavera \\
\hline & (inferior a direita) no ponto BSO. \\
\hline Figura 85 & Histogramas bivariados de Tp X Dp para verão (superior a esquerda), \\
\hline & outono (superior a direita), inverno (inferior a esquerda) e primavera \\
\hline & (inferior a direita) no ponto BSO. \\
\hline Figura 86 & Histogramas bivariados de Tp X Dp para verão (superior a esquerda), \\
\hline & outono (superior a direita), inverno (inferior a esquerda) e primavera \\
\hline & (inferior a direita) no ponto BSO. . \\
\hline Figura 87 & Histogramas bivariados de Tp X Dp para verão (superior a esquerda), \\
\hline & outono (superior a direita), inverno (inferior a esquerda) e primavera \\
\hline & (inferior a direita) no ponto BSO. \\
\hline Figura 88 & Ano climatológico de altura significativa no ponto BC. \\
\hline Figura 89 & Ano climatológico de altura significativa no ponto BSO. \\
\hline
\end{tabular}




\section{LISTA DE TABELAS}

Tabela 1 Modelos climáticos que geraram resultados para $\circ 4^{\circ}$ relatório do IPCC. 30

Tabela 2 Resumo dos dados de cada modelo climático utilizado. . . . . . . . . . . 33

Tabela $3 \quad$ Características dimensionais das grades utilizadas. . . . . . . . . . . . . 42

Tabela $4 \quad$ Características dimensionais das grades utilizadas. . . . . . . . . . . 47

Tabela 5 Coordenadas dos pontos para análises das séries temporais de agitação marítima geradas pelo WW3. . . . . . . . . . . . . . . . . . . . 61

Tabela 6 Tabela de valores médios e porcentagens de ocorrência de valores de hs nos 2 pontos analisados. . . . . . . . . . . . . . . . . . . . . 95

Tabela $7 \quad$ Tabela de valores máximos e valores dos desvios de hs nos 2 pontos analisados. . . . . . . . . . . . . . . . . . . . . 95

Tabela 8 Tabela de valores médios e porcentagens de ocorrência de valores de Tp nos 2 pontos analisados. . . . . . . . . . . . . . . . . . . 96

Tabela $9 \quad$ Tabela de valores máximos e valores dos desvios de Tp nos 2 pontos analisados. . . . . . . . . . . . . . . . . . . . 96 


\section{LISTA DE ABREVIATURAS E SIGLAS}

AR4

Fourth Assessment Report

AR5

Fifth Assessment Report

$\mathrm{BC}$

Ponto sobre Bacia de Campos

BRAMS

Brazilian Regional Atmospheric Model

BSO

Ponto sobre Bacia de Santos

CAM

Community Atmospheric Model

CAPES

Comissão de Aperfeiçoamento de Pessoal do Nível Superior

CCSM3.0

Community Climate System Model version 3.0

CCSR

Ocean Component Model

CENPES

Centro de Pesquisas da Petrobras

CLM

Community Land Model

CMIP5

Coupled Model Intercomparison Project Phase 5

CPTEC

Centro de Previsão de Tempo e Estudos Climáticos

CSIM

Community Sea Ice Model

Dp

direção de pico

$\mathrm{Dm}$

direção média

EMB

Environmental Modeling Center

GFDL

Geophysical Fluid Dynamics Laboratory da Universidade

$\mathrm{Hs}$

altura significativa

HadCM3

Hadley Centre Coupled Model version 3

IAG-USP

Instituto de Astronomia, Geofísica e Ciências Atmosféricas da Univer-

INPE sidade de São Paulo

Instituto Nacional de Pesquisas Espaciaiss

IO-USP

Instituto Oceanográfico da Universidade de São Paulo

IPCC Intergovernmental Panel on Climate Change

IVAM-OAS A Mudança do Clima e as Operações Oshore no Oceano Atlântico Sul

MASTER Meteorologia Aplicada a Sistemas de Tempo Regionais

MIROC Model for Interdisciplinary Research on Climate

MMA Marine Modeling and Analysis Branch

MPI Message Passing Interface

NASA National Aeronautics and Space Administration

NCAR National Center for Atmospheric Research

NCEP National Centers for Environmental Prediction

NOAA National Oceanic and Atmospheric Administration 
OISSTv2 Optimum Interpolation of Sea Surface Temperature

PCMDI Program for Climate Model Diagnosis and Intercomparison

PETROBRAS Petróleo Brasileiro SA

POP Parallel Ocean Program

RAMS Regional Atmospheric Modeling System

RMS Erro Quadrático Médio

SRESA1B Special Report on Emissions Scenarios - family A1B

SRESA2 Special Report on Emissions Scenarios - family A2

SRTM Shuttle Radar Topography Mission

Tp período de pico

Tm período médio

TSM Temperatura da Superfície do Mar

USGS U.S. Geological Survey

WCRP World Climate Research Programme 
SUMÁRIO

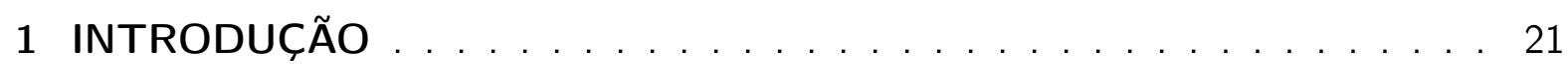

1.1 MUDANÇAS GLOBAIS E A CLIMATOLOGIA DE ONDAS . . . . . . . . . . 22

2 MÉTODO E BASE DE DADOS . . . . . . . . . . . . . . . . . . 26

2.1 DADOS DE REFERÊNCIA (CONTROLE) . . . . . . . . . . . . . 26

2.2 CENÁRIOS DE SIMULAÇÃO . . . . . . . . . . . . . . . . . 27

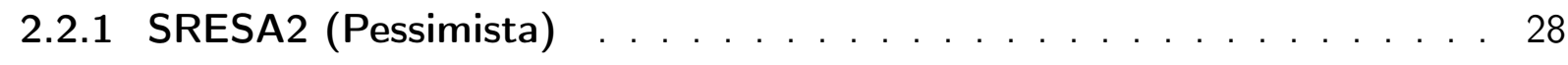

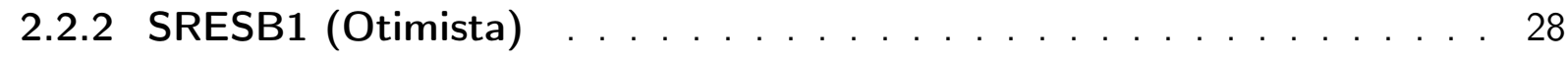

2.3 MODELOS CLIMÁTICOS GLOBAIS . . . . . . . . . . . . . . . . . . . 29

2.3 .1 GFDL-CM2.1 . . . . . . . . . . . . . . . . . . . . . . . . 30

2.3 .2 NCAR_CCSM3.0 $\ldots \ldots \ldots \ldots \ldots \ldots$

2.3 .3 MIROC3.2-medres $\ldots \ldots \ldots \ldots \ldots$

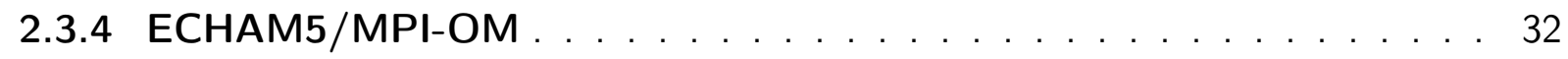

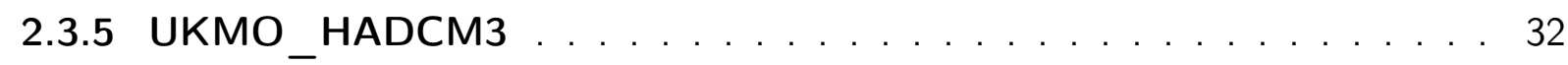

2.4 SINTESE DOS MODELOS $\ldots \ldots \ldots \ldots \ldots$

2.5 DEFINIÇÃO DE REGIÕES ... . . . . . . . . . . . . . . . 33

2.6 ESTATÍSTICAS PARA ESCOLHA DE MODELOS . . . . . . . . . . . . . . . 34

2.6 .1 Diagramas de Taylor . . . . . . . . . . . . . . . . . . . . 35

2.7 ETAPAS PARA REALIZAÇÃO DAS SIMULAÇÕES DE AGITAÇÃO . . . . . . . . 39

3 O DOWNSCALING ATMOSFÉRICO . . . . . . . . . . . . . . . . 40

3.1 MODELO REGIONAL ATMOSFÉRICO . . . . . . . . . . . . . . . 40

3.1 .1 Configuração do Modelo Atmosférico . . . . . . . . . . . . . . . . 41

3.1 .1 .1 Topografia . . . . . . . . . . . . . . . . . . . . . . . 44

3.1.1.2 Dados de Vegetação e Uso do Solo . . . . . . . . . . . . . . . . . . . 45

4 MODELO WAVEWATCH III $\ldots \ldots \ldots \ldots$

4.1 CONFIGURAÇÃO DO MODELO . . . . . . . . . . . . . . . . . . 46

4.2 CONFIGURAÇÃO DAS SIMULAÇÕES DE AGITAÇÃO . . . . . . . . . . . 46

4.2 .1 Dados de Entrada . . . . . . . . . . . . . . . . . 50

4.2 .1 .1 Reanálise I-NCEP/NCAR . . . . . . . . . . . . . . . 51

4.2.1.1.1 Temperatura da Superfície do Mar . . . . . . . . . . . . . . . 51

4.2.2 Dados de Entrada da Simulação CCSM3 IPCC AR4 (20c3m e Projeções) 52

4.2 .2 .0 .1 Temperatura da Superfície do Mar . . . . . . . . . . . 53

$4.3 \quad$ ESTRATÉGIA PARA AS SIMULAÇÕES $\ldots \ldots \ldots \ldots \ldots$ 


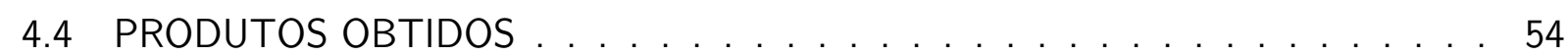

5 SÉCULO XX (CONTROLE) $\ldots \ldots \ldots \ldots \ldots \ldots$

5.1 ALTURA SIGNIFICATIVA . . . . . . . . . . . . . . . . . . . 56

5.1 .1 Variância de Altura Significativa . . . . . . . . . . . . . 57

5.2 PERíODO E DIREÇÃO (MÉDIOS) . . . . . . . . . . . . . . . . 58

5.2 .1 Médias de Período e Direção Médios . . . . . . . . . . . . . . 58

5.2 .2 Variância do Período Médio . . . . . . . . . . . . . . . . . . 60

5.3 ANÁLISE PONTUAL DE ALTURA SIGNIFICATIVA, PERÍODO DE PICO, DIREÇÃO DE PICO, PERÍODO MÉDIO E DIREÇÃO MÉDIA . . . . . . . . . . . 61

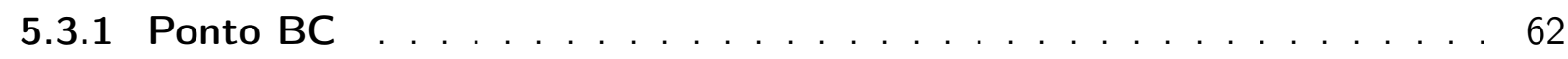

5.3 .2 Ponto BSO . . . . . . . . . . . . . . . . . . . . 63

6 SÉCULO XX (IPCC) . . . . . . . . . . . . . . . . . . . . 65

6.1 ALTURA SIGNIFICATIVA . . . . . . . . . . . . . . . . . . . . . . . . 65

6.1 .1 Variância de Altura Significativa . . . . . . . . . . . . . 66

6.2 PERÍODO E DIREÇÃO (MÉDIOS) . . . . . . . . . . . . . . . . . . . 67

6.2 .1 Médias de Período e Direção Médios . . . . . . . . . . . . . . . 67

6.2 .2 Variância do Período Médio . . . . . . . . . . . . . . . . . . . . . . 69

6.3 ANÁLISE PONTUAL DE ALTURA SIGNIFICATIVA, PERíODO DE PICO, DIREÇ̃̃O DE PICO, PERÍODO MÉDIO E DIREÇÃO MÉDIA . . . . . . . . . 70

6.3 .1 Ponto $\mathrm{BC} \ldots \ldots \ldots \ldots$

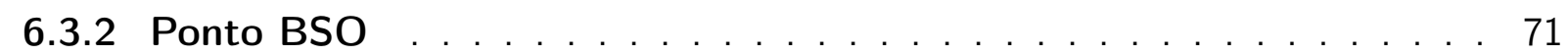

7 COMPARAÇÃO DOS CONJUNTOS PARA O SÉCULO XX . . . . . . . 73

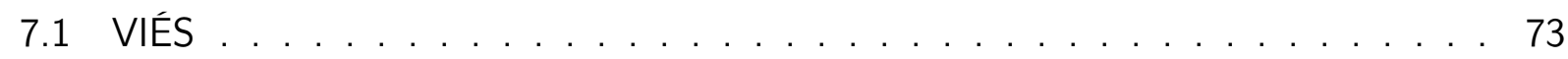

7.2 ERRO QUADRÁTICO MÉDIO . . . . . . . . . . . . . . . . . . 74

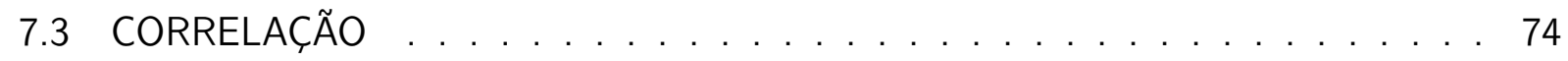

7.4 TENDÊNCIAS DE ALTURA SIGNIFICATIVA . . . . . . . . . . . . . . . . . 75

8 SÉCULO XXI SOB UMA ÓTICA PESSIMISTA (WW3/CCSM3 SRESA2) 78

8.1 ALTURA SIGNIFICATIVA . . . . . . . . . . . . . . . . . . . . . . . 78

8.2 PERÍODO E DIREÇÃO (MÉDIOS) . . . . . . . . . . . . . . . . . 80

8.2 .1 Médias de Período e Direção Médios . . . . . . . . . . . . . . 80

8.2 .2 Variância do Período Médio. . . . . . . . . . . . . . . . . . . . 82

8.3 ANÁLISE PONTUAL DE ALTURA SIGNIFICATIVA, PERÍODO DE PICO, DIREÇÃO DE PICO, PERÍODO MÉDIO E DIREÇÃO MÉDIA . . . . . . . . . . . 82

8.3 .1 Ponto $\mathrm{BC} \ldots \ldots \ldots \ldots \ldots$ 
8.3 .2 Ponto BSO . . . . . . . . . . . . . . . . . . . . 83

9 SÉCULO XXI SOB UMA ÓTICA OTIMISTA (WW3/CCSM3 SRESB1) 85

9.1 ALTURA SIGNIFICATIVA $\ldots \ldots \ldots \ldots \ldots$

9.2 PERÍODO E DIREÇÃO (MÉDIOS) . . . . . . . . . . . . . . . . 87

9.2 .1 Médias de Período e Direção Médios . . . . . . . . . . . . 87

9.2 .2 Variância do Período Médio. . . . . . . . . . . . . . . . . . . . 89

9.3 ANÁLISE PONTUAL DE ALTURA SIGNIFICATIVA, PERÍODO DE PICO, DIREÇÃO DE PICO, PERÍODO MÉDIO E DIREÇÃO MÉDIA . . . . . . . . . . 89

9.3 .1 Ponto $\mathrm{BC} \ldots \ldots \ldots \ldots$

9.3 .2 Ponto BSO . . . . . . . . . . . . . . . . . . . . . . . . 90

10 TENDÊNCIAS DE HS NO SÉCULO XXI . . . . . . . . . . . . 92

11 SíNTESE FINAL DA CLIMATOLOGIA DE ONDAS . . . . . . . . . . . . . 94

11.1 EXTREMOS NA CLIMATOLOGIA DE ONDAS $\ldots \ldots \ldots$

11.2 COMPARAÇÃO DOS ANOS CLIMATOLÓGICOS NOS CONJUNTOS SIMULA-

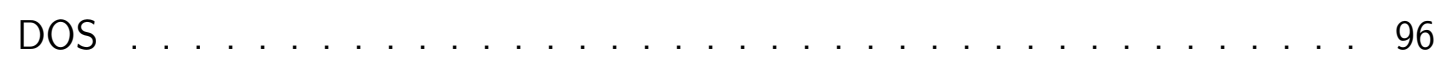

12 IMPACTOS DAS MUDANÇAS CLIMÁTICAS NA OCORRÊNCIA DE

SWELL E WIND SEA . . . . . . . . . . . . . . . . . . . . . . . . . . 98

13 CONCLUSÕES . . . . . . . . . . . . . . . . . . . 103

Anexo A - Variação Sazonal da Distribuição de Hs X Dm . . . . . . . . . . . 111

Anexo B - Variação Sazonal da Distribuição de Hs X Dp . . . . . . . . . 119

Anexo C - Variação Sazonal da Distribuição de Tm X Dm . . . . . . . . 127

Anexo D - Variação Sazonal da Distribuição de Tp X Dp . . . . . . . . . . . 135

Anexo E - Anos Climatológicos dos Conjunos Simulados . . . . . . . . . . 143 


\section{INTRODUÇÃO}

O IPCC - Intergovernmental Panel on Climate Change anunciou, no seu quarto Relatório de Avaliação (AR4 - Fourth Assessment Report) em 2007 (Solomon et al. [2007]), que o aquecimento do sistema climático é inequí-voco, como ficou evidente pelas observações dos aumentos de temperaturas médias globais da atmosfera e dos oceanos, da aceleração do derretimento do gelo marinho e continental, e da elevação do nível médio do mar. O aumento da temperatura média global do planeta, em relação ao nível médio de temperatura anterior à Revolução Industrial, é apontado pelo IPCC como uma conseqüência do aumento da concentração de gases de efeito estufa de origem antrópica na atmosfera. O IPCC também indica que o acréscimo global da concentração de dióxido de carbono se deve primeiramente ao uso de combustíveis fósseis e à mudança do uso da terra, enquanto que os acréscimos devidos ao metano e ao óxido nitroso são resultantes da agricultura.

A contínua emissão desses gases e a manutenção do desmatamento no século XXI, nas mesmas taxas que atualmente, têm potencial para causar mais aquecimento e levar às mudanças climáticas globais que serão muito provavelmente maiores que as observadas no século $\mathrm{XX}$. Os relatórios do IPCC AR4 e AR5 - Fifth Assessment Report discutem que é muito provável que os eventos climáticos extremos (ondas de calor, estiagem, tempestades severas, etc) serão mais freqüentes no futuro próximo (Solomon et al. [2007] Stocker 2014]). Pesquisadores de todo o mundo tentam entender há muitos anos o impacto que as mudanças globais causam, examinando esta questão em seus mais variados aspectos: ar, solo, água, economia, áreas de risco à ocupação humana, energia, entre outros. Mas, mesmo após tantos esforços, o nível de conhecimento obtido ainda é incompleto, sobretudo com relação aos impactos regionais do aquecimento devido ao aumento da concentração de gases de efeito estufa e com relação aos mecanismos físicos nos oceanos. Independentemente do cenário de emissões de gases do efeito estufa, o meio ambiente e a sociedade já vêm sofrendo as conseqüências do aumento da temperatura global. Desta maneira, este estudo contribuirá na descrição de como a mudança no clima alterará o regime de ondas para os próximos 20 anos.

No contexto das mudanças climáticas uma pergunta recorrente é: como as mudanças climáticas afetarão o clima de ondas e consequentemente regiões costeiras? Mudanças climáticas em escala oceânica podem alterar o clima de ondas. O Painel Intergovernamental de Mudanças Climáticas (IPCC AR4 e AR5) reconhece que mudanças na climatologia de ondas é um dos principais parâmetros para o entendimento dos efeitos das mudanças climáticas nos processos de erosão costeira e riscos para as populações destas regiões e seus ecossistemas associados (Nicholls et al. 2007]). A variabilidade interanual das ondas e marés meteorológicas, em alguns casos, estão ultrapassando a influência das projeções do aumento dos nível do mar 
(Coelho et al. [2009]).

Existem diversos outros exemplos da importância do entendimento das possíveis mudanças no clima de ondas. Um exemplo de efeito global pode ser dado ao se pensar que um campo de ondas pode penetrar nas camadas de coberturas de gelo dos polos, quebrando-os e acelerando os processos de derretimento dessas camadas. Este processos pode afetar diretamente as estimativas do tempo de decaimento das coberturas de gelo polar. Outro exemplo é citado por Cavaleri et al. 2012] com especulações sobre a circulação de Langmuir influenciando a dinâmica, termo-dinâmica e absorção de caborno nas camadas de mistura dos oceanos.

Projetos baseados em modelos atmosféricos como os de Yin 2005] e Catto et al. 2011] apontam mudanças no sentido da propagação de tempestades severas e diminuição no número total e intensidade de ciclones respectivamente. Estes alterações podem afetar diretamente os processos de geração de onda resultando em mudanças no clima de ondas em termos de altura de onda, período e direção. Nos relatórios de Solomon et al. 2007] e Stocker [2014] são citados uma série de mudanças potenciais nas climatologias regionais de ondas. Os poucos trabalhos existentes de projeções climáticas de clima de ondas como os de Wang and Swail [2006], Caires et al. 2006] e Mori et al. 2010], focados no Hemisfério Norte, mostram aumento nas alturas de ondas em determinadas regiões assim como diminuição em outras. No entanto todas as mudanças relatadas possuem ampla dependência com os cenários de emissões de gases estufas e com os próprios modelos utilizados.

\subsection{MUDANÇAS GLOBAIS E A CLIMATOLOGIA DE ONDAS}

As ondas superficiais dos oceanos podem ser a maior causa de desastres nas regiões costeiras e em operações offshore. Já na década de 60, o estudo de Longuet-Higgins and Stewart [1964] mostra que em regiões costeiras as ondas induzem gradientes de estresse de radiação que resultam em correntes atuantes na deriva litorânea, erosão costeira, e diversos outros processos. Apesar do grande papel na dinâmica costeira existem poucos estudos sobre o comportamento das ondas em resposta as mudanças climáticas. Young et al. [2011] comenta em seu artigo que estudos de mudanças climáticas tipicamente consideram medições ou previsões de temperatura em grandes períodos de tempo mas que entender o clima terrestre envolve muito mais variáveis do que somente a temperatura. Segundo Wang et al. 2014] este fato acontece porque as informações sobre o clima de ondas não são computadas nos modelos atuais de mudanças globais.

Durante as últimas quatro décadas diversos estudos foram feitos com o intuito de se analizar as mudanças no clima de ondas no Atlântico Norte. Trabalhos da década de 70 baseados em observações de navios revelam grande variabilidade nas estatísticas de ondas de ano para ano. 
Um aumento de $2.4 \mathrm{~cm} /$ ano na altura significativa das ondas foi reportardo por Bacon and Carter [1991] para o período de 1962-1986. Utilizando 40 anos de simulações pretéritas de ondas Wang and Swail [2002] obtiveram uma tendência positiva em extremos sazonais de altura significativa com maiores taxas durante os invernos da costa irlandesa. Por outro lado utilizando uma base de dados de 20 anos de séries temporais de dados de bóias na Baia de Biscaya Dupuis et al. 2006 não encontraram tendências para a altura significativa durante o período de 1980-1998. Utilizando uma técnica combinada de simulação pretérita (10 anos) e extrapolação estatística reversa no tempo Kushnir et al. [1997] sugerem uma diminuição da altura significativa das ondas nas proximidades de 40 graus Norte para o período de 1962 a 1986. A variabilidade climática de ondas no Leste do Atlântico Norte foi analisada por Dodet et al. [2010] com simulações pretéritas de 57 anos (1953-2009) mostrando que os invernos apresentam as maiores alturas e períodos e verões com as menores alturas e períodos mais curtos.

Os métodos utilizados para se obter projeções climáticas do clima de ondas são estatísticos ou dinâmicos. Métodos estatísticos geralmente utilizam reanálises climáticas atuais (atmosfera e ondas) para estabelecer uma relação estatística entre o preditor (pressão reduzida ao nível do mar ou ventos superficias) e o preditando (geralmente a altura significativa). Estas relações são extrapolados para as projeções. Nos métodos dinâmicos as forçantes superficiais geralmente derivam de modelos climáticos acoplados e que são utilizadas em um modelo espectral de ondas que por sua vez requer um grande esforço computacional. Segundo Fan et al. [2013] devido ao grande custo computacional e da grande dependência da resolução espaço-temporal dos ventos de superfície, as projeções dinâmicas do clima de ondas são realizadas em domínios regionais onde cenários pré selecionados dos modelos climáticos são utilizados como forçantes desses domínios. A maior parte destes trabalhos são realizados para o Hemisfério Norte.

Utilizando um método estatístico, Wang et al. [2014] realizaram projeções das mudanças no clima de ondas dos oceanos utilizando campos de pressão reduzida ao nível do mar proveniente do projeto CMIP5 - Coupled Model Intercomparison Project Phase 5 para o século XXI (20702099). Os resultados obtidos neste trabalho demonstram aumentos nas alturas signifcativas das ondas nos trópicos, principalmente para a porção leste tropical do Pacífico, e nas altas latitudes do Hemisfério Sul.

Um exemplo sobre a abordagem dinâmica é encontrado no trabalho de Fan et al. [2013] onde um modelo acoplado atmosférico-ondas foi utilizado para investigação do efeito do aquecimento dos oceanos sobre as ondas. Neste experimento foi utilizado modelos do IPCC AR4 (CMIP3) com o cenário SRESA1B - Special Report on Emissions Scenarios - family A1B (a família $A 1 B$ de cenários descrevem um mundo futuro com desenvolvimento econômico muito rápido com balanço na sua matriz energética entre combustíveis fósseis e não fósseis) para o 
final do século XXI. Os autores encontraram mudanças consistentes para as médias sazonais com aumento nos ventos de superfície e nas alturas significativas para o Hemisfério Sul durante o verão e inverno austral. Neste trabalho de abrangência global o maior detalhamento dos resultados foi para a região dos oceanos adjacentes a América do Norte.

Com uma técnica dinâmica e similar a do presente estudo Hemer et al. 2013 utilizou o cenário do IPCC de alta concentração de gases de efeito estufa (SRESA2 - Special Report on Emissions Scenarios - family A2) para realizar projeções climáticas de ondas para o século XXI (2070-2099). Os autores encontraram duas características bem marcantes, o aumento da geração de ondas que acarretaram num aumento de cerca de $10 \%$ no campo médio de altura significativa e uma diminuição das atividades de geração no Atlântico Norte.

Do ponto de vista observacional, a climatologia (tempo presente) de ondas no Brasil é um campo relativamente pouco estudado em função da escassez de dados disponíveis por períodos suficientemente longos. Sabe-se que a instalação e a manutenção de ondógrafos é bastante onerosa por demandar equipes e infra-estrutura para as operações, além dos instrumentos em si. As observações por satélites, apesar de muito úteis do ponto de vista da larga escala, são insuficientes para resolver a variabilidade temporal da agitação marítima em pontos específicos e também nas regiões costeiras. Neste contexto, a modelagem de ondas vem sendo aplicada para formação de bases de dados e compreensão do clima de ondas para, de certo modo, suprir a falta de observações sistemáticas e operacionais. Obviamente os resultados modelados não substituem de forma alguma as observações, mas um uso criterioso dos mesmos pode representar uma importante contribuição ao conhecimento das ondas e de seus padrões de variabilidade espaço-temporal que influenciam a região Oeste do Atlântico Sul.

O conhecimento existente sobre as características da agitação marítima na região de estudo remete à importância da propagação de ondulações geradas em áreas remotas, os quais são denominados por marulhos (ou swell conforme a bibliografia técnica, neste trabalho será utilizado este termo). Isto ocorre porque as ondas de gravidade superficiais podem se propagar por enormes distâncias com pequeno decaimento de energia, de modo que sua representação numérica em uma determinada região deve necessariamente considerar este. Do ponto de vista prático, isto significa que apenas um domínio de área limitada no Atlântico Sudoeste pode não ser suficientemente representativo para a caracterização das ondas de gravidade superficiais, o que remete à necessidade de adotar uma estratégia para tratar numericamente este assunto.

De acordo com Branco 2005] e Alves 2006, a opção mais adequada está na adoção de um domínio global em baixa resolução que permita representar as propagações de swell gerados nas áreas remotas que influenciam a área de estudo, seguido de um aninhamento unidirecional para um domínio regional em alta resolução. Neste processo de aninhamento, os pontos pertencentes aos contornos abertos do domínio regional são calculados explicitamente pela 
grade global, de modo a serem impostos como condições de contorno para as simulações em escala regional, as quais são forçadas com os campos de ventos obtidos pela regionalização (ou downscaling) atmosférico com o modelo BRAMS - Brazilian Regional Atmospheric Model (Freitas et al. [2009]).

Assim sendo, as análises dos resultados aqui que serão apresentados ao longo deste trabalho são fruto de um longo e criterioso procedimento de simulações numéricas, o qual demandou um enorme esforço computacional e disponibilidade de memória de armazenamento. Detalhes específicos e discussões encontram-se ao longo dos capítulos. 


\section{MÉTODO E BASE DE DADOS}

Este trabalho foi fruto de um projeto de pesquisa denominado IVAM-OAS - A Mudança do Clima e as Operações Oshore no Oceano Atlântico Sul financiado pela PETROBRAS - Petróleo Brasileiro SA e CAPES - Comissão de Aperfeiçoamento de Pessoal do Nível Superior contando com pesquisadores do IO-USP - Instituto Oceanográfico da Universidade de São Paulo, IAG-USP - Instituto de Astronomia, Geofísica e Ciências Atmosféricas da Universidade de São Paulo e CENPES - Centro de Pesquisas da Petrobras. Vale destacar que todo os processos de simulações numéricas da atmosfera e agitação foram desenvolvidos no laboratório MASTER - Meteorologia Aplicada a Sistemas de Tempo Regionais do IAG-USP. As simulações de agitação marítima foram inteiramente concluídas por minha própria responsabilidade, desde os processos de compilação do modelo, estabelecimento das grades, simulações, pós processamentos, elaboração de figuras e análises.

Várias etapas foram realizadas para alcançar um conjunto de informações representativas da agitação marítima para a região do Atlântico Sudoeste, desde a obtenção de dados globais atmosféricos até o resultado final da modelagem regional de ondas. Vale destacar características dos conjuntos de dados utilizados assim como a uma breve justificativa dos resultados dos modelos escolhidos.

Todas as informações usadas neste estudo referem-se a resultados numéricos oriundos de esforços conhecidos como análises (ou reanálises) de campos atmosféricos, assim como de modelos acoplados de circulação geral. Dentre os modelos climáticos foram escolhidos cinco modelos que foram utilizados no $4^{\circ}$ Relatório de Avaliação do IPCC, cujas simulações levam em conta diferentes cenários de aquecimento global em função do aumento na concentração de gases do efeito estufa.

\subsection{DADOS DE REFERÊNCIA (CONTROLE)}

Foi utilizado como base de referência para o século $X X$ campos de variáveis obtidas de reanálises de dados. É conveniente fazer rápidas considerações acerca dos procedimentos realizados para a obtenção destes campos espaço-temporais.

Através do uso conjunto de modelos numéricos de circulação geral - tanto da atmosfera quanto do oceano - e de técnicas de assimilação de dados observacionais, são gerados campos tridimensionais que descrevem o comportamento do fluido naquele instante específico de tempo. Esta é a forma com que dados meteorológicos e oceanográficos esparsos no espaço e no tempo são incorporados nas simulações numéricas com os modelos dinâmicos. Adicionalmente, ao considerar dados históricos arquivados, é possível resgatar condições para períodos 
relativamente longos.

A existência das denominações análise e reanálise tem explicação ao considerar o ponto de vista da previsão operacional de tempo, na qual é extremamente importante que novas observações sejam incorporadas para manter a representatividade dos prognósticos; por outro lado, não é possível aguardar até que todos os dados referentes àquele instante de tempo estejam disponíveis para uso nos grandes centros de previsão. Isso faz com que haja uma janela de tempo para que os dados sejam absorvidos pelo sistema para a geração do campos analisados (ou análises); por sua vez, os campos da reanálise são gerados posteriormente com a utilização de todas as informações de interesse. Neste trabalho optou-se por utilizar a Reanálise I do NCEP - National Centers for Environmental Prediction e NCAR - National Center for Atmospheric Research (NCEP/NCAR) cujo maiores detalhes serão descritos adiante.

\subsection{CENÁRIOS DE SIMULAÇÃO}

Em seu terceiro relatório divulgado no ano de 2001, o IPCC estabeleceu cenários de desenvolvimento mundiais que serviriam como padrão nas forçantes utilizadas nos modelos climáticos atuais (McCarthy [2001]). No presente estudo foram utilizadas as simulações que levam em consideração os dois seguintes cenários:

\section{$20 c 3 m$}

Essa simulação é iniciada a partir do último ano de uma integração de controle denotada de picntrl. Essa simulação de controle utiliza os dados oceânicos de temperatura e salinidade da climatologia Levitus (Levitus [1983]) como condições iniciais. Já a componente atmosférica é inicializada com uma concentração fixa de gases estufa, representando a concentração do período pré-industrial (1870), 348 ppmv. Essa simulação é rodada para um período de 100 anos (1761-1860). A simulação para o século XX (Climate of the 20th Century experiment $20 \mathrm{c} 3 \mathrm{~m}$ ) consiste de um esquema de 5 conjuntos (ensembles), em que se utiliza a sua média para eliminar a dependência de condições iniciais e variabilidade interna. Cada rodada cobre o período que vai de 1850 até 2000.

Os agentes forçantes nesse experimento incluem os registros históricos de gases estufa (CO2, $\mathrm{CH} 4, \mathrm{~N} 2 \mathrm{O}$ e CFCs), sulfatos troposféricos, atividades vulcânicas e forçantes solares (Yukimoto and Kodera 2005]). As concentrações desses gases nesse cenário é baseado nos registros históricos de Hansen et al. 1998. O propósito desse cenário foi reproduzir da maneira mais realista possível o clima do início do século XX até o ano de 2000. 


\subsubsection{SRESA2 (Pessimista)}

"Utiliza o fim da rodada do cenário 20c3m como condição inicial" - (presente - 2100) tem ênfase na riqueza humana regional e no uso dos recursos sem preocupação com uso eficiente ou o uso de tecnologias limpas. A linha de história do cenário A2 descreve um mundo muito heterogêneo. O tema de fundo consiste na preservação e auto suficiência de identidades locais. Padrões de fertilidade entre diferentes regiões convergem pouco, e isso resulta num crescimento contínuo da população mundial. O desenvolvimento econômico é orientado principalmente de modo regional e o crescimento per capita e tecnológico é mais fragmentado e mais devagar que em outros cenários.

\subsubsection{SRESB1 (Otimista)}

Representa um mundo globalizado, com ênfase na sustentabilidade e equidade global (desenvolvimento sustentável). Os cenários B1 descrevem um mundo convergente com a população global atingindo um pico no meio do século e depois declina. Apresenta rápidas mudanças nas estruturas econômicas em direção a uma economia de serviços, informações, com reduções da intensidade material e a introdução de tecnologias limpas e eficiente no uso dos recursos. A ênfase está em soluções globais para a sustentabilidade econômica, social e ambiental, incluindo a melhoria da eqüidade, mas sem iniciativas climáticas adicionais.

Para ilustração do impacto de cada cenário apresentado na temperatura média global podese observar o gráfico esquemático na figura 1 . 


\section{CCSM3 IPCC future scenarios [Oct 25 2004]}

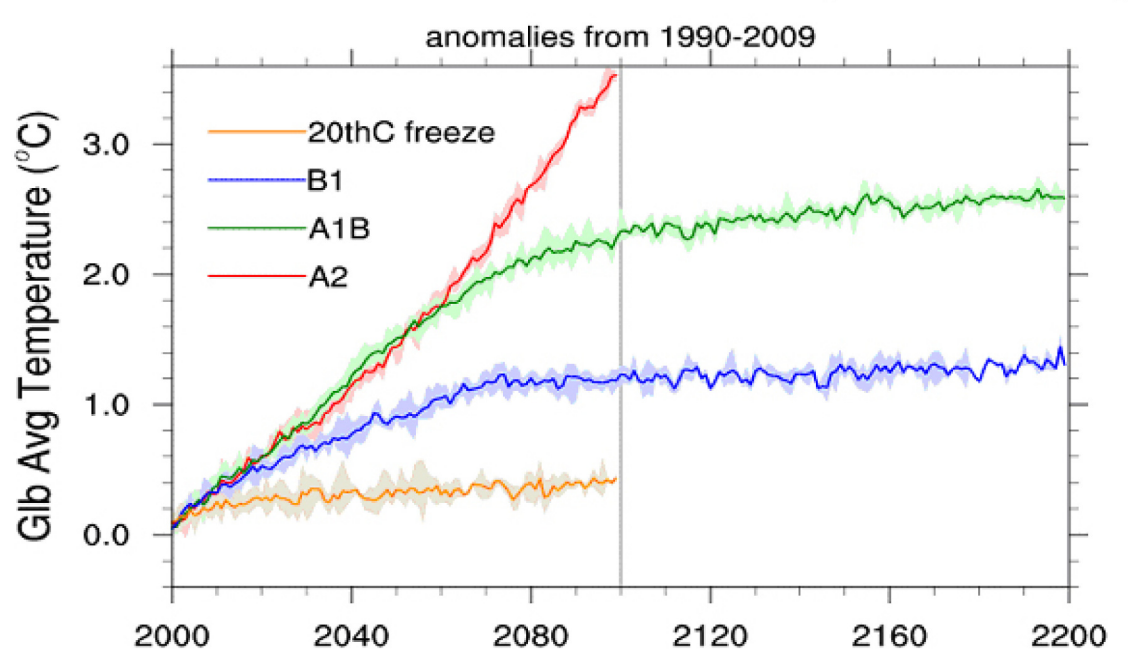

Figura 1 - Figura esquemática dos resultados de anomalia da temperatura média global, em relação à temperatura média de 1990 a 2009, para diferentes cenários, resultados do modelo CCSM3.0. O cenário A2 (vermelho) representa um futuro pessimista em termos de emissões de gases estufa, enquanto que o cenário B1 (azul) apresentam um futuro otimista. http://www.gisclimatechange.org/runSetsHelp.html.

\subsection{MODELOS CLIMÁTICOS GLOBAIS}

O WCRP - World Climate Research Programme através do portal de dados PCMDI Program for Climate Model Diagnosis and Intercomparison (PCMDI - www-pcmdi.llnl.gov/ ipcc/about_ipcc.php) organiza e disponibiliza mais de 35TB de dados climáticos resultantes de saídas de modelos climáticos globais de última geração [Meehl et al. [2007b]. Um dos objetivos dessa iniciativa é de servir como divulgador/servidor dos dados que são utilizados para a realização das análises e projeções feitas pelo Working Group 1 do IPCC.

O PCMDI disponibiliza a saída dos resultados de 23 diferentes modelos climáticos (tabela 1) com 12 diferentes cenários de desenvolvimento global. Nem todos os modelos apresentam resultados disponíveis no portal PCMDI para os três cenários apresentados e na resoluçao necessária para o trabalho, e por isso no presente estudo serão levados em consideração apenas o resultado de 5 modelos climáticos: CCSM3.0, ECHAM5/MPI-OM, GFDL-CM2.1, MIROC3.2(medres) e UKMO-HadCM3 . Detalhes dos demais modelos e cenários podem ser encontrados em Meehl et al. [2007a] A seguir, segue uma breve descrição dos modelos adotados nesse estudo. 
Tabela 1 - Modelos climáticos que geraram resultados para o $4^{\circ}$ relatório do IPCC.

\begin{tabular}{|c|c|}
\hline MODELO & PAís \\
\hline BCC-CM1 & China \\
\hline BCCR-BCM2.0 & Noruega \\
\hline CCSM3.0 & EUA \\
\hline CGCM3.1(T47) & Canadá \\
\hline CGCM3.1(T63) & Canadá \\
\hline CNRM-CM3 & França \\
\hline CSIRO-Mk3.0 & Austrália \\
\hline CSIRO-Mk3.5 & Austrália \\
\hline ECHAM5/MPI-OM & Alemanha \\
\hline ECHO-G & Alemanha/Coréia do Sul \\
\hline FGOALS-g1.0 & China \\
\hline GFDL-CM2.0 & EUA \\
\hline GFDL-CM2.1 & EUA \\
\hline GISS-AOM & EUA \\
\hline GISS-EH & EUA \\
\hline GISS-ER & EUA \\
\hline INGV-SXG & Itália \\
\hline INM-CM3.0 & Rússia \\
\hline IPSL-CM4 & França \\
\hline MIROC3.2(hires) & Japão \\
\hline PCM & EUA \\
\hline UKMO-HadCM3 & Reino Unido \\
\hline UKMO-HadGEM1 & Reino Unido \\
\hline
\end{tabular}

\subsubsection{GFDL-CM2.1}

O GFDL - Geophysical Fluid Dynamics Laboratory da Universidade de Princeton, desde 2004, passou a usar a denominação Climate Model 2.X para designar esforços de modelagem acoplada oceano-atmosfera. Para os propósitos deste trabalho, foi empregada a versão 2.1, aqui denominada GFDL-CM2.1. Ele é composto de quatro componentes que simulam a terra/biosfera, a criosfera, a atmosfera e o oceano. A resolução horizontal do modelo atmosférico é de $2,5^{\circ}$ em longitude por $2,0^{\circ}$ em latitude, com 24 níveis verticais. Algumas das 
inovações mais marcantes dessa última versão do modelo atmosférico é a variação da radiação solar ao longo do dia. Essa nova formulação permite um tratamento explícito de diversos gases traços, tais como ozônio, aerossóis naturais (vulcânicos) e atropogênicos (carbono negro) e partículas de pó. Uma descrição completa e detalhada da componente atmosférica é dada por Delworth et al. 2006.

A componente oceânica do modelo (Gnanadesikan et al. [2006] e Griffies et al. [2005]) possui uma resolução horizontal de $1^{\circ}$ em latitude e longitude, diminuindo meridionalmente em direção aos trópicos, chegando a $0,3333^{\circ}$ próximo ao equador. Possui 50 níveis verticais com 22 níveis equi-espaçados (10 metros) nos primeiros 220 metros de coluna de água.

$\mathrm{O}$ acoplamento entre o oceano e atmosfera ocorre em intervalos de duas horas, acoplando o ciclo diurno da atmosfera e do oceano [Knutson et al. [2006]]. Vale ressaltar que esse modelo não emprega correções de fluxos. O resultado final do GFDL-CM2.1 é disponibilizado em uma grade regular com 200 pontos de latitude, 360 de longitude e 50 níveis verticais para o oceano. Maiores informações sobre a disponibilização e formatos de saída desse modelo são encontradas em http://nomads.gfdl.noaa.gov/ CM2.X/.

\subsubsection{NCAR_CCSM3.0}

O CCSM3.0 - Community Climate System Model version 3.0 é um modelo climático acoplado composto por quatro componentes distintas e que simulam a atmosfera, o oceano, a superfície terrestre e o gelo marinho, além de um módulo central de acoplamento. O CCSM foi desenvolvido no NCAR em Boulder, Colorado, e apresenta suporte e colaboração de diversas instituições através de projetos financiados pela National Science Foundation e pelo Department of Energy and the National Air and Space Administration.

A componente atmosférica é composta pelo CAM - Community Atmospheric Model apresenta resolução horizontal de 128 pontos de longitude por 64 pontos de latitude (correspondente à designação T42, em razão do truncamento espectral do modelo), e possui 26 níveis verticais. O módulo sobre os continentes é o CLM - Community Land Model apresenta grade idêntica ao modelo atmosférico. O modelo oceânico é uma extensão do POP - Parallel Ocean Program e apresenta grade deslocada nos pólos e apresenta resolução com 320 pontos de longitude e 395 de latitude e 40 níveis verticais. A representação da criosfera é feita pelo CSIM - Community Sea Ice Model, cuja implementação utiliza grade compatível com a do modelo oceânico. A documentação completa do CCSM3.0 pode ser encontrada em http://www.cesm.ucar.edu/models/ ccsm3.0/. 


\subsubsection{MIROC3.2-medres}

O MIROC - Model for Interdisciplinary Research on Climate é um projeto mantido pelo Center for Climate System Research da Universidade de Tóquio, pelo National Institute for Environmental Studies e pelo Frontier Research Center for Global Change. Esse modelo, em sua versão Medres, consiste de 5 componentes: atmosfera, terra, descarga de rios, gelo marinho e oceano. A interação entre essas componentes ocorre por um acoplador de fluxos. As trocas entre a atmosfera e o oceano ocorrem exclusivamente através da atmosfera e do gelo marinho e não diretamente entre a atmosfera e o oceano Hasumi and Emori [2004]. A componente atmosférica apresenta uma resolução horizontal T42, equivalente a aproximadamente $2,8^{\circ}$, em 20 níveis verticais. A componente oceânica desse modelo é o CCSR - Ocean Component Model, a qual interage somente com o gelo marinho, e é disponibilizada em uma resolução horizontal com $1,4^{\circ}$ de longitude e latitude variando entre 0,5 e 1,4 $4^{\circ}$ com 43 níveis que vão da superfície até o fundo. Utiliza as equações primitivas do movimento em uma esfera, adotando as aproximações hidrostáticas e de Boussinesq.

\subsubsection{ECHAM5/MPI-OM}

O modelo climático acoplado ECHAM5/MPI-OM é desenvolvido pelo Max-Planck Institute für Meteorologie de Hamburgo. As duas componentes do modelo, MPIECHAM5 para a atmosfera e MPI-OM para o oceano, são descritas por Marsland et al. 2003] e Roeckner et al. [2003]]. O MPI-ECHAM5 possui uma resolução horizontal T63, o que equivale a aproximadamente $2,0^{\circ}$, e 31 níveis verticais híbridos com o nível mais alto localizado no nível de $10 \mathrm{hPa}$. $\mathrm{O}$ modelo oceânico MPI-OM é um modelo de equações primitivas de coordenadas verticais z. A resolução é maior, $\mathrm{O}(20$ - 40km), em regiões de formação de água profunda (Mar de Labrador, Mar da Groenlândia e Mar de Weddell). Ao longo do equador a resolução meridional é cerca de $0,5^{\circ}$. As camadas verticais possuem espessura variando de 10 metros próximo à superfície e 600 metros próximo ao fundo. O resultado final do MPI-OM/ECHAM5 é disponibilizado em uma grade regular com resolução horizontal de $1^{\circ}$ em longitude e latitude e 40 níveis verticais.

\subsubsection{UKMO_HADCM3}

O HadCM3 - Hadley Centre Coupled Model version 3, é um modelo de circulação geral acoplado oceano-atmosfera desenvolvido no Hadley Centre, no Reino Unido. O HadCM3 não necessita de ajuste de fluxo (adição de fluxos de calor "artificial" e de fluxos de água doce na superfície do oceano) para produzir uma boa simulação. Foi desenvolvido para produzir 
simulações para períodos de mais de mil anos, mostrando pouco desvio em seu clima de superfície. Ele é composto por duas componentes: o modelo atmosférico HadAM3 e o modelo oceânico HadOM3 (que inclui um modelo de gelo marinho). Suas simulações costumam usar um calendário de 360 dias, onde cada mês é de 30 dias.

O HadAM3, modelo atmosférico, possui uma resolução horizontal de $3,75^{\circ}$ graus de longitude por $2,75^{\circ}$ graus de latitude, enquanto na vertical existem 19 níveis. O HadOM3 tem resolução de $1,25^{\circ} \mathrm{em}$ longitude e latitude, 20 níveis de profundidade. O acoplamento ocorre da seguinte forma: o modelo atmosférico é rodado por um dia, e os fluxos (de calor, água e momento) na interface oceano-atmosfera é acumulado. O modelo oceânico é rodado por um dia, com os fluxos reversos acumulados. Isso é repetido ao longo de toda a simulação.

\subsection{SÍNTESE DOS MODELOS}

Na tabela 2 está descrita uma síntese de cada modelo citado. Na primeira coluna o nome do modelo, na segunda a resolução oceânica, na terceira a resolução atmosférica, na quarta o centro de origem e na quinta a referência bibliográfica para cada um.

Tabela 2 - Resumo dos dados de cada modelo climático utilizado.

\begin{tabular}{|c|c|c|c|c|c|}
\hline Modelo & Resolução Oceano & Resolução Atmosfera & Origem & \multicolumn{2}{|l|}{ Referência } \\
\hline NCAR_CCSM3.0 & $1,125^{\circ} \times 0,45^{\circ} \times 402,8^{\circ}$ & $2,8^{\circ} \times 2,8^{\circ} \times 26$ & NCAR (USA) & Collins et al. & 2006 \\
\hline GFDL_CM2.1 & $1^{\circ} \times 1^{\circ} \times 50$ & $2,5^{\circ} \times 2,0^{\circ} \times 24$ & NOAA (USA) & Delworth et al. & 2006 \\
\hline MPI_ECHAM5 & $1^{\circ} \times 1^{\circ} \times 40$ & $2,0^{\circ} \times 2,0^{\circ} \times 31$ & Max-Planck (Germany) & Roeckner et al. & 2003 \\
\hline MIROC3.2_MedRes & $1,4^{\circ} \times 0,94^{\circ} \times 33$ & $2,8^{\circ} \times 2,8^{\circ} \times 20$ & CCSR (Japan) & Hasumi and Emor & ori 2004 \\
\hline UKMO HADCM3 & $1,25^{\circ} \times 1,25^{\circ} \times 20$ & $3,75^{\circ} \times 2,75^{\circ} \times 19$ & Hadley Centre (UK) & Gordon et al. & 2000 \\
\hline
\end{tabular}

\subsection{DEFINIÇÃO DE REGIÕES}

As análises das diferentes variáveis foram realizadas considerando duas regiões de interesse: uma que abrange praticamente toda a bacia oceânica do Atlântico Sul e parte do Atlântico Tropical, e outra que focaliza a porção oeste do Atlântico Sul adjacente à costa brasileira. O propósito desta divisão é avaliar a representatividade dos conjuntos de dados para fenômenos em diferentes escalas espaciais, sempre tendo como base os correspondentes campos observacionais. Além disso, a quantificação do desempenho dos modelos na representação de cada variável é preliminarmente realizada através de uma métrica que considera valores médios espaço-temporais em sua avaliação, a qual varia em função da escolha do domínio analisado. 
Assim sendo, os domínios considerados nas análises foram escolhidos de forma a permitir um entendimento abrangente das variáveis atmosféricas e oceânicas em todo o Atlântico Sul, bem como um detalhamento destas características na região de maior interesse e atividade de exploração. As denominações e delimitações dos domínios são e podem ser observadas na figura 2 :

- Oceano Atlântico Sul: 65W-20E; 45S-5N; e

- Oceano Atlântico Sudoeste: 50W-30W; 35S-20S.

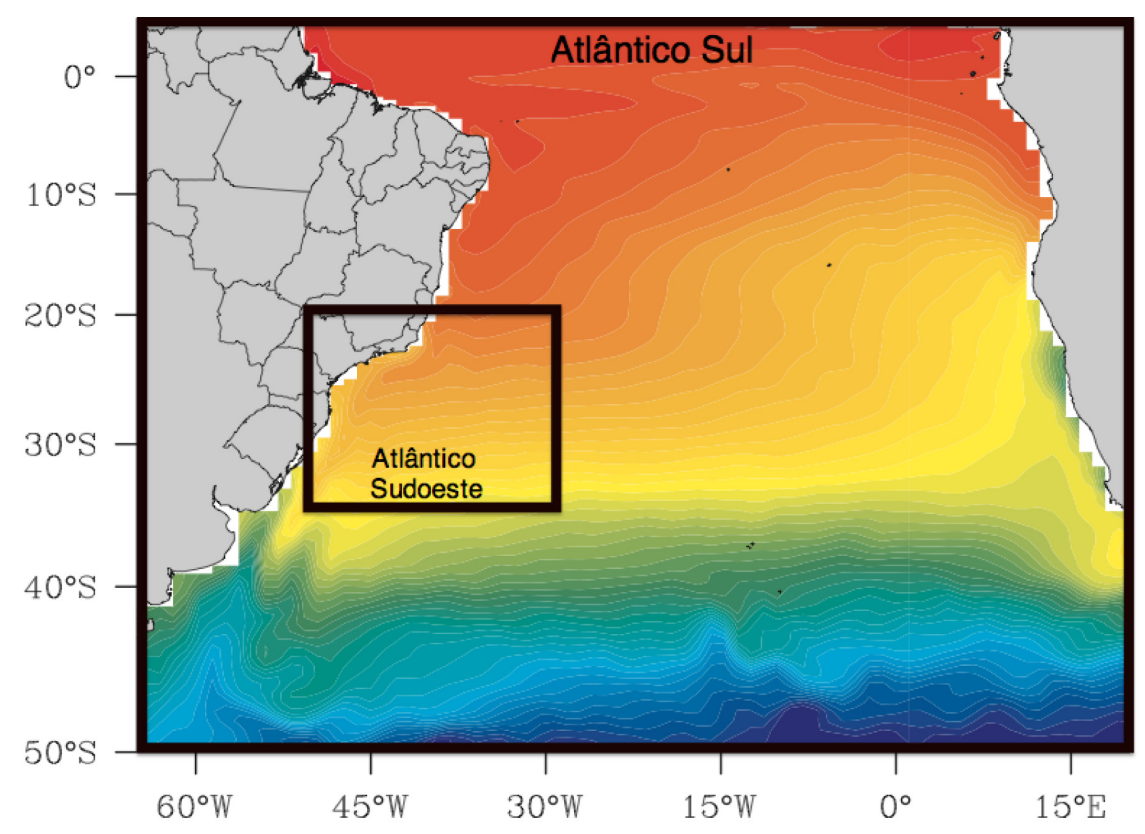

Figura 2 - Figura esquemática dos domínios regionais. O retângulo menor em preto representa o domínio do oceano Atlântico Sudoeste e o retângulo maior o oceano Atlântico Sul.

\subsection{ESTATÍSTICAS PARA ESCOLHA DE MODELOS}

Com o objetivo de avaliar os resultados numéricos do IPCC em relação aos campos observacionais, foram feitas análises do comportamento climatológico das variáveis de interesse, bem como determinações estatísticas que quantificam a representatividade de cada modelo. As estatísticas foram calculadas levando em consideração a resolução temporal original dos dados (médias mensais).

Para a elaboração do projeto completo foram feitas análises climatológicas dos campos, análise dos campos de viés, mapas de RMS - Erro Quadrático Médio, mapas de variâncias, correlação linear e Diagramas de Taylor. Neste texto somente será dada atenção aos diagramas de Taylor. 


\subsubsection{Diagramas de Taylor}

Para quantificar a destreza que os modelos apresentam para simular um determinado campo climático, o método de Taylor (Taylor 2001]) utiliza-se de três medidas estatísticas nãodimensionais:

- a razão entre as variâncias dos dois campos:

$$
\gamma^{2}=\frac{\sigma_{\text {modelo }}^{2}}{\sigma_{\text {reanálise }}^{2}}
$$

- a correlação entre os dois campos ( $R$, que é computada após a remoção dos médias globais);

- e o Erro Quadrático Médio normalizado (E) entre os dois campos (E, que é normalizado pelo desvio padrão da área observada).

A razão entre as variâncias indica a amplitude relativa das variações entre o modelo e a reanálise. A correlação indica se os campos têm padrões similares de variação, independentemente da amplitude. O erro quadrático médio normalizado pode ser entendido como uma composição das diferenças entre as médias globais $\left(E_{0}\right)$, com os erros no padrão de variação $\left(E^{\prime}\right)$. Essas três medidas são relacionadas através da seguinte equação:

$$
E^{\prime 2}=\sigma_{m o d}^{2}+\sigma_{o b s}^{2}-2 \sigma_{m o d} \sigma_{o b s} R
$$

Esta relação torna possível mostrar as três estatísticas em um gráfico bidimensional. O gráfico é construído baseado na Lei dos Cosenos $\left(c^{2}=a^{2}+b^{2}-2 a b \cos \phi\right)$. O campo observado é representado por um ponto nesse diagrama. Todos os outros pontos, que representam os campos simulados, estão posicionados de tal forma que $\gamma^{2}$ é a distância radial da origem, $R$ é o cosseno do ângulo azimutal e $E^{\prime}$ é a distância do ponto observado. Se a distância radial da referência até o ponto é relativamente curta, significa uma boa concordância entre os campos do modelo e da reanálise. Já a distância radial da origem até o ponto é proporcional ao desvio padrão contido no campo simulado pelo modelo.

As análises dos conjuntos de dados meteorológicos foram realizados para o período de 1950 a 1999. Os campos comparativos compreendem os resultados entre os modelos climáticos do $20 c 3 \mathrm{~m}$ e a reanálise do NCEP-I.

Foram utilizadas as variáveis de temperatura do ar a 2 metros, pressão reduzida ao nível do mar, vento zonal a 10 metros, vento meridional a 10 metros e umidade específica para elaboração dos diagramas entre os modelos do Cenário $20 \mathrm{c} 3 \mathrm{~m}$ e a reanálise do NCEP-I, para as regiões do Atlântico Sul (figura 3) e Atlântico Sudoeste (figura 4). 


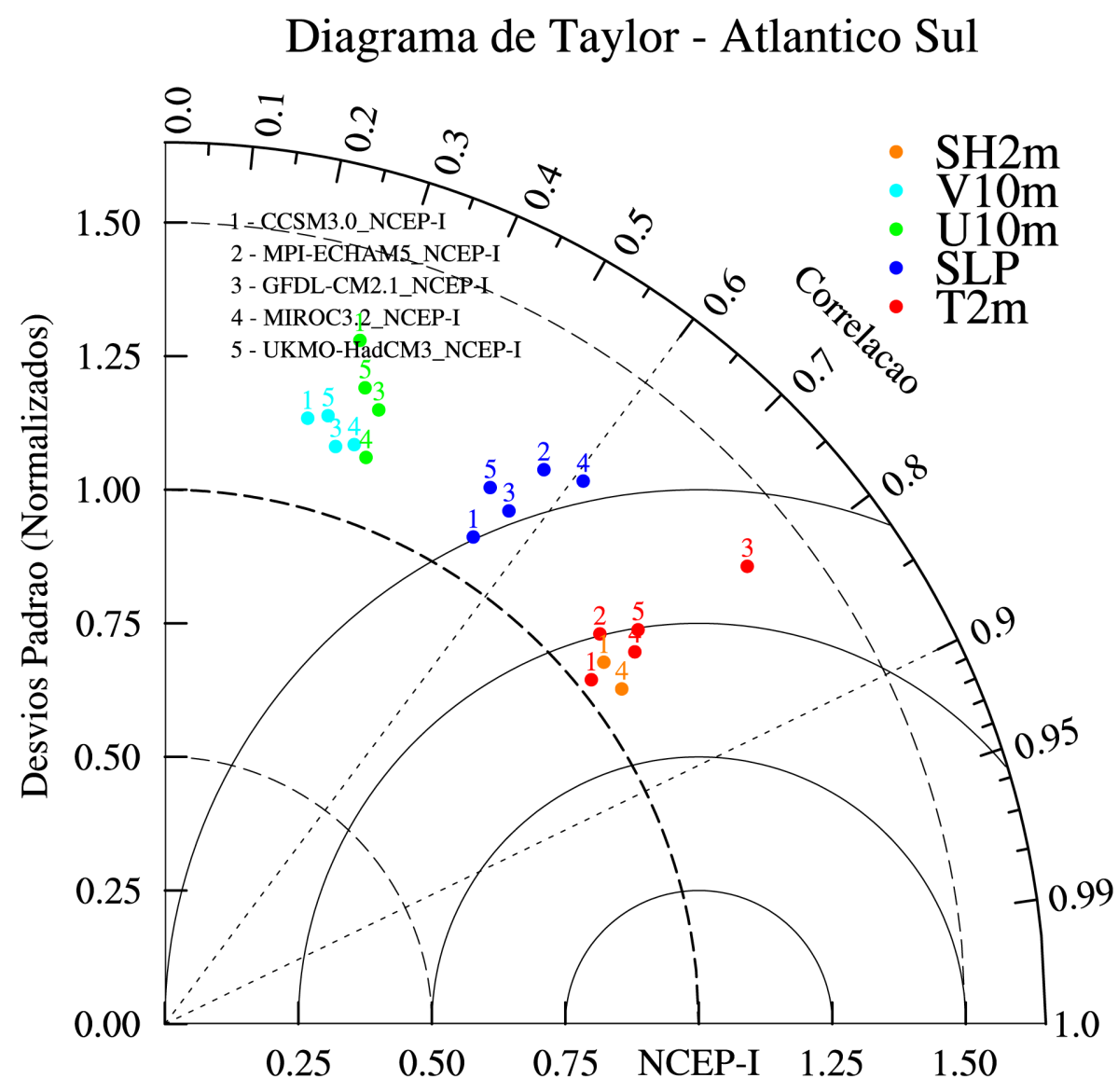

Figura 3 - Diagrama de Taylor para as variáveis atmosféricas incluindo temperatura (T2m) em vermelho, pressão reduzida ao nível do mar (SLP) em azul escuro, vento zonal (U10m) em verde, vento meridional (V10m) em azul claro e umidade específica $(\mathrm{SH} 2 \mathrm{~m})$ em laranja, em relação à referência NCEP-I para a região Atlântico Sul. Os números de 1 a 5 representam os modelos CCSM3.0, MPI-ECHAM5, GFDL-CM2.1, MIROC3.2 e UKMO-HadCM3, respectivamente, entre os anos de 1950 e 1999. Vale ressaltar que não estavam disponíveis as componente de vento para o modelo MPI-ECHAM5 e para o CCSM3.0 foram utilizados os campos de vento em 1000mb. A umidade específica só estava disponível para os modelos CCSM3.0 e MIROC3.2. 


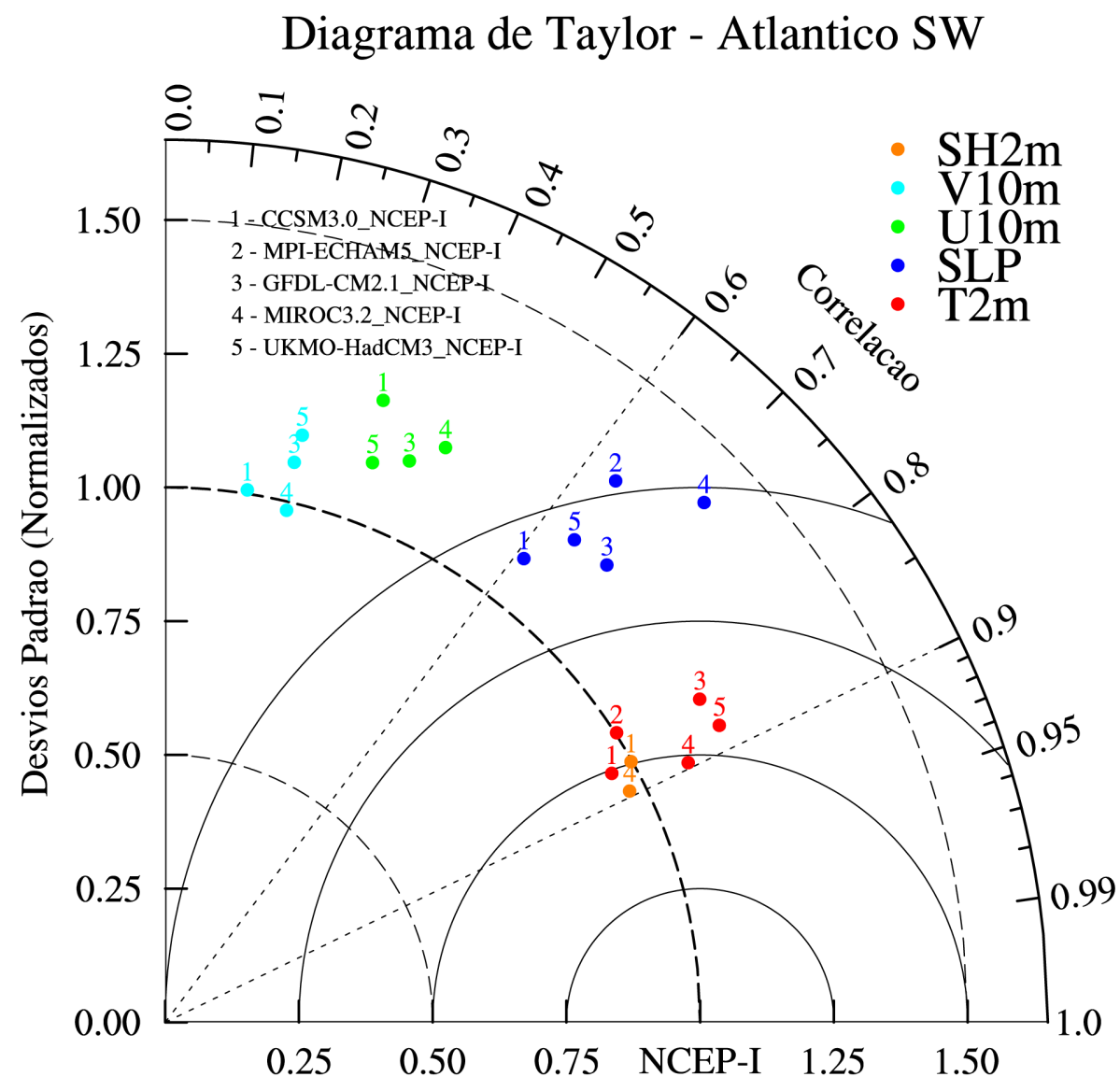

Figura 4 - Diagrama de Taylor para as variáveis atmosféricas incluindo temperatura (T2m) em vermelho, pressão reduzida ao nível do mar (SLP) em azul escuro, vento zonal (U10m) em verde, vento meridional (V10m) em azul claro e umidade específica $(\mathrm{SH} 2 \mathrm{~m})$ em laranja, em relação à referência NCEP-I para a região Atlântico Sudoeste. Os números de 1 a 5 representam os modelos CCSM3.0, MPI-ECHAM5, GFDLCM2.1, MIROC3.2 e UKMO-HadCM3, respectivamente, entre os anos de 1950 e 1999. Vale ressaltar que não estavam disponíveis as componente de vento para o modelo MPI-ECHAM5 e para o CCSM3.0 foram utilizados os campos de vento em $1000 \mathrm{mb}$. A umidade específica só estava disponível para os modelos CCSM3.0 e MIROC3.2.

No diagrama do Atlântico Sul é possível verificar que os modelos do $20 \mathrm{c} 3 \mathrm{~m}$ possuem uma correlação média de 0,8 para a temperatura a 2 metros, onde se destacam CCSM3.0 e MIROC3.2, com uma pequena vantagem para o CCSM3.0, que possui um desvio padrão normalizado mais próximo do ideal (igual a 1).

Para a umidade específica a 2 metros também é observada uma correlação média próxima a 0,8, novamente com CCSM3.0 e MIROC3.2 muito próximos, neste caso com pequena vantagem para o MIROC3.2 que possui correlação maior.

Os modelos apresentam correlação média em torno de 0,55 para a pressão reduzida ao nível do mar; o MIROC3.2 apresenta melhor correlação $(0,6)$ e o CCSM3.0 desvio padrão normalizado mais próximo ao ideal (com consequente menor valor de RMS, uma vez que essa 
grandeza é representada pela distância do ponto ao dados de referência).

Os dados de vento zonal e meridional a 10 metros (ou 1000hPa no caso do CCSM3.0) são os que apresentam menor representatividade em relação à referência, devido aos baixos valores de correlação.

No diagrama para o Atlântico Sudoeste foi verificado uma melhor representatividade de todas as variáveis analisadas anteriormente, indicando que na média os modelos do $20 \mathrm{c} 3 \mathrm{~m}$ representam bem a região. As correlação da temperatura e da umidade ficam entre 0,85 e 0,9 para todos os modelos, onde o CCSM3.0 e MIROC3.2 novamente se destacam pelas maiores correlação e menores RMS (com desvios padrão normalizados bem próximos a 1).

A correlação da pressão fica entre 0,6 (CCSM3.0) e 0,7 (MIROC3.2).

A correlação das componentes do vento a 10 metros continuam baixas, embora maiores do que no diagrama do Atlântico Sul. O vento zonal possui correlação maior do que o vento meridional, na média dos modelos.

Os diagramas de Taylor, tanto para o Atlântico Sul quanto para o Atlântico Sudoeste, apresentam características similares. Cada grandeza analisada não apresenta grandes variações entre os diferentes modelos, levando em consideração suas posições médias nos diagramas. A temperatura e a umidade são as variáveis com melhor representação pelos modelos, enquanto que as componentes do vento são as que mais distam da referência. É possível destacar pelos resultados de ambos os diagramas que os modelos CCSM3.0 e MIROC3.2 possuem uma representatividade, na média, melhor do que as demais simulações do 20c3m.

As componentes vetoriais, variáveis de grande importância para simulação dos campos de ondas, apresentam forte dependência de transientes (que são descartados ao se utilizar dados em médias mensais). Isso pode explicar a baixa correlação entre os resultados dos modelos em relação às referências e portanto as análises espaciais descritas anteriormente devem ser consideradas. Como nenhum modelo se destaca nos resultados obtidos com as variáveis vetoriais, qualquer um deles satisfaz os propósitos do presente estudo, motivo pelo qual variáveis como a temperatura superficial do mar, temperatura e umidade específica a $2 \mathrm{~m}$ receberam maior destaque na escolha do modelo.

Com base nestas afirmações, pode-se sugerir que o CCSM3.0 apresenta maior potencial para a representação em escala climática. Outro aspecto relevante que fortalece o uso do CCSM3.0 para as projeções climáticas futuras refere-se à possibilidade de obtenção de seus resultados na forma de campos médios diários e/ou eventualmente a cada 6 horas; isto foi um fator determinante, tendo em vista que campos médios mensais não contém informações suficientes que permitam caracterizar os regimes atmosféricos e oceânicos nos cenários futuros. 


\subsection{ETAPAS PARA REALIZAÇÃO DAS SIMULAÇÕES DE AGITAÇÃO}

Até agora foram descritas as etapas para escolha dos modelos climáticos que foram utilizados no downscaling do modelo atmosférico utilizado como forçante do modelo de ondas. Após serem concluídas todas as etapas de escolha dos modelos atmosféricos foram determinadas as etapas para a simulação dos campos de ondas.

Os esforços contemplaram as simulações do clima presente e das projeções do CCSM3, desde a grade global com 1 grau de resolução em latitude e longitude até a malha regional com 0,2 graus de resolução espacial, na qual foram empregados como forçantes os campos de vento provenientes do downscaling correspondente com o BRAMS.

Desta forma, cabe listar todas as etapas relativas ao procedimento de modelagem da agitação marítima:

- modelagem global de ondas para século XX utilizando como forçantes a Reanálise I do NCEP (Kalnay et al. [1996]), que fornecerá condições de contorno para simulação regional de referência;

- modelagem regional de ondas para o século XX utilizando como forçante o downscaling atmosférico com o modelo BRAMS/NCEP;

- modelagem global de ondas para século XX utilizando como forçantes o CCSM3, que fornecerá condições de contorno para simulação regional;

- modelagem regional de ondas para o século XX utilizando como forçante o downscaling atmosférico com o modelo BRAMS/CCSM3;

- modelagem global de ondas para século XXI utilizando como forçante o CCSM3 20c3m do IPCC AR4 SRESA2 (cenário pessimista), que fornecerá condições de contorno para simulação regional para o século $\mathrm{XXI}$;

- modelagem regional de ondas para o século XXI utilizando como forçante o downscaling atmosférico com o modelo BRAMS/RESA2;

- modelagem global de ondas para século XXI utilizando como forçante o CCSM3 20c3m do IPCC AR4 SRESB1 (cenário otimista), que fornecerá condições de contorno para simulação regional para o século XXI;

- modelagem regional de ondas para o século XXI utilizando como forçante o downscaling atmosférico com o modelo BRAMS/RESB1. 


\section{O DOWNSCALING ATMOSFÉRICO}

O principal objetivo deste capítulo é apresentar o procedimento do downscaling atmosférico utilizado no projeto IVAM-OAS. As etapas relativas à atmosfera são: 1) downscaling para século XX utilizando como condição inicial e de contorno a reanálise do NCEP, que foi considerada como simulação de referência; 2) downscaling para século XX utilizando como condição inicial e de contorno o CCSM3 20c3m do IPCC AR4; 3) downscaling para o século XXI utilizando as projeções SRESA2 (cenário pessimista) e SRESB1 (cenário otimista) do CCSM3 IPCC AR4. Os resultados obtidos com as simulações não serão abordados neste trabalho, eles foram utilizados como forçante para o downscaling das simulações de agitação detalhado no próximo capítulo.

\subsection{MODELO REGIONAL ATMOSFÉRICO}

O BRAMS (Freitas et al. [2009]) é um modelo derivado do RAMS - Regional Atmospheric Modeling System(Cotton et al. [2003]), criado para ser uma versão melhor ajustada para os trópicos, com inclusão de diversas melhorias, sub-modelos e parametrizações. É um projeto desenvolvido por algumas instituições, como o IAG-USP e o CPTEC - Centro de Previsão de Tempo e Estudos Climáticos do INPE - Instituto Nacional de Pesquisas Espaciaiss. É um modelo versátil, onde é possível simular circulações em diversas escalas espaciais, sendo mais frequentemente aplicado na mesoescala (escala de centenas de quilômetros). Sua construção foi baseada nas equações da dinâmica e termodinâmica da atmosfera, complementado com parametrizações de difusão turbulenta, radiação, processos úmidos incluindo a formação e a interação de nuvens, água líquida e gelo, calor sensível e latente, camadas de solo, vegetação entre outros processos. As opções físicas e parametrizações são configuradas a partir de um arquivo do tipo namelist, conhecido como RAMSIN. A versão utilizada neste trabalho é a 4.2 (disponível no site do modelo BRAMS - www.cptec.inpe.br/brams).

O BRAMS possui um esquema de aninhamento múltiplo de grades como mútua interação. As grades de maior dimensão espacial, geralmente de menor resolução, são utilizadas para simular sistemas de larga escala que vão interagir com os sistemas de mesoescala modelados nas grades mais finas, aninhadas à grade de maior dimensão espacial, através das condições de contorno internas do modelo. O ajuste nas fronteiras é dado por uma função de nudging, que determina um peso de influência do dado que está sendo assimilado. Nas laterais são aplicadas condições de contorno que permitem a passagem de ondas de gravidade e outros fenômenos que chegam à fronteira, com o intuito de eliminar a reflexão para o interior da área de domínio. No topo é aplicado um nudging, também em relação ao dado do modelo global. 
A condição de contorno na base está relacionada com as trocas de calor, momentum e massa entre a superfície e atmosfera logo acima dela, simulada em conjunto com o modelo como um todo.

A projeção horizontal é estereográfica, com pólo de projeção próximo ao centro da área de domínio com o objetivo de diminuir distorções na área de interesse. Na vertical existem duas opções de discretização: uma que acompanha o terreno, denominada sigma-z (Tripoli and Cotton [1982]) e uma segunda conhecida como shaved-ETA (Tremback and Walko [2004]), que é uma grade cartesiana onde as células de grade interceptam a topografia.

Freitas et al. 2009] fazem uma avaliação do BRAMS para a América do Sul mostrando que o desempenho pode ser considerado muito bom quando testado frente a medidas experimentais e operacionais. Diversas configurações operacionais do modelo também estão em constante avaliação na página de "Intercomparação de Modelos", desenvolvida em parceria entre o Laboratório MASTER e o CPTEC.

\subsubsection{Configuração do Modelo Atmosférico}

O modelo BRAMS é um programa computacional, codificado em linguagem Fortran- 90 e com suporte a utilização de paralelismo através do uso da biblioteca MPI - Message Passing Interface. É portável - em tese qualquer equipamento ou sistema operacional que tenha compiladores de linguagem Fortran-90 pode executar o BRAMS - e fica a cargo da biblioteca MPI disponível no equipamento permitir que o modelo seja executado em paralelo. Porém mesmo sendo portável o BRAMS é bastante complexo, e esta complexidade pode apresentar incompatibilidades em vários tipos e modelos e computadores.

De forma a diminuir ao máximo as incompatibilidades o modelo foi então compilado em um equipamento tipo PC, com central de processamento com vários núcleos (multicore), com sistema operacional Linux e biblioteca MPI. Esta configuração do modelo, equipamento e bibliotecas é a mais comum entre os usuários do BRAMS e se mostra bastante estável.

Para obter um downscaling consistente e com resultados que apresentam melhoria significativa em relação ao dado original (no nosso caso a reanálise), é preciso encontrar uma boa relação entre refinamento, ajuste e estabilidade da simulação. Isso porque muitas vezes um maior detalhamento aumenta a complexidade dos campos simulados, podendo gerar erros na representação de determinados padrões atmosféricos provenientes de aproximações numéricas que são dependentes da escala da simulação.

O BRAMS não foi desenvolvido especificamente para simulações longas, da ordem de dezenas de anos. Consequentemente, a primeira decisão relativa à configuração do downscaling do IVAM-OAS foi a realização de simulações em "blocos" mensais, com 2 dias de overlap 
entre elas. Cada simulação é iniciada com 2 dias de antecedência que são descartados por serem considerados um período de ajuste do modelo às condições iniciais, fenômeno conhecido como spin-up. Segundo testes realizados, 2 dias de spinup pareceram adequados para aquecer o modelo sem impactar negativamente no tempo de máquina necessário para executar cada bloco. Os blocos mensais (360 blocos no total) são então agrupados, resultando na série de 30 anos de dados.

A região de interesse do projeto foi o Oceano Atlântico Sudoeste (OAS). Sendo assim, a grade do modelo atmosférico é suficientemente grande para permitir um desenvolvimento completo do mar pelo fator pista de vento, imprescindível para implementação da mesoescala dos modelos de circulação e agitação. Uma grande região continental foi considerada no domínio para incluir o efeito do continente no oceano adjacente. A simulação foi configurada com 2 grades, com as características dimensionais apresentadas na tabela 3.

Tabela 3 - Características dimensionais das grades utilizadas.

\begin{tabular}{|c|c|c|c|c|c|c|}
\hline & LONGITUDE & LATITUDE & RESOLUÇÃO & $\mathrm{Nx}$ & $\mathrm{Ny}$ & $\mathrm{Nz}$ \\
\hline \hline GRADE1 & $73,33 \mathrm{~W}$ a $1,65 \mathrm{~W}$ & $47,57 \mathrm{~S}$ a $14,41 \mathrm{~N}$ & $1 \times 1$ grau & 68 & 65 & 37 \\
\hline GRADE2 & $63,50 \mathrm{~W}$ a $10,68 \mathrm{~W}$ & $42,25 \mathrm{~S}$ a $6,73 \mathrm{~N}$ & $0,25 \times 0,25$ grau & 198 & 200 & 37 \\
\hline
\end{tabular}

O principal motivo da utilização de 2 grades foi a grande diferença de resolução horizontal entre a condição de contorno e a simulação do downscaling: a reanálise do NCEP possui resolução da ordem de 2.5 grau, enquanto que a simulação do BRAMS chega a 0.25 grau, ou seja, a diferença entre a GRADE2 do BRAMS e a do NCEP é de uma ordem de grandeza, algo muito grande para este tipo de operação. Para que a melhoria de resolução fosse relativamente suave, configurou-se uma grade intermediária que, no caso do IVAM-OAS, possuía resolução da ordem de 1 grau e área de abrangência um pouco maior do que a GRADE2. A princípio somente a GRADE2 será utilizada para as análises e geração de produtos para os modelos oceânicos. A figura 5 apresenta o domínio das grades descritas na 3 . 


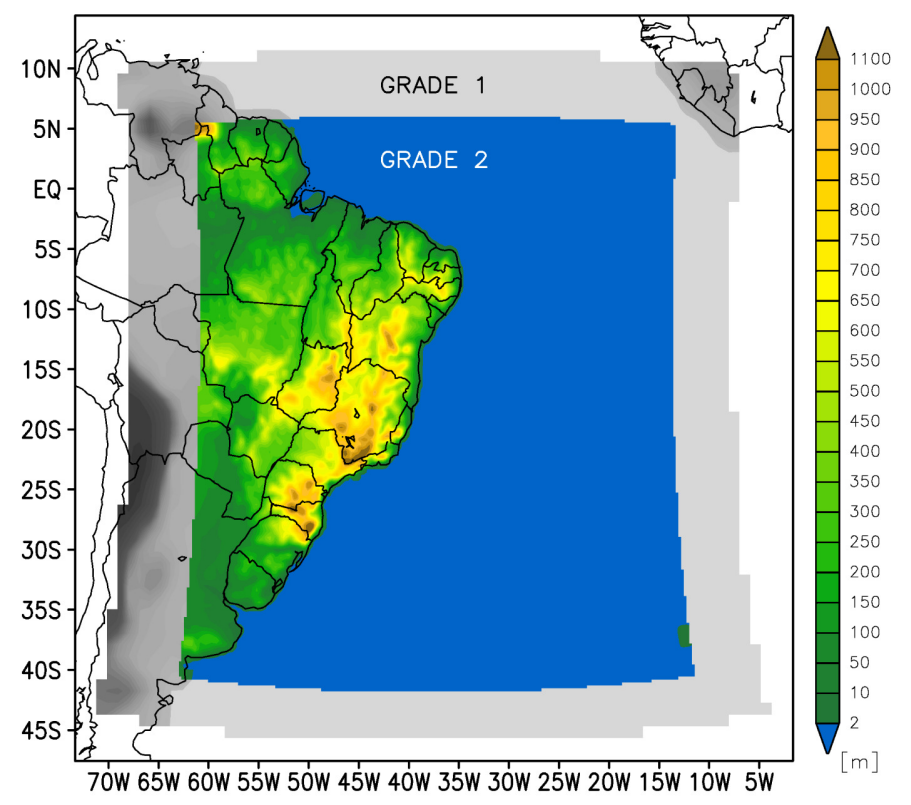

Figura 5 - Grades utilizadas para o downscaling atmosférico

A influência da condição de contorno, como já mencionado, é determinado por uma função de nudging. Esta função foi configurada para dar bastante influência da reanálise sobre as grades 1 e 2 do downscaling, tanto nas laterais, quanto no centro e no topo da grade, uma vez que a melhoria de resolução não deveria negligenciar os campos de larga escala provenientes do NCEP, mesmo na grade interna (GRADE2). A discretização vertical escolhida foi do tipo shaved-ETA, onde os níveis verticais interceptam a topografia, pois se apresentou mais estável nos testes. A resolução vertical é maior próximo à superfície e diminui com a altura.

As saídas de dados foram configuradas para gravar resultados a cada 3 horas, suficientes para descrever bem o ciclo diurno, simulando inclusive sistemas de mesoescala e de escala local, como brisas marítimas e frentes frias. O resultado obtido a cada 3 horas é a informação instantânea retirada da integração, não representando uma média entre os horários. As simulações se iniciam no ano de 1982 e terminam em 2011 (30 anos) devido à disponibilidade de informações necessárias para alimentar o modelo, como por exemplo, a temperatura da superfície do mar semanal.

Os esquemas de radiação no BRAMS se diferem basicamente pela interação ou não com as nuvens. O esquema utilizado realiza uma solução completa da equação de transferência radiativa, permitindo que o conteúdo de água líquida e o vapor presentes na atmosfera influenciem os fluxos de radiação solar e terrestre (Chen and Cotton [1988]).

Existem duas formas de produção de precipitação no BRAMS. A primeira é pela parametrização de microfísica (Meyers et al. [1997]), que especifica a complexidade dos processos de mudança de fase da água em seus três estados (sólido, liquido e gasoso), incluindo as trocas 
de calor envolvidas nas mudanças, calculados explicitamente em cada ponto de grade. São consideradas diferentes categorias de hidrometeoros:

- fase gasosa: vapor d'água;

- fase líquida: gotículas de nuvem e gotas de chuva;

- fase sólida: gelo primário, neve e agregados;

- fase mista entre líquido e sólido: granizos e pequenos granizos.

A utilização de cada categoria pode ser escolhida pelo usuário, definindo o nível de complexidade da simulação. Em simulações da ordem de 20 quilometros de espaçamento horizontal a precipitação estratiforme, que abrange grandes extensões horizontais e com evolução temporal relativamente lenta, é bem resolvida por esse esquema. Em contrapartida, para descrever sistemas convectivos utilizando a microfísica seria necessário resoluções de poucos quilometros ou mesmo centenas de metros, uma vez que os movimento internos associados a essas nuvens são desta ordem (Biazeto and Silva Dias [2012]). Para este trabalho foi escolhida uma categoria de complexidade da microfísica que considera os efeitos positivos de flutuação do vapor d'água e gotículas de nuvem na equação do movimento vertical, mas a precipitação não é considerada.

A solução para resolver a precipitação em mesoescala, com resolução da ordem de $20 \mathrm{~km}$, é utilizar a segunda forma de produção de precipitação, conhecida como parametrização de cumulus. Essa parametrização é utilizada para redistribuir verticalmente calor e umidade em uma coluna de ar atmosférica quando o modelo cria uma região convectivamente instável e a resolução horizontal da grade é muito grosseira para que o modelo resolva adequadamente as circulações convectivas. Sendo assim, as simulações do IVAM-OAS utilizam o esquema de parametrização de cumulus de Grell (Grell and Devenyi [2002]), pois acredita-se que o mesmo seja suficiente para reproduzir a precipitação na escala dos downscalings, tanto de sistemas convectivos quanto estratiformes.

Foram utilizados como condição inicial e de contorno os dados de reanálise do NCEP, além de informações de vegetação e uso do solo, topografia e temperatura da superfície do mar que, em conjunto, contribuem para o refinamento que o downscaling exige. A seguir segue uma breve descrição de tais informações.

\subsubsection{Topografia}

A topografia utilizada tem origem nos dados do USGS - U. S. Geological Survey, http: //www.usgs.gov), com $1 \mathrm{~km}$ de resolução horizontal. Para cada simulação os dados são interpolados pelo próprio BRAMS para a resolução da mesma, que no caso da GRADE2 aqui apresentada é de 0.25 grau (aproximadamente $25 \mathrm{~km}$ no Equador). No início do projeto 
preocupou-se em representar da melhor maneira possível a linha de costa na resolução pretendida de 25 km, utilizando-se a topografia do SRTM - Shuttle Radar Topography Mission da NASA - National Aeronautics and Space Administration (http://www2.jpl.nasa.gov/srtm/), originalmente com 90 metros de resolução horizontal. A interpolação desta topografia acarretou em problemas que serão descritos ao longo do documento, invalidando 30 anos de simulações.

\subsubsection{Dados de Vegetação e Uso do Solo}

São incluídas informações do tipo de cobertura vegetal sobre o continente, assim como a localização de áreas urbanas, que vão influenciar diretamente os fluxos de superfície. Superfícies de água, como oceanos, rios e lagos também são considerados (dependendo da resolução do arquivo utilizado). As informações sobre a cobertura vegetal utilizadas possuem $1 \mathrm{~km}$ de resolução e o de textura solo possuem $4 \mathrm{~km}$ de resolução, ambos disponibilizados pelo INPE. 


\section{MODELO WAVEWATCH III}

O modelo utilizado para as simulações dos campos de ondas de gravidade superficiais foi o WAVEWATCH III versão 3.14 (WW3, Tolman 2009]). Este é um modelo de terceira geração, desenvolvido pelo MMA - Marine Modeling and Analysis Branch do EMB - Environmental Modeling Center do NOAA - National Oceanic and Atmospheric Administration. No WW3, a evolução do campo de ondas é simulada através da utilização do espectro direcional de ondas no espaço dos números de onda. Esta versão apresenta opções de aninhamento de grades do tipo único ou múltiplo, neste caso com interação mútua entre as grades. Também apresenta opções de física de propagação de ondas em águas rasas.

O WW3 está em constante desenvolvimento e é amplamente utilizado tanto para pesquisa como para sistemas operacionais de previsão de ondas em diversos centros de pesquisa nacionais e internacionais como NCEP e INPE.

\subsection{CONFIGURAÇÃO DO MODELO}

O modelo WW3 é um programa computacional, codificado em linguagem Fortran-90 e com suporte a utilização de paralelismo através do uso da biblioteca MPI. É portável, qualquer equipamento ou sistema operacional que tenha compiladores de linguagem Fortran-90 pode executar o WW3 e fica a cargo da biblioteca MPI disponível no equipamento permitir que o modelo seja executado em paralelo.

Em função do enorme esforço computacional envolvido e pela facilidade de uso de equipamentos aloucados no laboratório MASTER/IAG/USP, seja pela manipulação de grandes volumes de dados, computadores idênticos tipo $P C$, com central de processamento com vários núcleos (multi-core), com sistema operacional Linux e biblioteca MPI foram utilizados simultaneamente. De forma a diminuir ao máximo qualquer eventual incompatibilidade entre os resultados, o modelo foi compilado em um dos equipamentos e replicado para os demais, de modo a garantir reprodutibilidade binária entre resultados de simulações idênticas realizadas em diferentes equipamentos. Esta estabilidade alcançada agrega confiabilidade ao downscaling realizado.

\subsection{CONFIGURAÇÃO DAS SIMULAÇÕES DE AGITAÇÃO}

Para se obter o campo de ondas em escala regional preservando a propagação de swell gerados fora da área de interesse, conforme abordado em Branco [2005] e Alves [2006], foi implementado um sistema de modelagem utilizando duas malhas de cálculo: uma grade global 
que garante a propagação do swell e que permite especificar as condições de fronteira nas bordas de uma grade regional com maior resolução visando o Oceano Atlântico Sudoeste (OAS).

O aninhamento adotado foi unidirecional, permitindo que a grade de menor resolução influencie a grade de maior resolução, mas não o contrário. Foram determinados 635 pontos na grade global coincidentes com as bordas da grade regional, para os quais foram extraídos e aplicados os espectros direcionais como condição de fronteira para as simulações do OAS. As grades para as simulações foram configuradas com as características dimensionais apresentadas na Tabela 4

Tabela 4 - Características dimensionais das grades utilizadas.

\begin{tabular}{cccccc} 
& LONGITUDE & LATITUDE & RESOLUÇÃO & $\mathrm{Nx}$ & $\mathrm{Ny}$ \\
\hline \hline GLOBAL & $180 \mathrm{~W}$ a $180 \mathrm{E}$ & $-80 \mathrm{~S}$ a $80 \mathrm{~N}$ & $1 \times 1$ grau & 360 & 161 \\
\hline \hline OAS & $63 \mathrm{~W}$ a $1 \mathrm{~W}$ & $40 \mathrm{~S}$ a $5 \mathrm{~N}$ & $0,2 \times 0,2$ grau & 241 & 221 \\
\hline
\end{tabular}

A configuração da grade global utilizada para geração das condições de fronteira do domínio OAS pode ser observada na figura 6. O domínio global possui longitudes variando de $-180 \mathrm{~W}$ a 180W, de modo que a condição cíclica não seja aplicada em Greenwich e sim na linha de data, bem distante da região de interesse do projeto. Na figura 6 também estão identificados 373 pontos de saídas pontuais da simulação, para os quais foram gerados arquivos com a evolução temporal dos espectros de ondas assim como diversas outras variáveis. Considerando que a resolução espacial da grade não é suficiente para resolver pequenas ilhas presentes nos oceanos e que influenciam a propagação do campo de ondas conforme descrito por Tolman [2003], foi aplicada uma grade auxiliar, compatível com as características da grade global, onde é destacada a informação de pequenas ilhas. Esta grade possui informações de ilhas oceânicas menores que a resolução da grade principal, o uso dela possibilita o modelo contabilizar barreiras físicas que influenciam diretamente na propagação do campo de ondas. Detalhes deste procedimento pode ser encontrando em Tolman [2003. 


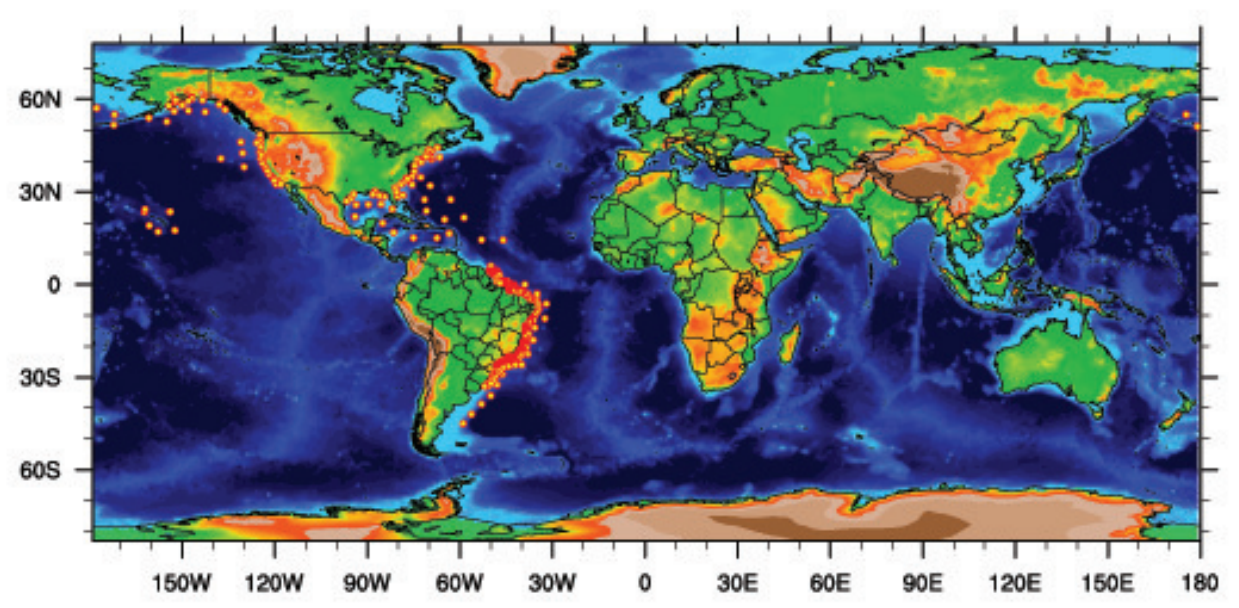

Figura 6 - Grade global utilizada para simulação dos campos de agitação global.

A grade regional estabelecida para as simulações no OAS pode ser observada na Figura 7. Nesta grade a porção sudoeste do Atlântico Sul foi estrategicamente posicionada na parte central do domínio. Nos contornos abertos são aplicados os espectros oriundos das simulações globais, de maneira a garantir a entrada de energia gerada fora do domínio. Nesta figura também podem ser observados 270 pontos de saídas pontuais do modelo, da mesma forma realizada para o domínio global. Tanto a grade global como a grade regional foram estabelecidas com a compilação de diversos dados de batimetria de alta resolução disponíveis como os ETOPOs, GEBICO, ... 


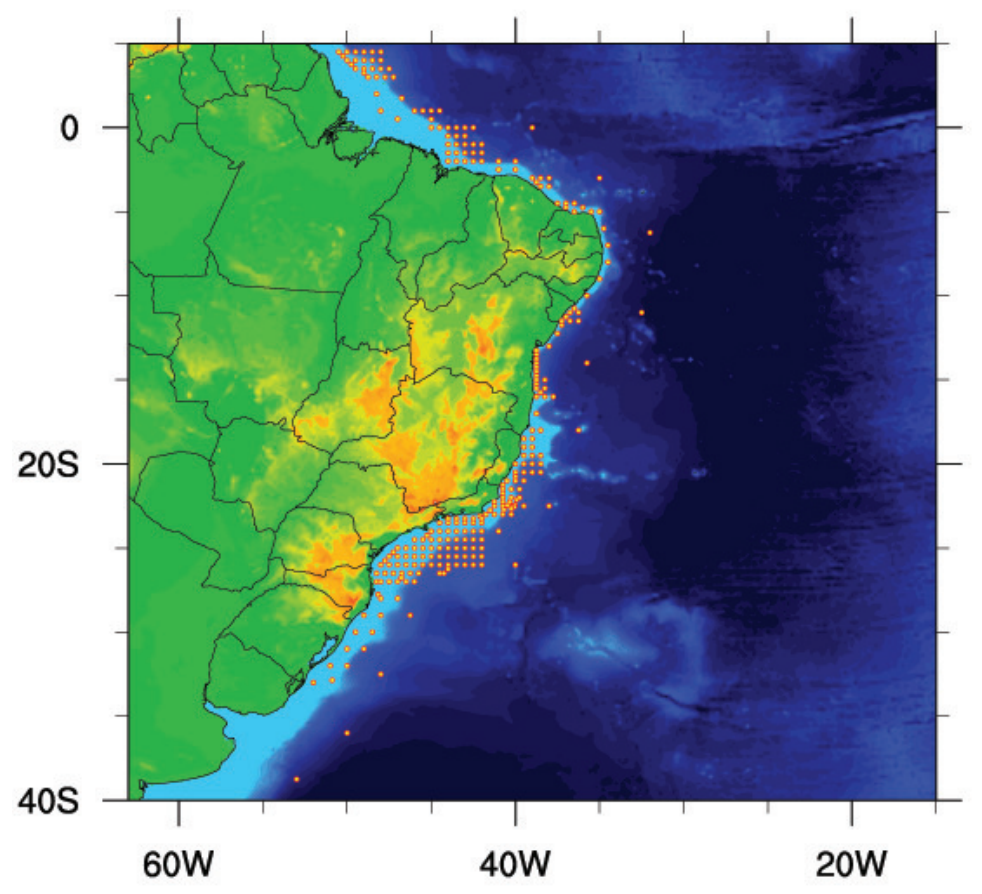

Figura 7 - Grade regional utilizada para simulação dos campos de agitação.

Nesta versão do WW3, a utilização de uma grade variável de números de onda incorpora naturalmente as mudanças nos números de onda devido a processos de águas rasas. A grade de número de onda local correspondente é obtida diretamente da grade de frequência através da relação de dispersão, se tornando assim dependente da profundidade local. De modo correspondente, foi aplicada uma grade invariante de frequências que é uma função logarítmica, representada na Figura 8 .

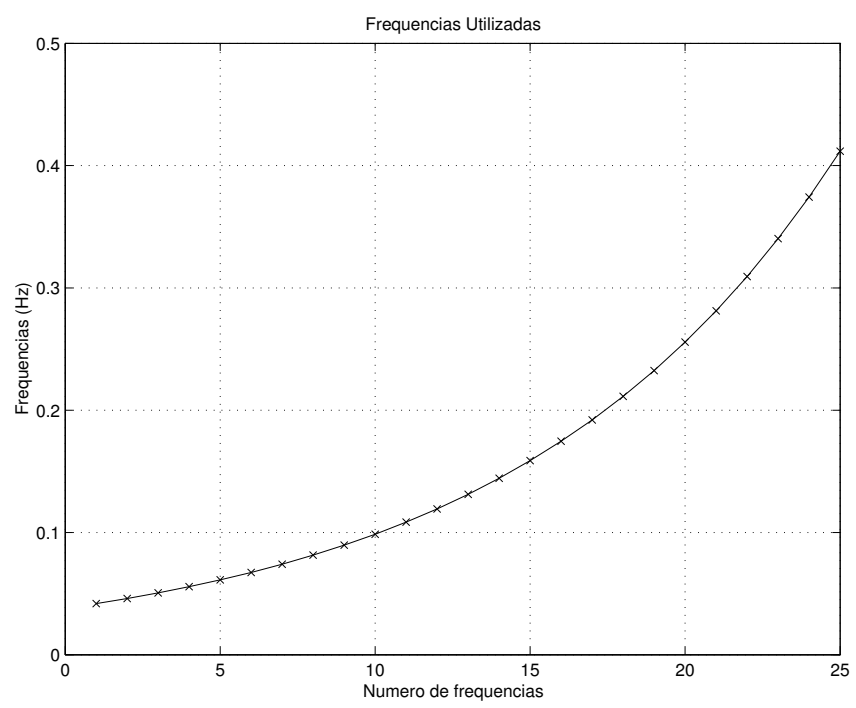

Figura 8 - Função de definição das aplicadas nas simulações de agitação. 
A grade espectral utilizada na configuração do WW3 consiste na combinação das frequências (8) com as direções que variam de 0 a 360 graus em intervalos de 10 graus no caso desta implementação. Na figura 9 está representa de maneira esquemática a grade espectral aplicada no modelo. A forma desta grade garante que em todos os intervalos de direções o swell seja resolvido corretamente pois a grade de frequência apresenta menor espaçamento para frequências menores (períodos mais longos).

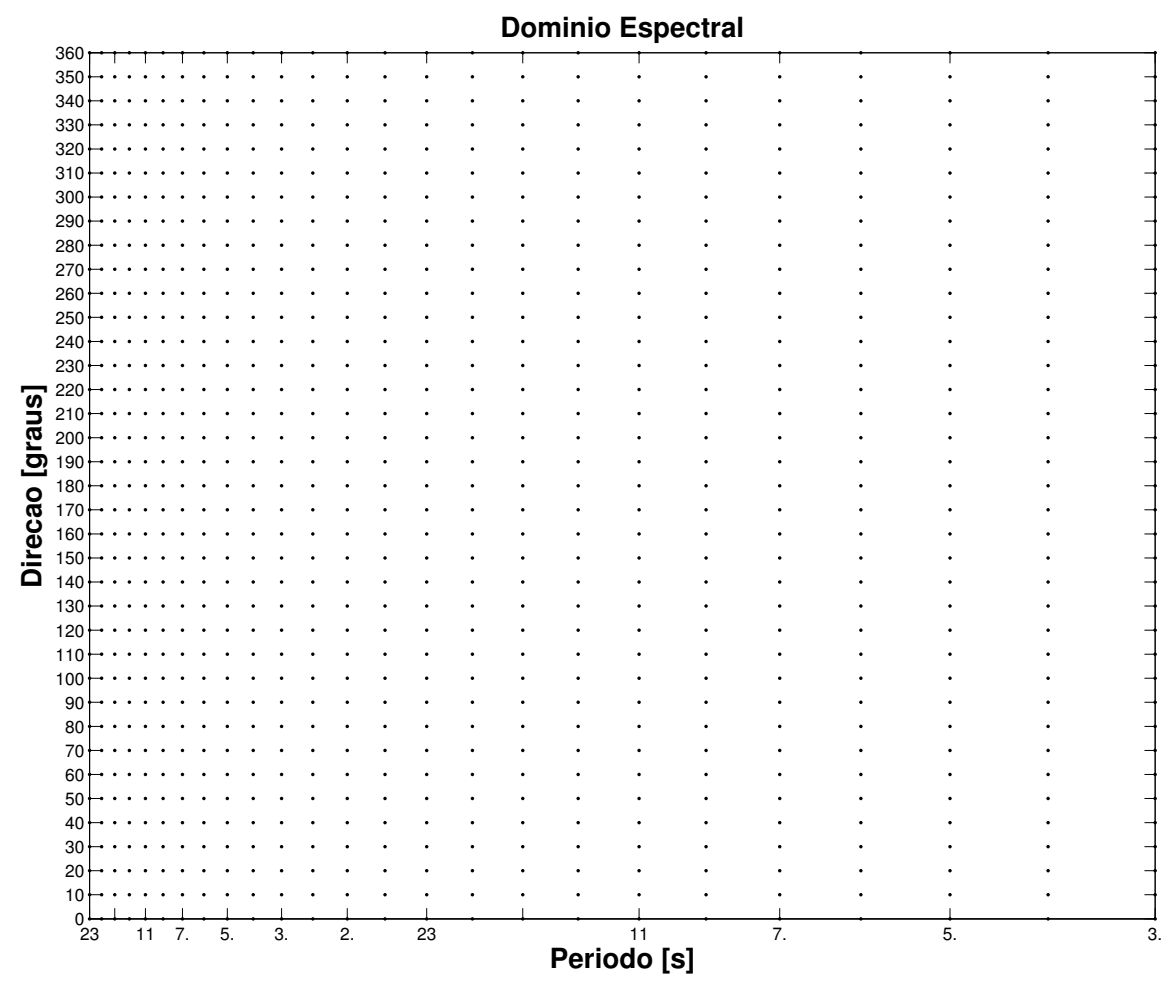

Figura 9 - Esquema gráfico da grade espectral aplicada nas simulações.

O modelo foi configurado para gravar resultados a cada 3 horas, suficientes para descrever sistemas de larga e de mesoescala, e até mesmo a brisa marítima. Os passos de tempo de integração foram estabelecidos de maneira que o resultado obtido a cada 3 horas é a informação instantânea retirada da integração, não representando portanto uma média entre os horários.

\subsubsection{Dados de Entrada}

No modelo de ondas são especificadas as forçantes com os dados de superfície provenientes da reanálise do NCEP (Kalnay et al. [1996]): vento a 10 metros, temperatura do ar em 2 metros, cobertura de gelo polar além de informações da temperatura da superfície do mar. A seguir segue uma descrição de tais informações. 


\subsubsection{Reanálise I - NCEP/NCAR}

Uma grande vantagem desta base de dados é o número elevado de parâmetros disponíveis, tanto em superfície quanto em altitude, os quais apresentam consistência física e dinâmica com absoluta regularidade no espaço e no tempo. Relembrando as s características que merecem maior destaque são:

- dados disponibilizados de Janeiro de 1948 até o presente;

- 4 horários por dia (00Z, 06Z, $12 Z$ e 18Z);

- Grade Global (144x73 pontos): 0E a 357,5E e 90N a 90S;

- Zonal: $2,5^{\circ}$;

- Meridional: $2,5^{\circ}$;

- 17 níveis de pressão (mb): 1000; 925; 850; 700; 600; 500; 400; 300; 250; 200; 150; 100; $70 ; 50 ; 30 ; 20 ; 10$.

As variáveis de superfície utilizadas são:

- Temperatura do Ar em 2 metros $\left[{ }^{\circ} \mathrm{C}\right.$ ];

- Componentes Zonal e Meridional do Vento a 10 metros [ m/s ];

- Cobertura de gelo [\%].

\subsection{Temperatura da Superfície do Mar}

A TSM - Temperatura da Superfície do Mar utilizada é fornecida pelo NOAA (http://www. noaa.gov/), conhecida como OISSTv2 - Optimum Interpolation of Sea Surface Temperature. É um conjunto de dados com resolução espacial de 1 grau em latitude e longitude, com cobertura global. Os dados são disponibilizados semanalmente e a nova condição é obtida através de uma combinação (merge) da última TSM disponibilizada com a condição dinâmica climatológica para o mês correspondente. A especificação de TSM nas simulações foi realizada nos dias com observações disponíveis, inclusive ao longo da simulação.

A utilização das variáveis de temperatura do ar e TSM entram na formulação aplicada para o desenvolvimento do mar segundo Tolman and Chalikov [1996] e garantem que processos relacionados a instabilidade atmosférica sejam levados em consideração na formulação da geração de ondas. Estas informações entram na forma de campos de diferença de temperaturas ar-mar. 


\subsubsection{Dados de Entrada da Simulação CCSM3 IPCC AR4 (20c3m e Projeções)}

As forçantes atmosféricas utilizadas, assim como a TSM, são oriundas das simulações do modelo CCSM3, do relatório AR4 do IPCC.

$\operatorname{CCSM} 3.0$

O CCSM3 é um modelo climático acoplado composto por quatro modelos distintos e que simulam a atmosfera, o oceano, a superfície terrestre e o gelo marinho, além de um módulo central de acoplamento. O CCSM3 foi desenvolvido no NCAR em Boulder, Colorado, e apresenta suporte e colaboração de diversas instituições através de projetos financiados pela National Science Foundation e pelo Department of Energy and the National Air and Space Administration.

A componente atmosférica datada é composta pelo CAM e apresenta como principais características:

- dados disponibilizados de 1900 até 1999 (20c3m) e de 2000 a 2100 (projeções);

- 4 horários por dia (00Z, 06Z, $12 Z$ e 18Z);

- grade global, com resolução horizontal de 256 pontos de longitude por 128 pontos de latitude (correspondente à designação T84, em razão do truncamento espectral do modelo);

- 26 níveis verticais híbridos: 992,556; 970,555; 929,649; 867,161; 787,702; 696,796; 600,$524 ; 510,455 ; 433,895 ; 368,818 ; 313,501 ; 266,481 ; 226,513 ; 192,540 ; 163,662$; 139,$115 ; 118,250 ; 100,515 ; 85,439 ; 70,059 ; 53,115 ; 37,230 ; 23,945 ; 13,967 ; 7,3889$; 3,545 ;

As variáveis de superfície utilizadas são:

- Temperatura do $\operatorname{Ar}$ em 2 metros $\left[{ }^{\circ} \mathrm{C}\right]$;

- Componentes Zonal e Meridional do Vento a 10 metros [ m/s ];

- Cobertura de gelo marinho [\%].

A documentação completa do CCSM3.0 pode ser encontrada em http://www.cesm.ucar. edu/models/ccsm3.0/ e os dados datados de 6 em 6 horas foram obtidos em http://www. cgd.ucar.edu/ccr/strandwg/ccsm_6hr_data.html. 


\subsection{Temperatura da Superfície do Mar}

Foi utilizada a variável "temperatura da superfície", que descreve a temperatura da superfície do continente e do oceano, obtida a partir do dado original do CCSM3. Essa variável possui atualização diária para o oceano.

\subsection{ESTRATÉGIA PARA AS SIMULAÇÕES}

As simulações do século XX iniciam no ano de 1982. O início da década de 1980 foi caraterizada pela disponibilidade de dados satelitais, os quais inovaram a meteorologia e a oceanografia de larga escala. Para as condições do clima presente, foram simulados 30 anos WW3 com forçantes da Reanálise I do NCEP e 20 anos com forçantes do CCSM3. Para as projeções, foram simulados 20 anos com cada cenário pessimista e otimista, finalizando no final do ano de 2049.

Uma sequência de procedimentos foi estabelecida para obtenção dos resultados finais. De forma objetiva e resumida, esta sequência pode ser itemizada como:

- obtenção das forçantes globais;

- formatação dos dados para o formato de leitura do WW3;

- interpolação dos dados para a resolução da grade da simulação;

- execução do modelo global gerando as condições de contorno para o domínio regional;

- processamento das forçantes regionais;

- execução do modelo regional;

- pós-processamento das saídas do WW3 para permitir a visualização dos resultados (formato binário do software Grid Analysis and Display System - GrADS);

- conversão dos dados pós-processados para NetCDF (formato que permite abertura em diversos softwares);

Exceto pela obtenção das forçantes globais, todos os demais procedimentos são repetidos para cada uma das simulações. Para as simulações regionais é necessário dispor dos resultados das simulações atmosféricas para obtenção das forçantes para o modelo de agitação.

Para todas as simulações de ondas foi dado um período de aquecimento (spinup) de dois meses antes do início de cada conjunto. Por exemplo, para simulações iniciadas em janeiro de 1982 foi feito o aquecimento do modelo do início de novembro 1981 até a hora 00:00z 
de janeiro de 1982. Este procedimento é necessário para total desenvolvimento e propagação de swell nas maiores bacias oceânicas como na região do Pacífico e Índico Sul pois grande parte da energia de ondas geradas nestas regiões pode afetar diretamente o clima de ondas nas regiões sul e sudeste do Brasil (Branco 2005]).

O modelo de ondas foi configurado para uma rotina de simulação mensal de maneira que para cada mês foi gerado um arquivo de condições iniciais. Esse procedimento foi adotado de modo a oferecer maior possibilidade de controle das simulações e evitando erros que poderiam atrasar todo o processo, bem como na eventual necessidade de refazer algum período com informações corrompidas. Para cada mês de simulação foi gerado um arquivo de condições iniciais tanto para a grade global quanto para a grade regional. No caso das simulações regionais o modelo lê as informações de condições iniciais junto com as informações de condições de contorno geradas com a simulação global.

\subsection{PRODUTOS OBTIDOS}

O modelo WW3 produz como resultados dois arquivos codificados para cada ciclo (neste caso cada mês), um arquivo com as informações de campo e outro arquivo para saídas pontuais com informações dos espectros de ondas de onde é possível a obtenção da maioria dos parâmetros de ondas. O processamento destes arquivos para formatos de leitura e processamento é feito por rotinas de pós-processamento fornecidas junto com o próprio código do modelo.

Os dados utilizados para análise da agitação marítima no contexto deste documento referemse a:

- campos de Hs - altura significativa;

- campos de Tm - período médio;

- campos de Dm - direção média;

- séries temporais de Hs;

- séries temporais de Tp - período de pico e

- séries temporais de Dp - direção de pico.

Cabe esclarecer que não serão explorados os resultados da grade global, a qual foi empregada para melhor representar a região de estudo do ponto de vista da propagação de swell por longas distâncias. Referências as simulações globais serão abordadas na exemplificação de um nova etapa para explorar ainda mais os resultados obtidos com os campos de onda. 
Além disso, as análises aqui apresentadas focalizaram a parte sul do domínio regional no Oeste do Atlântico Sul, onde estão localizadas as Bacias de Campos e de Santos, de modo a diminuir a abrangência espacial das análises. 


\section{SÉCULO XX (CONTROLE)}

A Reanálise do NCEP é considerada uma informação de referência, muito utilizada na literatura científica. Dentre os principais destaques desse conjunto de dados pode-se mencionar a inclusão de observações através de esquemas de assimilação de dados e o longo período disponível sem descontinuidade, além de outras características descritas anteriormente.

Os processamentos que tiveram como forçantes os dados do NCEP e os resultados do downscaling obtidos com o BRAMS/NCEP são adotadas como simulações de referência para este estudo.

\subsection{ALTURA SIGNIFICATIVA}

\section{Médias de Altura Significativa}

A Figura 10 apresenta o campo médio de 20 anos para de altura significativa. Pode-se observar que as áreas com maiores valores de altura estão localizadas na porção sudeste do domínio, região de passagem de ciclones extra-tropicais e nas proximidades de toda a fronteira leste.

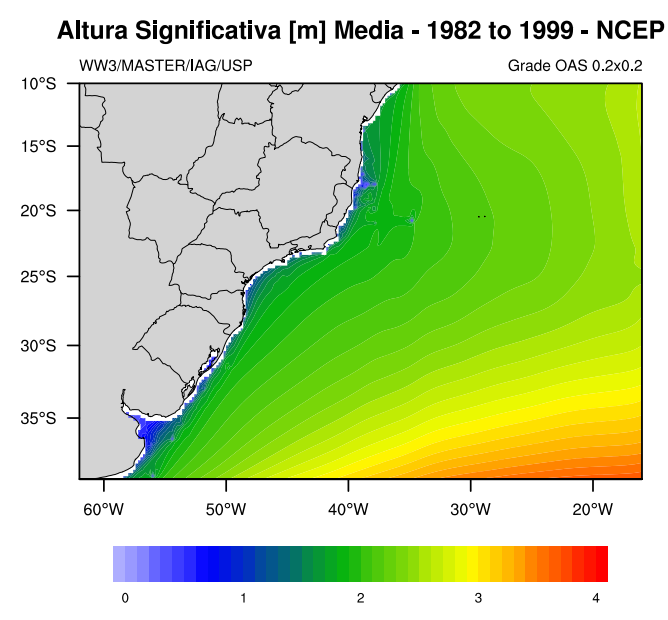

Figura 10 - Média da Altura Significativa [m] ao longo de 20 anos forçados com o downscaling BRAMS/NCEP.

Ao longo das estações do ano a região que apresenta os maiores valores no campo de altura significativa também é a região que apresenta maior variação sazonal. Este fato é facilmente observado com a comparação visual apresentada na figura 11 . Durante os meses de verão são observados os menores valores no campo. Para os meses de outono observa-se um pequeno aumento do valor médio de Hs chegado ao máximo dos valores para os meses de inverno, quando contornos de Hs mais elevados se aproximam da linha de costa. Nos meses 
de primavera a situação do campo é bem semelhante aos meses de outono, diminuindo os valores de Hs quando comparado aos meses correspondentes ao inverno.

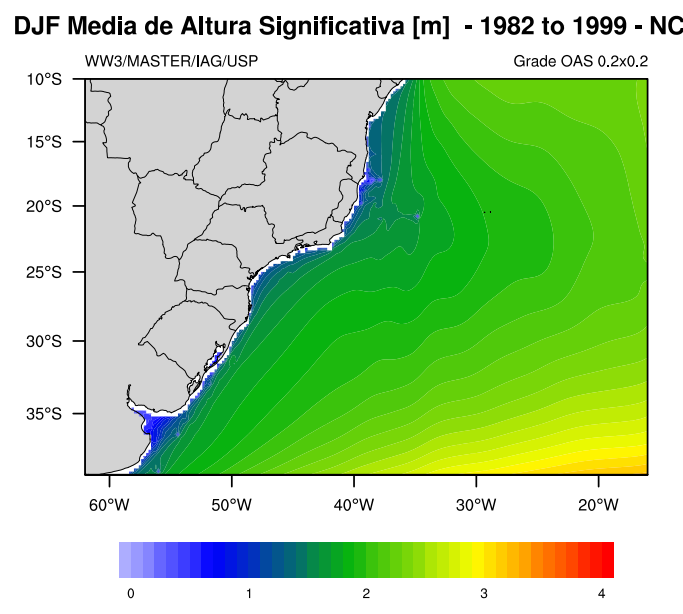

JJA Media de Altura Significativa [m] - 1982 to 1999 - NCEP

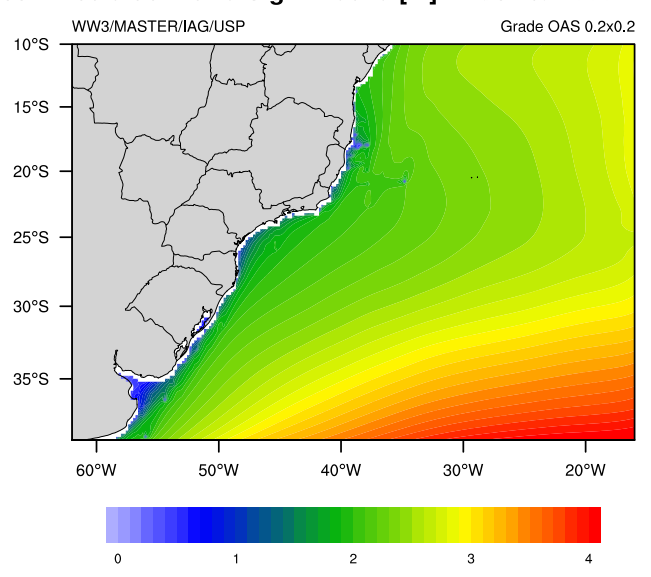

MAM Media de Altura Significativa [m] - 1982 to 1999 - NCEP

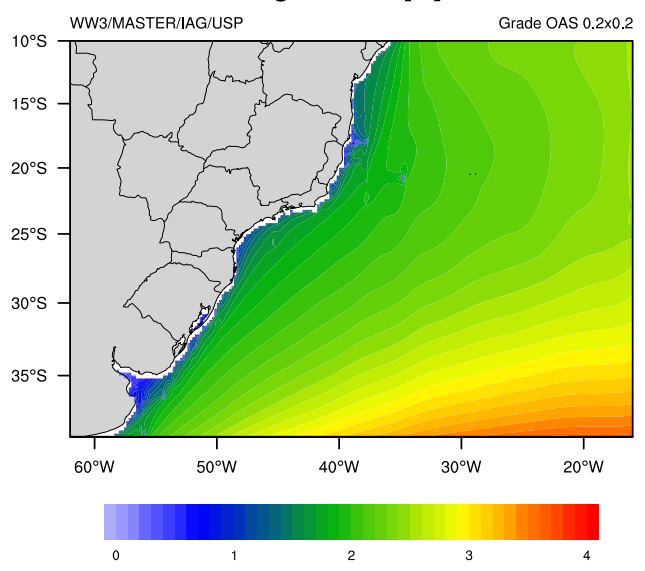

SON Media de Altura Significativa [m] - 1982 to 1999 - NCEP

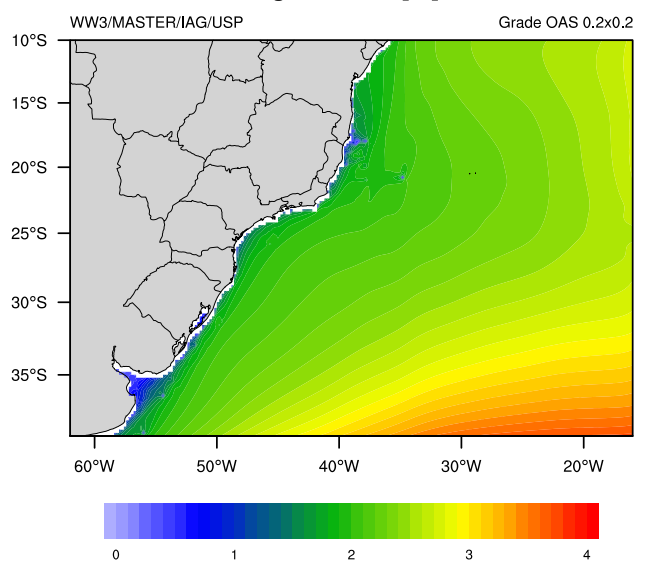

Figura 11 - Médias sazonais de Altura Significativa [m] ao longo de 20 anos forçados com o downscaling BRAMS/NCEP. Verão (superior esquerdo), outono (superior direito), inverno (inferior esquerdo) e primavera (inferior direito).

\subsubsection{Variância de Altura Significativa}

As diferenças sazonais do campo de altura significativa ilustradas na figura 11 corroboram com o mapa de variância apresentado na figura 12 . Existem maiores valores de variância na porção sudeste do domínio, que é justamente a região onde encontram-se as maiores diferenças sazonais. Para a região Oeste do Atlântico Sul, a variância de uma maneira geral é bem pequena. 


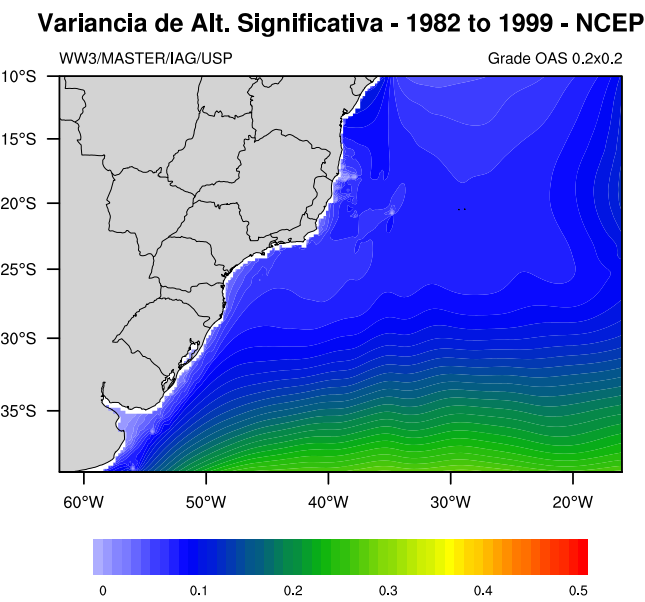

Figura 12 - Variância da Altura Significativa ao longo de 20 anos forçados com o downscaling BRAMS/NCEP.

\subsection{PERÍODO E DIREÇÃO (MÉDIOS)}

Nesta seção serão descritos os campos médios de Período Médio (Tm) e Direção Média (Dm) obtidos dos espectros direcionais em cada ponto de grade do modelo ao longo dos anos analisados. Por se tratarem de valores médios de espectros ao longo de grandes períodos de integração, estes campos precisam ser analisados com bastante parcimônia. Vale destacar que em termos de climatologia de campo o período médio e direção média foram escolhidos por considerar toda a energia do espectro, levando em consideração tanto a geração de ondas remota (swell) e geração local (sea) pois já é sabido que na porção de interesse do projeto não é difícil a ocorrências de mares bi ou até mesmo tri-modais. Tanto o período de pico como a direção de pico são analisados pontualmente ao longo deste documento.

\subsubsection{Médias de Período e Direção Médios}

Ao se observar a figura 13 facilmente é percebido que o comportamento médio do Tm apresenta um padrão do tipo menores valores próximos a linha de costa e períodos mais longos ao largo. Os vetores indicados nesta figura correspondem ao sentido médio de propagação do campo de ondas. Imaginando uma linha na altura do Cabo de São Tomé no RJ percebe-se que para regiões abaixo desta linha predominam direções de sudoeste e para regiões acima desta linha predominam direções de sul-sudeste. O sentido de sudoeste aponta para uma linha de período médio máximo de 12 segundos que pode ser associado a energia dominante dos espectros relacionada a passagem de sistemas transientes. Por sua vez, o sentido de sudeste corresponde ao somatório de espectros dominados por energia de transientes atuando mais 
ao sul combinado com a influência da energia de sistemas de ondas gerados pelos ventos provenientes da Alta Subtropical do Atlântico Sul.

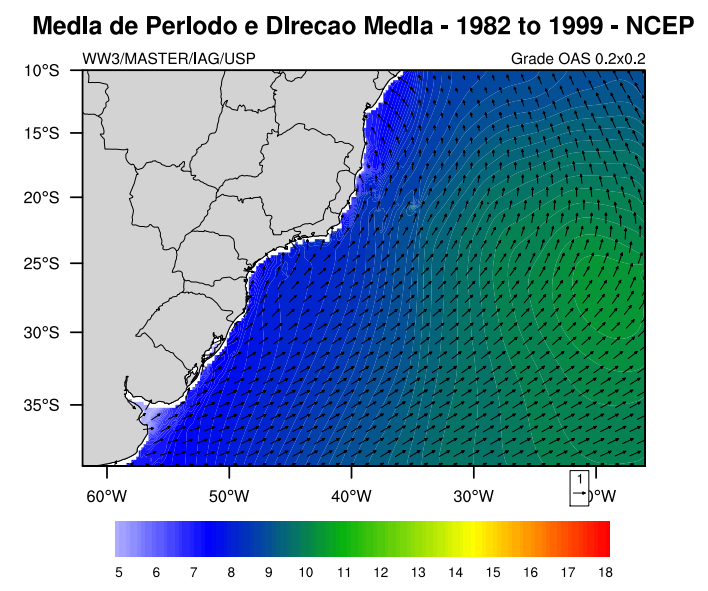

Figura 13 - Médias de Período Médio [s] e Direção média ao longo de 20 anos forçados com o downscaling BRAMS/NCEP.

A variação sazonal dos campos de Tm e Dm pode ser observada através dos mapas das figura 14. O campo referente aos meses de verão apresenta valores de Tm menores nas áreas mais costeiras quando comparado com os meses de inverno. Nota-se que o núcleo com os maiores valores de período médio encontra-se totalmente no interior do domínio no verão e mais deslocado para leste nos meses de inverno. As direções nessas estações refletem claramente uma maior influência da Alta Subtropical do Atlântico Sul nos meses do verão e maior influência de sistemas transientes de latitudes médias para os meses de inverno.

Nos meses de outono e primavera observa-se claramente uma situação de transição entre os extremos do verão e inverno. O núcleo com os maiores valores de Tm apresenta-se levemente deslocado para leste nos meses de outono com presença de períodos mais longos nas regiões mais próximas à costa quando comparado aos meses de verão. As direções praticamente são todas provenientes dos quadrantes sudoeste e sudeste. Nos meses de primavera observa-se exatamente o comportamento de transição entre o inverno e verão com o núcleo de maiores valores de Tm um pouco deslocado para oeste e menores valores nas regiões costeiras quando comparado aos meses de inverno. O sentido médio de propagação dos campos de ondas corresponde ao mesmo dos meses de outono. 
DJF Media de Periodo e Direcao Media - 1982 to 1999 - NCEP

MAM Media de Periodo e Direcao Media - 1982 to 1999 - NCEP
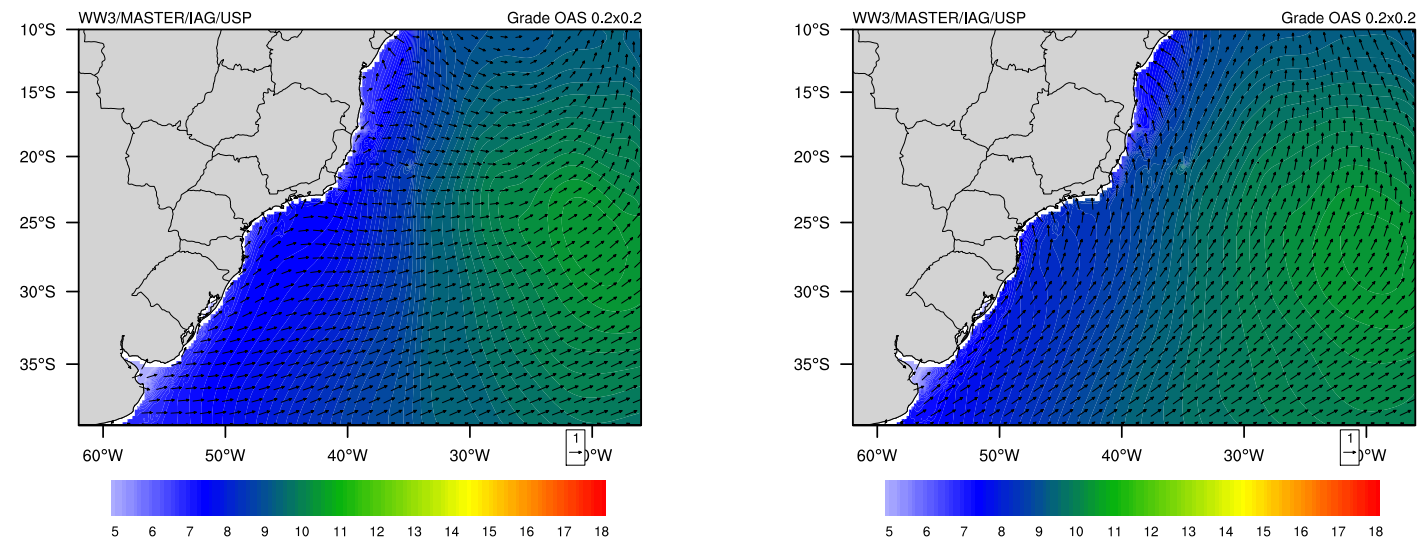

JJA Media de Periodo e Direcao Media - 1982 to 1999 - NCEP

SON Media de Periodo e Direcao Media - 1982 to 1999 - NCEP
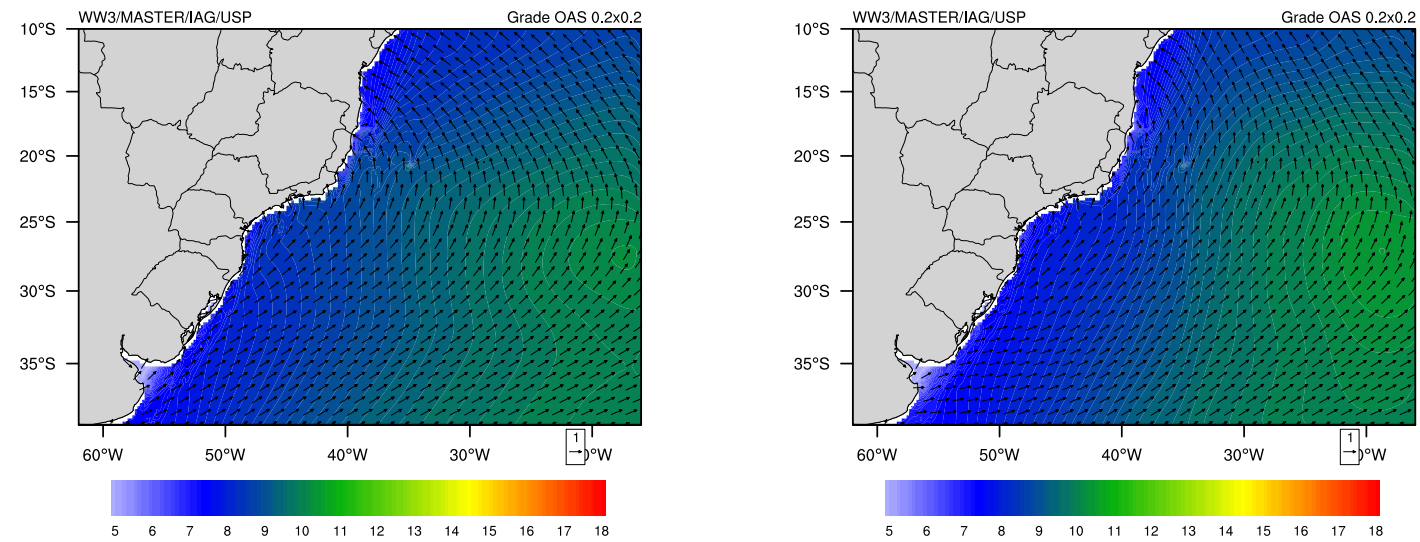

Figura 14 - Médias sazonais de Período Médio [s] e Direção Média ao longo de 20 anos forçados com o downscaling BRAMS/NCEP. Verão (superior esquerdo), outono (superior direito), inverno (inferior esquerdo) e primavera (inferior direito).

\subsubsection{Variância do Período Médio}

A variância do campo de Tm pode ser observada no mapa da figura 15. Os maiores valores são encontrados ao longo da região costeira principalmente nas proximidades do litoral dos estados do ES, RJ e SP. É interessante destacar pequenos máximos de variância em pontos como a cadeia Vitória-Trindade e Abrolhos, uma vez que a barreira física influencia a propagação de ondas fazendo com que determinadas direções sejam desviadas.

O deslocamento do núcleo de valores máximos no campo de Tm pode ser observado com a concavidade das curvas de variância nas proximidades de 020W 30S. Um prolongamento da região de maiores valores de variância pode ser observado na fronteira norte do domínio, a qual está relacionada com a variação da formação de pistas de ventos influenciadas pela Alta Subtropical do Atlântico Sul. 


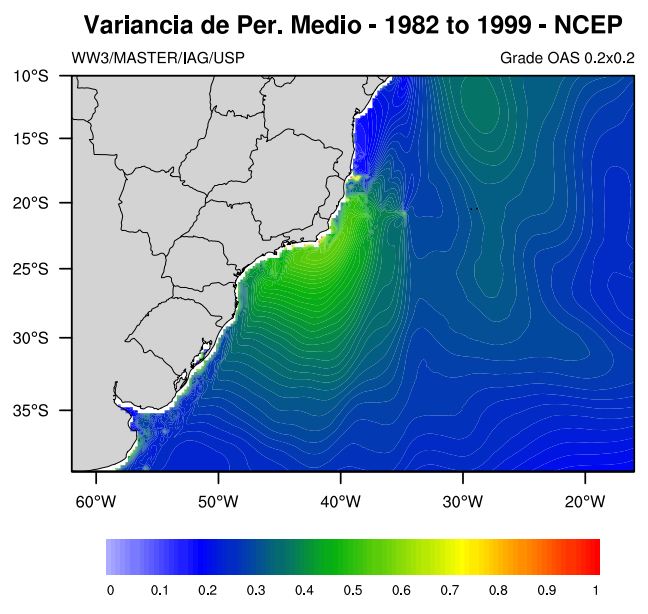

Figura 15 - Variância de Período Médio ao longo de 20 anos forçados com o downscaling BRAMS/NCEP.

\subsection{ANÁlise PONTUAL De ALTURA SIGNIFICATIVA, PERÍOdO DE PICO, DIREÇÃO DE PICO, PERÍODO MÉDIO E DIREÇÃO MÉDIA}

Nesta seção serão analisadas saídas pontuais do modelo em 2 pontos pré determinados. Na tabela 5 encontram-se a localização dos pontos escolhidos para as análises. Vale destacar que um ponto encontra-se sobre a Bacia de Campos (BC - Ponto sobre Bacia de Campos) e o outro sobre a Bacia de Santos (BSO - Ponto sobre Bacia de Santos), ambos de grande importância para as atividades offshore que são amplamente desenvolvidas na região.

Três propriedades essenciais para o estudo da climatologia de ondas foram analisadas em conjunto: altura, período e direção. Desta maneira em cada ponto selecionado serão apresentados histogramas polares bivariados destas 3 propriedades. As variáveis escolhidas foram Altura Significativa (Hs), Período de Pico (Tp), Direção de Pico (Dp), Período Médio (Tm) e Direção Média (Dm). Vale destacar que o Período de Pico e a Direção de Pico correspondem ao valor máximo dessas grandezas encontradas no espectro direcional de ondas.

Tabela 5 - Coordenadas dos pontos para análises das séries temporais de agitação marítima geradas pelo WW3.

\begin{tabular}{ccc}
\hline PONTO & LONGITUDE & LATITUDE \\
\hline \hline BC & $-40,07$ & $-22,50$ \\
\hline BSO & $-42,00$ & $-25,50$ \\
\hline
\end{tabular}




\subsubsection{Ponto BC}

Na figura 16 estão apresentados os histogramas polares bivariados de $\mathrm{Hs} X \mathrm{Dm}, \mathrm{Hs} X$ $\mathrm{Dp}, \mathrm{Tm} \times \mathrm{Dm}$ e $\mathrm{Tp} \times \mathrm{Dp}$ no ponto $\mathrm{BC}$ para todo o período de simulação. Neste ponto existe predominância de ondas do quadrante sul com maior parte das ocorrências variando de 2 a 4 metros. Comparando os gráficos de $\mathrm{Hs}$ X Dm e Hs X Dp (superiores esquerdo e direito respectivamente), nota-se que as direções de pico mais abundantes são de sul-sudoeste porem direções médias mais abundantes acontecem de sul-sudeste. Para as componentes de nordeste-leste (menos abundantes) existe pouca diferença quando se compara a componente média com a componente de pico, para a direção média existe um aumento das componentes de leste e este aumento é mais significativo nas componentes de nordeste.

Levando em consideração os períodos, pode-se dizer que neste ponto, períodos mais longos são provenientes do quadrante sul com maior parte da ocorrência variando entre 8 e 12 segundos para o período médio e de 10 a 18 segundos para o período de pico. Levando em consideração somente o período de pico, nota-se claramente a maior contribuição de ondas de sul-sudoeste. As componentes de nordeste-leste apresentam predominância de 6 a 8 segundos no período médio e de 6 a 14 segundos para período de pico com a maior contribuição de ondas de leste. 

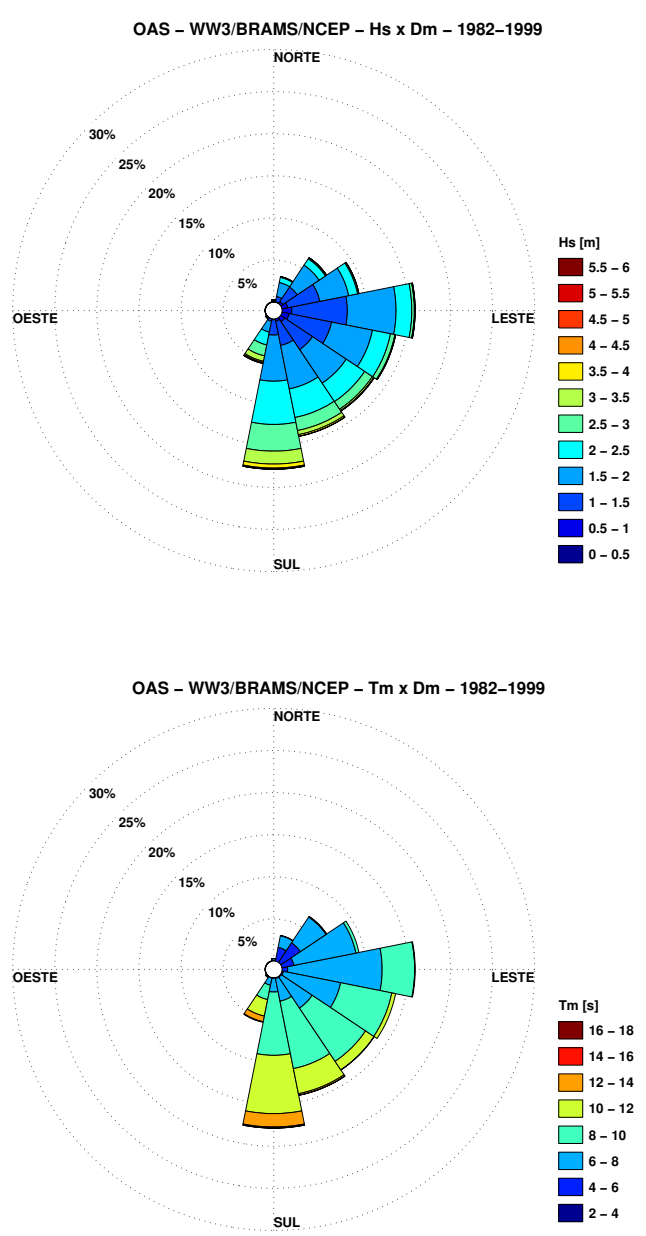
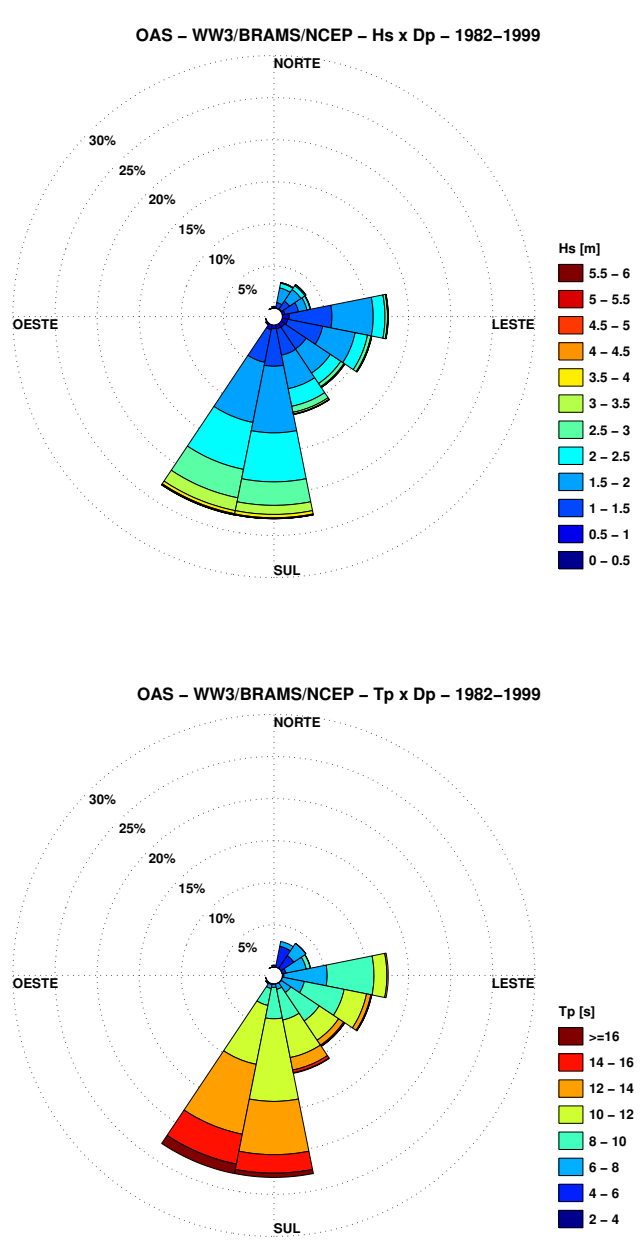

Figura 16 - Histogramas bivariados de $\mathrm{Hs} X \mathrm{Dm}$ (superior a esquerda), $\mathrm{Hs} X \mathrm{Dp}$ (superior a direita), Tm X Dm (inferior a esquerda) e Tp X Dp (inferior a direita) para o ponto BC.

Ao longo do ano as distribuições variam sazonalmente com aumento nas componentes de nordeste-leste no verão e aumento das componentes de sul-sudoeste no inverno. Nas estações de transição há um aumento das componentes de sul-sudeste. Nas figuras 56, 64, 72 e 80 é possível observar detalhes sobre a variabilidade sazonal para este ponto.

\subsubsection{Ponto BSO}

Na figura na página seguinte estão apresentados as distribuições bivariadas de Hs X Dm, Hs $X \mathrm{Dp}, \mathrm{Tm} X \mathrm{Dm}$ e Tp X Dp no ponto BSO para todo o período de simulação. Neste ponto existe predominância de ondas do quadrante sul com maior parte das ocorrências variando de 1,5 a 4,5 metros. Comparando os gráficos de $\mathrm{Hs} X \mathrm{Dm}$ e Hs $X \mathrm{Dp}$ (superiores esquerdo e direito respectivamente), nota-se que as direções de pico mais abundantes são de sul-sudoeste e direções médias de sul-sudeste. Para as componentes de nordeste-leste (menos abundantes) 
existe um aumento das componentes de nordeste.

Levando em consideração os períodos, pode-se dizer que neste ponto, períodos mais longos são provenientes do quadrante sul com maior parte da ocorrência variando entre 8 e 14 segundos para o período médio e de 10 a 18 segundos para o período de pico. Levando em consideração somente o período de pico nota-se claramente a maior contribuição de ondas de sul-sudoeste e uma porção relevante de sudeste. As componentes de nordeste-leste apresentam predominância de 6 a 10 segundos no período médio e de 6 a 12 segundos para período de pico com a maior contribuição de ondas de leste.
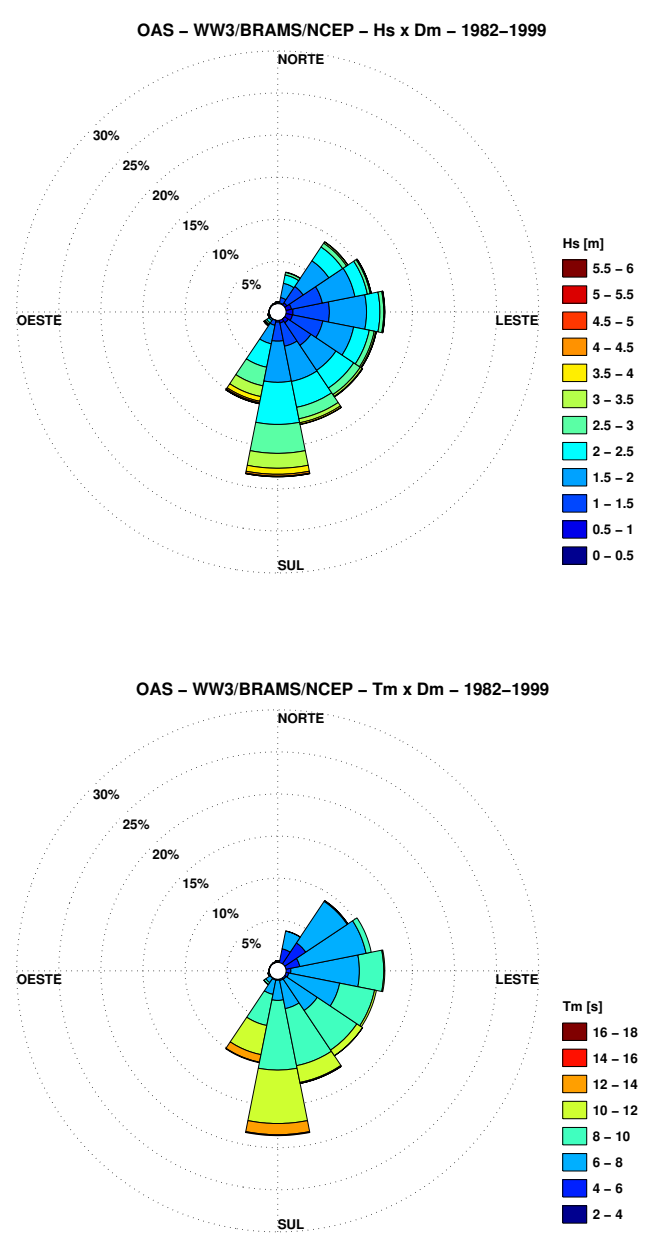
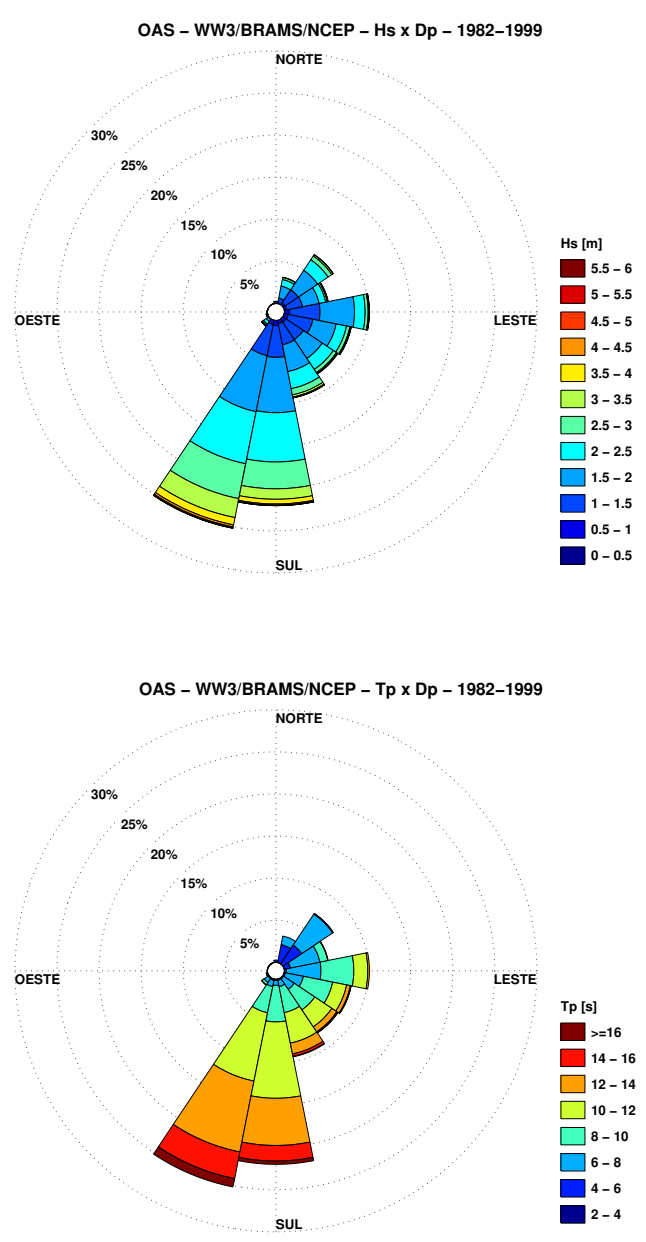

Figura 17 - Histogramas bivariados de Hs X Dm (superior a esquerda), Hs X Dp (superior a direita) , Tm X Dm (inferior a esquerda) e Tp X Dp (inferior a direita) para o ponto BSO.

Ao longo do ano as distribuições variam sazonalmente com aumento nas componentes de nordeste-leste no verão e aumento das componentes de sul-sudoeste no inverno. Nas estações de transição há um aumento das componentes de sul-sudeste. A variabilidade sazonal pode ser observada mais a frente nas figuras 60, 68, 76 e 84 onde pode se observar detalhes específicos de cada estação do ano. 


\section{SÉCULO XX (IPCC)}

De maneira análoga ao capítulo anterior, também foi realizado um conjunto de simulações para o Século XX utilizando o downscaling BRAMS/CCSM3. Neste capítulo serão apresentados resultados referentes a estas simulações.

\subsection{ALTURA SIGNIFICATIVA}

\section{Médias de Altura Significativa}

De maneira geral o campo médio de Hs obtido com esta forçante apresenta características semelhantes às simulações forçadas com o conjunto BRAMS/NCEP. Os maiores valores ocorrem nas fronteiras sudeste e leste com máximos em torno de 4 metros, conforme pode ser observado na figura 18 . Visualmente este campo médio apresenta maiores valores que o correspondente com o BRAMS/NCEP.

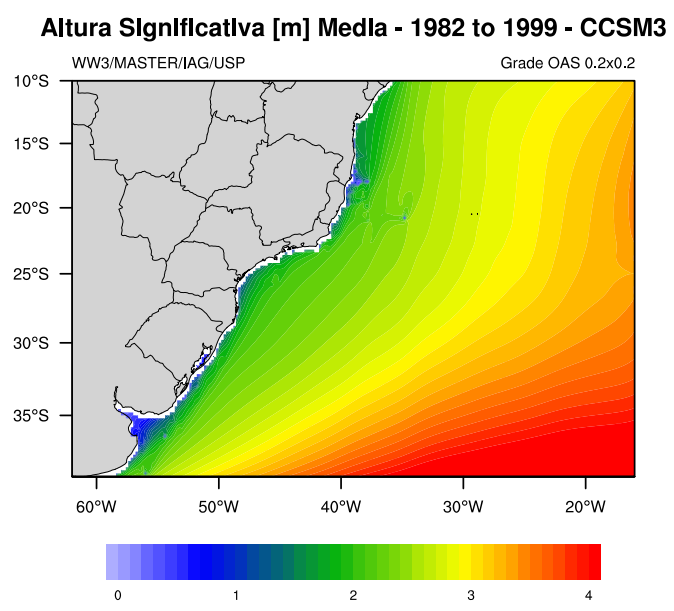

Figura 18 - Média da Altura Significativa [m] ao longo de 20 anos forçados com o downscaling BRAMS/CCSM3.

A variação sazonal deste campo pode ser observada na figura 19 . Os menores valores são encontrados nos meses de verão e os maiores nos meses de inverno; no entanto, durante os meses de outono é maior a área com valores mais elevados de Hs média em relação ao inverno. Na primavera acontece uma retração da área de maiores valores diminuindo gradualmente os valores do campo médio, tornando-se semelhante ao verão. 
DJF Media de Altura Significativa [m] - 1982 to 1999 - CCSM3

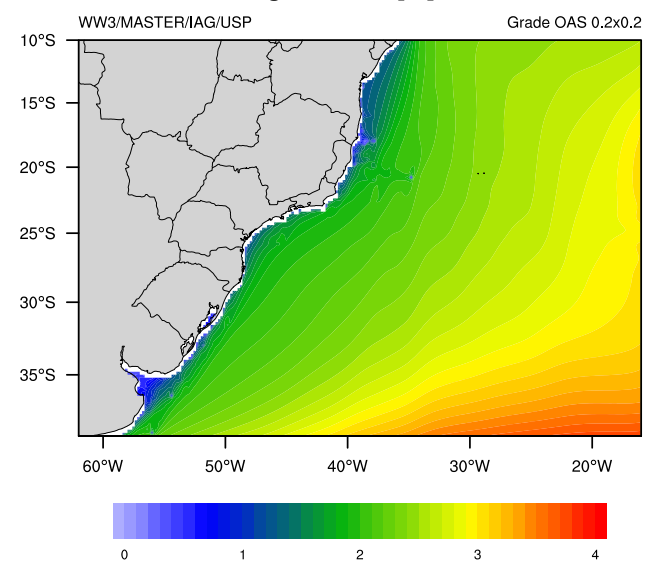

JJA Media de Altura Significativa [m] - 1982 to 1999 - CCSM3

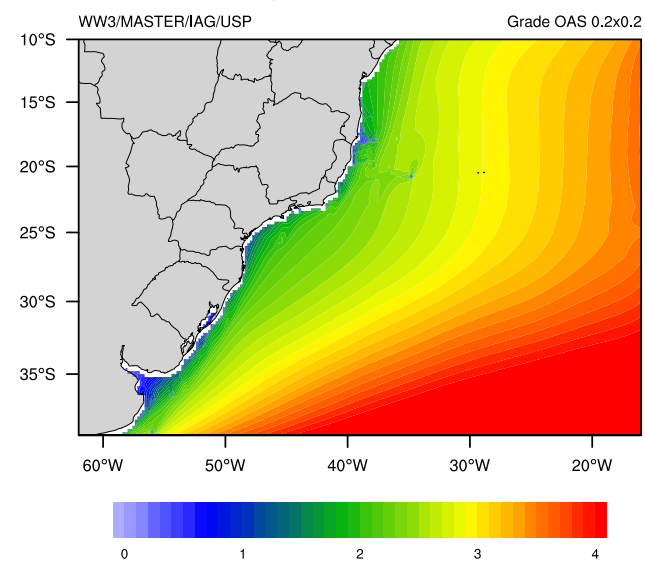

MAM Media de Altura Significativa [m] - 1982 to 1999 - CCSM3

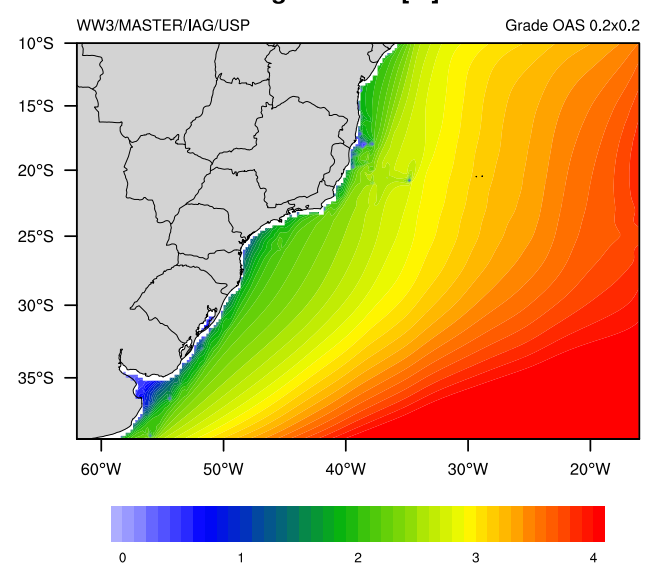

SON Media de Altura Significativa [m] - 1982 to 1999 - CCSM3

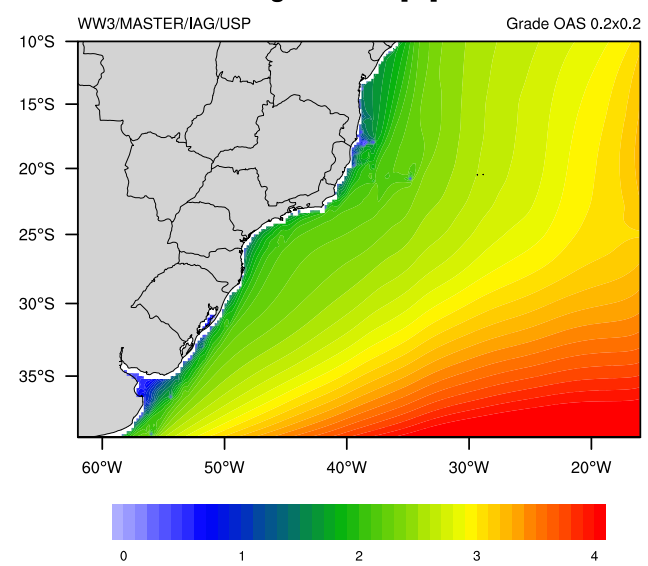

Figura 19 - Médias sazonais da Altura Significativa [m] ao longo de 20 anos forçados com o downscaling BRAMS/CCSM3. Verão (superior esquerdo), outono (superior direito), inverno (inferior esquerdo) e primavera (inferior direito).

\subsubsection{Variância de Altura Significativa}

A variância do campo de Hs para este conjunto de simulações apresenta menores valores em regiões próximas à linha de costa e maiores valores próximos aos contornos sudeste e leste (figura 20). Este comportamento acontece principalmente de acordo com a variação sazonal deste campo conforme descrita no item anterior. Apesar da variância apresentar maiores valores para esta forçante ela apresenta características semelhantes com o conjunto de simulações forçadas com o BRAMS/NCEP (figura na página 58). 
Variancia de Alt. Significativa - 1982 to 1999 - CCSM3

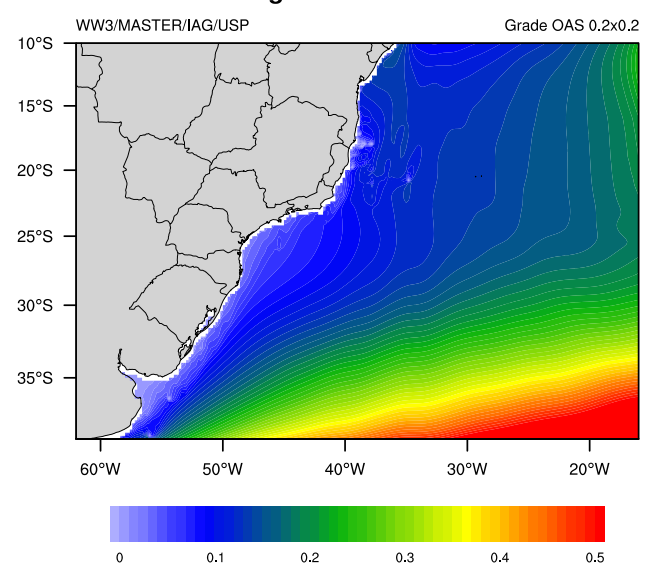

Figura 20 - Variância da Altura Significativa ao longo de 20 anos forçados com o downscaling BRAMS/CCSM3.

\subsection{PERÍODO E DIREÇÃO (MÉDIOS)}

\subsubsection{Médias de Período e Direção Médios}

O campo da média total dos 20 anos simulados pode ser observado na figura 21. Os maiores valores de Tm são encontrados em todo o domínio da parte central até a borda leste, com os menores valores nas proximidades da linha de costa. Na porção sul do domínio, a média das direções médias é de sudoeste, sul na parte central do domínio e sudeste na parte superior. Ao longo da linha de costa as direções se apresentam de sudoeste e sul até o estado do RJ e de sudeste do litoral do ES até o litoral do NE.

Comparativamente com a simulação BRAMS/NCEP (figura na página 59), o campo é bastante similar com relação a média das direções médias com uma pequena tendência a se manter mais de sul no caso BRAMS/CCSM3. Outra diferença notável é com relação ao valor da média dos períodos médios, os quais são maiores em todo o domínio no conjunto ora descrito. 
Media de Periodo e Direcao Media - 1982 to 1999 - CCSM3
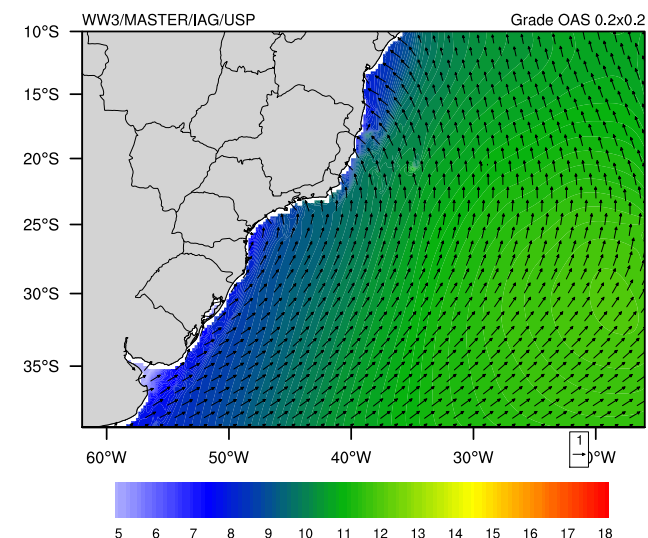

Figura 21 - Médias de Período Médio [s] e Direção Média ao longo de 20 anos forçados com o downscaling BRAMS/CCSM3.

Ao longo do ano acontecem variações relacionadas ao ciclo sazonal, e este comportamento pode ser observado na figura 22. As principais variações do campo médio de Tm e Dm acontecem durante os meses de verão e estão relacionadas à direção predominante na porção mais ao norte do domínio, onde aparecem direções médias de sudoeste e até mesmo oeste no lugar da direção sudeste presente nas outras estações do ano. Outra característica marcante é que nos meses de outono acontecem os máximos de Tm. 
DJF Media de Periodo e Direcao Media - 1982 to 1999 - CCSM3

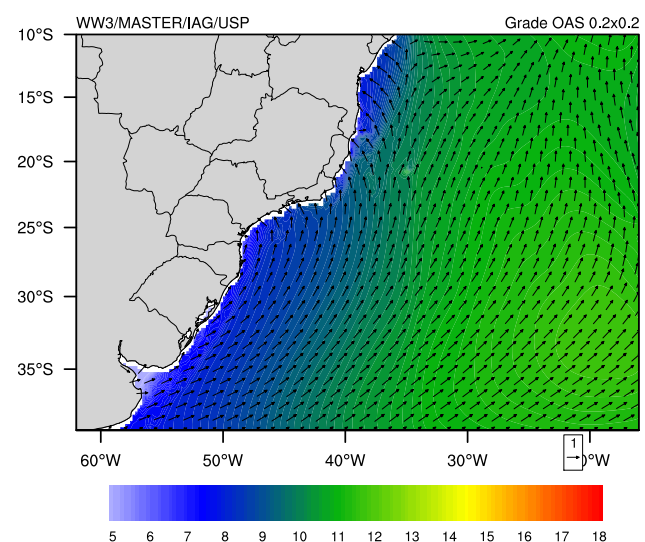

JJA Media de Periodo e Direcao Media - 1982 to 1999 - CCSM3

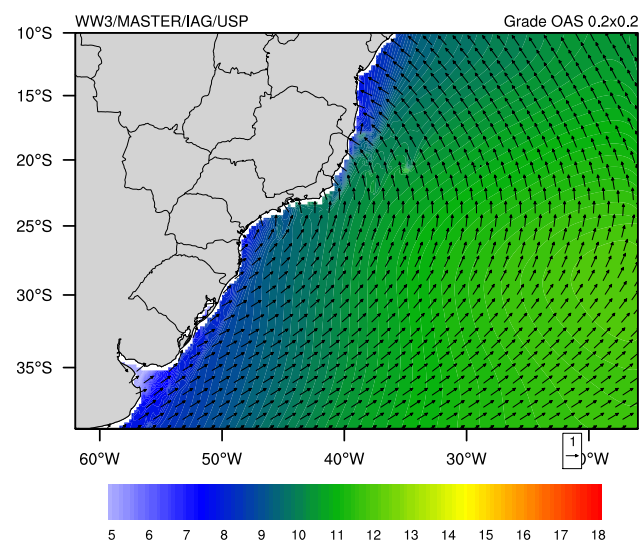

MAM Media de Periodo e Direcao Media - 1982 to 1999 - CCSM3

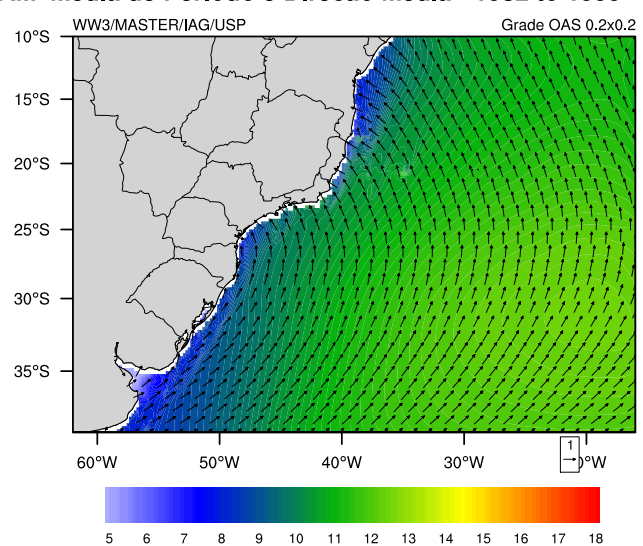

SON Media de Periodo e Direcao Media - 1982 to 1999 - CCSM3

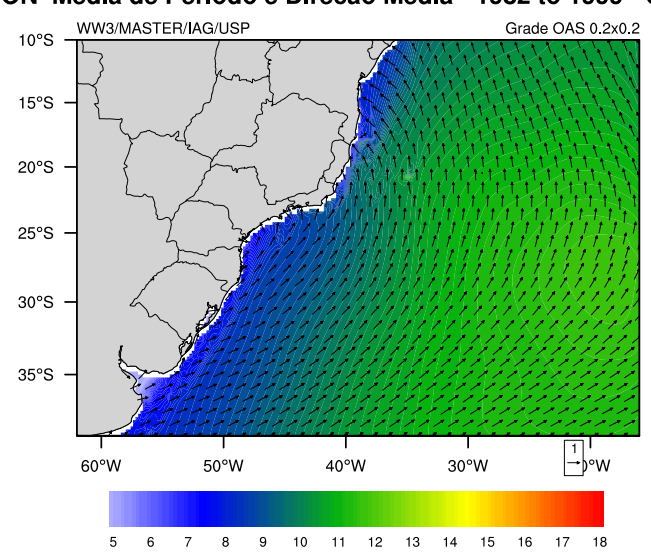

Figura 22 - Médias sazonais de Período Médio [s] e Direção Média ao longo de 20 anos forçados com o downscaling BRAMS/CCSM3. Verão (superior esquerdo), outono (superior direito), inverno (inferior esquerdo) e primavera (inferior direito).

\subsubsection{Variância do Período Médio}

A variância do campo de período médio ao longo dos 20 anos simulados acontece com máximos nas proximidades do litoral sudeste-sul do Brasil, alongando-se em direção à parte central do domínio até a borda leste (figura 23). Na fronteira norte acontece outra região de máxima variância, a qual é prolongada na parte central delimitando dois núcleos de mínima variância entre a costa da Bahia e a borda leste do domínio. 


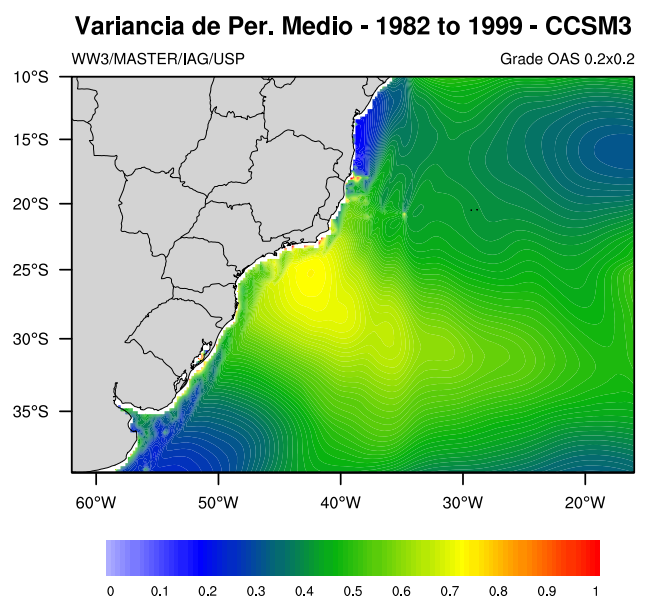

Figura 23 - Variância do Período Médio ao longo de 20 anos forçados com o downscaling BRAMS/CCSM3.

\subsection{ANÁLISE PONTUAL DE ALTURA SIGNIFICATIVA, PERÍODO DE PICO, DIREÇÃO DE PICO, PERÍODO MÉDIO E DIREÇÃO MÉDIA}

Assim como nas simulações forçadas com o BRAMS/NCEP foram analisadas distribuições bivariadas para os mesmos pontos citados anteriormente (BC e BSO conforme descritos na tabela na página 61).

\subsubsection{Ponto BC}

O ponto BC (figura 24) apresenta dominância de direção sul com maior parte dos valores de Hs variando de 2 a 5 metros podendo chegar a valores maiores que 5 metros. A maior parte dos períodos médios associados a esta direção variam de 8 a 16 segundos, mas podem ultrapassar 18 segundos. É possível observar na figura 24 a presença de uma pequena componente média de sudoeste que corresponde a cerca de $5 \%$ do total da série com características semelhantes à componente de sul. Grande parte das ocorrências acontecem com direções médias variando de sul a leste, com menores valores de Hs e períodos médios mais curtos chegando até 12 segundos. Quase não se é percebido a contribuição de nordeste com valores de Hs geralmente inferiores a 1,5 metros e períodos médios menores que 8 segundos.

Para os parâmetros de pico (gráficos a direita da figura 24), a componente de sudoeste corresponde a mais de 30\% de ocorrência na série, ultrapassando inclusive a componente de sul. Ambas apresentam maior parte dos valores de Hs variando de 1,5 a 3,5 metros e podendo ultrapassar 5,5 metros em períodos de pico, os quais na maioria dos casos estão na faixa de 14s, mas que podem ultrapassar 18s. A proporção das componentes leste-sudeste e leste-nordeste 
diminui em relação as componentes médias.
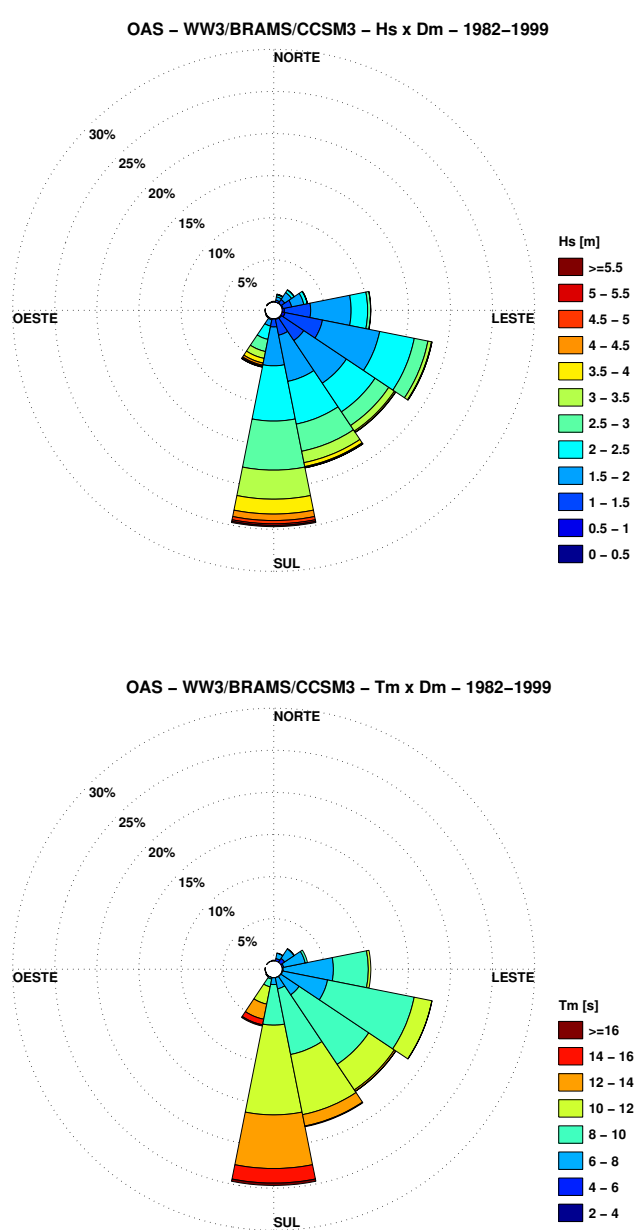
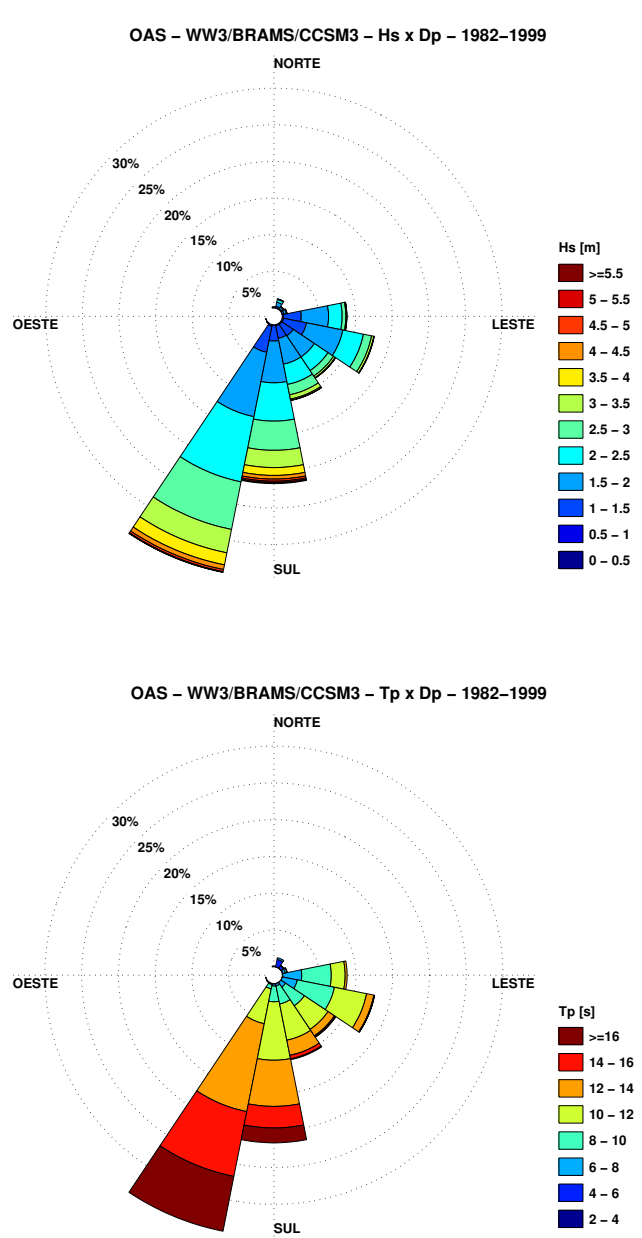

Figura 24 - Histogramas bivariados de Hs X Dm (superior a esquerda), Hs X Dp (superior a direita), Tm X Dm (inferior a esquerda) e Tp X Dp (inferior a direita) para o ponto BC.

Ao longo do ano estas distribuições variam sazonalmente com aumento nas componentes de nordeste-leste no verão e aumento das componentes de sul-sudoeste no inverno. Nas estações de transição há um aumento das componentes de sul-sudeste. Estes o outros detalhes sobre a variabilidade sazonal podem ser encontrados nas figuras 57, 65, 73 e 81 dos Anexos.

\subsubsection{Ponto BSO}

O ponto BSO (Figura 25) apresenta dominância de direção sul com maior parte dos valores de Hs variando de 1,5 a 5,5 metros. A maior parte dos períodos médios associados a esta direção variam de 8 a 16 segundos, mas podem ultrapassar 16 segundos. Grande parte das ocorrências acontecem com direções médias variando de sul a leste, com menores valores de Hs e períodos médios mais curtos chegando até 14 segundos. É percebido a contribuição de 
nordeste com valores de Hs geralmente inferiores a 2,5 metros e períodos médios menores que 8 segundos.

Para os parâmetros de pico (gráficos a direita da Figura 25), a componente de sudoeste ultrapassa 30\% de ocorrência na série, a componente de sul apresenta ocorrência em torno de $20 \%$. Ambas apresentam maior parte dos valores de $\mathrm{Hs}$ variando de 1,5 a 4,5 metros e podendo ultrapassar 5,5 metros em períodos de pico, os quais na maioria dos casos estão na faixa de $14 \mathrm{~s}$, mas que podem ultrapassar 16 segundos. A proporção das componentes leste-sudeste e leste-nordeste diminui em relação as componentes médias.
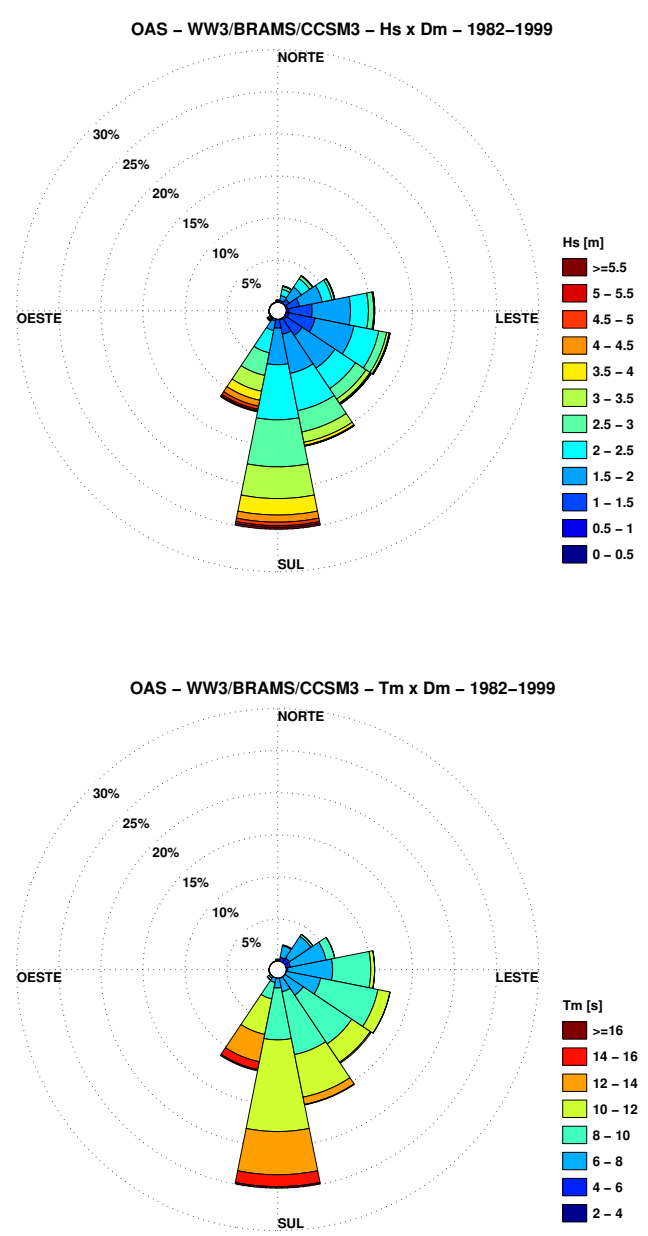
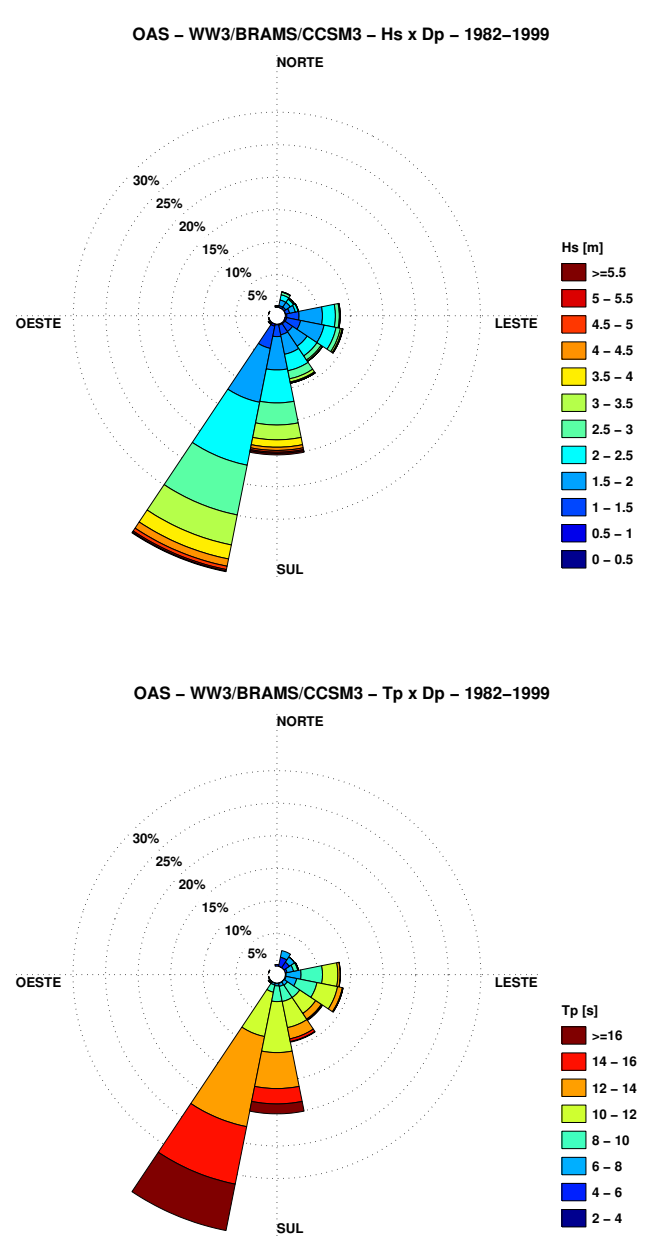

Figura 25 - Histogramas bivariados de $\mathrm{Hs} X \mathrm{Dm}$ (superior a esquerda), $\mathrm{Hs} \times \mathrm{Dp}$ (superior a direita), Tm X Dm (inferior a esquerda) e Tp X Dp (inferior a direita) para o ponto BSO.

Ao longo do ano estas distribuições variam sazonalmente, detalhes sobre a variabilidade sazonal podem ser encontrados nas figuras 61, 69, 77 e 85 dos Anexos. 


\section{COMPARAÇÃO DOS CONJUNTOS PARA O SÉCULO XX}

Neste capítulo serão apresentados resultados estatísticos para comparação entre as simulações do Século XX. O intuito é entender como o conjunto forçado com o downscaling proveniente do modelo CCSM3 (BRAMS/CCSM3) se comporta em relação ao conjunto de referência forçado com o downscaling proveniente da Reanálise do NCEP (BRAMS/NCEP). Para isto serão analisados campos de viés (bias), RMS, correlação, tendência e séries de tendências para os três pontos estabelecidos.

\subsection{VIÉS}

Ao se comparar as simulações forçadas com o downscaling do CCSM3 com o downscaling do NCEP percebe-se que, de maneira geral, as simulações com o CCSM3 sempre sugerem maiores valores de Altura Significativa e de Período Médio. Este fato pode ser observado na Figura 26 .

O campo de viés da altura significativa apresenta os menores valores próximos à costa, com aumento gradativo em direção aos contornos leste e sudeste do domínio com valores máximos sempre abaixo de 1 metro. Para o período médio, os menores valores de viés também são encontrados próximos a linha de costa, porém este campo aumenta gradativamente conforme se aproxima dos contornos leste e sudeste.
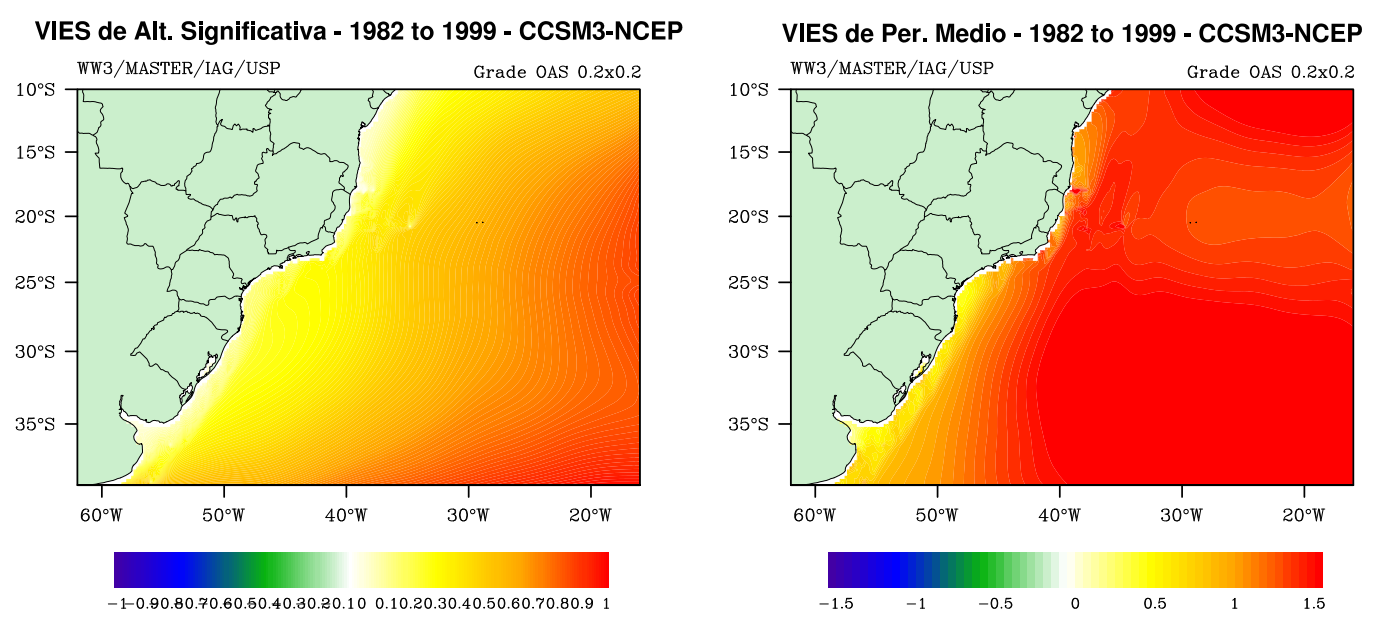

Figura 26 - Viés da Altura Significativa (esquerda) e Período Médio (direita) de 1982 a 1999. 


\subsection{ERRO QUADRÁTICO MÉDIO}

Os campo de erro quadrático médio (RMS) de altura significativa (lado esquerdo da figura 27) apresenta comportamento similar ao campo de viés com aumento gradativo conforme se afasta das regiões mais costeiras e se aproxima dos contornos leste e sudeste com valores predominantemente menores do que 1.

Apesar do campo de RMS de período médio também apresentar menores valores próximos a linha de costa, ele não é gradual como no caso do parâmetro Hs. Na figura 27 (lado direito), estão representados um núcleo de máximo RMS na porção sudeste, seguido por uma região de mínimo que por sua vez começa a ser seguida por outra região de máximo de RMS. Este comportamento pode ser associado ao padrão de propagação dos períodos das ondas, que por sua vez se relaciona com o padrão de circulação atmosférica. O máximo de RMS mais ao sul pode estar associado a passagem de sistemas transientes e o máximo mais ao norte pode estar relacionado a influência dos ventos da Alta Subtropical do Atlântico Sul.
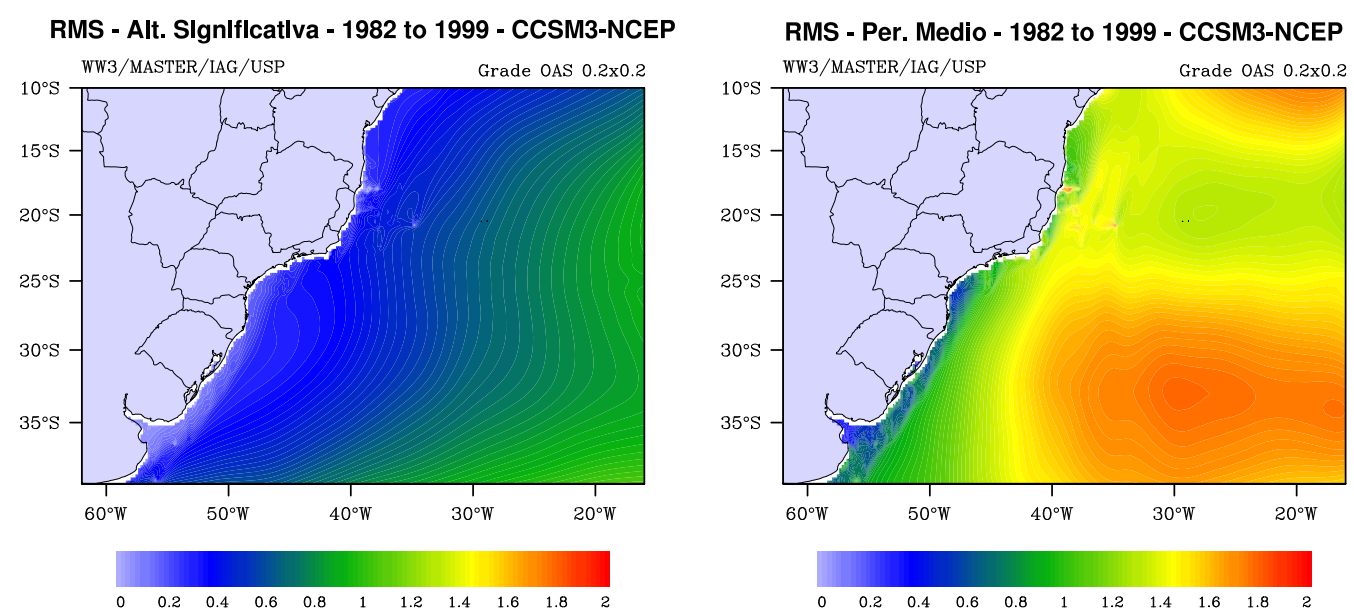

Figura 27 - RMS para Altura Significativa (esquerda) e Período Médio (direita) de 1982 a 1999.

\subsection{CORRELAÇÃO}

O campo de correlação de altura significativa e do período médio entre os dois conjuntos de simulações para o Século XX pode ser observado na figura 28. Para Hs, o campo apresenta valores positivos em sua totalidade com valores bem próximos a 1 na porção ao sul do domínio e diminuindo em direção à borda norte.

O campo de período médio apresenta valores de correlação positivos e negativos limitados por uma faixa de correlação nula. Ao largo do litoral sudeste são encontrados os maiores valores de correlação positiva, enquanto os menores valores situam-se nas proximidades do 
litoral da Bahia. A região de correlação negativa deve estar relacionada ao posicionamento da Alta Subtropical do Atlântico Sul, a qual pode impulsionar propagação de trens de ondas de sentido oposto ao predominante; desta forma, a correlação fica negativa na parte central da borda leste do domínio, aumentando em todas as outras áreas do domínio.
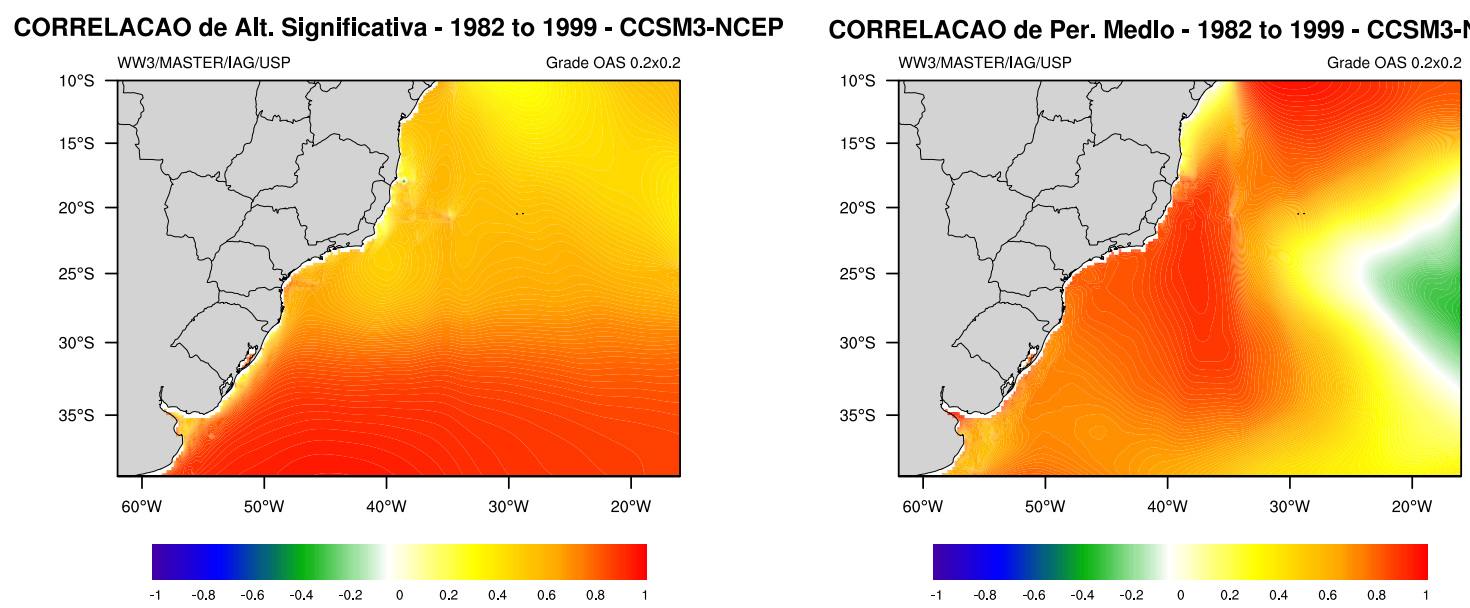

Figura 28 - Correlação para Altura Significativa (esquerda) e Período Médio (direita) de 1982 a 1999.

\subsection{TENDÊNCIAS DE ALTURA SIGNIFICATIVA}

Foram elaborados dois mapas representativos das tendências do campo de $\mathrm{Hs}$ para cada conjunto de simulação do Século XX. Ao se observar à tendência dos campos forçados com o BRAMS/CCSM3 (figura 29a), nota-se que a maior parte dele possui uma pequena tendência para aumento dos valores de Hs. Ao largo do litoral sudeste pode ser observada uma área com leve tendência negativa.

O campo para o conjunto de simulações forçadas com o BRAMS/NCEP também apresenta tendência positiva do campo na maior parte do domínio (figura 29p). Os valores da tendência para este conjunto são maiores quando comparados com as tendências do conjunto anterior. Na região ao largo do litoral sudeste, o campo apresenta valores de tendência bem pequenos porém maiores que zero. 
TENDENCIA: HS (1982-1999)

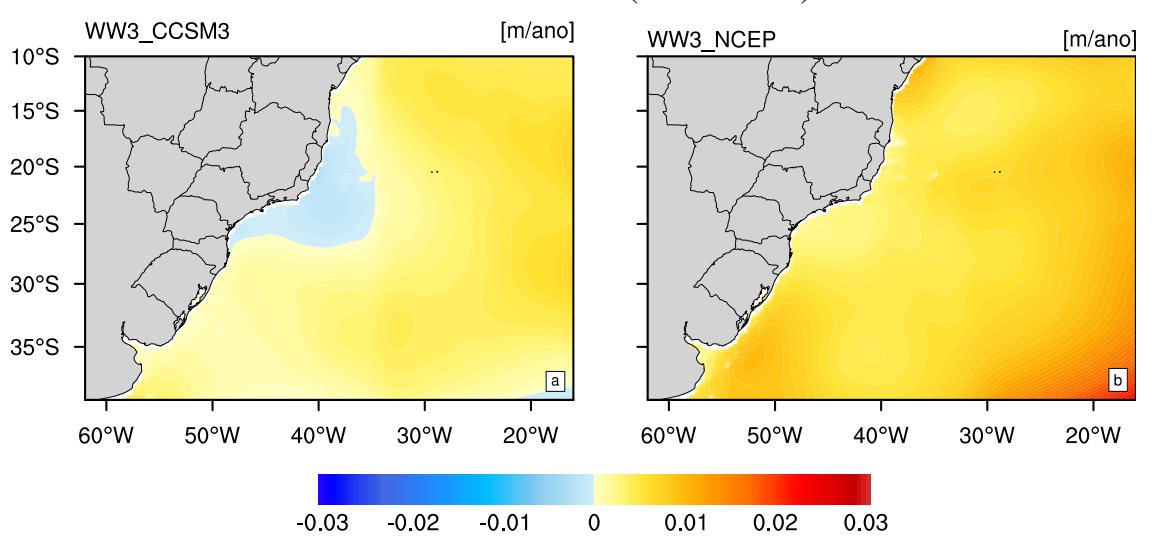

Figura 29 - Tendência da Altura Significativa [m/ano] ao longo de 20 anos forçados com o downscaling BRAMS/CCSM3 (a) e BRAMS/NCEP (b).

Ao se observar a evolução temporal da tendência nos pontos BC e BSO (figura 30), notase que o conjunto forçado com o BRAMS/NCEP apresenta maiores valores de tendência positiva nestes três pontos, sendo a maior delas correspondente ao ponto $\mathrm{BC}$. Para o conjunto BRAMS/CCSM3, o pontos BS também apresentaram tendência positiva, mas bem próxima a zero. Os pontos BC e BSO possuem tendências negativas, com o ponto BCO apresentando valores tendência bem próximos a zero. 

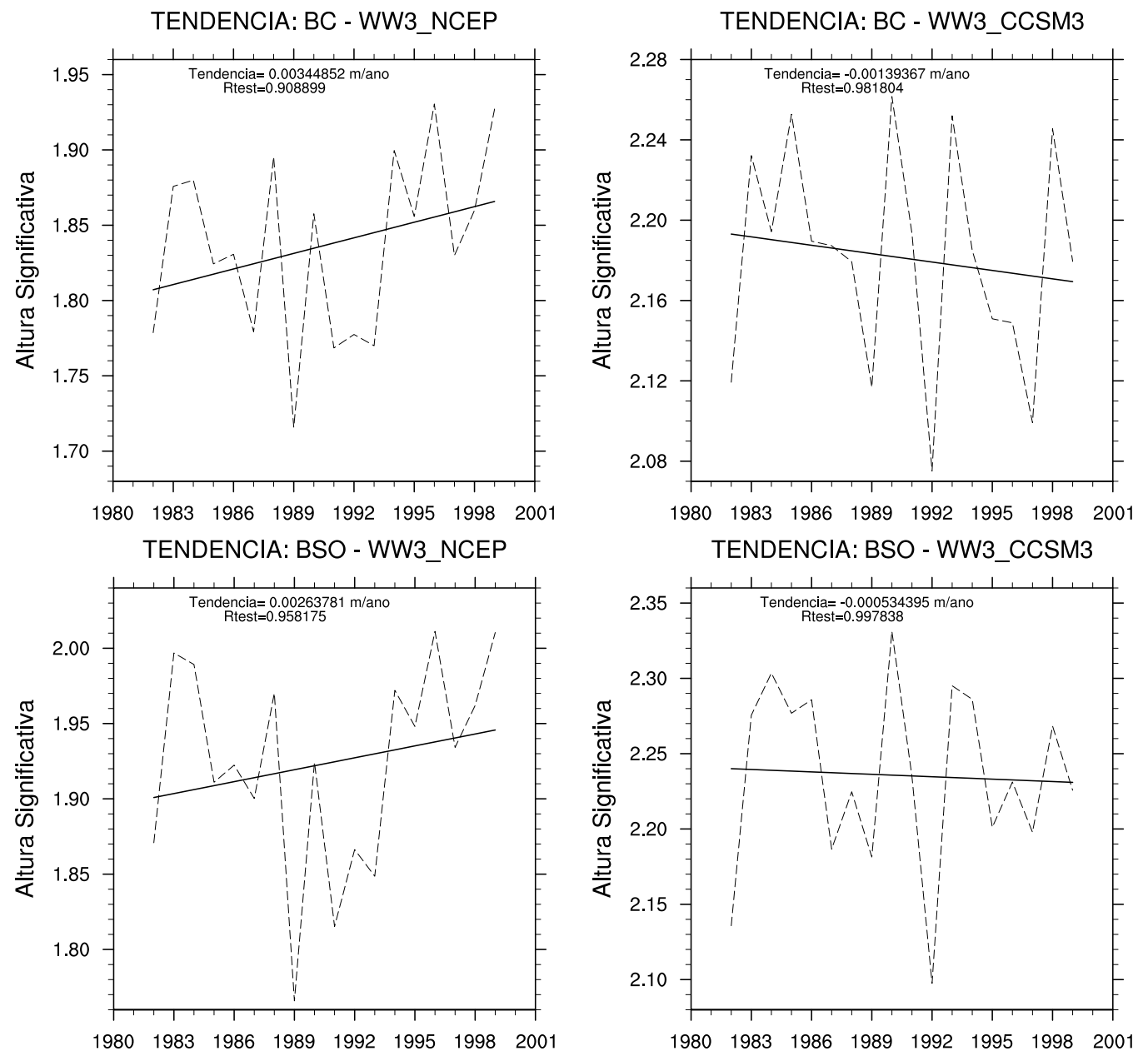

Figura 30 - Variação temporal dos valores médios anuais de altura significativa [m] nos pontos BC e BSO (de cima para baixo) para as simulações forçadas com o downscaling BRAMS/NCEP (gráficos a esquerda) e BRAMS/CCSM3 (gráficos a direita) . 


\section{SÉCULO XXI SOB UMA ÓTICA PESSIMISTA (WW3/CCSM3 SRESA2)}

Neste capítulo serão apresentados os resultados obtidos pelas simulações de agitação marítima forçadas com o downscaling para a projeção do cenário pessimista SRESA2, as quais são identificadas por BRAMS/RESA2.

\subsection{ALTURA SIGNIFICATIVA}

\section{Médias de Altura Significativa}

O campo médio de Hs para o conjunto forçado com o downscaling BRAMS/RESA2 pode ser observado na figura 31. De modo geral este campo apresenta características similares aos campos médios dos conjuntos BRAMS/NCEP e BRAMS/CCSM3, com maiores valores próximos aos contornos sudeste-sul diminuindo gradativamente em direção a linha de costa onde encontram-se os menores valores. Vale destacar que, na média, os valores de Hs encontrados para este conjunto são mais elevados que nos conjuntos citados anteriormente.

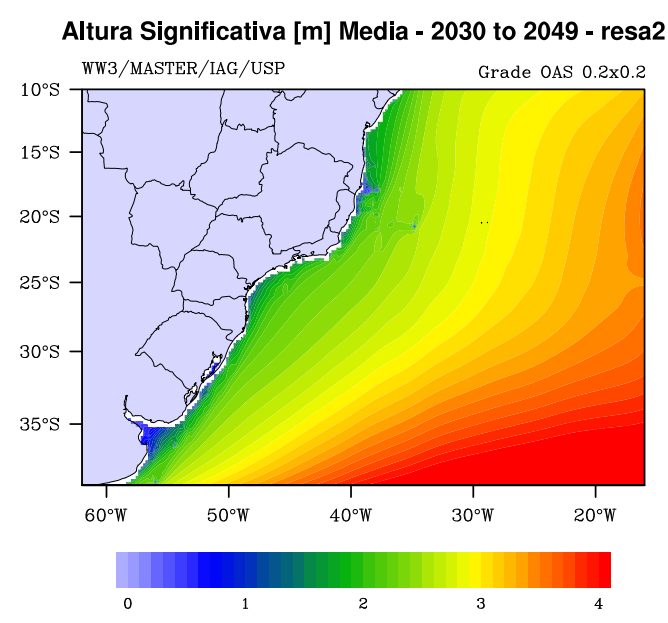

Figura 31 - Média da Altura Significativa [m] ao longo de 20 anos forçados com o downscaling BRAMS/RESA2.

Sazonalmente a média de Hs apresenta os maiores valores nos meses de inverno e outono e os menores, nos meses de verão e primavera. Vale destacar que nos meses de outono os contornos de Hs próximos a borda leste apresentam os valores mais elevados. Este comportamento pode ser observado através da figura 32. 
DJF Media de Altura Significativa [m] - 2030 to 2049 - resa2

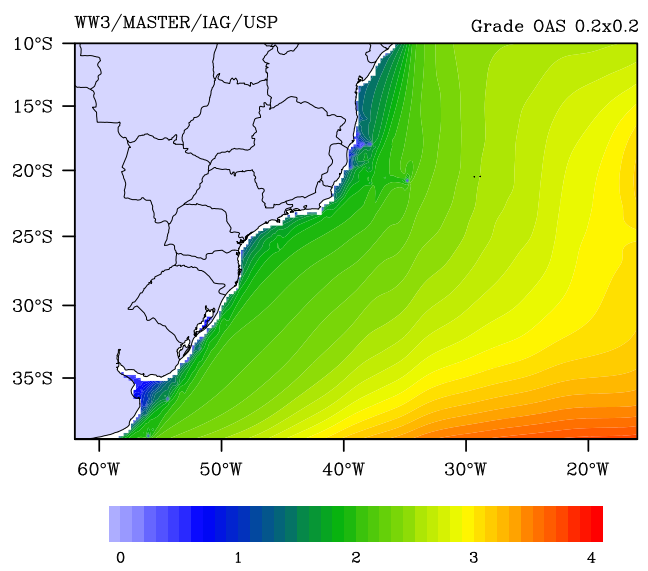

JJA Media de Altura Significativa [m] - 2030 to 2049 - resa2

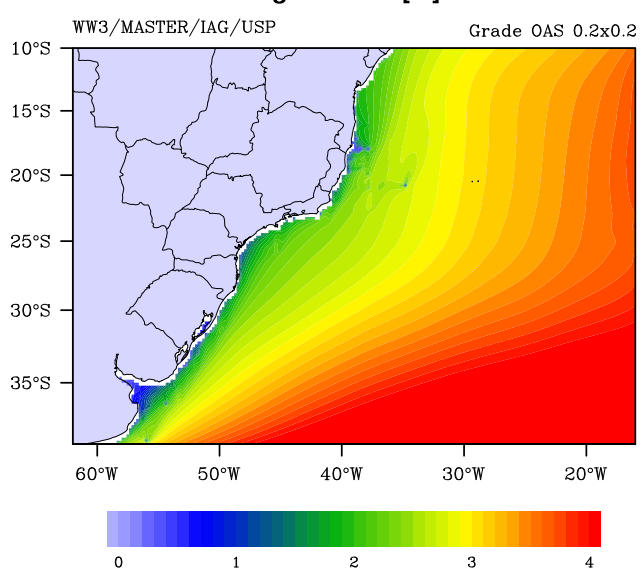

MAM Media de Altura Significativa [m] - 2030 to 2049 - resa2

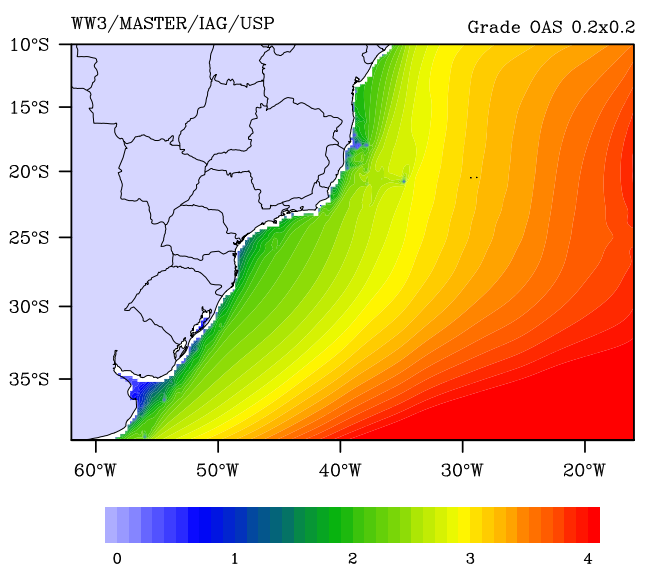

SON Media de Altura Significativa [m] - 2030 to 2049 - resa2

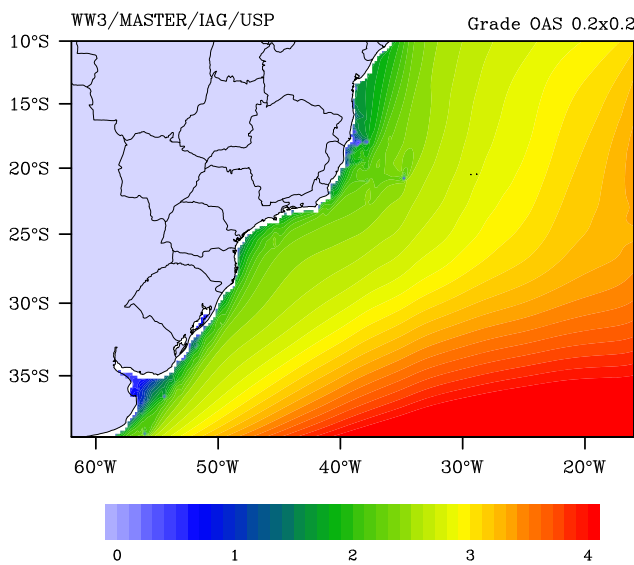

Figura 32 - Médias sazonais da Altura Significativa [m] ao longo de 20 anos forçados com o downscaling BRAMS/RESA2. Verão (superior esquerdo), outono (superior direito), inverno (inferior esquerdo) e primavera (inferior direito).

\section{Variância de Altura Significativa}

A variância da altura significativa para este conjunto está representada na figura 33 . Os maiores valores acontecem ao longo da fronteira sul do domínio especialmente junto ao limite sudeste. Os valores da variância diminuem chegando perto da linha de costa. Este campo apresenta baixos valores de variância, no entanto mais elevados que a variância dos conjuntos anteriormente apresentados nas Figuras 12 e 20. 


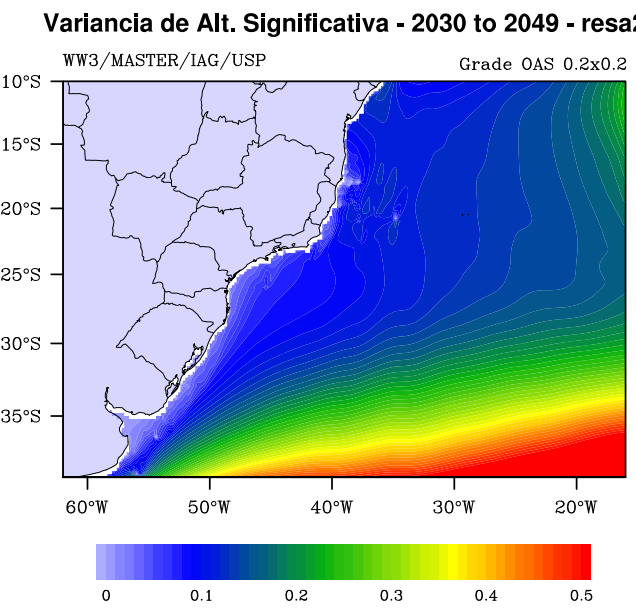

Figura 33 - Variância da Altura Significativa [m] ao longo de 20 anos forçados com o downscaling BRAMS/RESA2.

\subsection{PERÍODO E DIREÇÃO (MÉDIOS)}

\subsubsection{Médias de Período e Direção Médios}

Tanto o período médio como a direção média obtidos com este conjunto apresentam comportamento muito semelhantes aos campos obtidos com o conjunto BRAMS/CCSM3 (figura 21). As direções apresentam o mesmo comportamento conforme pode ser observado na figura 34. Os valores de médios de Tm encontrados são ligeiramente maiores com destaque da área ao largo do litoral sudeste.

As direções médias variam bem pouco ao longo do ano, apenas para os meses de verão podese perceber diferença nas proximidades da fronteira norte do domínio apresentado. Os maiores valores de Tm são encontrado nos meses de inverno e outono e novamente e perceptível de modo visual ao largo do litoral sudeste. Esta variação sazonal está representada na figura 35. 
Media de Periodo e Direcao Media - 2030 to 2049 - resa2

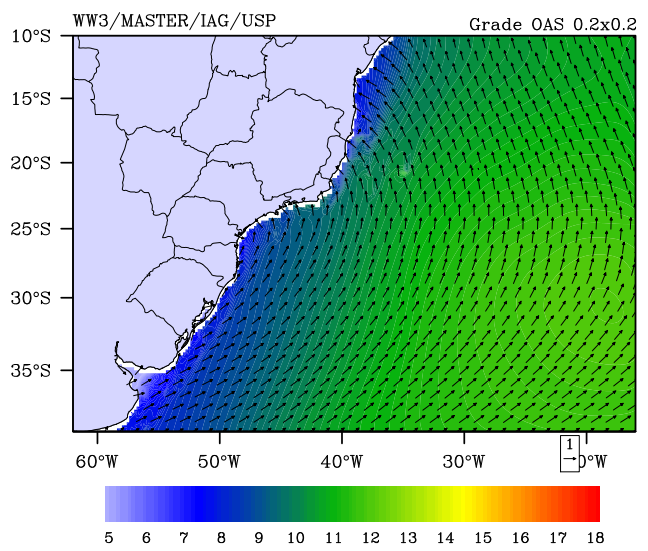

Figura 34 - Média de Período Médio [s] e Direção Média ao longo de 20 anos forçados com o downscaling BRAMS/RESA2.

DJF Media de Periodo e Direcao Media - 2030 to 2049 - resa2

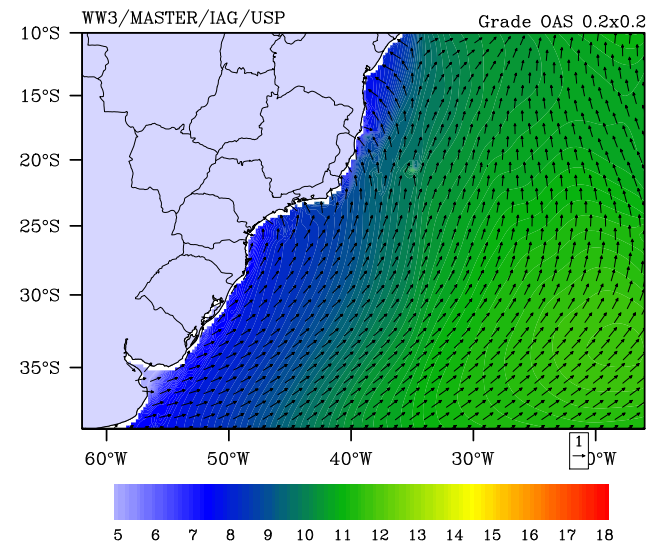

JJA Media de Periodo e Direcao Media - 2030 to 2049 - resa2

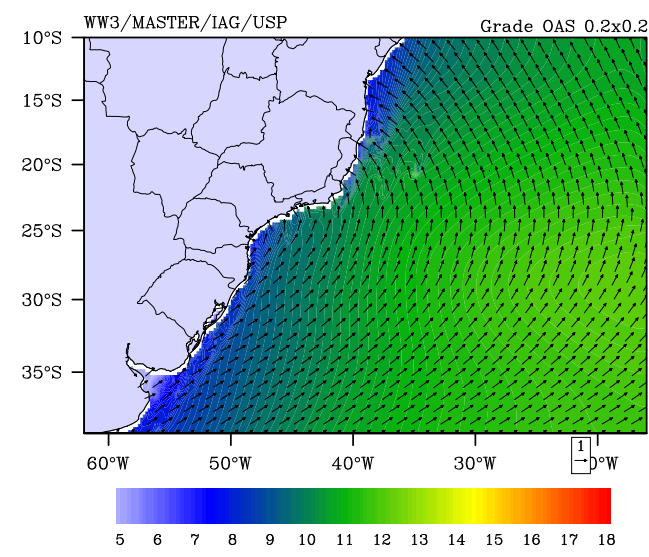

MAM Media de Periodo e Direcao Media - 2030 to 2049 - resa2

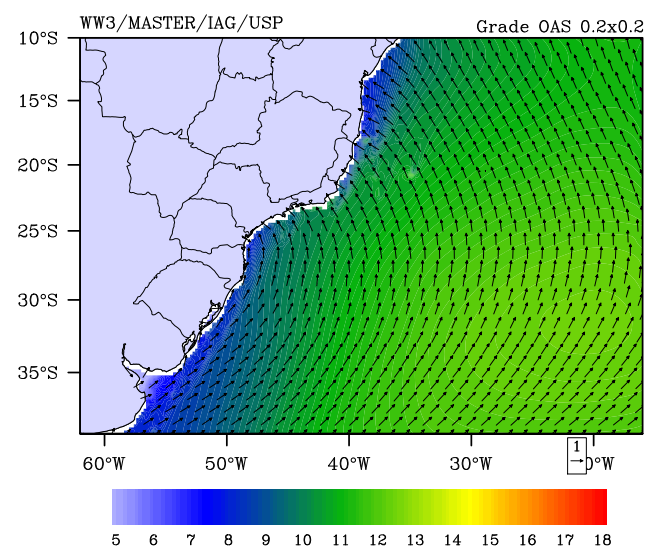

SON Media de Periodo e Direcao Media - 2030 to 2049 - resa2

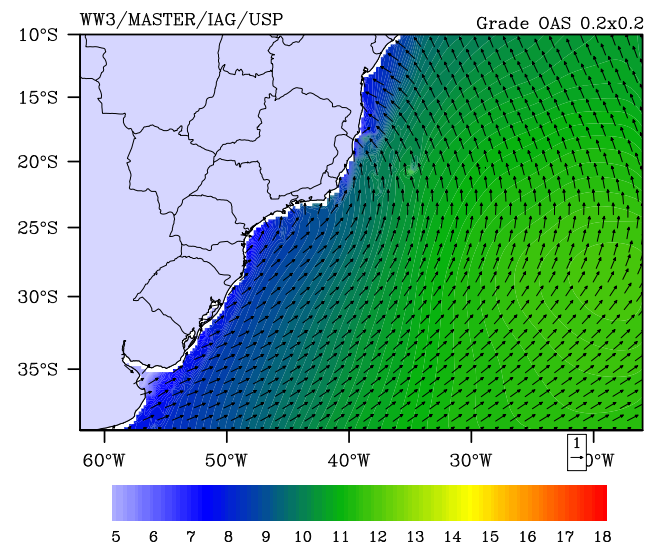

Figura 35 - Médias sazonais de Período Médio [s] e Direção Média ao longo de 20 anos forçados com o downscaling BRAMS/RESA2. Verão (superior esquerdo), outono (superior direito), inverno (inferior esquerdo) e primavera (inferior direito). 


\subsubsection{Variância do Período Médio}

Conforme destacado anteriormente a região de maior variabilidade em termos de Tm encontrase nas proximidades do litoral sudeste. Este fato pode ser confirmado ao se observar o campo de variância na figura 36, onde se destaca a presença de um núcleo de variância mais elevado ao largo do litoral sudeste. Este núcleo se espalha e diminui os valores em direção sudeste e leste do domínio, ocupando quase que toda a parte central da área apresentada.

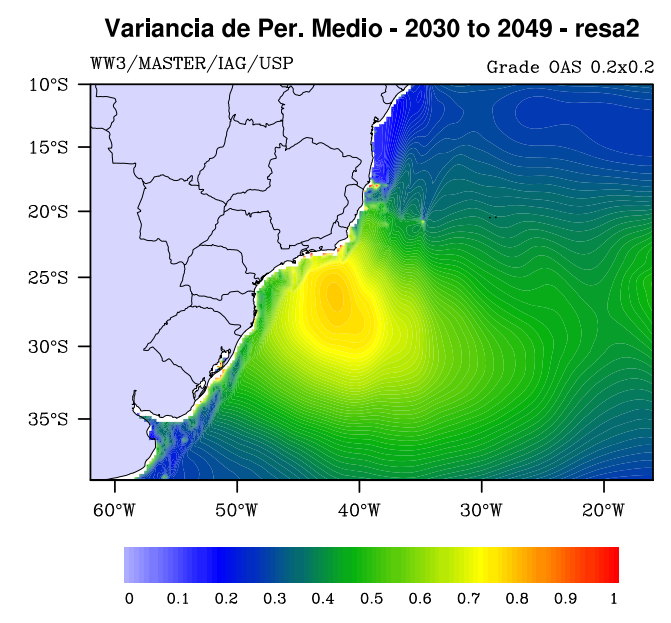

Figura 36 - Variância do Período Médio [s] ao longo de 20 anos forçados com o downscaling BRAMS/RESA2.

\subsection{ANÁlise PONTUAL DE ALTURA SIGNIFICATIVA, PERÍODO DE PICO, DIREÇÃO DE PICO, PERÍODO MÉDIO E DIREÇÃO MÉDIA}

\subsubsection{Ponto BC}

O ponto BC (Tabela 5) também apresenta distribuição dos parâmetros de ondas semelhante à distribuição correspondente para o Século XX. Merecem destaque algumas diferenças nas proporções de ocorrência de maiores períodos e maiores valores de Hs para este conjunto em relação ao Século XX. Nos parâmetros médios, destaca-se o aumento da ocorrência da componente de sudoeste e, em menor proporção, o aumento da ocorrência da componente de leste. Também vale destacar a diminuição da ocorrência da componente de sul (Figura 37 à esquerda).

Ao considerar as distribuições dos parâmetros de pico (Figura 37 à direita), a componente de sul aumenta a proporção de ocorrência de ondas entre 3 e 5 metros e de períodos de pico que variam entre 14 a valores maiores que 16 segundos.

A variação sazonal destes parâmetros pode ser observada nas figuras 58, 66, 74 e 82 dos 
Anexos. As maiores diferenças são observadas entre os meses de verão e inverno.
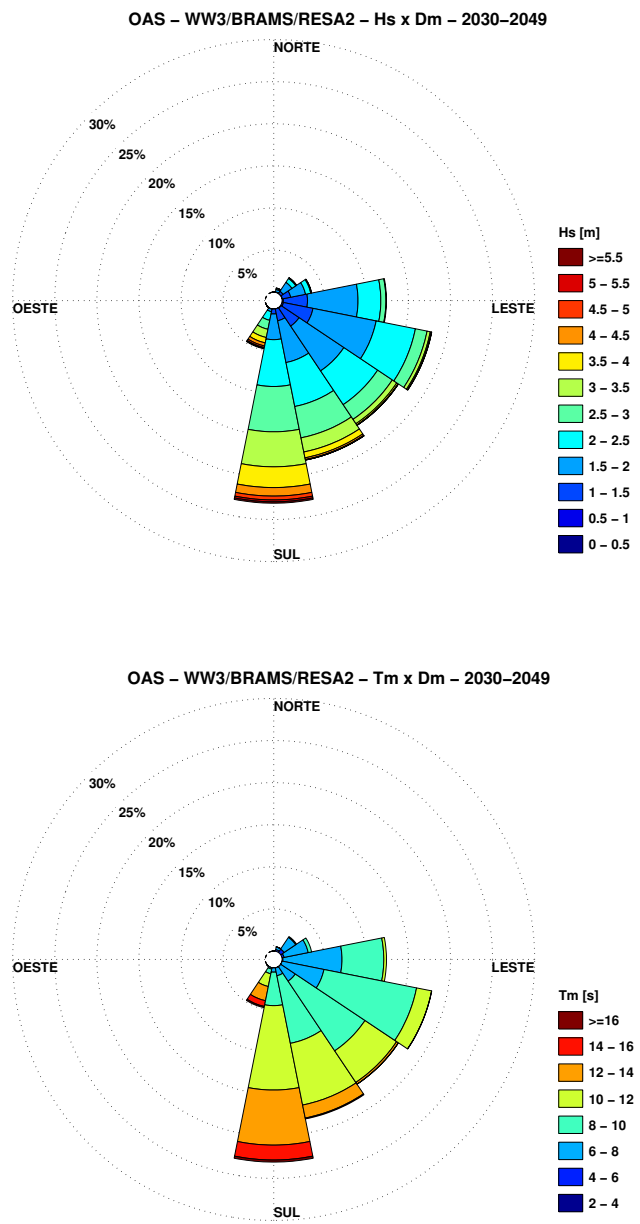
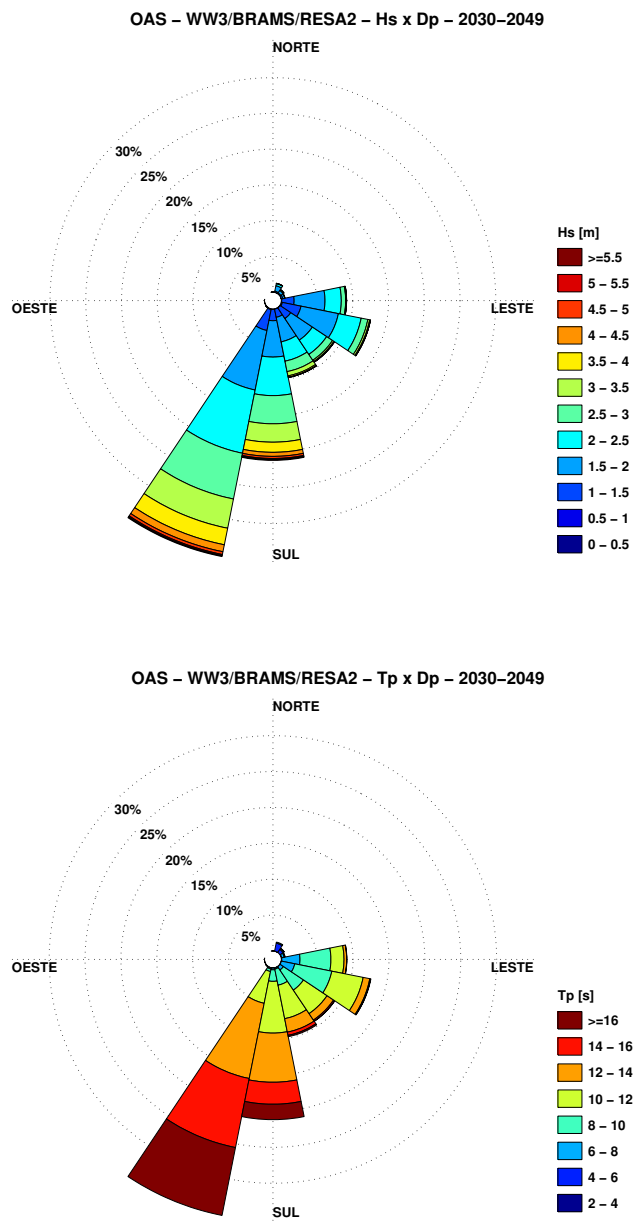

Figura 37 - Histogramas bivariados de Hs X Dm (superior a esquerda), Hs X Dp (superior a direita) , Tm X Dm (inferior a esquerda) e Tp X Dp (inferior a direita) para o ponto BC.

\subsubsection{Ponto BSO}

O ponto BSO (Tabela 5) também apresenta distribuição dos parâmetros de ondas semeIhante à distribuição correspondente para o Século XX. Merecem destaque algumas diferenças nas proporções de ocorrência de maiores períodos e maiores valores de Hs para este conjunto em relação ao Século XX. Nos parâmetros médios, destaca-se a diminuição das ocorrências das componentes de sudoeste e sul, e, o aumento da ocorrência das componentes de leste-nordeste (Figura 38 à esquerda).

Ao considerar as distribuições dos parâmetros de pico (Figura 38 à direita), a componente de sul aumenta a proporção de ocorrência de ondas entre 3,5 e 5,5 metros e de períodos de pico que variam entre 14 a valores maiores que 16 segundos. 
A variação sazonal destes parâmetros pode ser observada nas figuras 62, 70, 78 e 86 dos Anexos. As maiores diferenças são observadas entre os meses de verão e inverno.
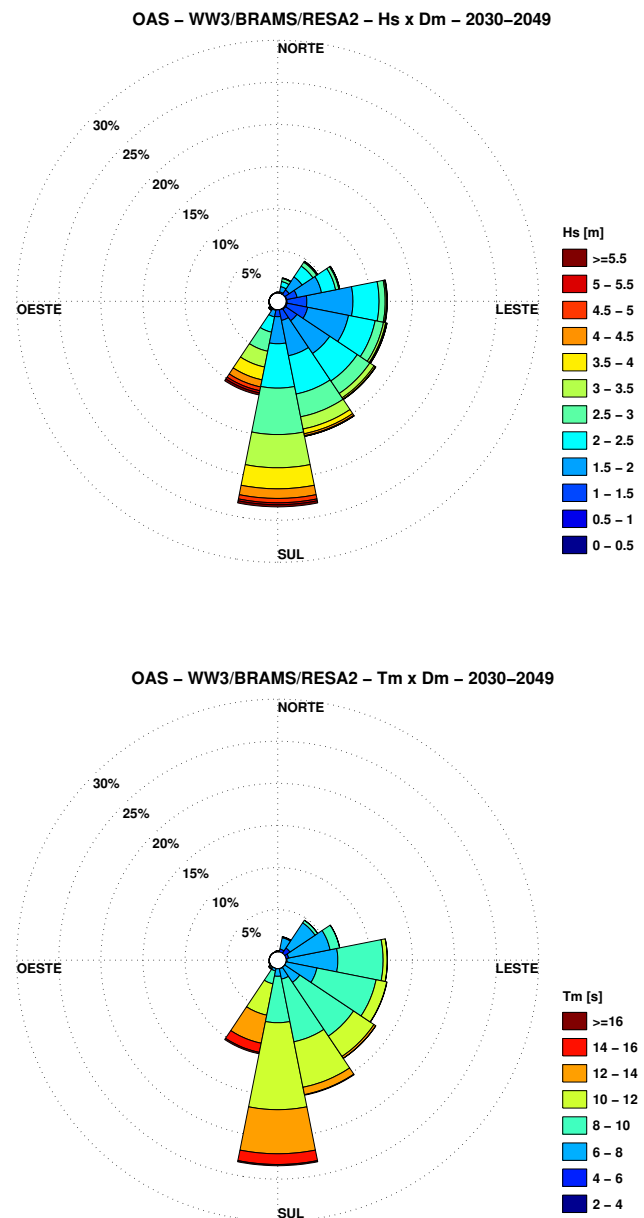

OAS - WW3/BRAMS/RESA2 - Hs x Dp - 2030-2049 NORTE

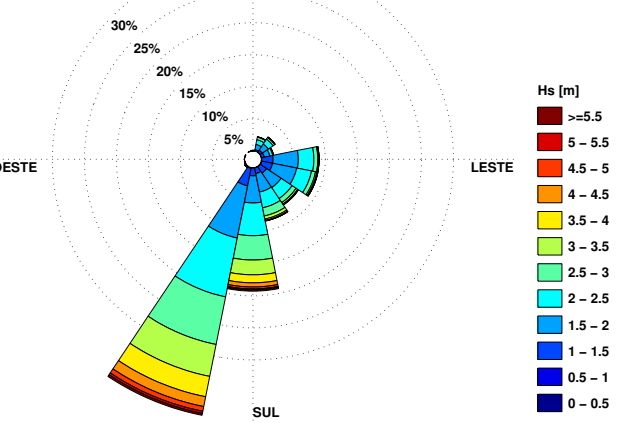

OAS - WW3/BRAMS/RESA2 - Tp x Dp - 2030-2049

NORTE

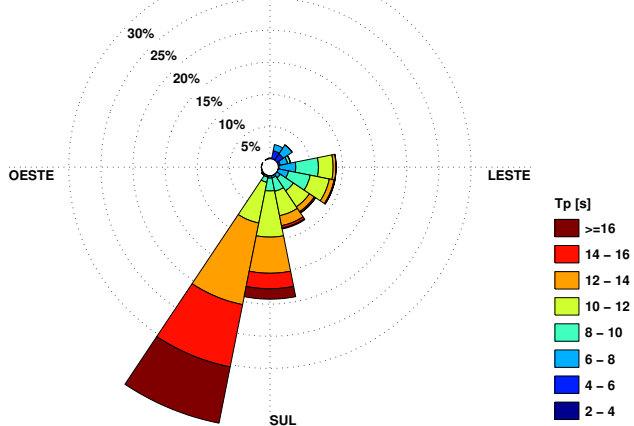

Figura 38 - Histogramas bivariados de Hs X Dm (superior a esquerda), Hs X Dp (superior a direita) , Tm X Dm (inferior a esquerda) e Tp X Dp (inferior a direita) para o ponto BSO. 


\section{SÉCULO XXI SOB UMA ÓTICA OTIMISTA (WW3/CCSM3 SRESB1)}

Neste capítulo serão apresentados os resultados obtidos com as simulações de agitação marítima forçadas com o downscaling da projeção do cenário otimista, SRESB1 que serão identificadas por BRAMS/RESB1.

\subsection{ALTURA SIGNIFICATIVA}

\section{Médias de Altura Significativa}

O campo médio de altura significativa para o conjunto BRAMS/RESB1 para o Século XXI (figura 39) também apresenta características semelhantes ao conjunto BRAMS/CCSM3 para o Século XX. Os menores valores estão distribuídos nas regiões mais costeiras e aumentam conforme se afasta na direção sudeste do domínio apresentado.

A variação sazonal acontece como descrito para os outros conjuntos, com os maiores valores nos meses de inverno e outono e os menores nos meses verão e primavera (figura 40). As maiores variações acontecem nas proximidades dos contornos sul e leste.

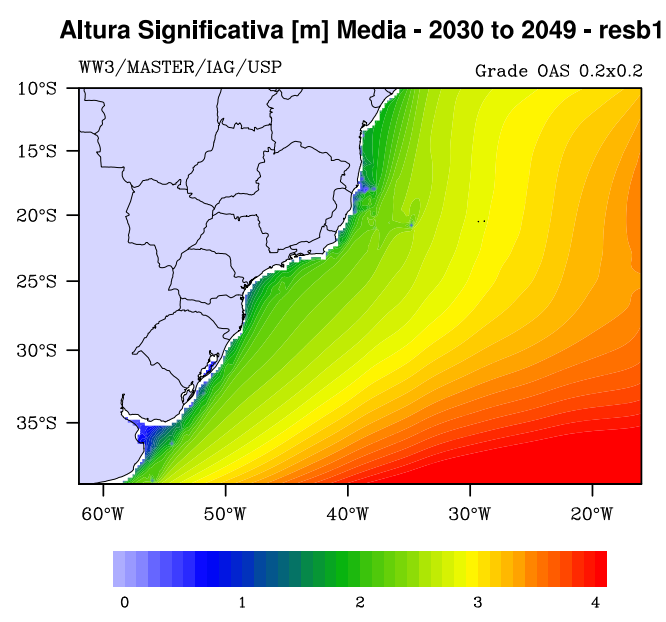

Figura 39 - Média da Altura Significativa [m] ao longo de 20 anos forçados com o downscaling BRAMS/RESB1. 
DJF Media de Altura Significativa [m] - 2030 to 2049 - resb1

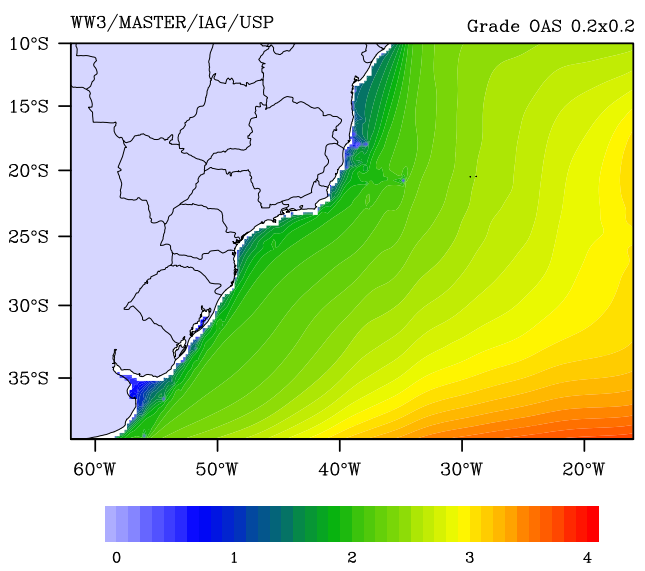

JJA Media de Altura Significativa [m] - 2030 to 2049 - resb1

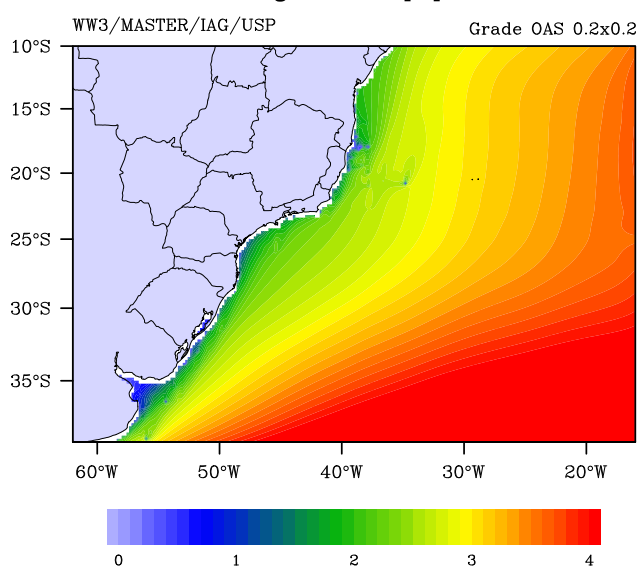

MAM Media de Altura Significativa [m] - 2030 to 2049 - resb1

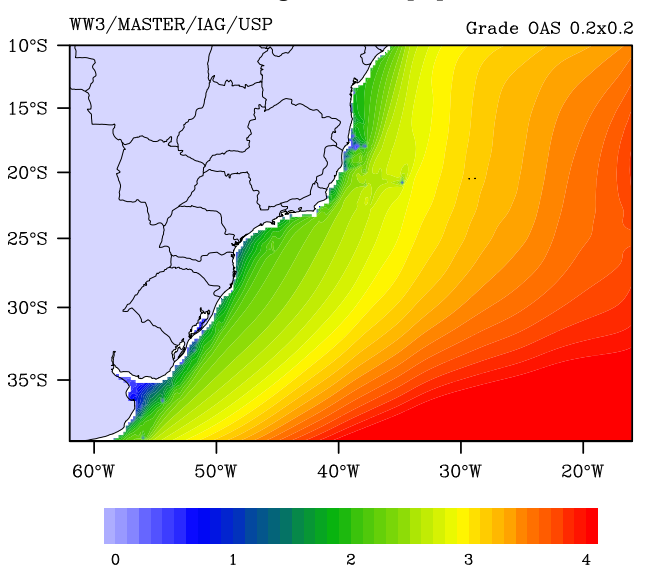

SON Media de Altura Significativa [m] - 2030 to 2049 - resb1

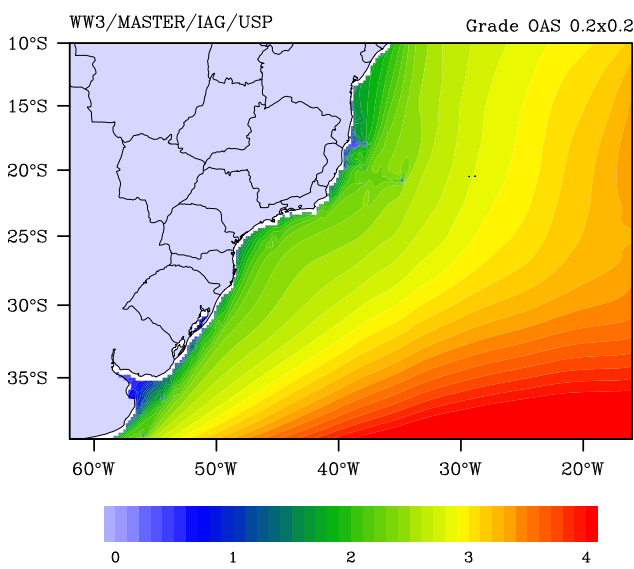

Figura 40 - Média sazonal da Altura Significativa [m] ao longo de 20 anos forçados com o downscaling BRAMS/RESB1. Verão (superior esquerdo), outono (superior direito), inverno (inferior esquerdo) e primavera (inferior direito).

\section{Variância de Altura Significativa}

A variância do campo de altura significativa (figura 41) apresenta comportamento semeIhante ao campo do BRAMS/CCSM3 confirmando que as maiores variações no campo de $\mathrm{Hs}$ acontecem nas proximidades dos contornos sul e leste. Neste cenário é interessante comentar que o campo de variância apresenta valores mais baixos na região central do domínio em relação aos valores encontrados para o conjunto BRAMS/CCSM3. 


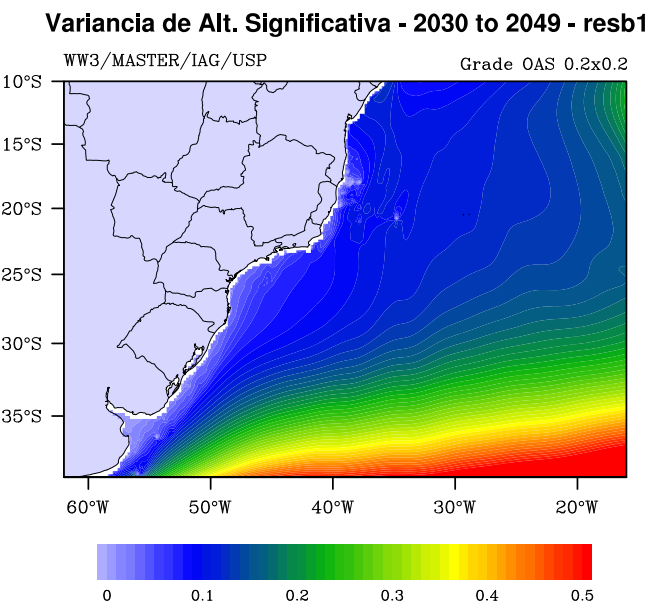

Figura 41 - Variância da Altura Significativa ao longo de 20 anos forçados com o downscaling BRAMS/RESB1.

\subsection{PERÍODO E DIREÇÃO (MÉDIOS)}

\subsubsection{Médias de Período e Direção Médios}

A média total do período médio para o Século XXI, assim como a orientação da média dos vetores de direção média, são similares aos do conjunto BRAMS/CCSM3 no Século XX. Ao comparar estas variáveis na figura 42 com a respectiva para o Século $X X$, pouca diferença pode ser percebida.

A variação das médias sazonais representadas na figura 43 também é bem próxima à variação do conjunto BRAMS/CCSM3. No entanto, durante os meses de inverno, a região ao largo do litoral sudeste apresenta valores de Tm maiores quando comparado com a mesma região do conjunto BRAMS/CCSM3. 
Media de Periodo e Direcao Media - 2030 to 2049 - resb1

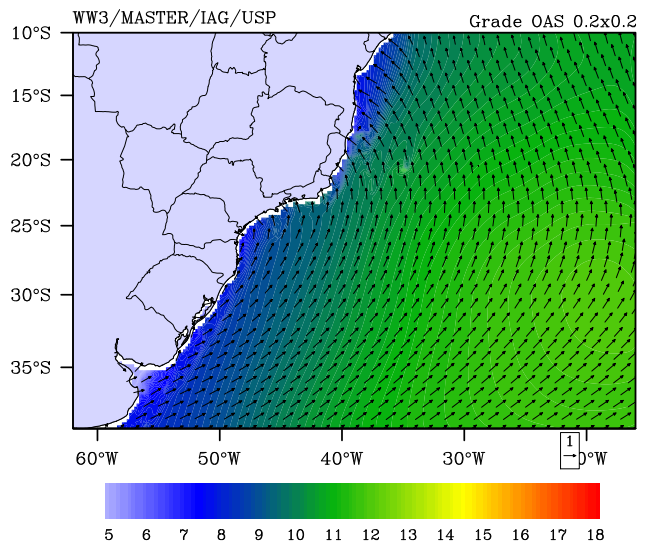

Figura 42 - Média de Período Médio [s] e Direção Média ao longo de 20 anos forçados com o downscaling BRAMS/RESB1.

DJF Media de Periodo e Direcao Media - 2030 to 2049 - resb1

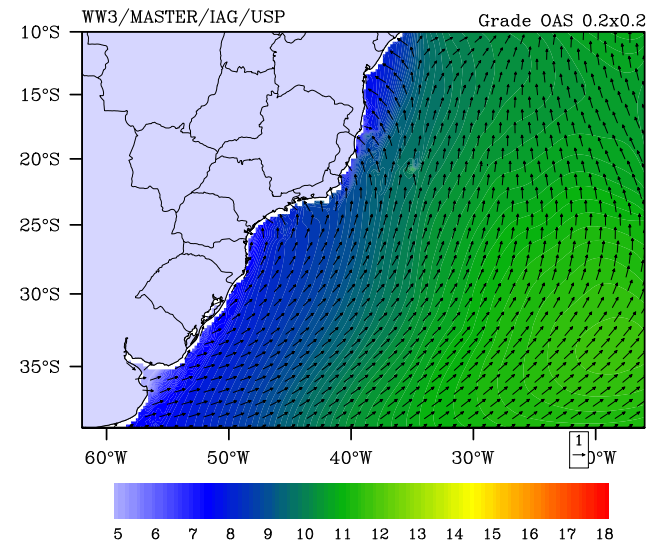

MAM Media de Periodo e Direcao Media - 2030 to 2049 - resb1

JJA Media de Periodo e Direcao Media - 2030 to 2049 - resb1
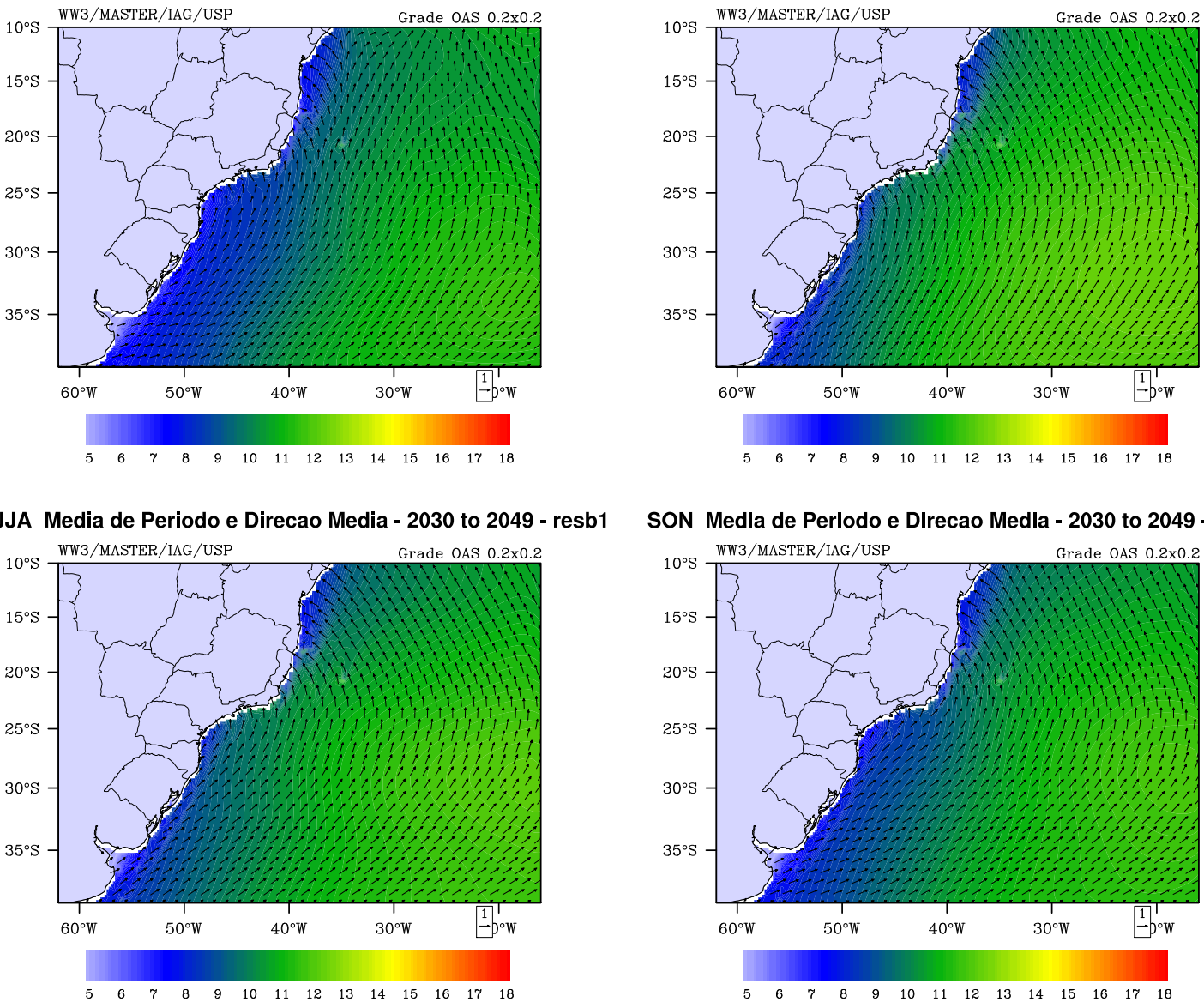

SON Media de Periodo e Direcao Media - 2030 to 2049 - resb1

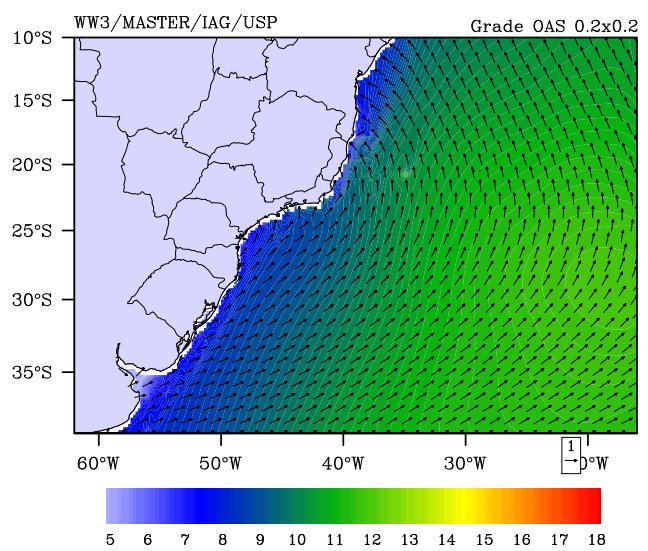

Figura 43 - Médias sazonais de Período Médio [s] e Direção Média ao longo de 20 anos forçados com o downscaling BRAMS/RESB1. Verão (superior esquerdo), outono (superior direito), inverno (inferior esquerdo) e primavera (inferior direito). 


\subsubsection{Variância do Período Médio}

O mapa de variância do período médio evidencia que os maiores valores se encontram numa região nas proximidades do litoral entre o estado do RJ e SP. Este núcleo se alonga para o interior do domínio com diminuição de intensidade, mas novamente começa a aumentar nas proximidades do contorno leste, o que é insignificante para a região de estudo. Um aspecto relevante da variância de Tm é que nas proximidades da fronteira norte do domínio a variância é menor quando comparada com a do conjunto BRAMS/CCSM3 (Figura 23).

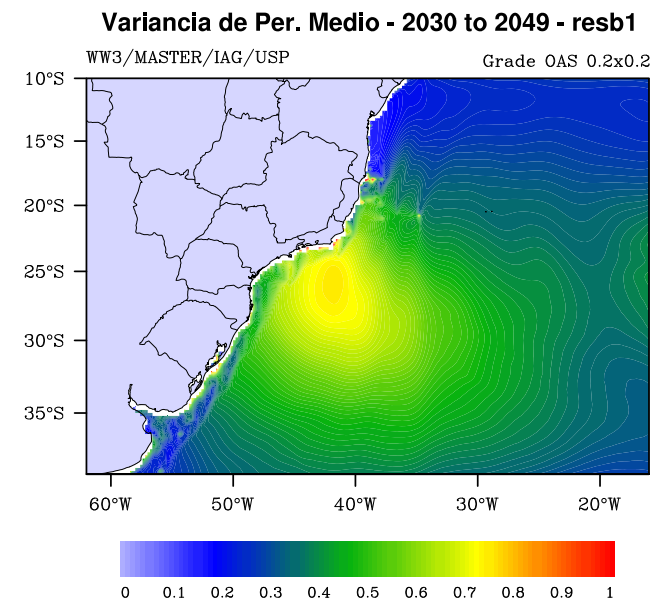

Figura 44 - Variância do Período Médio [s] ao longo de 20 anos forçados com o downscaling BRAMS/RESB1.

\subsection{ANÁLISE PONTUAL DE ALTURA SIGNIFICATIVA, PERÍODO DE PICO, DIREÇÃO DE PICO, PERÍODO MÉDIO E DIREÇÃO MÉDIA}

\subsubsection{Ponto BC}

A distribuição direcional da ocorrência dos parâmetros médios e de pico novamente é muito semelhante ao obtido com o BRAMS/CCSM3 (figura 45). Percebe-se que a diferença básica entre o presente e o futuro sob este cenário é um pequeno aumento da ocorrência de componentes de leste, tanto para a direção média quanto para a direção de pico. Também pode ser observado um ligeiro aumento na ocorrência de ondas de período de pico entre 14 e maiores que 16 segundos na componente de sudoeste.

Sazonalmente, a diferença entre este cenário e o Século XX é a diminuição das componentes de leste durante os meses de inverno, e aumento nos meses de verão. A componente de sudoeste tem sua ocorrência diminuída no verão, e aumenta nos meses de inverno até mesmo quando comparado com o Século XX. Detalhes das variações sazonais de todas as distribuições 
destes parâmetros podem ser observados nas figuras 59, 67, 75, e 83 dos Anexos.
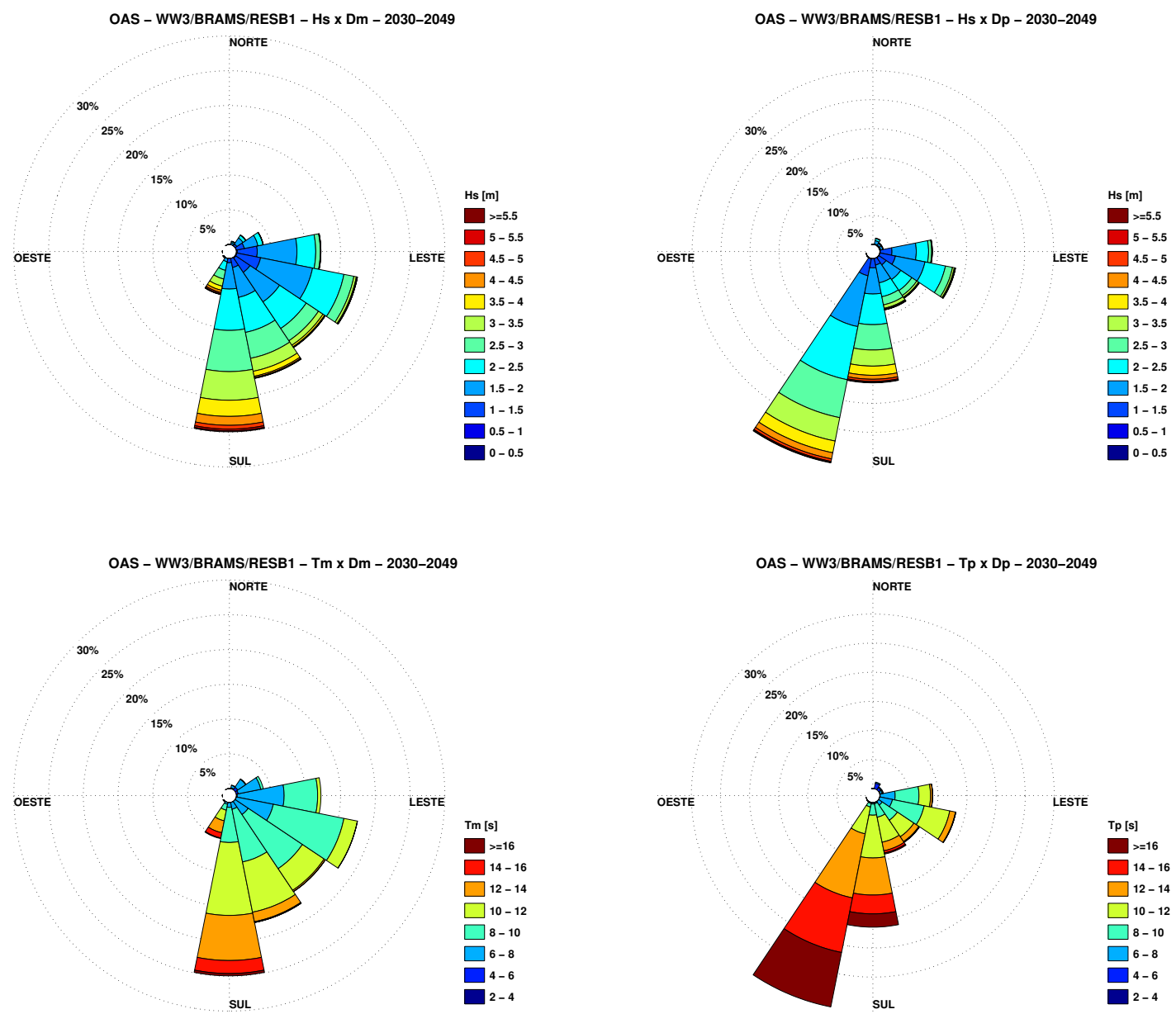

Figura 45 - Histogramas bivariados de $\mathrm{Hs} X \mathrm{Dm}$ (superior a esquerda), Hs X Dp (superior a direita), Tm X Dm (inferior a esquerda) e Tp X Dp (inferior a direita) para o ponto BC.

\subsubsection{Ponto BSO}

A distribuição direcional da ocorrência dos parâmetros médios e de pico novamente é muito semelhante ao obtido com o BRAMS/CCSM3 (figura 46). Percebe-se que a diferença básica entre o presente e o futuro sob este cenário é um pequeno aumento da ocorrência de componentes de nordeste, tanto para a direção média quanto para a direção de pico. Também pode ser observado um ligeiro aumento na ocorrência de ondas de período de pico entre 14 e maiores que 16 segundos tanto na componente de sudoeste como nas componentes de nordeste-leste, obviamente com períodos menores (pico é médio).

Detalhes das variações sazonais de todas as distribuições destes parâmetros podem ser observados nas figuras 63, 71, 79 e 87 dos Anexos. 

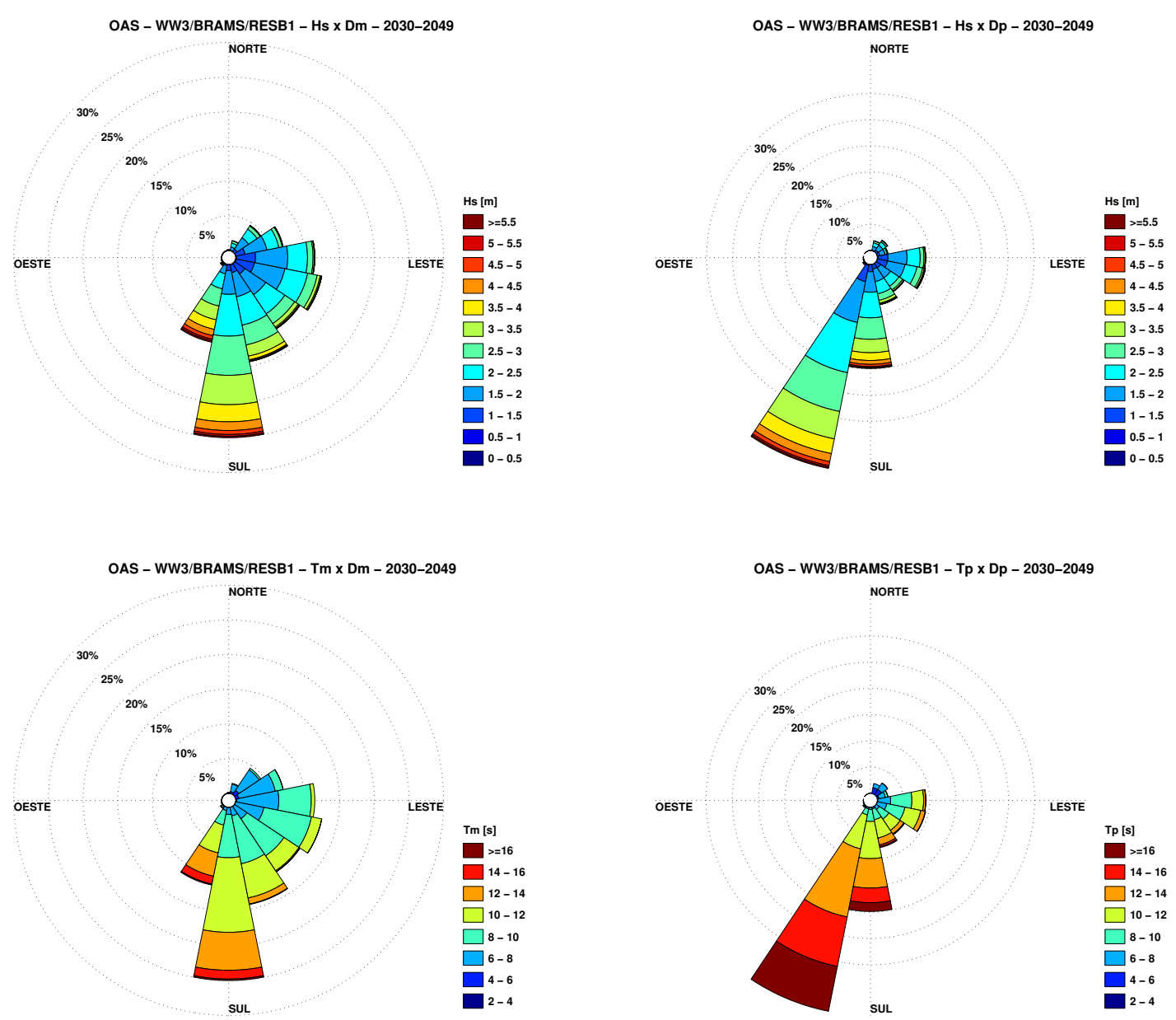

Figura 46 - Histogramas bivariados de Hs X Dm (superior a esquerda), Hs X Dp (superior a direita), Tm X Dm (inferior a esquerda) e Tp X Dp (inferior a direita) para o ponto BSO. 


\section{TENDÊNCIAS DE HS NO SÉCULO XXI}

Foram elaborados dois mapas representativos das tendências do campo de Hs para cada conjunto de simulação do século XXI. Ao se observar o mapa (a) da figura 47 referente a tendência dos campos forçados com o BRAMS/RESA2, nota-se que a menor parte do campo possui uma pequena tendência para aumento dos valores de Hs nas proximidades da linha de costa excluindo-se as proximidades dos estados do Rio de Janeiro, Espírito Santo e Bahia. O restante do campo apresenta pequena tendência negativa.

O campo para o conjunto de simulações forçadas com o BRAMS/RESB1, gráfico (b) da figura 47 também apresenta tendência negativa para maior parte do domínio. Neste caso até mesmo nas proximidades de quase toda a costa, excluindo-se apenas no estado da Bahia. Os valores em módulo da tendência para este conjunto são menores quando comparados com a do conjunto anterior.

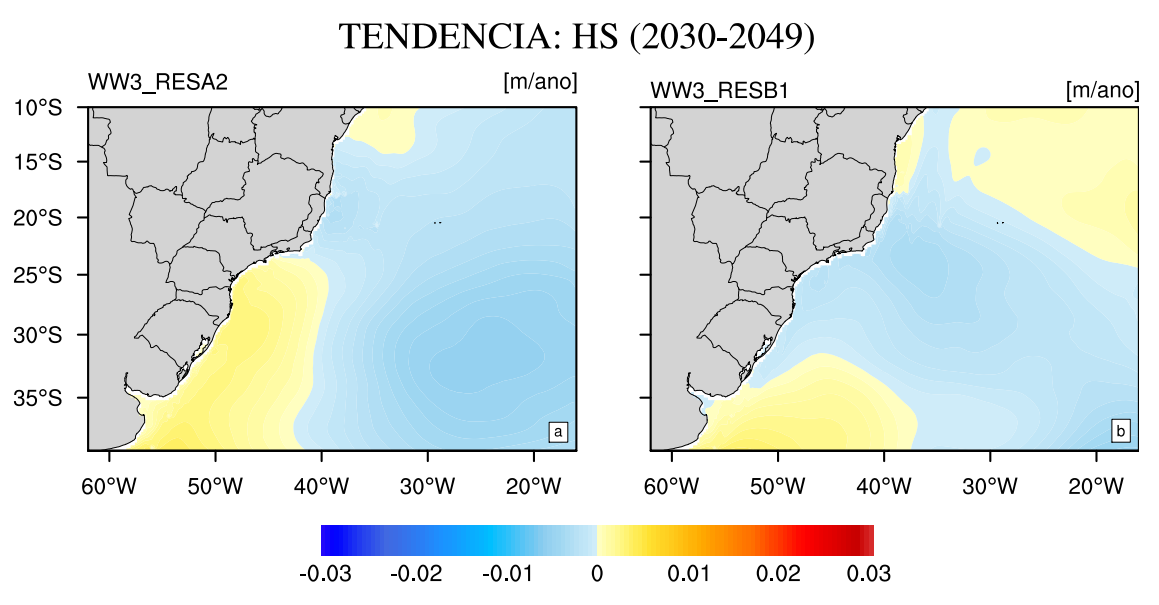

Figura 47 - Tendência de altura significativa [m/ano] ao longo de 20 anos forçados com o downscaling BRAMS/RESA2 (a) e BRAMS/RESB1 (b).

Ao se observar a evolução temporal da tendência nos pontos BC e BSO, figura 93 nota-se que o conjunto forçado com o BRAMS/RESB1 apresenta pequena tendência negativa nos dois pontos. Para o conjunto BRAMS/RESA2 o ponto BSO apresentam tendência positiva e também é observado pequena tendência negativa no ponto $B C$. 

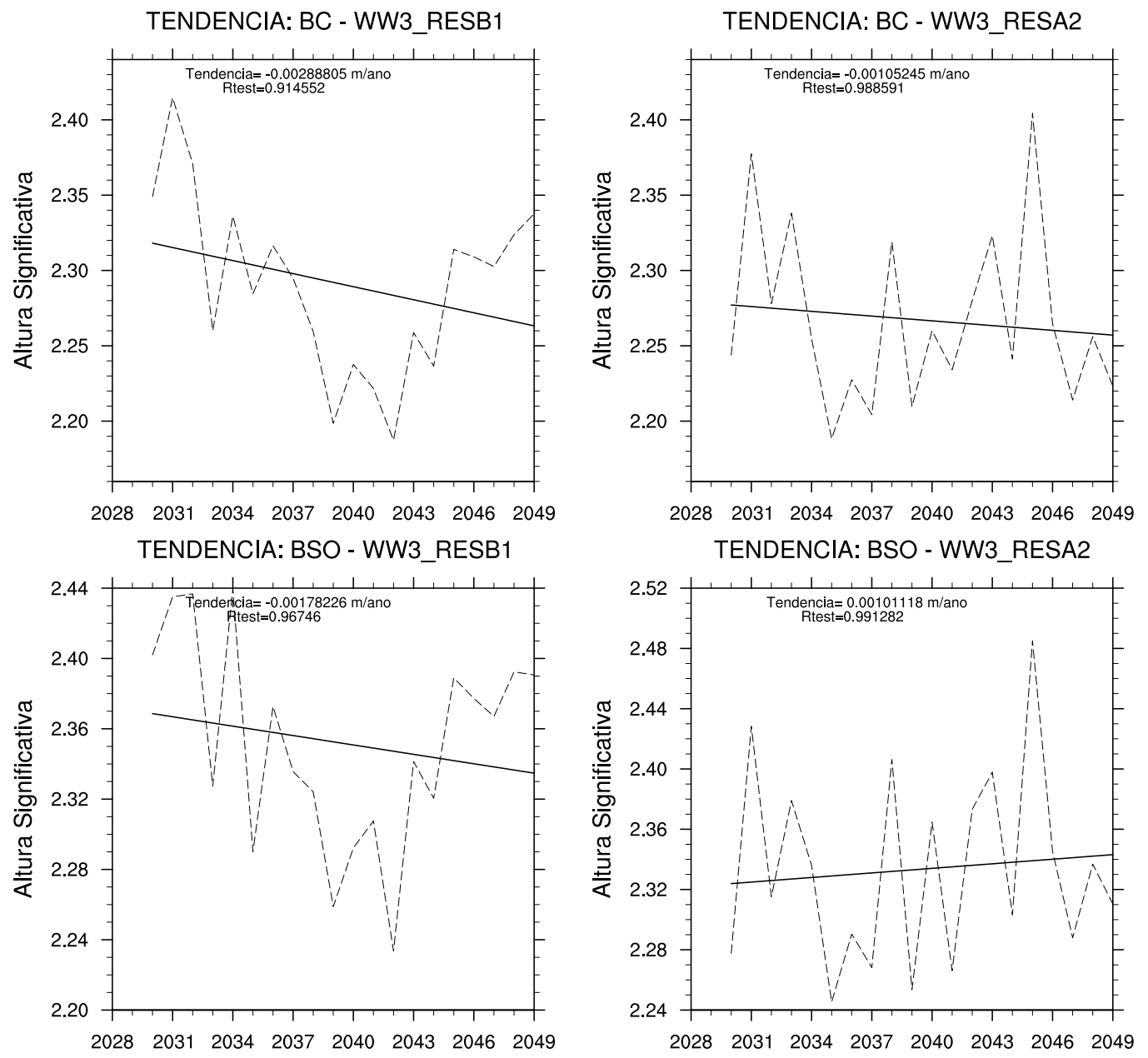

Figura 48 - Variação temporal dos valores médios anuais de altura significativa [m] nos pontos BC e BSO (de cima para baixo) para as simulações forçadas com o downscaling BRAMS/RESB1 (gráficos a esquerda) e BRAMS/RESA2 (gráficos a direita) . 


\section{SÍNTESE FINAL DA CLIMATOLOGIA DE ONDAS}

Neste capítulo são analisadas diferenças encontradas entre os conjuntos simulados para o OAS. A primeira diferença corresponde à frequência de ocorrência de eventos extremos em cada ponto selecionado. A segunda diferença é uma comparação climatológica dos parâmetros de Altura Significativa e Período de Pico em cada ponto analisado.

\subsection{EXTREMOS NA CLIMATOLOGIA DE ONDAS}

Para cada ponto de cada conjunto de simulação foi construída uma série temporal de altura significativa de onde foram contabilizados o valor médio da série, porcentagem de ocorrências de eventos que superam o valor de 1, 2 e 3 desvios padrões. Na figura 49 está exemplificado como foi contabilizado a quantidade de eventos extremos ocorrentes em cada série para cada ponto. Este exemplo corresponde ao conjunto BRAMS/NCEP para o ponto do domínio. A média do valor de Hs ficou em aproximadamente 2.01 metros, as porcentagens de ocorrência de casos superiores a 1, 2 e 3 desvios são respectivamente: $15,34 \% ; 4,33 \%$ e 0,89\%.

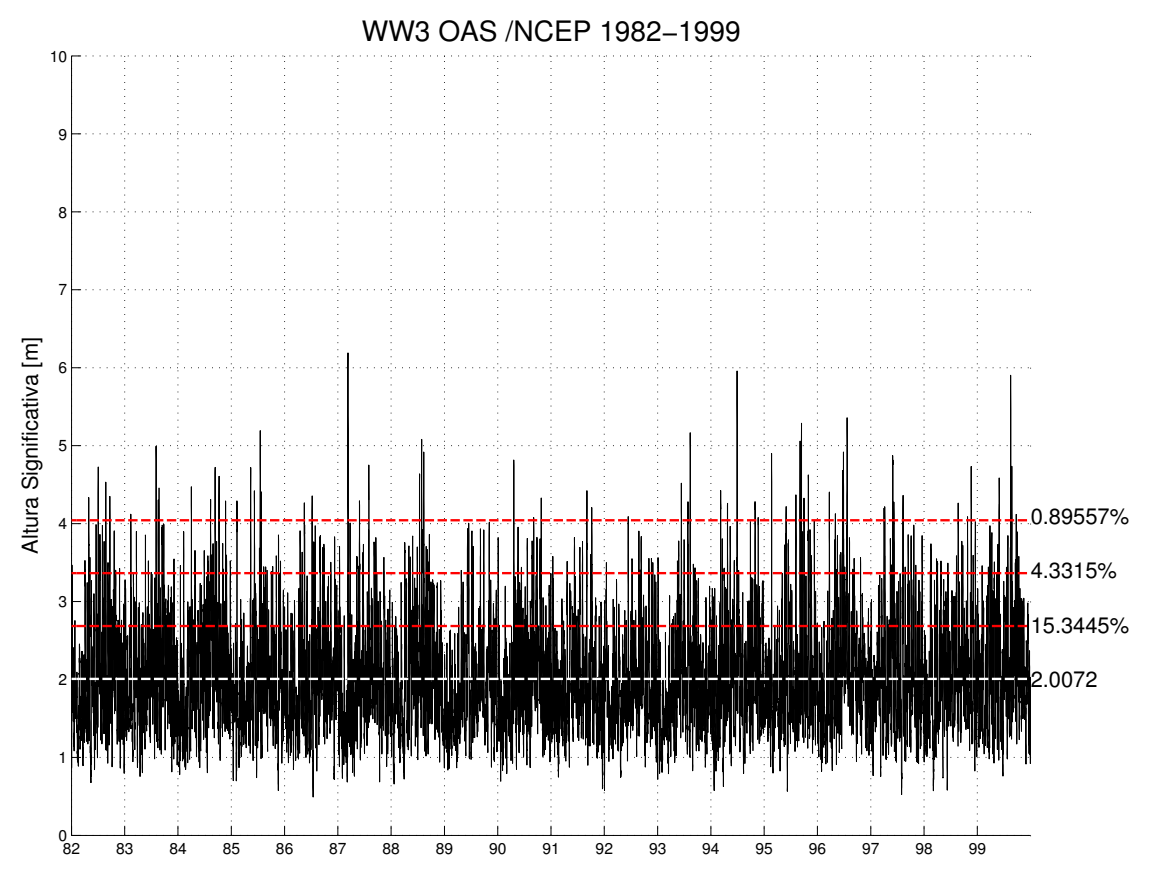

Figura 49 - Série temporal de Hs em um ponto arbitrário para o conjunto de simulações representativas do séc. XX forçadas com o downscaling BRAMS/NCEP.

As Tabelas 6, 7, 8 e 9 sintetizam esta análise. Nela as siglas $M, 1 D, 2 D, 3 D$ e Max correspondem a média, 1 desvio, 2 desvios e 3 desvios e valor máximo. Os valores de $\mathrm{M}$ e 
Max são dados em metros ou em segundos e os valores de 1D, 2D e 3D em porcentagem de ocorrência na série temporal nas tabelas 6 e 8 e na grandeza correspondente nas tabelas 7 e 9. Vale destacar que esta análise não faz sentido para a direção de pico por se tratar de uma grandeza cíclica.

Tabela 6 - Tabela de valores médios e porcentagens de ocorrência de valores de hs nos 2 pontos analisados.

\begin{tabular}{|c|c|c|c|c|c|c|c|c|}
\hline PONTO & \multicolumn{4}{|c|}{ NCEP } & \multicolumn{4}{|c|}{ CCSM3 } \\
\hline \multirow{2}{*}{$B C$} & $M$ & 1D & $2 \mathrm{D}$ & 3D & $M$ & 1D & $2 \mathrm{D}$ & $3 D$ \\
\hline & 1,82 & 15,00 & 4,28 & 0,98 & 2,15 & 14,61 & 4,21 & 1,26 \\
\hline \multirow{3}{*}{ BSO } & $M$ & 1D & $2 \mathrm{D}$ & 3D & $M$ & 1D & $2 \mathrm{D}$ & $3 D$ \\
\hline & 1,92 & 15,09 & 4,33 & 0,94 & 2,24 & 14,37 & 4,26 & 1,35 \\
\hline & \multicolumn{4}{|c|}{ RESA2 } & \multicolumn{4}{|c|}{ RESB1 } \\
\hline \multirow{2}{*}{$\mathrm{BC}$} & $M$ & 1D & $2 \mathrm{D}$ & $3 D$ & $M$ & 1D & $2 \mathrm{D}$ & $3 D$ \\
\hline & 2,24 & 14,98 & 4,44 & 1,22 & 2,26 & 14,84 & 4,52 & 1,22 \\
\hline \multirow{2}{*}{ BSO } & $M$ & 1D & $2 \mathrm{D}$ & 3D & $M$ & 1D & $2 \mathrm{D}$ & $3 D$ \\
\hline & 2,34 & 14,72 & 4,51 & 1,26 & 2,36 & 14,60 & 4,52 & 1,23 \\
\hline
\end{tabular}

Tabela 7 - Tabela de valores máximos e valores dos desvios de hs nos 2 pontos analisados.

\begin{tabular}{|c|c|c|c|c|c|c|c|c|}
\hline PONTO & \multicolumn{4}{|c|}{ NCEP } & \multicolumn{4}{|c|}{ CCSM3 } \\
\hline \multirow{2}{*}{$B C$} & Max & 1D & $2 \mathrm{D}$ & 3D & Max & 1D & $2 \mathrm{D}$ & $3 D$ \\
\hline & 5,29 & 2,41 & 2,99 & 3,58 & 6,59 & 2,89 & 3,62 & 4,36 \\
\hline \multirow{3}{*}{ BSO } & Max & 1D & $2 \mathrm{D}$ & 3D & Max & 1D & $2 \mathrm{D}$ & $3 D$ \\
\hline & 5,86 & 2,58 & 3,24 & 3,90 & 7,32 & 3,03 & 3,83 & 4,62 \\
\hline & \multicolumn{4}{|c|}{ RESA2 } & \multicolumn{4}{|c|}{ RESB1 } \\
\hline \multirow{2}{*}{$B C$} & Max & $1 \mathrm{D}$ & $2 \mathrm{D}$ & 3D & Max & 1D & $2 \mathrm{D}$ & $3 D$ \\
\hline & 6,81 & 3,01 & 3,76 & 4,52 & 8,08 & 3,04 & 3,81 & 4,58 \\
\hline \multirow{2}{*}{ BSO } & Max & 1D & $2 \mathrm{D}$ & 3D & Max & $1 \mathrm{D}$ & $2 \mathrm{D}$ & $3 D$ \\
\hline & 7,44 & 3,17 & 4,00 & 4,83 & 8,66 & 3,19 & 4,03 & 4,87 \\
\hline
\end{tabular}


Tabela 8 - Tabela de valores médios e porcentagens de ocorrência de valores de Tp nos 2 pontos analisados.

\begin{tabular}{|c|c|c|c|c|c|c|c|c|}
\hline \multirow{3}{*}{$\frac{\text { PONTO }}{\text { BC }}$} & \multicolumn{4}{|c|}{ NCEP } & \multicolumn{4}{|c|}{ CCSM3 } \\
\hline & $M$ & $1 \mathrm{D}$ & $2 \mathrm{D}$ & $3 D$ & $M$ & $1 \mathrm{D}$ & $2 \mathrm{D}$ & $3 D$ \\
\hline & 10,26 & 16,43 & 2,68 & 0,18 & 11,92 & 14,39 & 3,33 & 0,67 \\
\hline \multirow{3}{*}{ BSO } & $M$ & $1 \mathrm{D}$ & $2 \mathrm{D}$ & $3 D$ & $M$ & 1D & $2 \mathrm{D}$ & $3 D$ \\
\hline & 9,99 & 16,25 & 2,42 & 0,18 & 11,71 & 13,77 & 3,10 & 0,59 \\
\hline & \multicolumn{4}{|c|}{ RESA2 } & \multicolumn{4}{|c|}{ RESB1 } \\
\hline \multirow{2}{*}{$B C$} & $M$ & 1D & $2 \mathrm{D}$ & $3 D$ & $M$ & 1D & $2 \mathrm{D}$ & $3 D$ \\
\hline & 12,11 & 15,63 & 3,35 & 0,40 & 12,07 & 15,69 & 3,34 & 042 \\
\hline \multirow{2}{*}{ BSO } & $M$ & $1 \mathrm{D}$ & $2 \mathrm{D}$ & $3 D$ & $M$ & $1 \mathrm{D}$ & $2 \mathrm{D}$ & $3 D$ \\
\hline & 11,84 & 14,81 & 3,10 & 0,36 & 11,81 & 14,79 & 3,16 & 0,40 \\
\hline
\end{tabular}

Tabela 9 - Tabela de valores máximos e valores dos desvios de Tp nos 2 pontos analisados.

\begin{tabular}{|c|c|c|c|c|c|c|c|c|}
\hline PONTO & \multicolumn{4}{|c|}{ NCEP } & \multicolumn{4}{|c|}{ CCSM3 } \\
\hline \multirow{2}{*}{$\mathrm{BC}$} & Max & 1D & $2 \mathrm{D}$ & 3D & Max & 1D & $2 \mathrm{D}$ & 3D \\
\hline & 25,06 & 12,91 & 15,55 & 18,20 & 25,06 & 15,00 & 18,08 & 21,17 \\
\hline \multirow{3}{*}{ BSO } & Max & 1D & $2 \mathrm{D}$ & $3 D$ & Max & 1D & $2 \mathrm{D}$ & 3D \\
\hline & 21,50 & 12,70 & 15,41 & 18,12 & 25,06 & 14,90 & 18,08 & 21,27 \\
\hline & \multicolumn{4}{|c|}{ RESA2 } & \multicolumn{4}{|c|}{ RESB1 } \\
\hline \multirow{2}{*}{$B C$} & Max & 1D & $2 \mathrm{D}$ & 3D & Max & 1D & $2 \mathrm{D}$ & $3 \mathrm{D}$ \\
\hline & 25,06 & 15,30 & 18,49 & 21,69 & 25,06 & 15,29 & 18,52 & 21,74 \\
\hline \multirow{2}{*}{ BSO } & Max & 1D & $2 \mathrm{D}$ & 3D & Max & 1D & $2 \mathrm{D}$ & 3D \\
\hline & 25,06 & 15,15 & 18,47 & 21,78 & 25,06 & 15,14 & 18,47 & 21,80 \\
\hline
\end{tabular}

\subsection{COMPARAÇÃO DOS ANOS CLIMATOLÓGICOS NOS CONJUNTOS SIMULADOS}

Para se obter uma maneira prática de comparação foi estabelecido um "ano climatológico" de altura significativa nos pontos analisados para todos os conjuntos de simulações. Esta climatologia foi feita com as médias mensais de cada conjunto: BRAMS/NCEP, BRAMS/CCSM3, BRAMS/RESA2 e BRAMS/RESB1. Esta metodologia consiste em esperar mensalmente todos os valores do parâmetro de onda em questão em um determinado ponto para cada ano e 
calcular a média ao longo de todos os anos simulados.

Tomando o ponto BC como exemplo, o ano climatológico do conjunto BRAMS/NCEP apresenta os menores valores de Hs (Figura 50). Os valores máximos destes parâmetros acontecem em setembro e em julho respectivamente. O conjunto CCSM3 apresenta valores máximos de Hs em abril. Os conjuntos RESA2 e RESB1 apresentam valores mais próximos e quase sempre maiores que os do conjunto CCSM3 na maioria dos casos.

As médias climatológicas para o ponto BSO podem ser observadas nas figuras 89 no capítulo de anexos.

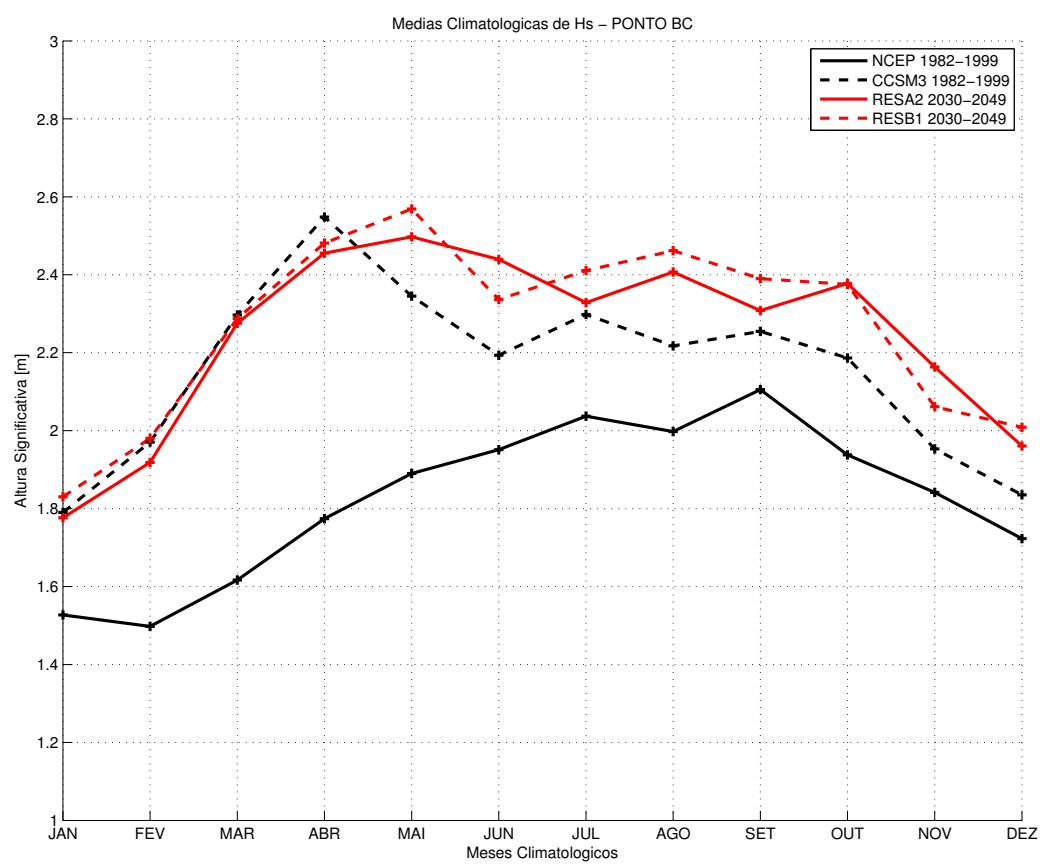

Figura 50 - Ano climatológico de Altura Significativa no ponto 1. 


\section{IMPACTOS DAS MUDANÇAS CLIMÁTICAS NA OCORRÊNCIA DE SWELL E WIND SEA}

De acordo com a teoria de modelagem de ondas, os ventos de superfície e as alturas das ondas seguem uma relação monotônica do estágio inicial do desenvolvimento do mar até o estágio de desenvolvimento completo. Este estágio final é alcançado quando a velocidade de fase correspondente ao pico de onda ultrapassa a velocidade do vento imediatamente acima. Diversos autores propuseram diferentes formulações para expressar esse desenvolvimento, neste trabalho será adotada a formulação proposta por Group 1988 que para mares completamente desenvolvidos as alturas podem ser obtidas por:

$$
H=1,614 \times 10^{-2} U^{2}
$$

para $\left(0 \leq U \leq 7,5 m s^{-1}\right)$ e

$$
H=10^{-2} U^{2}+8,134 \times 10^{-4} U^{3}
$$

para $\left(7,5 \mathrm{~ms}^{-1}<U \leq 50 \mathrm{~ms}^{-1}\right)$. Onde $U$ é a intensidade do vento a 10 metros e $\mathrm{H}$ $(\mathrm{m})$ é a altura significativa das das ondas. A partir desta relação são estabelecidos limiares teóricos para separação do estado do mar em swell e wind sea. Na figura está exemplificado graficamente as expressões acima através da curva em preto. Ao se obter o diagrama de espalhamento entre $\mathrm{Hs}$ e $\mathrm{U}$ tem-se que casos de swell aparecem acima da curva e casos de wind sea ficam abaixo da curva. Na figura está representada a densidade de ocorrência de classes de vento e altura significativa com o conjunto NCEP para o ano de 1999, seguindo os critérios estatísticos descritos em Eilers and Goeman [2004]. A curva em preto é obtida com as equações 11.1 e 11.2 . 


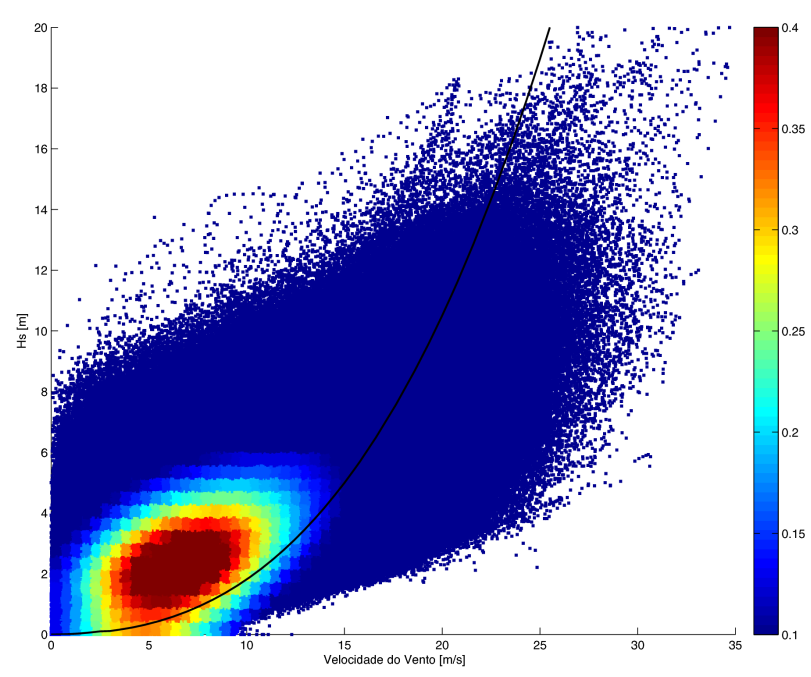

Figura 51 - Diagrama de espalhamento de vento de superfície e altura de onda. Os ventos correspondem a reanálise do NCEP e as alturas de onda são obtidas com a simulação do modelo WW3. A linha em preto corresponde as alturas teóricas obtidas com a relação descritas nas equações 11.1 e 11.2. Casos de swell são considerados acima da linha teórica de desenvolvimento completo, casos de wind sea estão abaixo desta linha. Neste exemplo são utilizados ventos e alturas para o ano de 1999.

A partir da contagem dos casos de swell $\left(N_{S}\right)$ e de caos de wind sea $\left(N_{W}\right)$ em uma determinada série temporal pode-se ser estabelecida as probabilidades de ocorrência de swell e wind sea de acordo com as relações a seguir:

$$
\begin{gathered}
P_{S}=\frac{N_{S}}{N} \\
P_{W}=\frac{N_{W}}{N}
\end{gathered}
$$

onde $N$ corresponde ao número de elementos da série. Desta forma $N=N_{S}+N_{W}$, e assim $P_{S}+P_{W}=1$, significando que qualquer caso é considerado dominado por swell (casos acima da curva de desenvolvimento completo) ou dominado por wind sea (casos abaixo da curva de desenvolvimento completo).

Para este trabalho foi desenvolvida rotinas de cálculo das probabilidades segundo o trabalho de Chen et al. 2002] utilizando a altura significativa obtida com as simulações, desta forma $H$ corresponde a altura significativa proveniente do modelo e $U$ a intensidade do vento a 10 metros utilizada para forçar as simulações.

Na figura 52 está exemplificado o campo das probabilidades de ocorrência de swell para a simulação global a partir do conjunto NCEP durante os anos de 1982 a 1999. Por ela, nota-se claramente a dominância de swell na parte central das grandes bacias oceânicas sugerindo que as ondas geradas em latitudes mais altas dos dois Hemisférios se propagam para regiões 
equatoriais. Outro aspecto importante é diferença entre as bordas leste e oeste de cada oceano com as bordas de leste sujeita a maior probabilidade de ocorrência de swell que as bordas de oeste. Regiões de maior atividade ciclônica, de maneira geral, apresentam menores valores de probabilidade de swell.

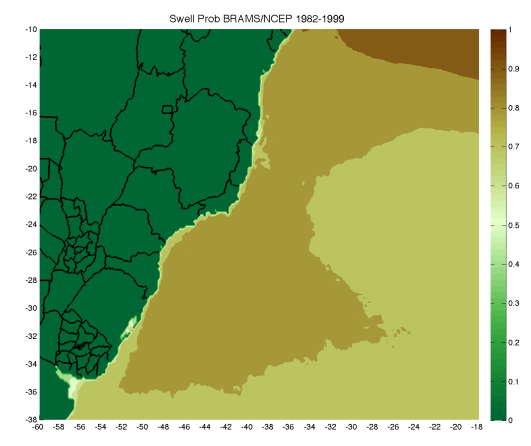

Figura 52 - Probabilidade de ocorrência de swell para a simulação global a partir da reanálise do NCEP entre os anos de 1982 a 1999.

A variação sazonal do campo da probabilidade de swell pode ser observada nos mapas da figura 53 . Durante os meses de verão (DJF) observa-se que o Hemisfério Norte apresenta menor probabilidade de ocorrência de swell coerente com a maior atividade ciclogenética durante estes meses. Durante os meses do outono (MAM) observa-se que os Hemisférios apresentam uma distribuição mais homogênea das probabilidades. Na porção do Atlântico Sudoeste percebe-se claramente o aumento da área de menor probabilidade de swell. Nos meses de inverno ocorre o aposto aos meses de verão com o Hemisfério Sul apresentando as menores probabilidades, nota-se porém que esta diferença é sempre mais marcada no H.N pois este apresenta valores ainda mais baixos durante os meses de verão que o HS apresenta nos meses de inverno. No Atlântico Sudoeste aumenta a área de mínimo de probabilidade que nesses meses se estende até regiões mais centrais. Nos meses de primavera (SON) é observada uma situação de transição, ou seja, o H.N. começa a diminuir os valores da probabilidade. Novamente o Atlântico Sudoeste diminui as áreas de menor probabilidade começando a formar uma espécie de língua de penetração de menores valores até aproximadamente ao largo do litoral do ES. 

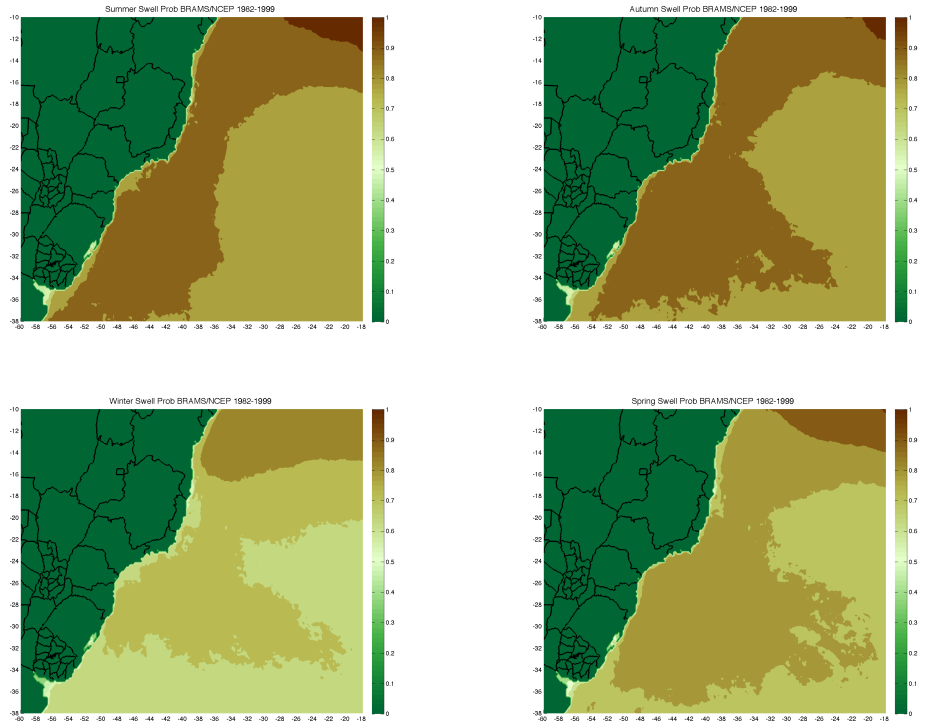

Figura 53 - Variação Sazonal da probabilidade de ocorrência de swell para a simulação global a partir da reanálise do NCEP entre os anos de 1982 a 1999.

A quantificação das diferenças de probabilidades entre as simulações do conjunto CCSM3 e NCEP podem ser observadas na figura 54. Sua quantificação sazonal pode ser considerada uma forma de se exemplificar a variabilidade anual da geração de ondas pelo conjunto CCSM3.

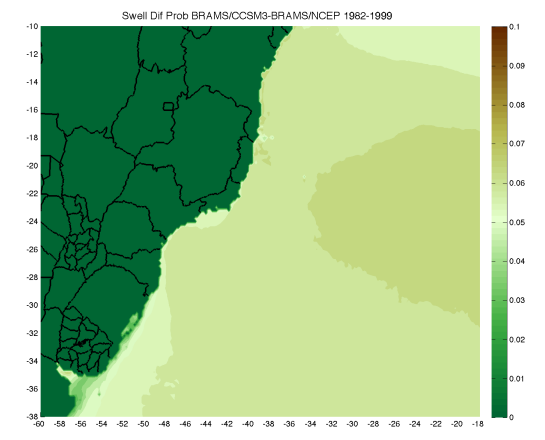

Figura 54 - Diferença da probabilidade de ocorrência de swell entre os conjuntos CCSM3 e NCEP entre os anos de 1982 a 1999.

De acordo com a figura 55 pode ser observado que a superestimativa nas probabilidades de ocorrência de swell ocorrem principalmente na região offshore, próximo da borda leste e ao longo de todo o ano, particularmente ficando mais intensa durante os meses de inverno (campo inferior a esquerda da figura 55). As diferenças das probabilidades diminuem ao se aproximar da linha de costa na porção mais ao Sul, indicando grande correspondencia entre as representações do conjunto NCEP e CCSM3 que são igualmente governados pela ação dos 
ventos locais e propagação de ondas geradas remotamente.
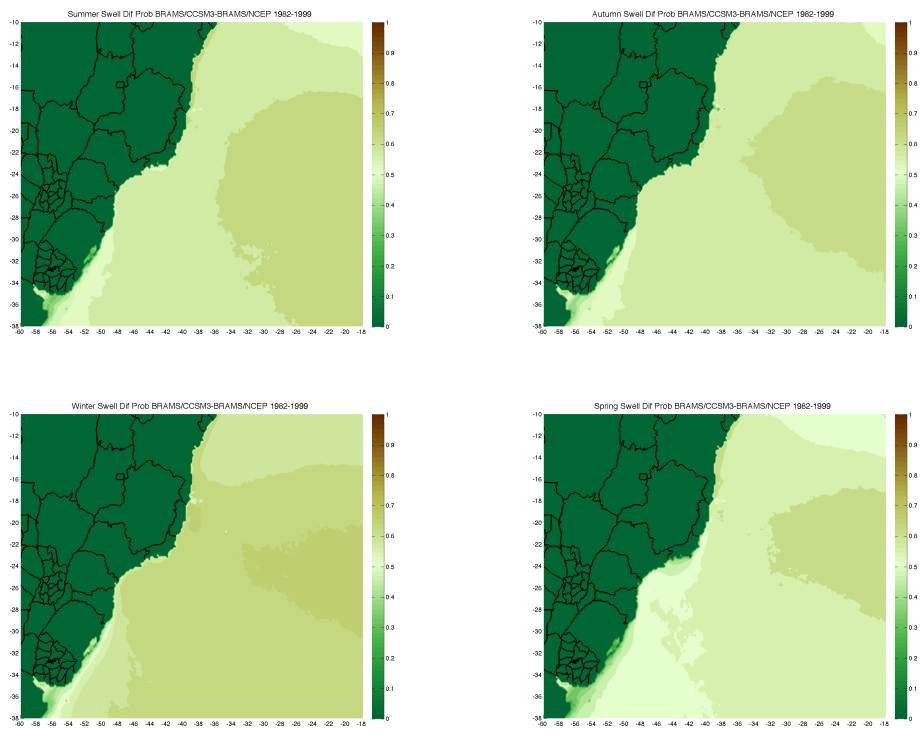

Figura 55 - Variação Sazonal das diferenças de probabilidade de ocorrência de swell entre os conjuntos CCSM3 e NCEP para os anos de 1982 a 1999. 


\section{CONCLUSÕES}

O período de 1982-1999 foi adotado para caracterização das condições do século XX para o conjuntos de downscaling do BRAMS forçado com a Reanálise do NCEP e com a fase histórica do CCSM3. A comparação entre esses conjuntos de simulações leva a destacar três pontos principais:

- o conjunto BRAMS/CCSM3 superestima as alturas significativas ao serem comparadas com a referência BRAMS/NCEP;

- os valores máximos do ciclo anual são aumentados da primavera para outono;

- as probabilidades de ocorrência de swell também é superestimada pelo conjunto BRAMS/CCSM3.

Estes três aspectos estão diretamente relacionados aos padrões de grande escala do modelo acoplado CCSM3 que é preservado no downscaling obtido com o BRAMS.

A análise da tendência de alura significativa para as projeções dos cenários SRESB1 e SRESA2 do CCSM3 considerando as médias anuais do período de 2030-2049 revelam um padrão variável na área de estudo. No entanto pode-se destacar uma particularidade nos dois que é a diminuição das alturas de ondas no oceano aberto e nas proximidades da plataforma próximo a latitude de $20^{\circ} \mathrm{S}$. Ao mesmo tempo também foi observado um pequeno aumento na porção sudoeste da área do estudo.

A comparação do clima de ondas obtido com o conjunto controle (BRAMS/NCEP) com os conjuntos obtidos com as forçantes dos modelos do IPCC para os pontos utilizados revelam que o conjunto BRAMS/CCSM3 apresenta um pequeno aumento de ocorrência de casos extremos no século XX em média e em máximos. Este fato deve ser levado em consideração ao olhar o clima de ondas sugerido pelos conjuntos forçados com as projeções, onde os resultados obtidos revelam que tanto a média das altura das ondas e seus valores máximos sofrem um aumento perceptível para o período de 2030-2049 onde a ocorrência de eventos extremos aumenta para as os dois cenários analisados.

Esta análise dos resultados numéricos obtidos com o modelo de agitação marítima WW3 procurou trazer à tona as características climatológicas das ondas de gravidade superficiais na região Oeste do Atlântico Sul. O emprego de médias mensais e sazonais dos parâmetros de interesse certamente não evidencia a variabilidade da agitação marítima do ponto de vista dos sistemas transientes de tempo, os quais efetivamente influenciam as operações em mar aberto. De qualquer maneira, indiretamente, a atuação destes transientes fica evidenciada nos campos médios de altura significativa e de períodos (médio e de pico), bem como nas correspondentes direções. 
Pode-se dizer objetivamente que nenhuma diferença significativa mereça grande destaque com relação ao clima de ondas conhecido para a região. Uma análise refinada acerca do comportamento dos transientes atmosféricos ainda é possível com base em todos os conjuntos de resultados obtidos, considerando o downscaling atmosférico com o BRAMS de maneira conjunta com as simulações das ondas de gravidade superficiais com o WW3.O trabalho aqui apresentado é uma técnica pioneira para estudo de projeções climáticas em agitação marítima. Este foi o primeiro trabalho desenvolvido na América do Sul com metodologia inédita, e que apesar de todas as incertezas envolvidas é a única maneira de se realmente avaliar o impacto das mudanças do clima de maneira regional com ênfase nas ondas de gravidade geradas por vento.

Mesmo com uma análise simples e fundamental este trabalho apresenta uma caracterização do clima de ondas para a porção sudoeste do Atlântico Sul tendo como base simulações numéricas. A estratégia para alcançar condições realísticas de onda consiste em considerar um domínio global para reprsentar a influência de campos de swell gerados remotamente associado a um domínio regional incluindo os processos atmosféricos de mesoescala. Este procedimento foi implementado adequadamente nos esquemas de simulações e os resultados podem ser considerados como prova de sua relevância. O modelo WAVEWATCH III foi aplicado para as simulações de agitação e o modelo BRAMS para obtenção das forçantes atmosféricas de mesoescala. 


\section{Referências Bibliográficas}

Jose-Henrique GM Alves. Numerical modeling of ocean swell contributions to the global wind-wave climate. Ocean Modelling, 11(1):98-122, 2006.

S. Bacon and D. J. T. Carter. Wave climate changes in the north atlantic and north sea. International Journal of Climatology, 11(5), 1991.

B. Biazeto and M.A.F. Silva Dias. Analysis of the impact of rainfall assimilation during LBA atmospheric mesoscale missions in Southwest Amazon. Atmospheric Research, 2012.

Fabrício Vasconcelos Branco. Contribuições de swell gerado em tempestades distantes para o clima de ondas na costa brasileira. PhD thesis, Dissertação de Mestrado, Instituto de Astronomia, Geofísica e Ciências Atmosféricas, Departamento de Ciências Atmosféricas, Universidade de São Paulo, 2005.

Sofia Caires, Val R Swail, and Xiaolan L Wang. Projection and analysis of extreme wave climate. Journal of Climate, 19(21):5581-5605, 2006.

Jennifer L Catto, Len C Shaffrey, and Kevin I Hodges. Northern hemisphere extratropical cyclones in a warming climate in the higem high-resolution climate model. Journal of Climate, 24(20):5336-5352, 2011.

L Cavaleri, B Fox-Kemper, and Mark Hemer. Wind waves in the coupled climate system. Bulletin of the American Meteorological Society, 93(11):1651-1661, 2012.

Ge Chen, Bertrand Chapron, Robert Ezraty, and Douglas Vandemark. A global view of swell and wind sea climate in the ocean by satellite altimeter and scatterometer. Journal of atmospheric and Oceanic Technology, 19(11):1849-1859, 2002.

S. Chen and W. Cotton. The sensitivity of a simulated extratropical mesoscale convection system to longwave radiation and ice-phase microphysics. Journal of the atmospheric sciences, 45(24):3897-3910, 1988.

Carlos Coelho, Raquel Silva, Fernando Veloso-Gomes, and Francisco Taveira-Pinto. Potential effects of climate change on northwest portuguese coastal zones. ICES Journal of Marine Science: Journal du Conseil, 66(7):1497-1507, 2009.

William D Collins, Cecilia M Bitz, Maurice L Blackmon, Gordon B Bonan, Christopher S Bretherton, James A Carton, Ping Chang, Scott C Doney, James J Hack, Thomas B Hen- 
derson, et al. The community climate system model version 3 (ccsm3). Journal of Climate, 19(11):2122-2143, 2006.

W.R. Cotton, RA Pielke Sr, RL Walko, GE Liston, CJ Tremback, H. Jiang, RL McAnelly, JY Harrington, ME Nicholls, GG Carrio, et al. RAMS 2001: Current status and future directions. Meteorology and Atmospheric Physics, 82(1):5-29, 2003.

Thomas L Delworth, Anthony J Broccoli, Anthony Rosati, Ronald J Stouffer, V Balaji, John A Beesley, William F Cooke, Keith W Dixon, John Dunne, KA Dunne, et al. Gfdl's cm2 global coupled climate models. part i: Formulation and simulation characteristics. Journal of Climate, 19(5):643-674, 2006.

G. Dodet, X. Bertin, and R. Taborda. Wave climate variability in the North-East Atlantic Ocean over the last six decades. Ocean Modelling, 31:120-131, 2010.

H. Dupuis, D. Michel, and A. Sottolichio. Wave climate evolution in the Bay of Biscay over two decades. Journal of Marine Systems, 63:105-114, December 2006.

Paul HC Eilers and Jelle J Goeman. Enhancing scatterplots with smoothed densities. Bioinformatics, 20(5):623-628, 2004.

Yalin Fan, Isaac M Held, Shian-Jiann Lin, and Xiaolan L Wang. Ocean warming effect on surface gravity wave climate change for the end of the twenty-first century. Journal of Climate, 26(16):6046-6066, 2013.

S.R. Freitas, K.M. Longo, M.A.F. Silva Dias, R. Chatfield, P. Silva Dias, P. Artaxo, M.O. Andreae, G. Grell, L.F. Rodrigues, A. Fazenda, et al. The coupled aerosol and tracer transport model to the Brazilian developments on the Regional Atmospheric Modeling System (CATT-BRAMS)-Part 1: Model description and evaluation. Atmospheric Chemistry and Physics, 9(8):2843-2861, 2009.

Anand Gnanadesikan, Keith W Dixon, Stephen M Griffies, V Balaji, Marcelo Barreiro, J Anthony Beesley, William F Cooke, Thomas L Delworth, Rudiger Gerdes, Matthew J Harrison, et al. Gfdl's cm2 global coupled climate models. part ii: The baseline ocean simulation. Journal of Climate, 19(5):675-697, 2006.

Chris Gordon, Claire Cooper, Catherine A Senior, Helene Banks, Jonathan M Gregory, Timonthy C Johns, John FB Mitchell, and Richard A Wood. The simulation of sst, sea ice extents and ocean heat transports in a version of the hadley centre coupled model without flux adjustments. Climate Dynamics, 16(2-3):147-168, 2000. 
G. Grell and D. Devenyi. A generalized approach to parameterizing convection combining ensemble and data assimilation techniques. Geophysical Research Letters, 29(14):38-1, 2002.

SM Griffies, AWDK Gnanadesikan, Keith W Dixon, JP Dunne, Rüdiger Gerdes, Matthew J Harrison, Anthony Rosati, JL Russell, Bonita L Samuels, Michael J Spelman, et al. Formulation of an ocean model for global climate simulations. Ocean Science, 1(1):45-79, 2005.

The Wamdi Group. The wam model-a third generation ocean wave prediction model. Journal of Physical Oceanography, 18(12):1775-1810, 1988.

James E Hansen, Makiko Sato, Andrew Lacis, Reto Ruedy, Ina Tegen, and Elaine Matthews. Climate forcings in the industrial era. Proceedings of the National Academy of Sciences, 95 (22):12753-12758, 1998.

H Hasumi and S Emori. K-1 coupled model (miroc) description. k-1 technical report 1. Center for Climate System Research, University of Tokyo, Tokyo, 2004.

Mark A Hemer, Jack Katzfey, and Claire E Trenham. Global dynamical projections of surface ocean wave climate for a future high greenhouse gas emission scenario. Ocean Modelling, 70:221-245, 2013.

E. Kalnay, M. Kanamitsu, R. Kistler, W. Collins, D. Deaven, L. Gandin, M. Iredell, S. Saha, G. White, J. Woollen, Y. Zhu, A. Leetmaa, B. Reynolds, M. Chelliah, W. Ebisuzaki, W. Higgins, J. Janowiak, K. Mo, C. Ropelewski, J. Wang, R. Jenne, and D. Joseph. The NCEP/NCAR 40-year reanalysis project. Bulletin of the American Meteorological Society, 77(3):437-471, 1996.

Thomas R Knutson, TL Delworth, KW Dixon, IM Held, J Lu, V Ramaswamy, MD Schwarzkopf, G Stenchikov, and RJ Stouffer. Assessment of twentieth-century regional surface temperature trends using the gfdl cm2 coupled models. Journal of Climate, 19(9):1624-1651, 2006.

Y. Kushnir, V. J. Cardone, J. G. Greenwood, and M. A. Cane. The recent increase in north atlantic wave heights. Journal of Climate, 10(8):2107-2113, 1997.

Sydney Levitus. Climatological atlas of the world ocean. Eos, Transactions American Geophysical Union, 64(49):962-963, 1983. 
Michael S Longuet-Higgins and RW Stewart. Radiation stresses in water waves; a physical discussion, with applications. In Deep Sea Research and Oceanographic Abstracts, volume 11, pages 529-562. Elsevier, 1964.

Simon J Marsland, Helmuth Haak, Johann H Jungclaus, Mojib Latif, and Frank Röske. The max-planck-institute global ocean/sea ice model with orthogonal curvilinear coordinates. Ocean modelling, 5(2):91-127, 2003.

James J McCarthy. Climate change 2001: impacts, adaptation, and vulnerability: contribution of Working Group II to the third assessment report of the Intergovernmental Panel on Climate Change. Cambridge University Press, 2001.

Gerald A Meehl, Curt Covey, Karl E Taylor, Thomas Delworth, Ronald J Stouffer, Mojib Latif, Bryant McAvaney, and John FB Mitchell. The wcrp cmip3 multimodel dataset: A new era in climate change research. Bulletin of the American Meteorological Society, 88(9): 1383-1394, 2007a.

Gerard A Meehl, Thomas F Stocker, William D Collins, Pierre Friedlingstein, Amadou T Gaye, Jonathan M Gregory, Akio Kitoh, Reto Knutti, James M Murphy, Akira Noda, et al. Global climate projections. Climate change, 3495:747-845, 2007b.

M.P. Meyers, R.L. Walko, J.Y. Harrington, and W.R. Cotton. New RAMS cloud microphysics parameterization. Part ii: The two-moment scheme. Atmospheric Research, 45(1):3-39, 1997.

Nobuhito Mori, Tomohiro Yasuda, Hajime Mase, Tracey Tom, and Yuichiro Oku. Projection of extreme wave climate change under global warming. Hydrological Research Letters, 4: 15-19, 2010.

Robert J Nicholls, Poh Poh Wong, Virginia Burkett, Jorge Codignotto, John Hay, Roger McLean, Sachooda Ragoonaden, Colin D Woodroffe, PAO Abuodha, J Arblaster, et al. Coastal systems and low-lying areas. 2007.

Erich Roeckner, G Bäuml, L Bonaventura, Renate Brokopf, Monika Esch, Marco Giorgetta, Stefan Hagemann, Ingo Kirchner, Luis Kornblueh, Elisa Manzini, et al. The atmospheric general circulation model echam 5. part i: Model description. 2003.

S. Solomon, Intergovernmental Panel on Climate Change, and Intergovernmental Panel on Climate Change. Working Group I. Climate Change 2007 - The Physical Science Basis: Working 
Group I Contribution to the Fourth Assessment Report of the IPCC. Assessment report (Intergovernmental Panel on Climate Change): Working Group. Cambridge University Press, 2007.

Thomas F Stocker. Climate change 2013: the physical science basis: Working Group I contribution to the Fifth assessment report of the Intergovernmental Panel on Climate Change. Cambridge University Press, 2014.

Karl E Taylor. Summarizing multiple aspects of model performance in a single diagram. Journal of Geophysical Research: Atmospheres, 106(D7):7183-7192, 2001.

Hendrik L Tolman. Treatment of unresolved islands and ice in wind wave models. Ocean Modelling, 5(3):219-231, 2003.

Hendrik L Tolman. User manual and system documentation of wavewatch iii tm version 3.14. Technical note, MMAB Contribution, (276), 2009.

Hendrik L Tolman and Dmitry Chalikov. Source terms in a third-generation wind wave model. Journal of Physical Oceanography, 26(11):2497-2518, 1996.

C. Tremback and R.L. Walko. Implementing very-high resolution capabilities into a mesoscale atmospheric model: New capabilities for the Regional Atmospheric Modeling System (RAMS). Mesoscale and CFD Modeling for Military Applications, 2004.

G.J. Tripoli and W.R. Cotton. The Colorado State University three-dimensional cloud mesoescale model-1982. Part. i: General theoretical framework and sensitivity experiments. Journal de Recherches Atmospheriques, 16(3):185-220, 1982.

Xiaolan L. Wang and Val R. Swail. Trends of atlantic wave extremes as simulated in a 40yr wave hindcast using kinematically reanalyzed wind fields. Journal of Climate, 15(9): 1020-1035, 2002.

Xiaolan L Wang, Yang Feng, and Val R Swail. Changes in global ocean wave heights as projected using multimodel cmip5 simulations. Geophysical Research Letters, 41(3):10261034, 2014.

XiaolanL. Wang and ValR. Swail. Climate change signal and uncertainty in projections of ocean wave heights. Climate Dynamics, 26(2-3):109-126, 2006. ISSN 0930-7575.

Jeffrey $\mathrm{H}$. Yin. A consistent poleward shift of the storm tracks in simulations of 21st century climate. Geophysical Research Letters, 32(18):n/a-n/a, 2005. 
IR Young, S Zieger, and Alexander V Babanin. Global trends in wind speed and wave height. Science, 332(6028):451-455, 2011.

Seiji Yukimoto and Kunihiko Kodera. Interdecadal arctic oscillation in twentieth century climate simulations viewed as internal variability and response to external forcing. Geophysical research letters, 32(3), 2005. 
Anexo A - Variação Sazonal da Distribuição de Hs X Dm

VARIAÇÃO SAZONAL DA DISTRIBUIÇÃO DE HS X DM

\section{Ponto BC}

Século XX BRAMS/NCEP
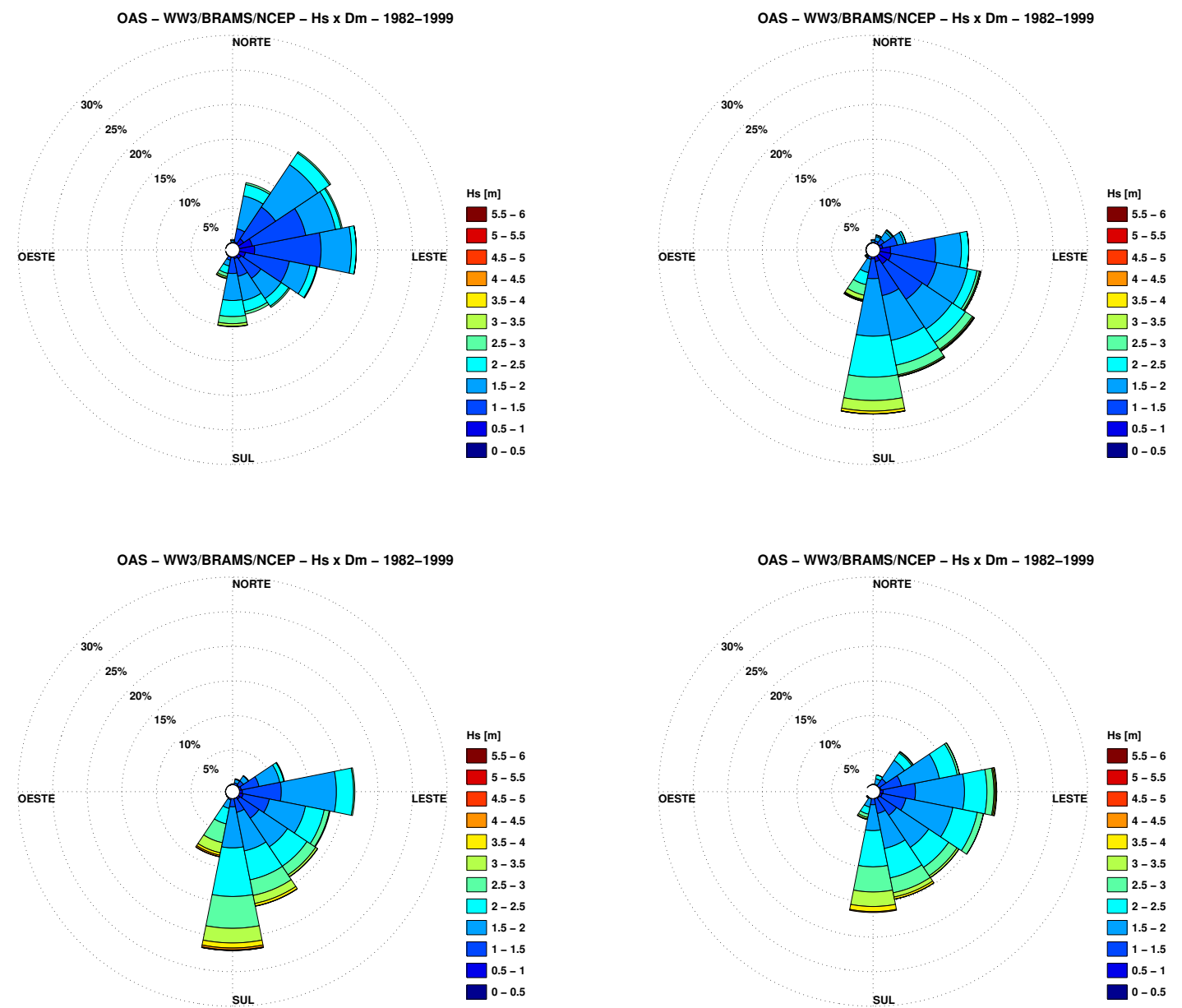

Figura 56 - Histogramas bivariados de Hs X Dm para verão (superior a esquerda), outono (superior a direita), inverno (inferior a esquerda) e primavera (inferior a direita) no ponto BC. 
Século XX BRAMS/CCSM3

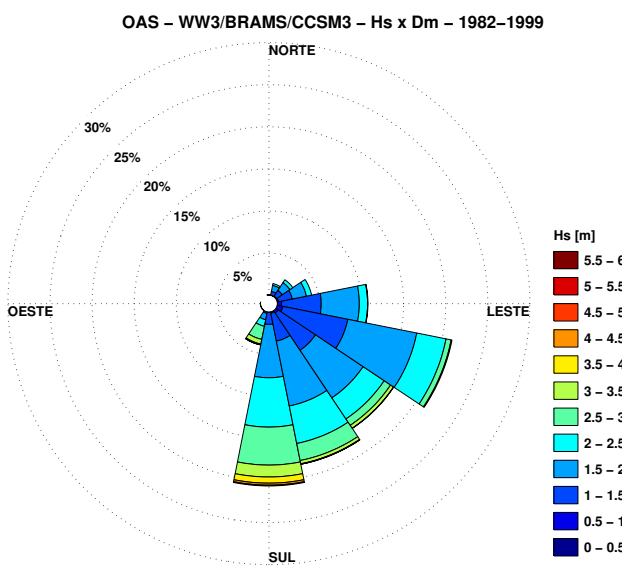

OAS - WW3/BRAMS/CCSM3 - Hs x Dm - 1982-1999 NORTE

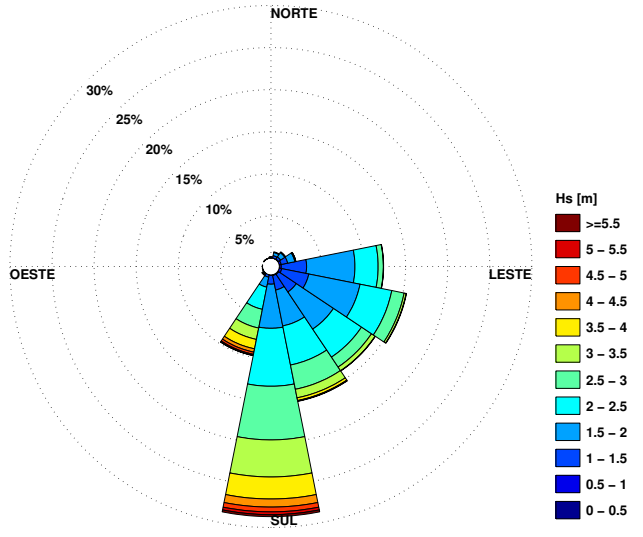

OAS - WW3/BRAMS/CCSM3 - Hs x Dm - 1982-1999 NORTE

$30 \%$

$25 \%$

$20 \%$

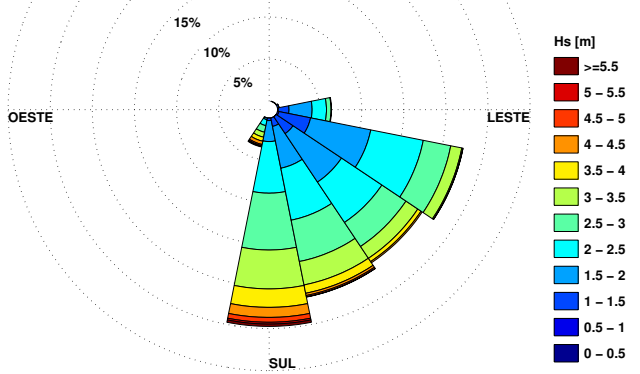

OAS - WW3/BRAMS/CCSM3 - Hs x Dm - 1982-1999 NORTE

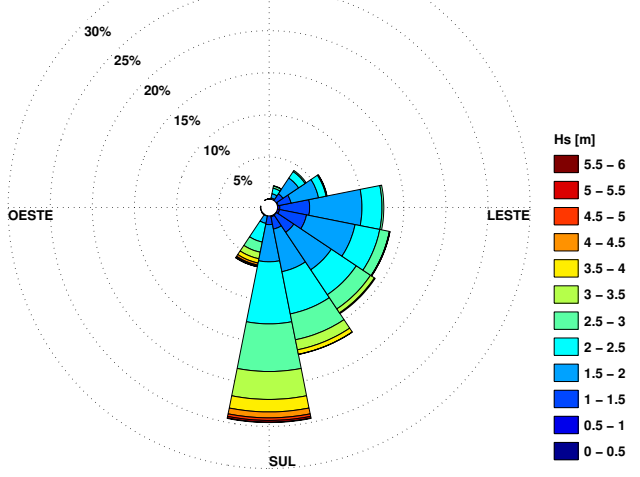

Figura 57 - Histogramas bivariados de Hs X Dm para verão (superior a esquerda), outono (superior a direita), inverno (inferior a esquerda) e primavera (inferior a direita) no ponto BC. 
Século XXI BRAMS/RESA2

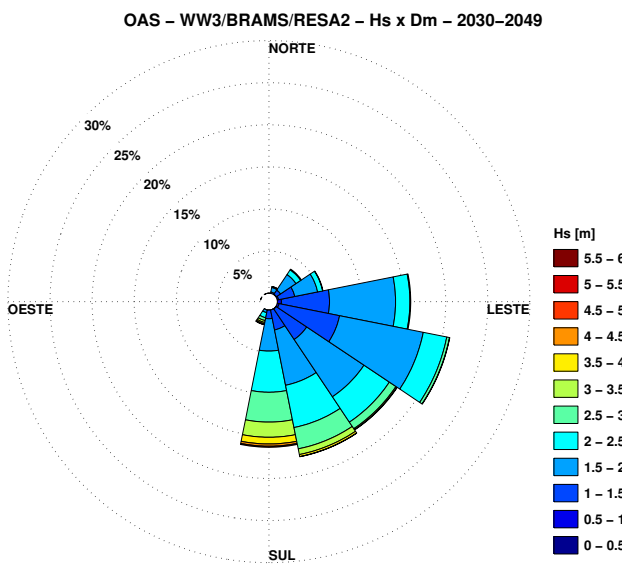

OAS - WW3/BRAMS/RESA2 - Hs x Dm - 2030-2049 NORTE

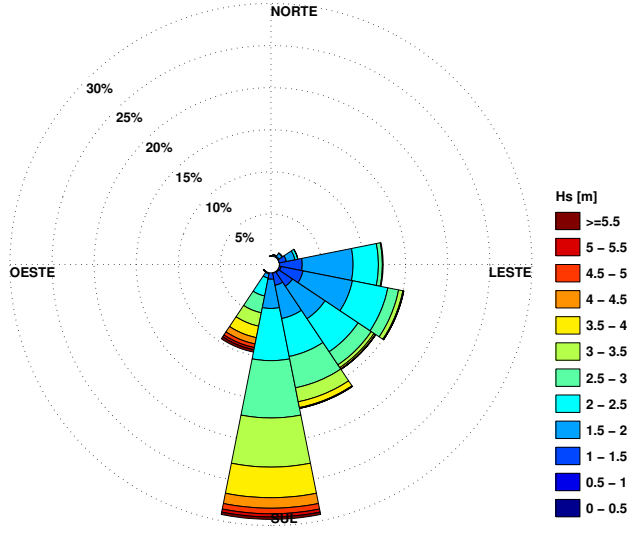

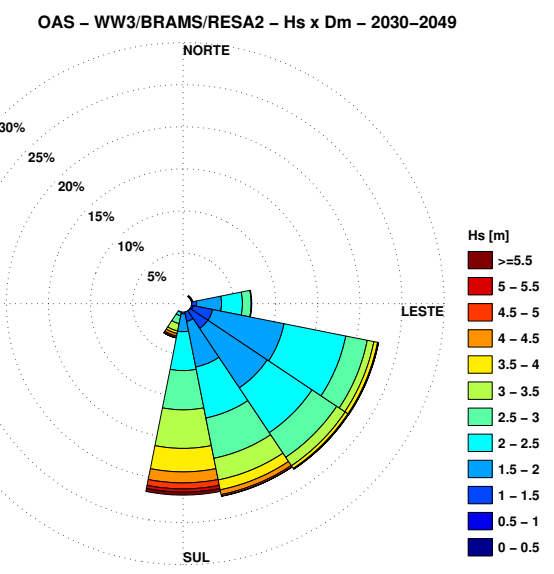

OAS - WW3/BRAMS/RESA2 - Hs x Dm - 2030-2049 NORTE

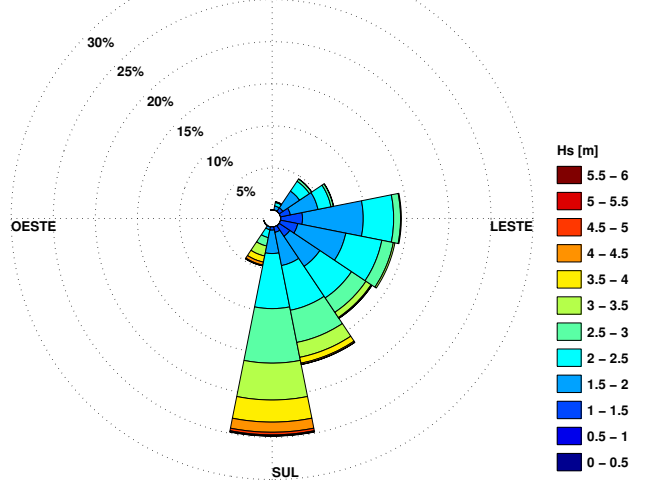

Figura 58 - Histogramas bivariados de Hs X Dm para verão (superior a esquerda), outono (superior a direita), inverno (inferior a esquerda) e primavera (inferior a direita) no ponto BC. 
Século XXI BRAMS/RESB1
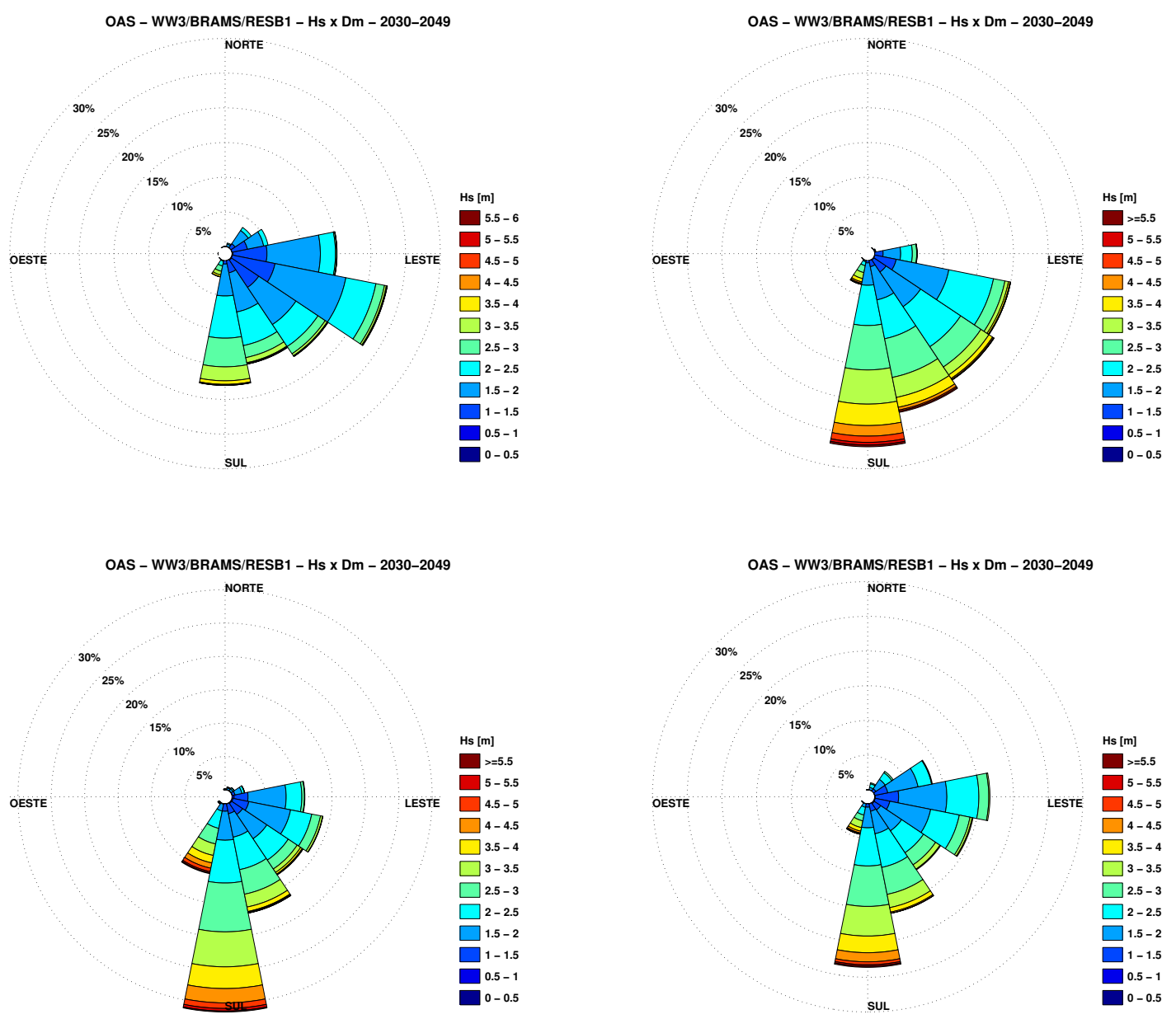

Figura 59 - Histogramas bivariados de Hs X Dm para verão (superior a esquerda), outono (superior a direita), inverno (inferior a esquerda) e primavera (inferior a direita) no ponto BC. 


\section{Ponto BSO}

Século XX BRAMS/NCEP
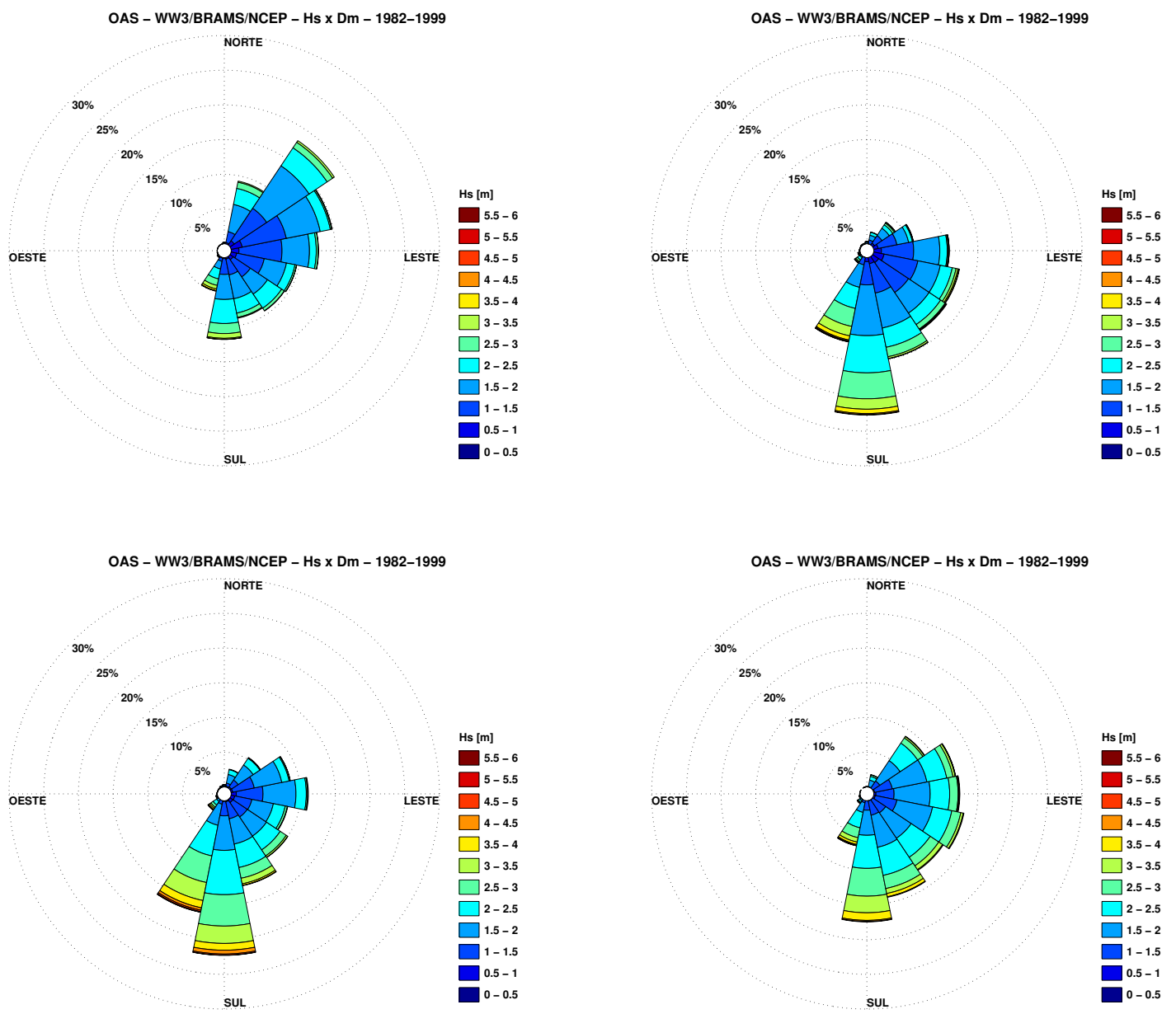

Figura 60 - Histogramas bivariados de Hs X Dm para verão (superior a esquerda), outono (superior a direita), inverno (inferior a esquerda) e primavera (inferior a direita) no ponto BSO. 
Século XX BRAMS/CCSM3

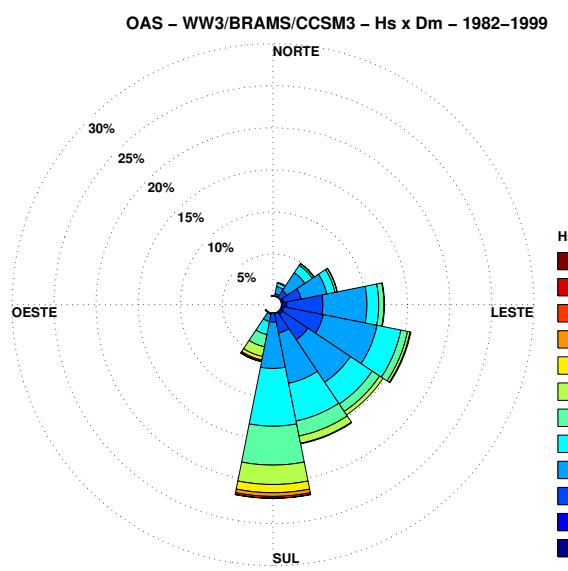

OAS - WW3/BRAMS/CCSM3 - Hs x Dm - 1982-1999 NORTE

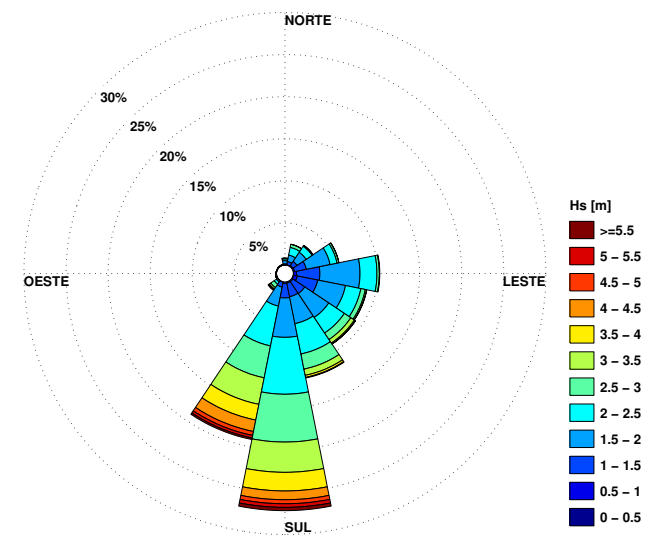

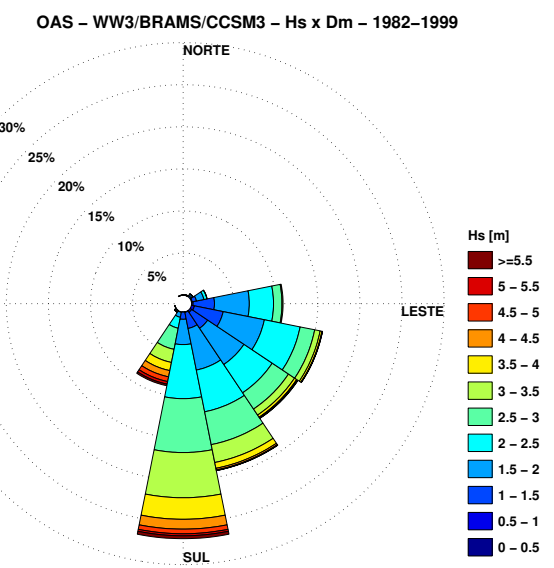

OAS - WW3/BRAMS/CCSM3 - Hs x Dm - 1982-1999 NORTE

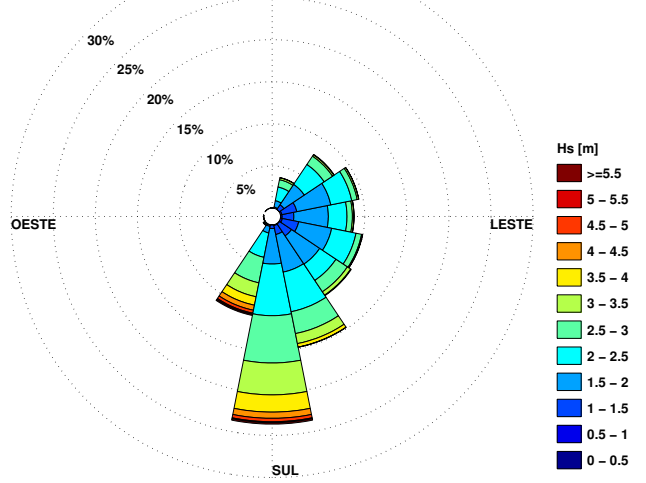

Figura 61 - Histogramas bivariados de Hs X Dm para verão (superior a esquerda), outono (superior a direita), inverno (inferior a esquerda) e primavera (inferior a direita) no ponto BSO. 
Século XXI BRAMS/RESA2
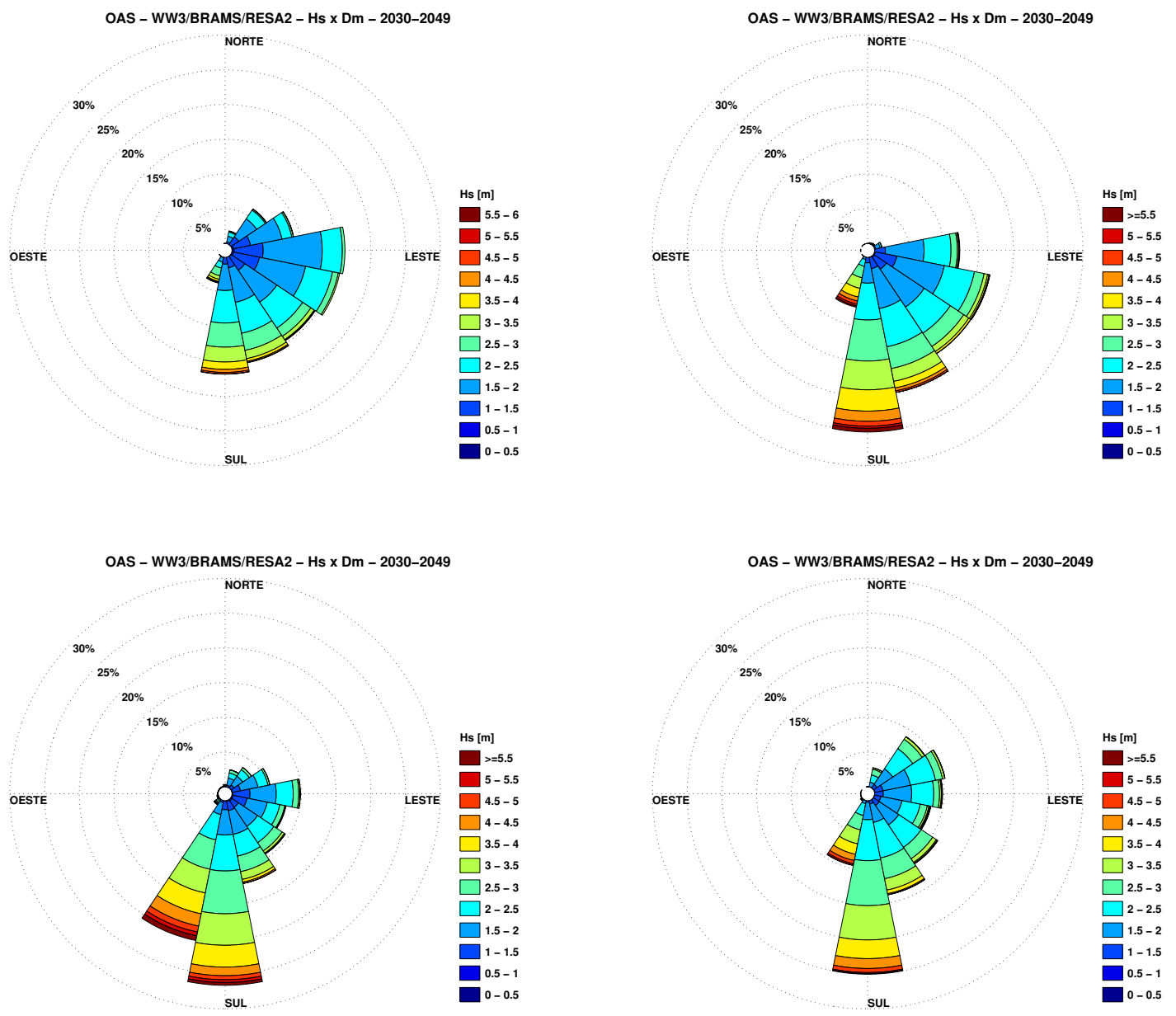

Figura 62 - Histogramas bivariados de Hs X Dm para verão (superior a esquerda), outono (superior a direita), inverno (inferior a esquerda) e primavera (inferior a direita) no ponto BSO. 
Século XXI BRAMS/RESB1
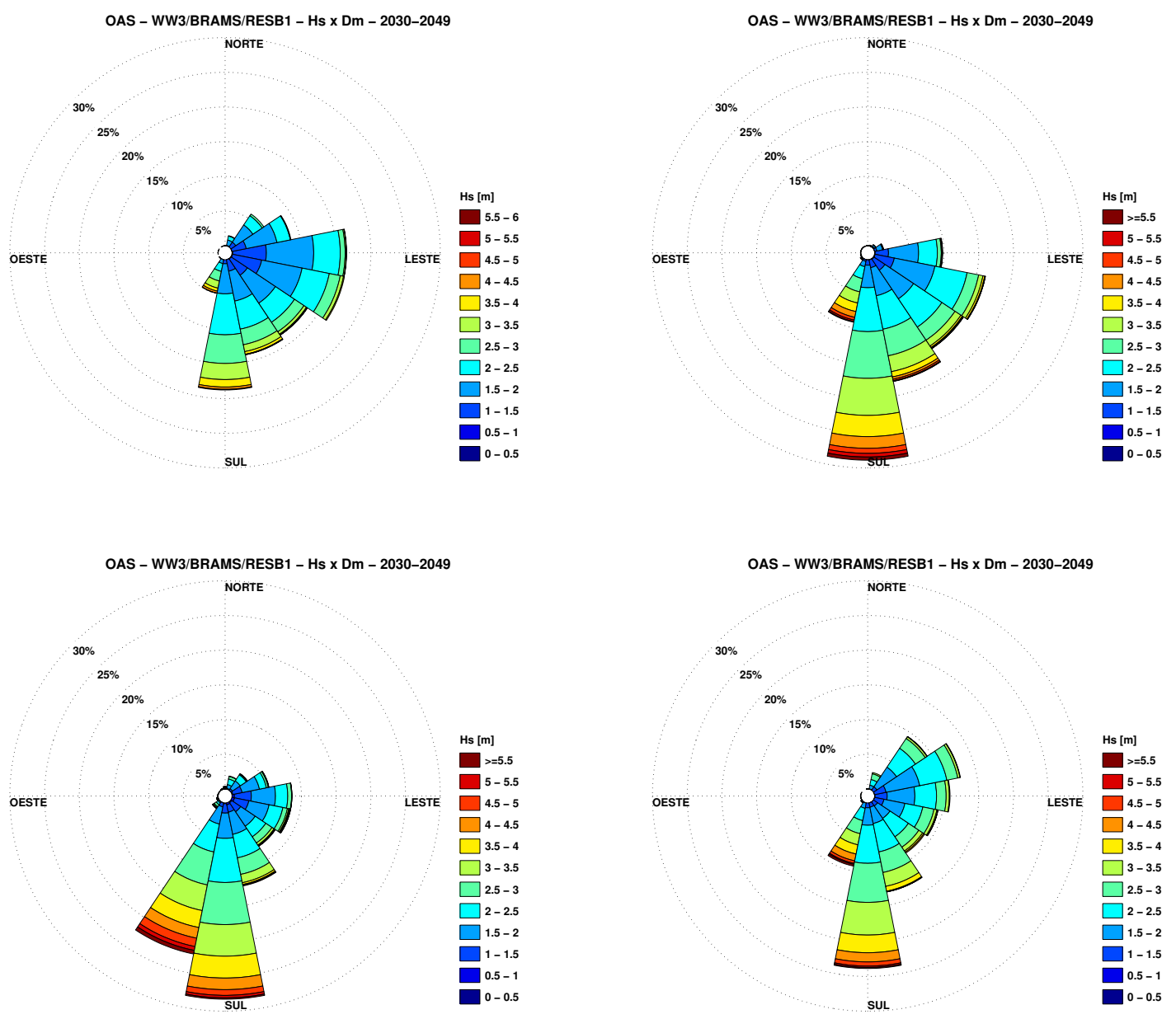

Figura 63 - Histogramas bivariados de Hs X Dm para verão (superior a esquerda), outono (superior a direita), inverno (inferior a esquerda) e primavera (inferior a direita) no ponto BSO. 


\section{Anexo B - Variação Sazonal da Distribuição de Hs X Dp}

\section{Ponto BC}

Século XX BRAMS/NCEP

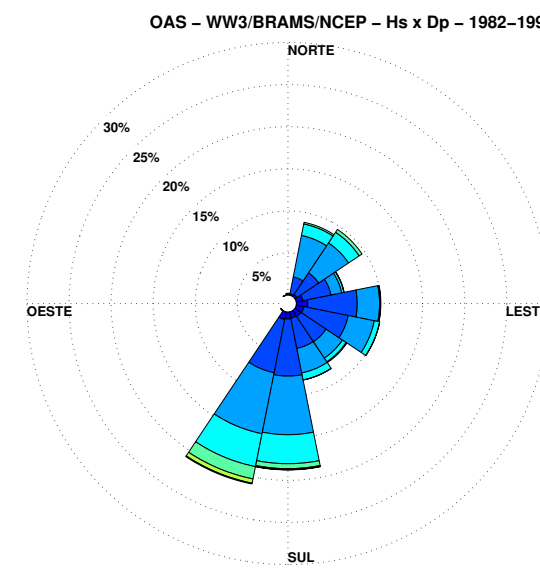

OAS - WW3/BRAMS/NCEP - Hs X Dp - 1982-1999 NORTE

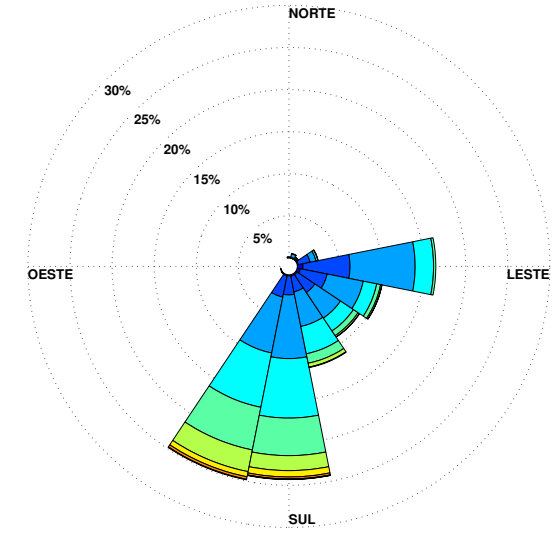

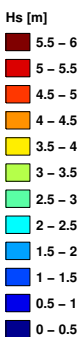

$\square^{5-5.5}$

$\square .5-5$

$\square$ 3.5-4

$\square 3-3.5$

$\square^{2-2.5}$

$0.5-1$

$0-0.5$

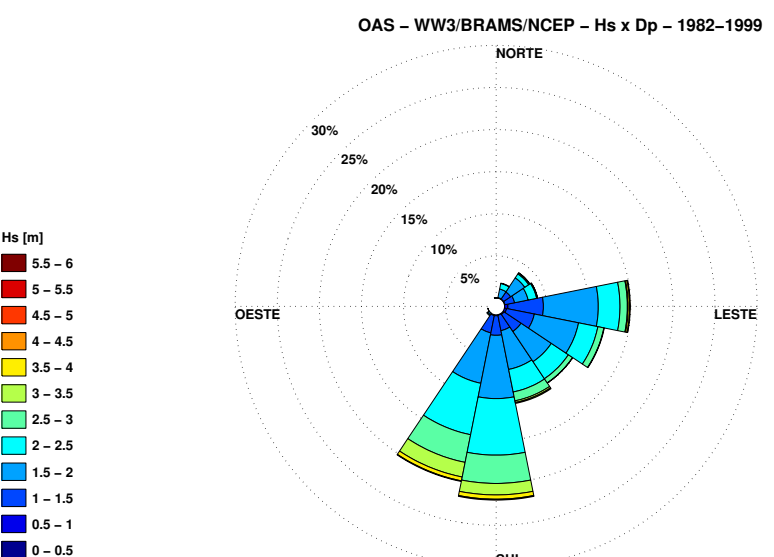

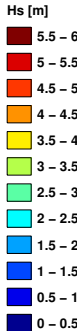

OAS - WW3/BRAMS/NCEP - Hs x Dp - 1982-1999 NORTE

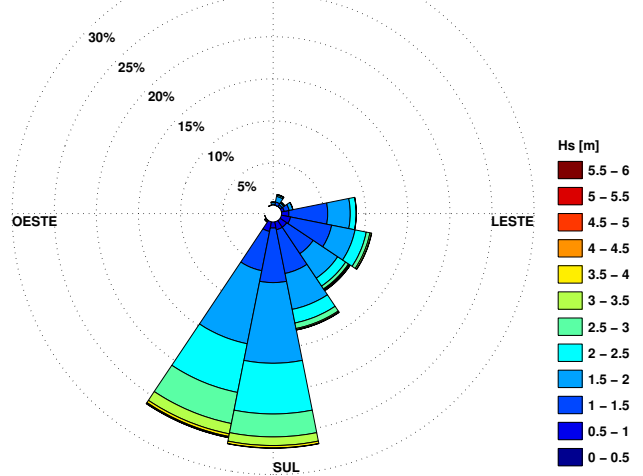

sut

Figura 64 - Histogramas bivariados de Hs X Dp para verão (superior a esquerda), outono (superior a direita), inverno (inferior a esquerda) e primavera (inferior a direita) no ponto BC. 
Século XX BRAMS/CCSM3
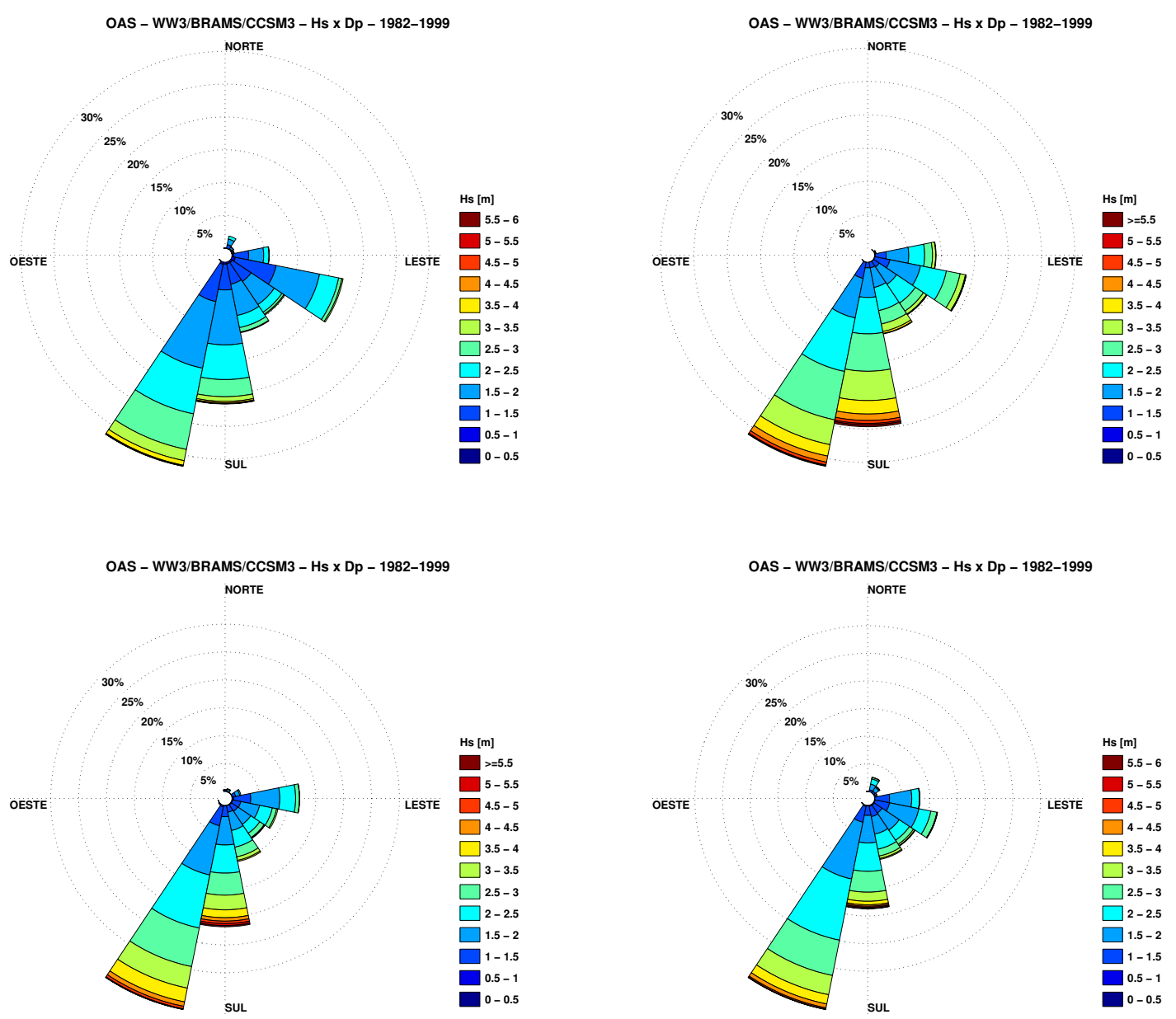

Figura 65 - Histogramas bivariados de Hs X Dp para verão (superior a esquerda), outono (superior a direita), inverno (inferior a esquerda) e primavera (inferior a direita) no ponto BC. 
Século XXI BRAMS/RESA2
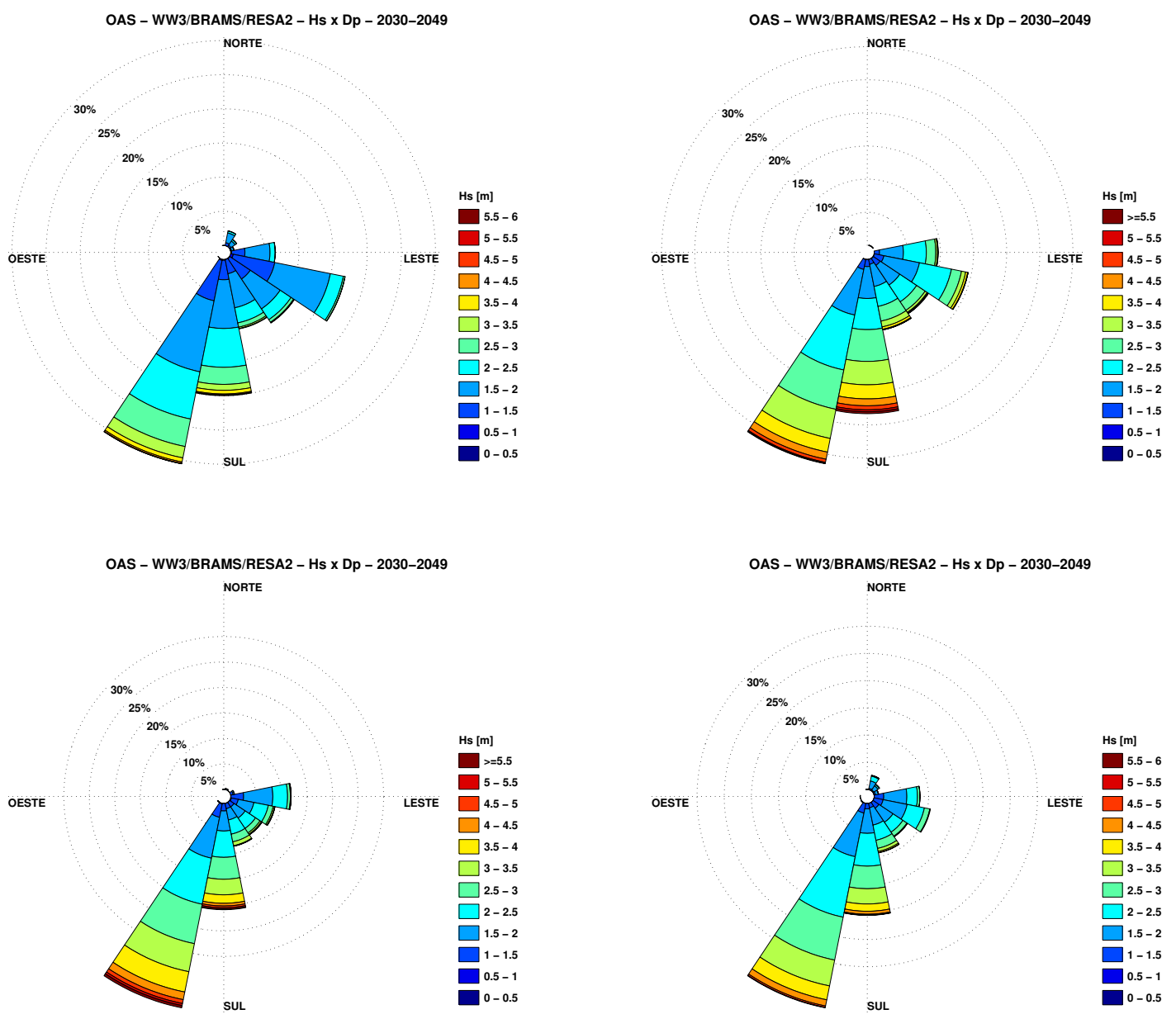

Figura 66 - Histogramas bivariados de Hs X Dp para verão (superior a esquerda), outono (superior a direita), inverno (inferior a esquerda) e primavera (inferior a direita) no ponto BC. 
Século XXI BRAMS/RESB1
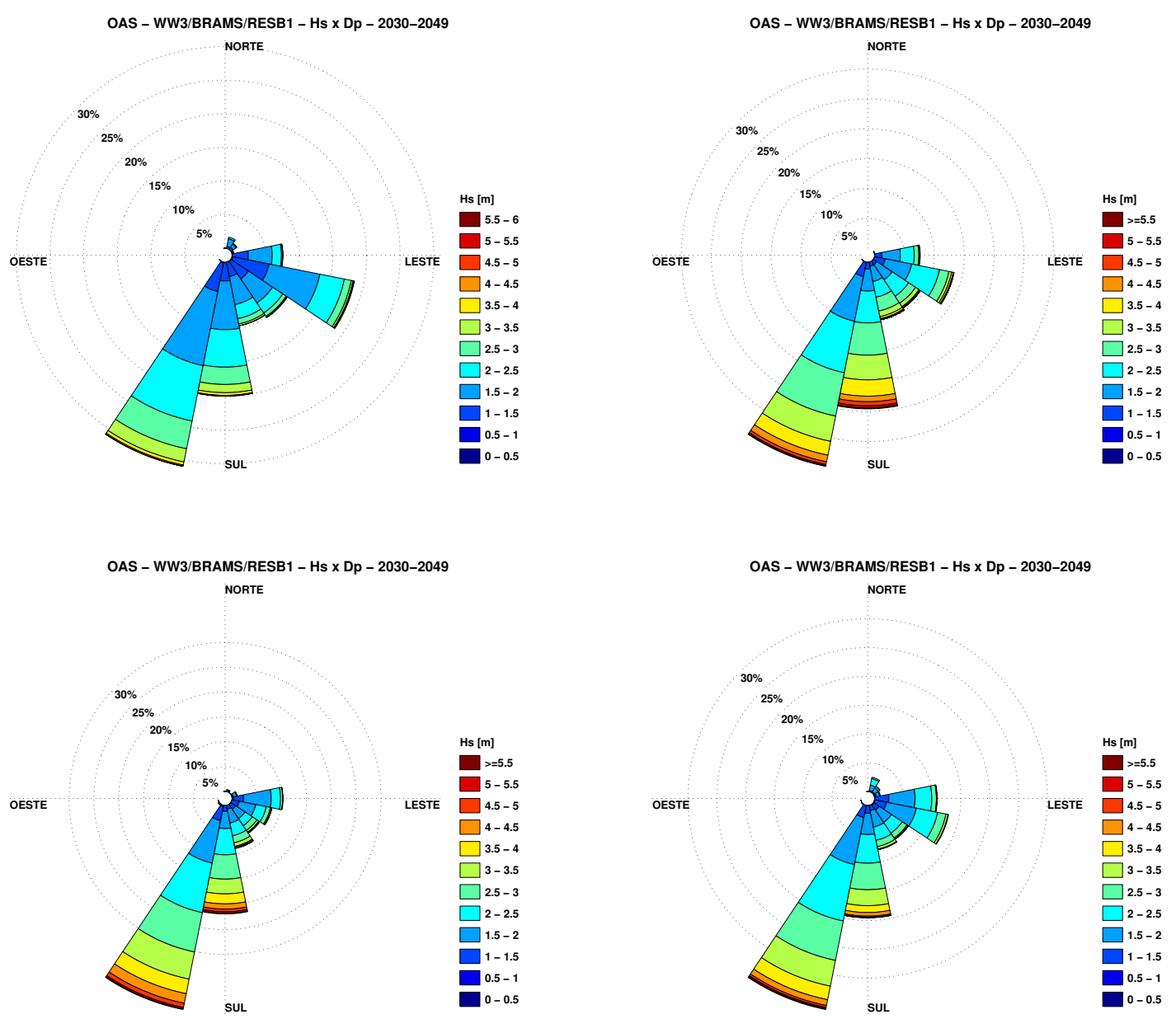

Figura 67 - Histogramas bivariados de Hs X Dp para verão (superior a esquerda), outono (superior a direita), inverno (inferior a esquerda) e primavera (inferior a direita) no ponto BC. 


\section{Ponto BSO}

Século XX BRAMS/NCEP
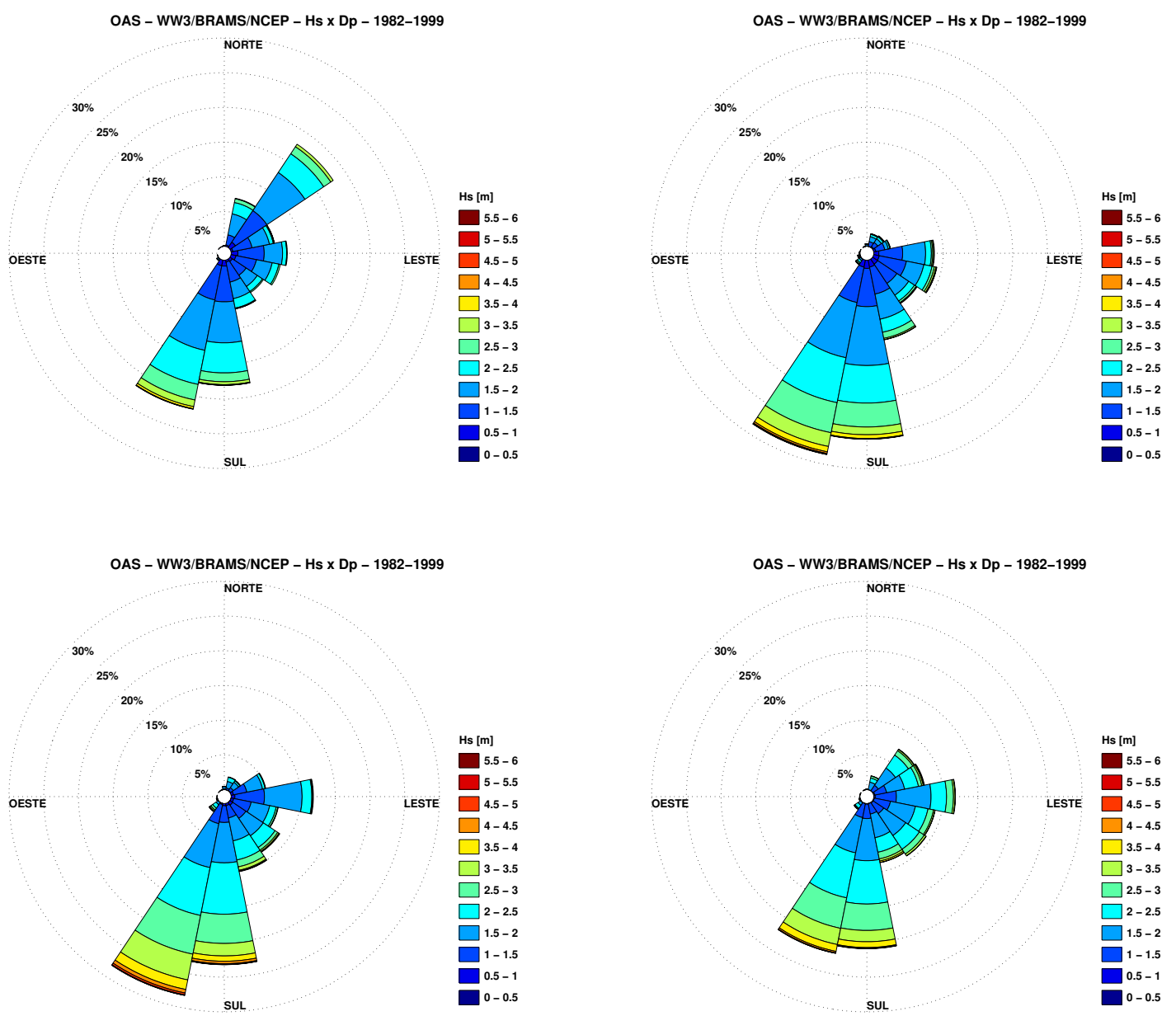

Figura 68 - Histogramas bivariados de Hs X Dp para verão (superior a esquerda), outono (superior a direita), inverno (inferior a esquerda) e primavera (inferior a direita) no ponto BSO. 
Século XX BRAMS/CCSM3
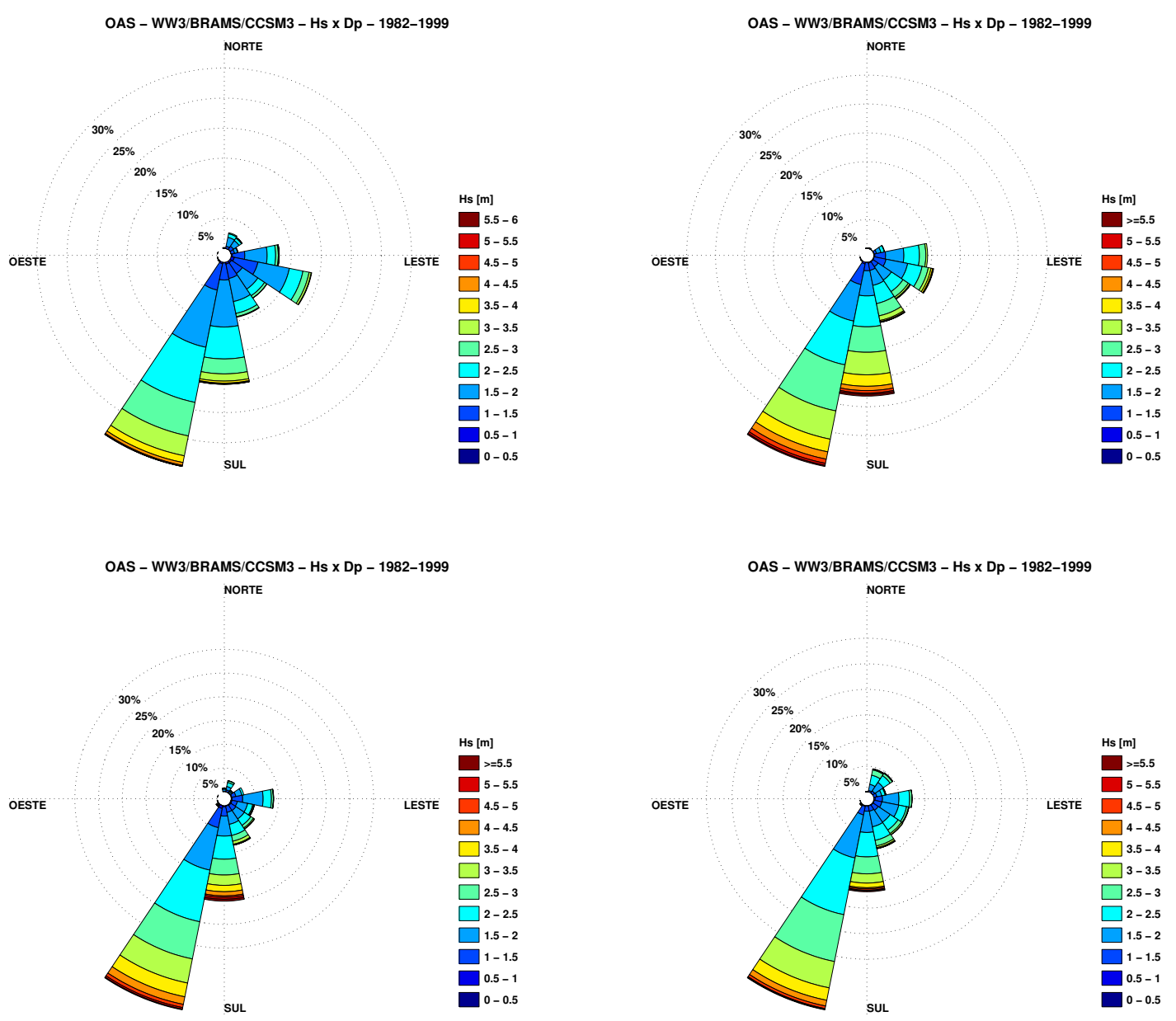

Figura 69 - Histogramas bivariados de Hs X Dp para verão (superior a esquerda), outono (superior a direita), inverno (inferior a esquerda) e primavera (inferior a direita) no ponto BSO. 
Século XXI BRAMS/RESA2
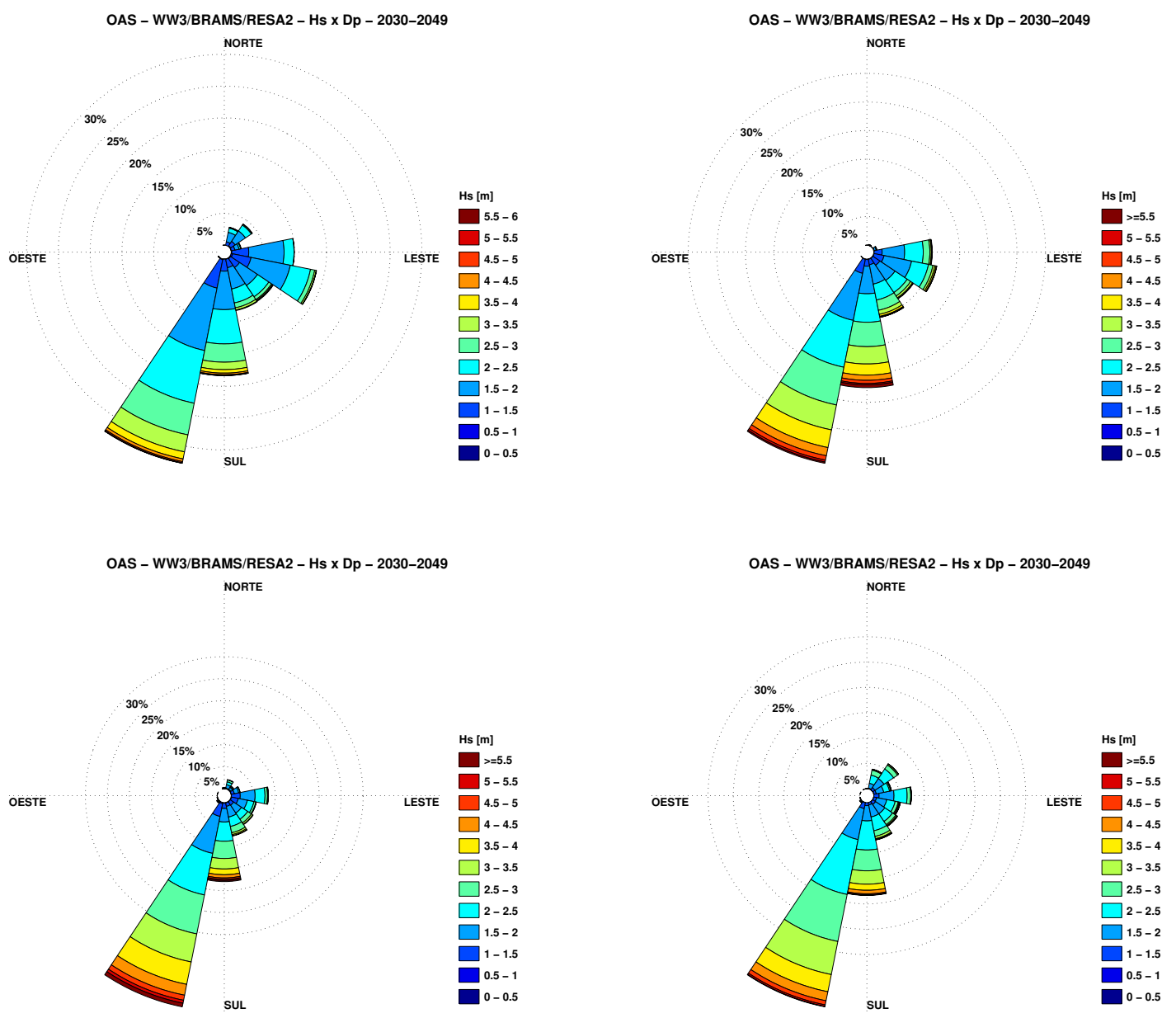

Figura 70 - Histogramas bivariados de Hs X Dp para verão (superior a esquerda), outono (superior a direita), inverno (inferior a esquerda) e primavera (inferior a direita) no ponto BSO. 
Século XXI BRAMS/RESB1
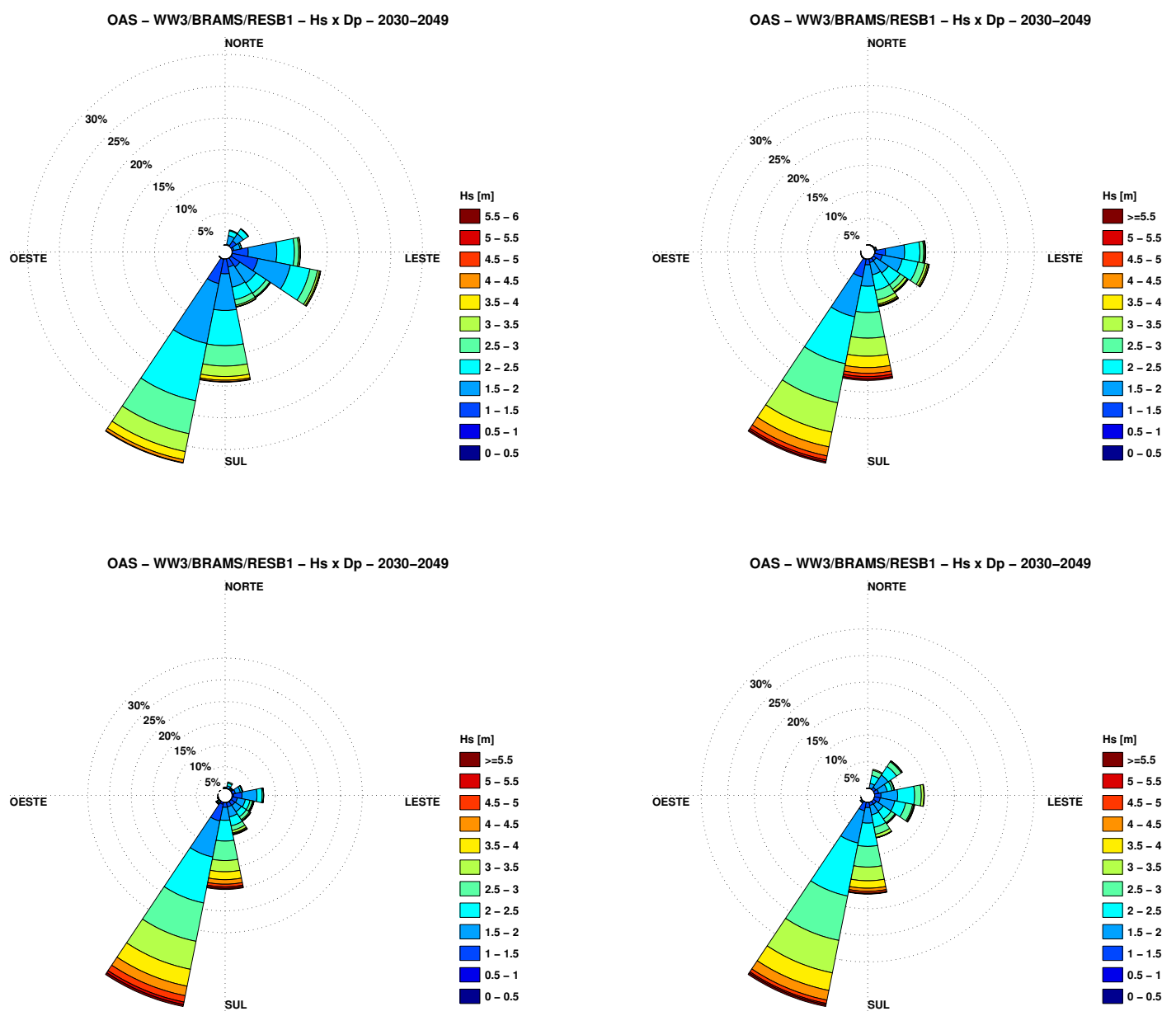

Figura 71 - Histogramas bivariados de Hs X Dp para verão (superior a esquerda), outono (superior a direita), inverno (inferior a esquerda) e primavera (inferior a direita) no ponto BSO. 


\section{Anexo C - Variação Sazonal da Distribuição de Tm X Dm}

\section{Ponto BC}

Século XX BRAMS/NCEP
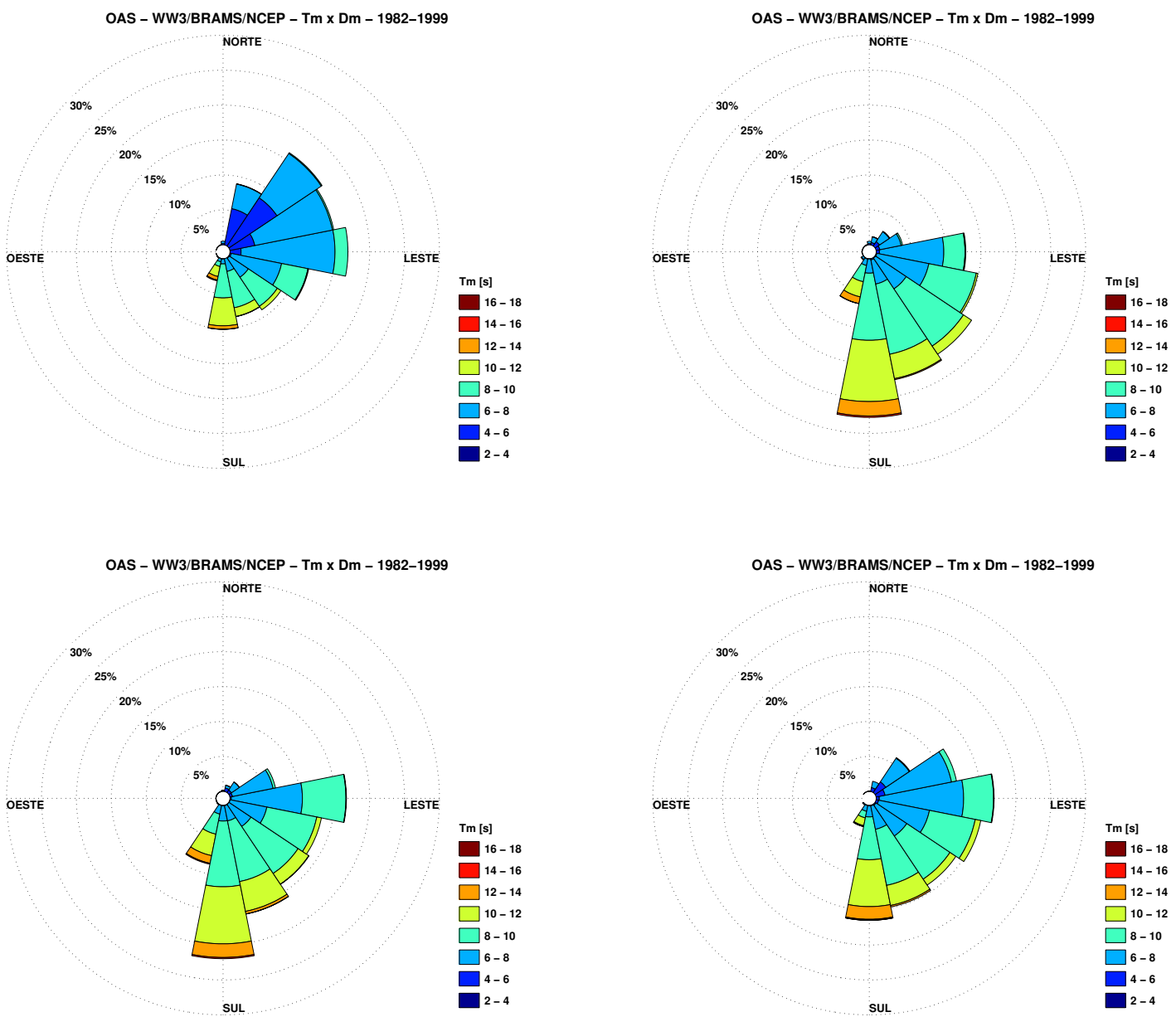

Figura 72 - Histogramas bivariados de Tm X Dm para verão (superior a esquerda), outono (superior a direita), inverno (inferior a esquerda) e primavera (inferior a direita) no ponto BC. 
Século XX BRAMS/CCSM3
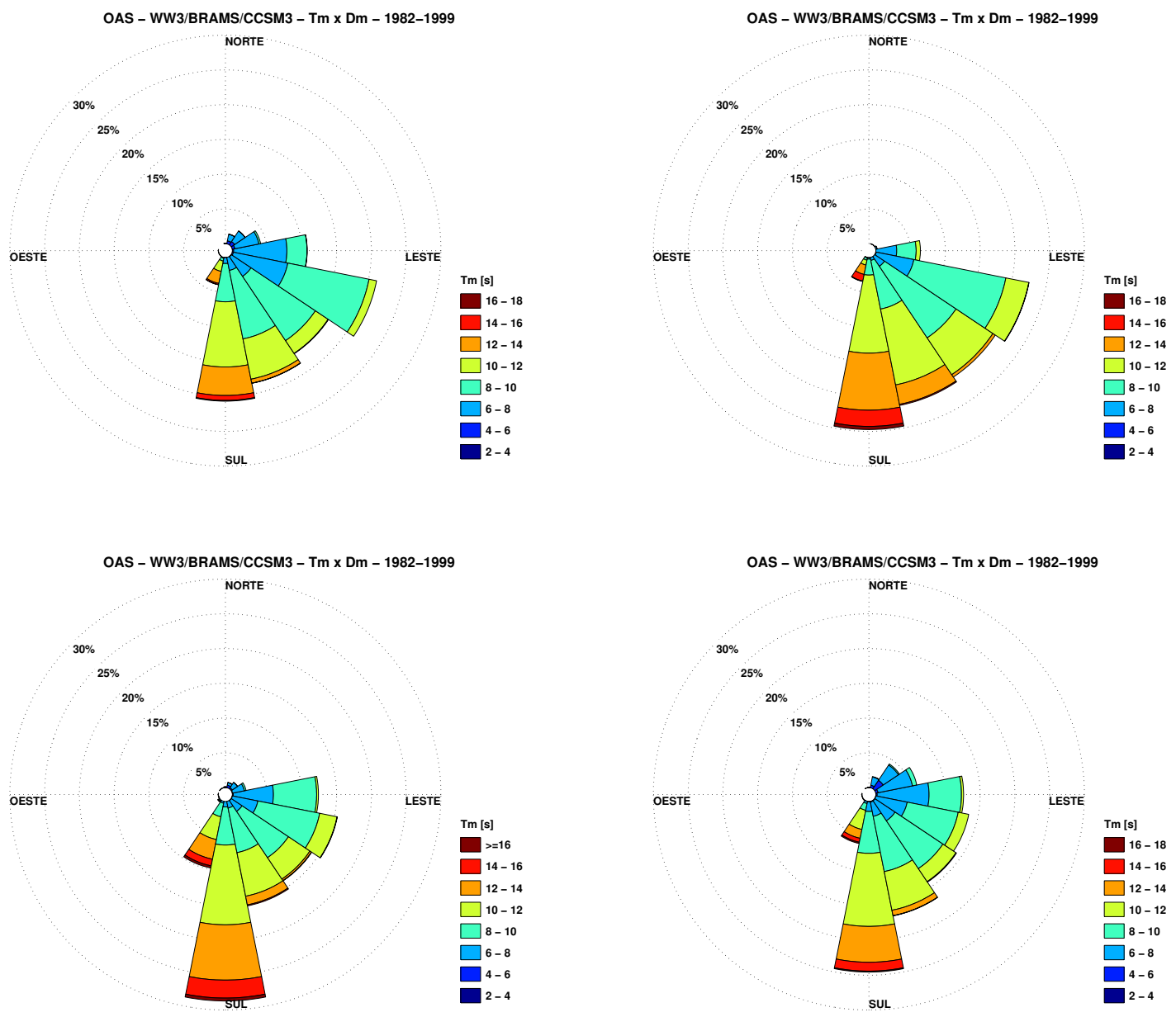

Figura 73 - Histogramas bivariados de Tm X Dm para verão (superior a esquerda), outono (superior a direita), inverno (inferior a esquerda) e primavera (inferior a direita) no ponto BC. 
Século XXI BRAMS/RESA2

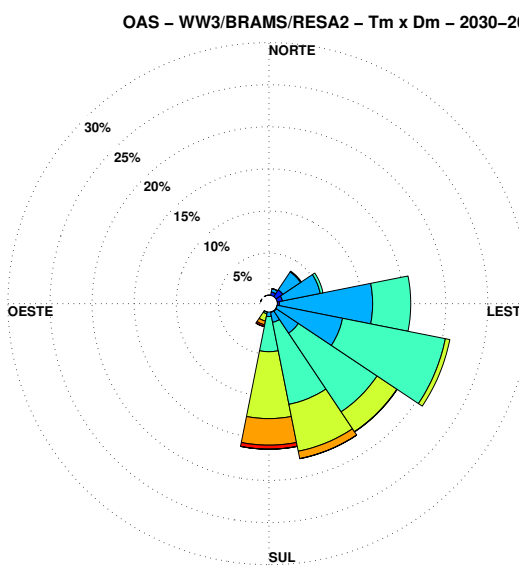

OAS - WW3/BRAMS/RESA2 - Tm x Dm - 2030-2049 NORTE

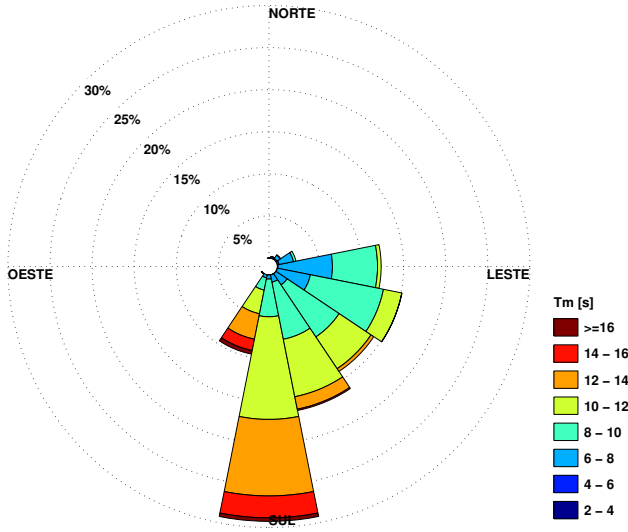

OAS - WW3/BRAMS/RESA2 - Tm x Dm - 2030-2049 NORTE

$30 \%$

$25 \%$

$20 \%$

$10 \%$

$5 \%$

OESTE
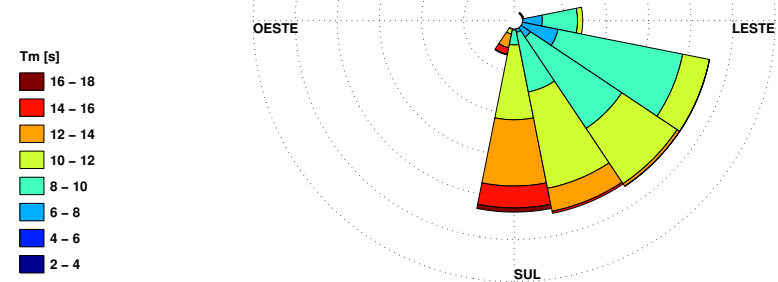

sul

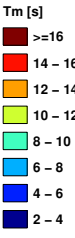

OAS - WW3/BRAMS/RESA2 - Tm x Dm - 2030-2049 NORTE

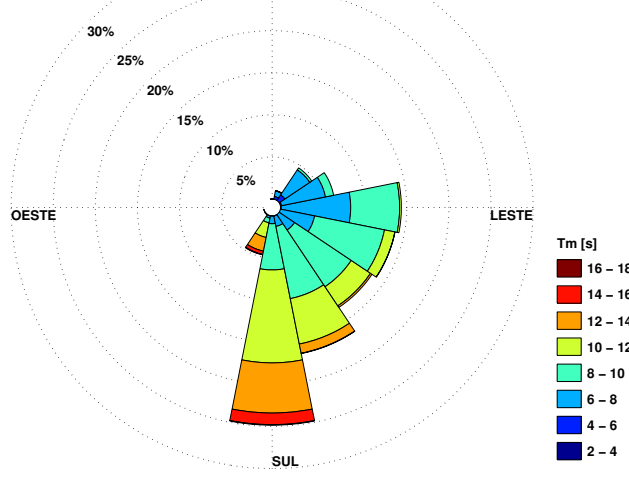

Figura 74 - Histogramas bivariados de Tm X Dm para verão (superior a esquerda), outono (superior a direita), inverno (inferior a esquerda) e primavera (inferior a direita) no ponto BC. 
Século XXI BRAMS/RESB1
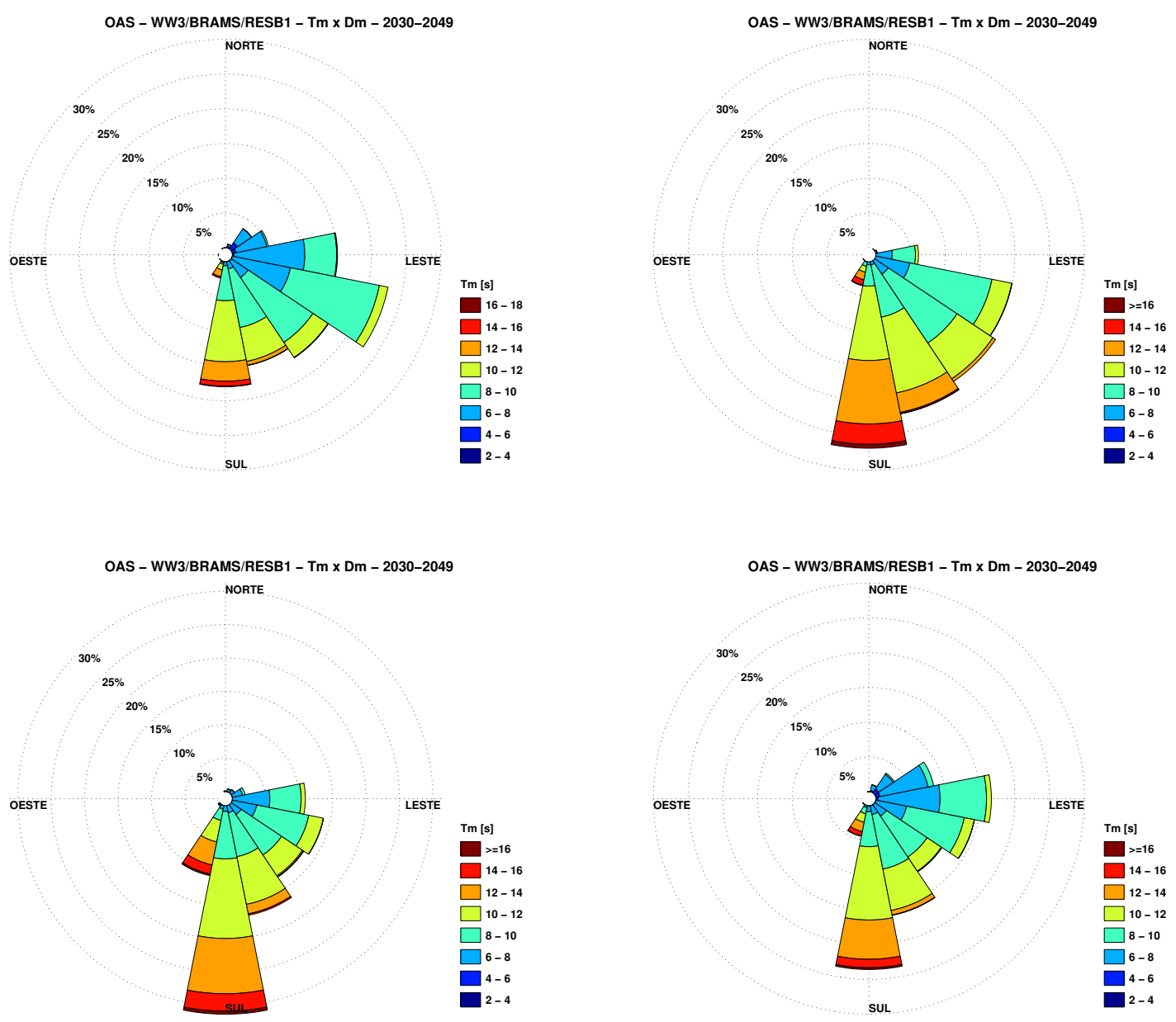

Figura 75 - Histogramas bivariados de Tm X Dm para verão (superior a esquerda), outono (superior a direita), inverno (inferior a esquerda) e primavera (inferior a direita) no ponto BC. 


\section{Ponto BSO}

Século XX BRAMS/NCEP
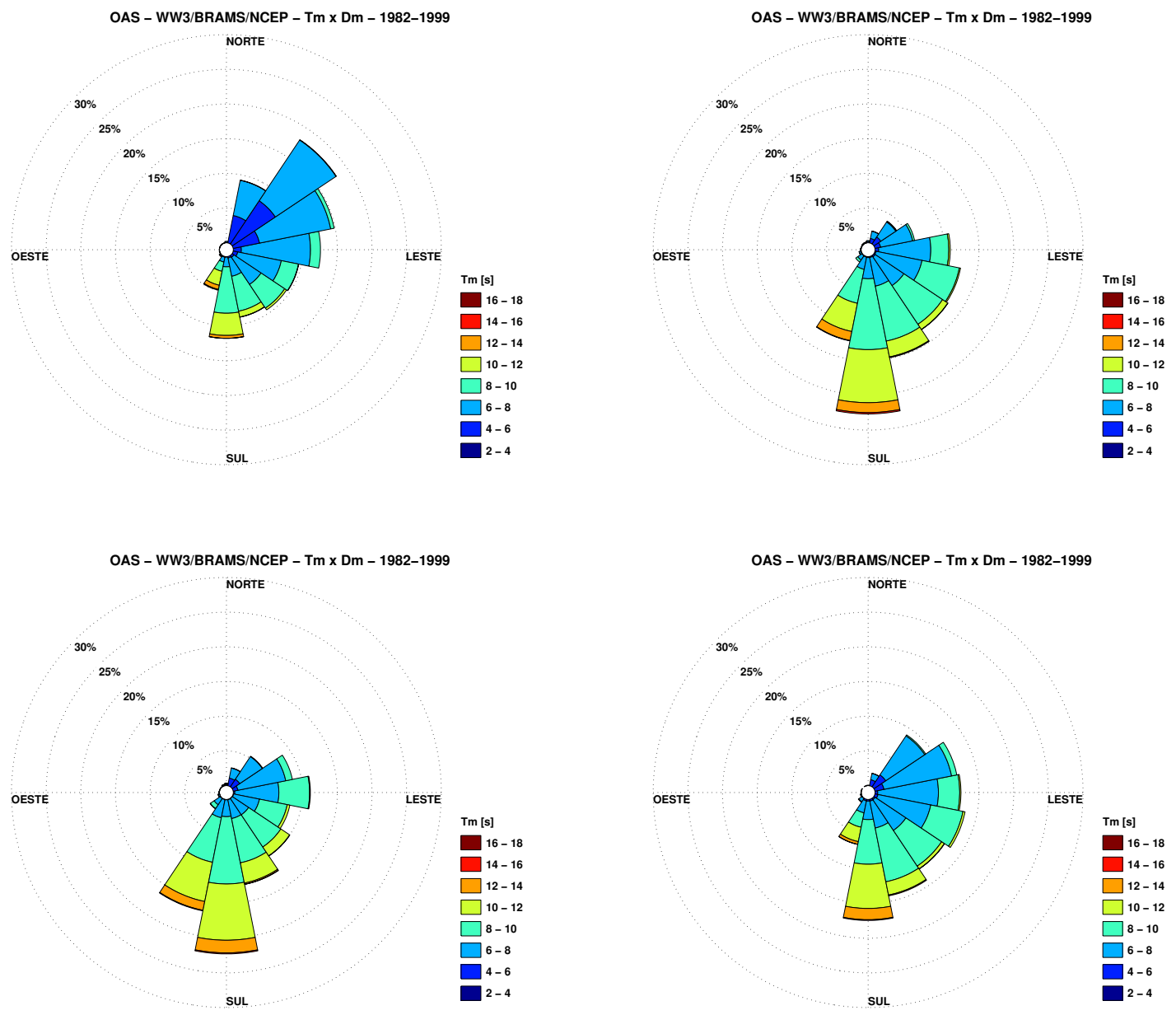

Figura 76 - Histogramas bivariados de Tm X Dm para verão (superior a esquerda), outono (superior a direita), inverno (inferior a esquerda) e primavera (inferior a direita) no ponto BSO. 
Século XX BRAMS/CCSM3

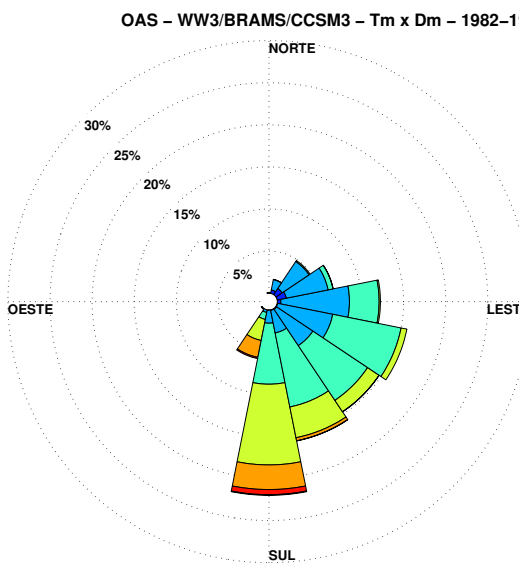

OAS - WW3/BRAMS/CCSM3 - Tm x Dm - 1982-1999 NORTE

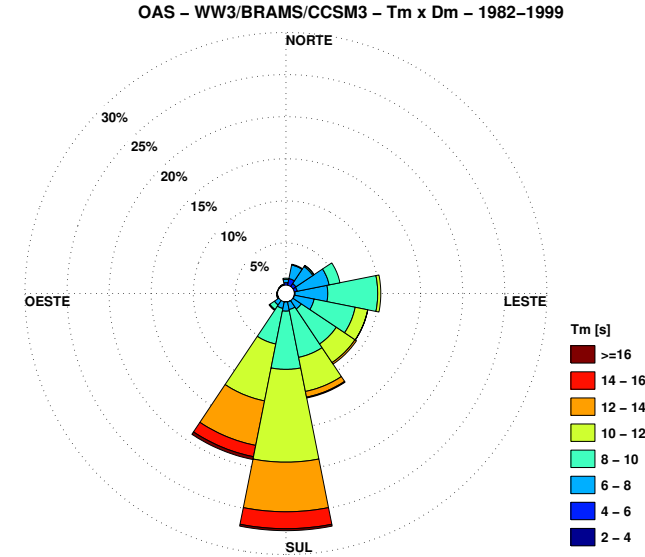

OAS - WW3/BRAMS/CCSM3 - Tm x Dm - 1982-1999 NORTE

$30 \%$

$25 \%$

$20 \%$

$10 \%$

OESTE $5 \%$
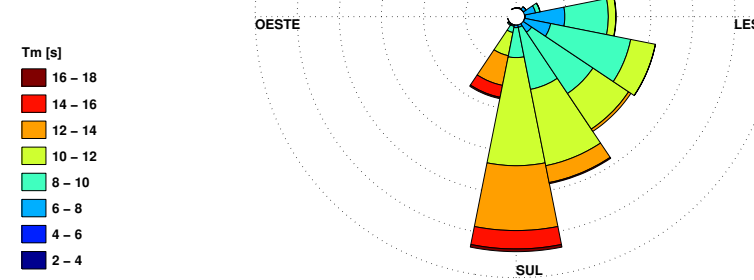

Tm [s]

$\square=16$

$\square 12-14$

$\square 10-12$

$\square 8-10$

$\square^{2-4}$

OAS - WW3/BRAMS/CCSM3 - Tm x Dm - 1982-1999 NORTE

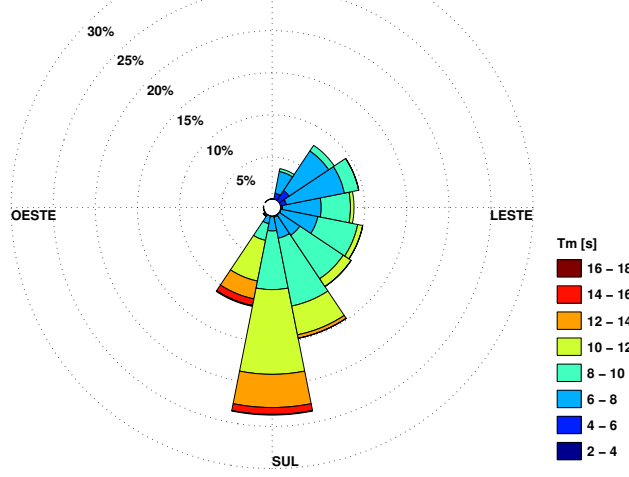

Figura 77 - Histogramas bivariados de Tm X Dm para verão (superior a esquerda), outono (superior a direita), inverno (inferior a esquerda) e primavera (inferior a direita) no ponto BSO. 
Século XXI BRAMS/RESA2

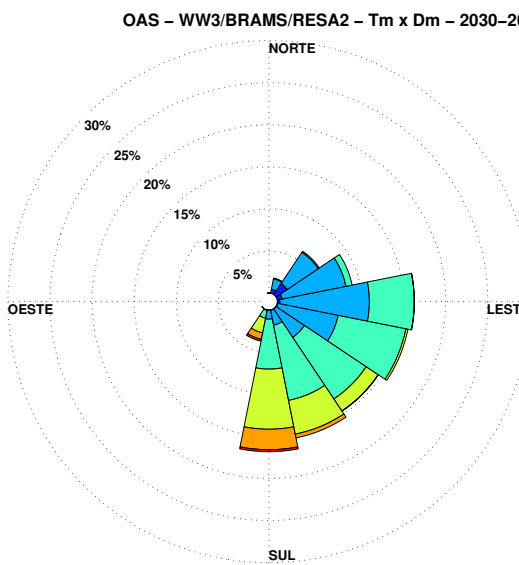

OAS - WW3/BRAMS/RESA2 - Tm x Dm - 2030-2049 NORTE

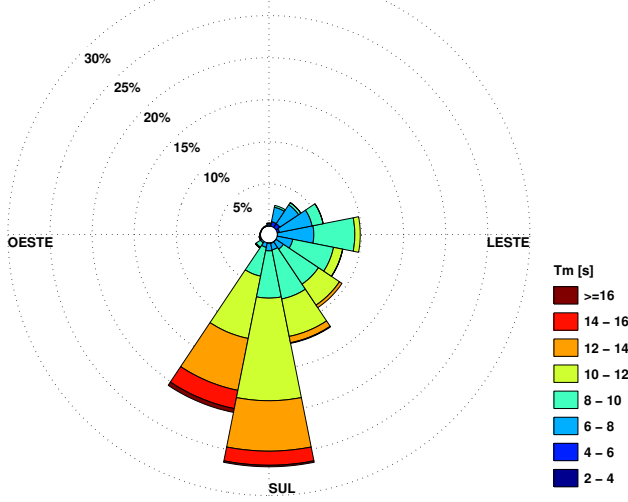

OAS - WW3/BRAMS/RESA2 - Tm x Dm - 2030-2049 NORTE

$30 \%$

$25 \%$

$20 \%$

$10 \%$

OESTE

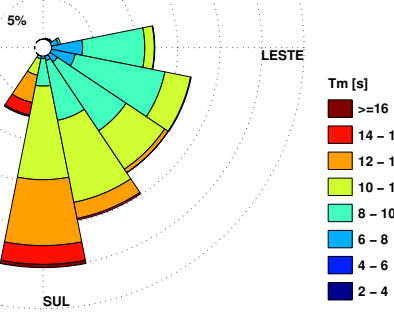

OAS - WW3/BRAMS/RESA2 - Tm x Dm - 2030-2049 NORTE

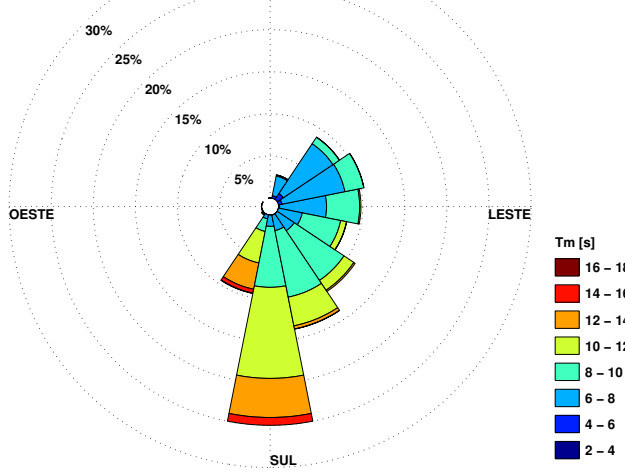

Figura 78 - Histogramas bivariados de Tm X Dm para verão (superior a esquerda), outono (superior a direita), inverno (inferior a esquerda) e primavera (inferior a direita) no ponto BSO. 
Século XXI BRAMS/RESB1

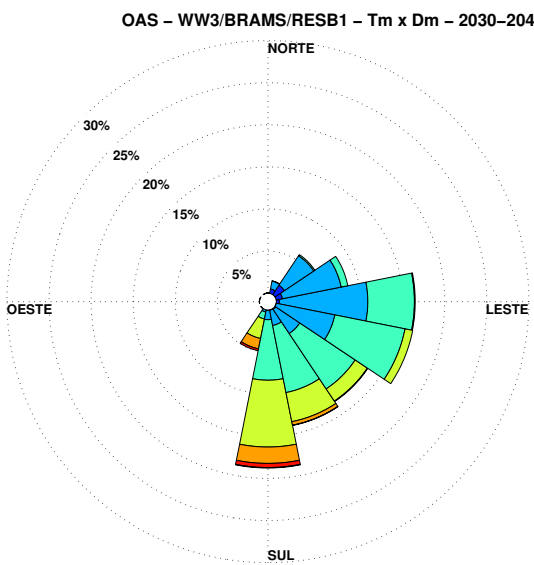

OAS - WW3/BRAMS/RESB1 - Tm x Dm - 2030-2049 NORTE

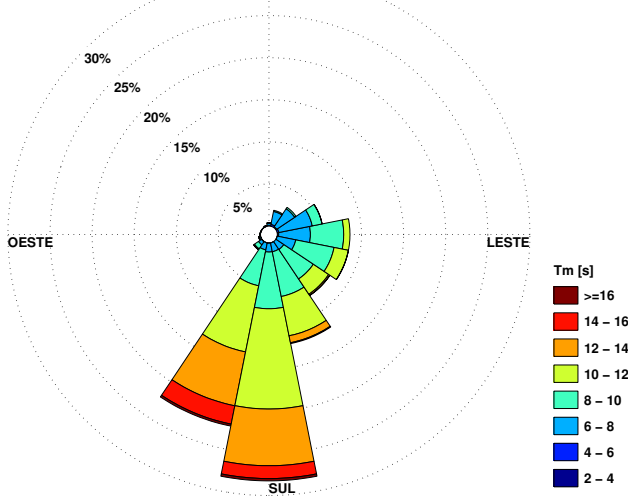

Tm [s]
$\square_{16-18}$
$\square_{14-16}$
$\square_{12-14}$
$\square 10-12$
$\square$ 8-10
$\square$ 6-8
$\square_{-6}^{4-6}$
$\square^{2-4}$
OAS - WW3/BRAMS/RESB1 - Tm x Dm - 2030-2049 NORTE

$30 \%$

$25 \%$

$20 \%$

$10 \%$

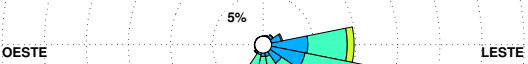

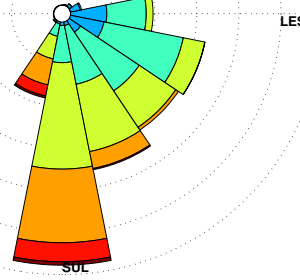

$\operatorname{Tm}[s]$

$>=16$
$\square 14-16$

$\square 12-14$

$\square 10-12$

$\square 8-10$

$\square^{4-6}$

OAS - WW3/BRAMS/RESB1 - Tm x Dm - 2030-2049 NORTE

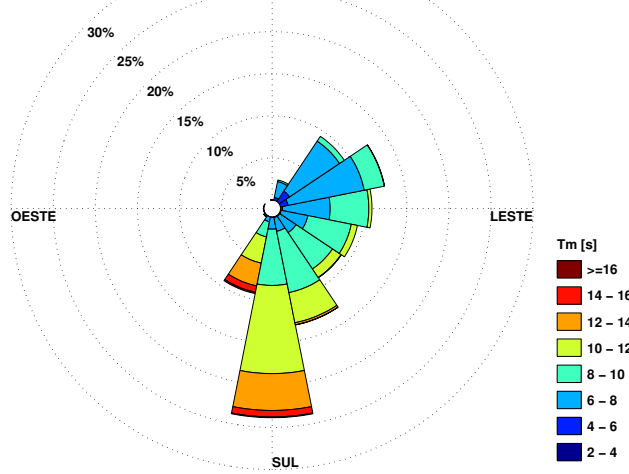

Figura 79 - Histogramas bivariados de Tm X Dm para verão (superior a esquerda), outono (superior a direita), inverno (inferior a esquerda) e primavera (inferior a direita) no ponto BSO. 


\section{Anexo D - Variação Sazonal da Distribuição de Tp X Dp}

\section{Ponto BC}

Século XX BRAMS/NCEP
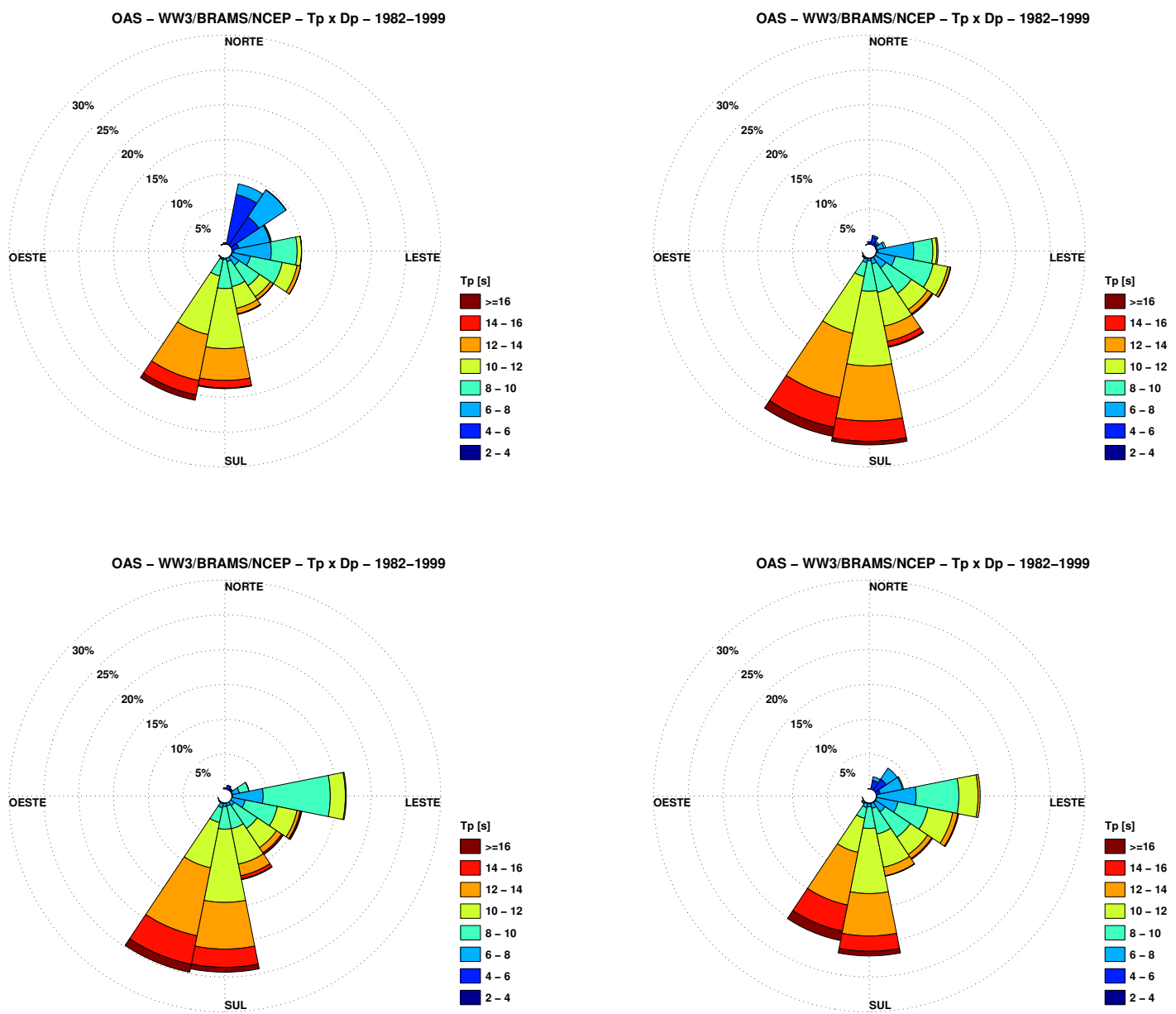

Figura 80 - Histogramas bivariados de Tp X Dp para verão (superior a esquerda), outono (superior a direita), inverno (inferior a esquerda) e primavera (inferior a direita) no ponto BC. 
Século XX BRAMS/CCSM3
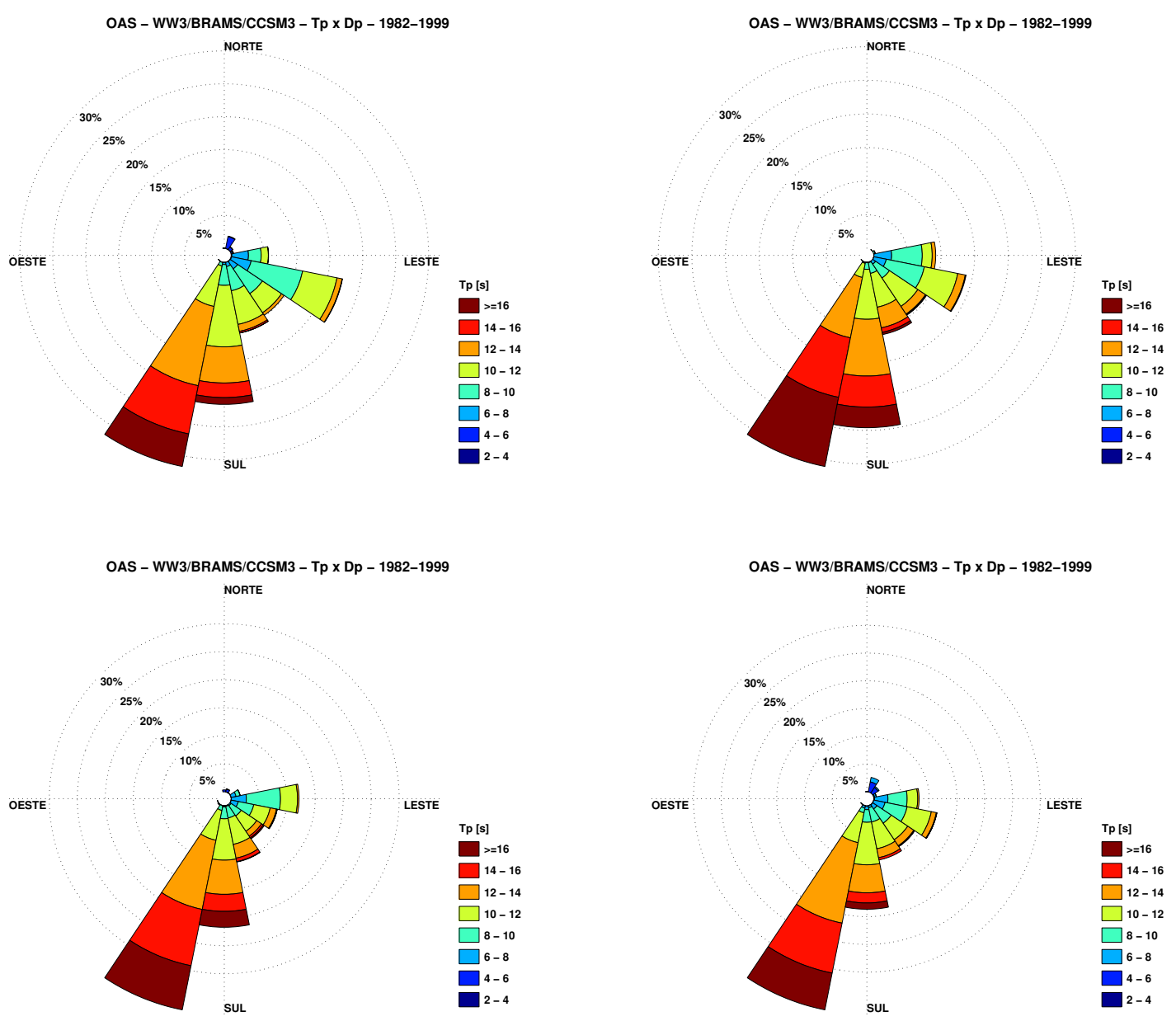

Figura 81 - Histogramas bivariados de Tp X Dp para verão (superior a esquerda), outono (superior a direita), inverno (inferior a esquerda) e primavera (inferior a direita) no ponto BC. 
Século XXI BRAMS/RESA2
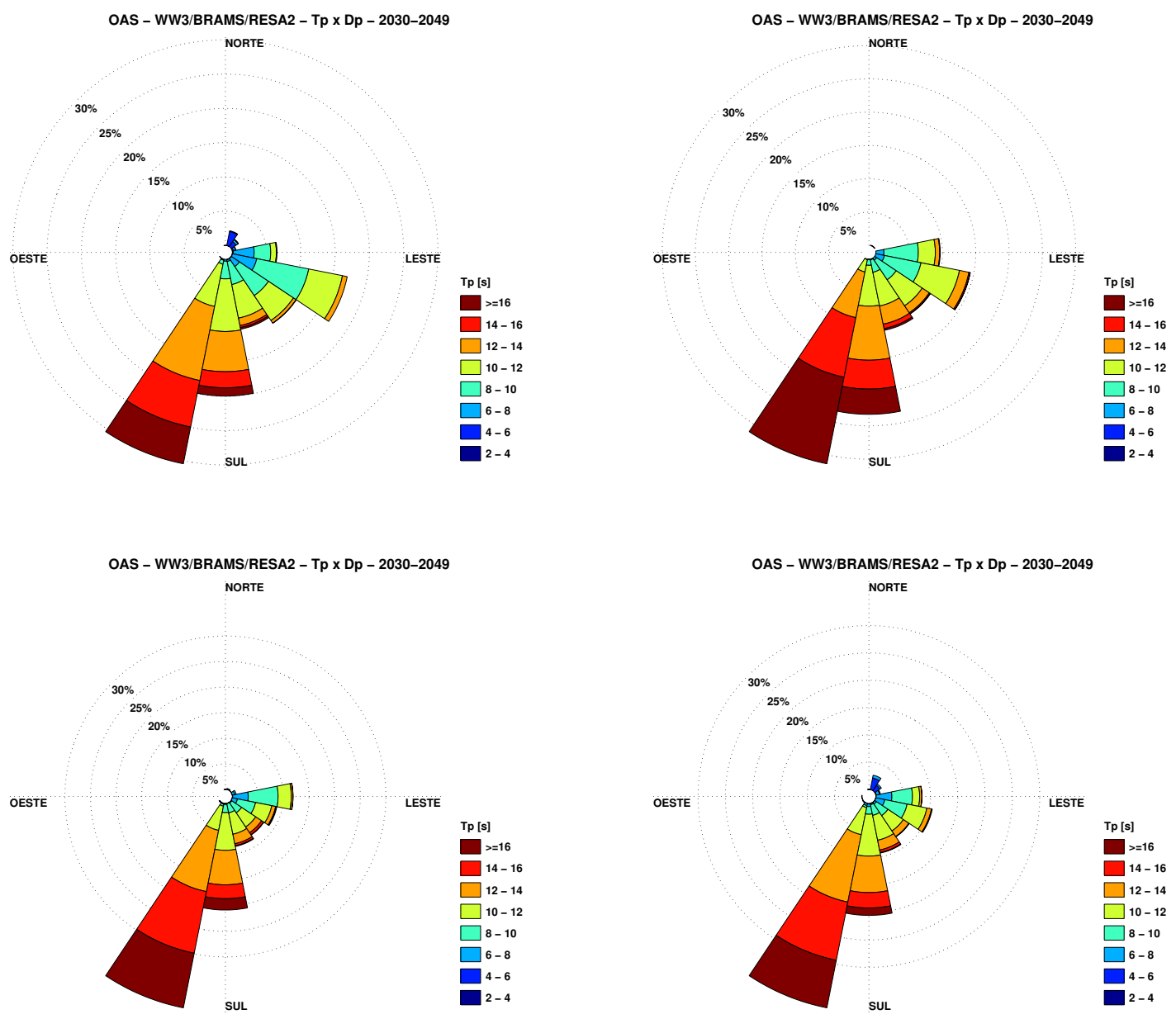

Figura 82 - Histogramas bivariados de Tp X Dp para verão (superior a esquerda), outono (superior a direita), inverno (inferior a esquerda) e primavera (inferior a direita) no ponto BC. 
Século XXI BRAMS/RESB1
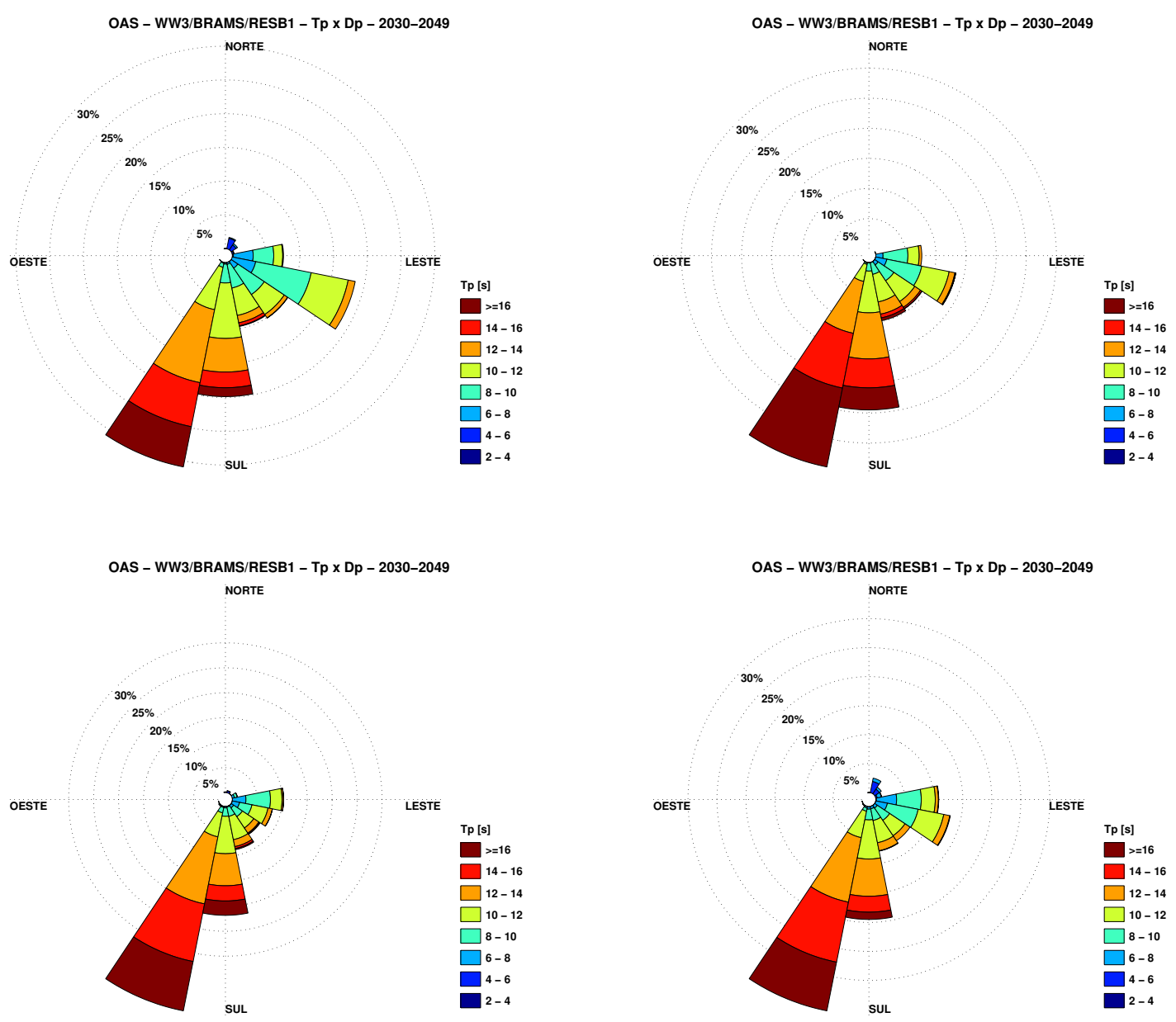

Figura 83 - Histogramas bivariados de Tp X Dp para verão (superior a esquerda), outono (superior a direita), inverno (inferior a esquerda) e primavera (inferior a direita) no ponto BC. 


\section{Ponto BSO}

Século XX BRAMS/NCEP
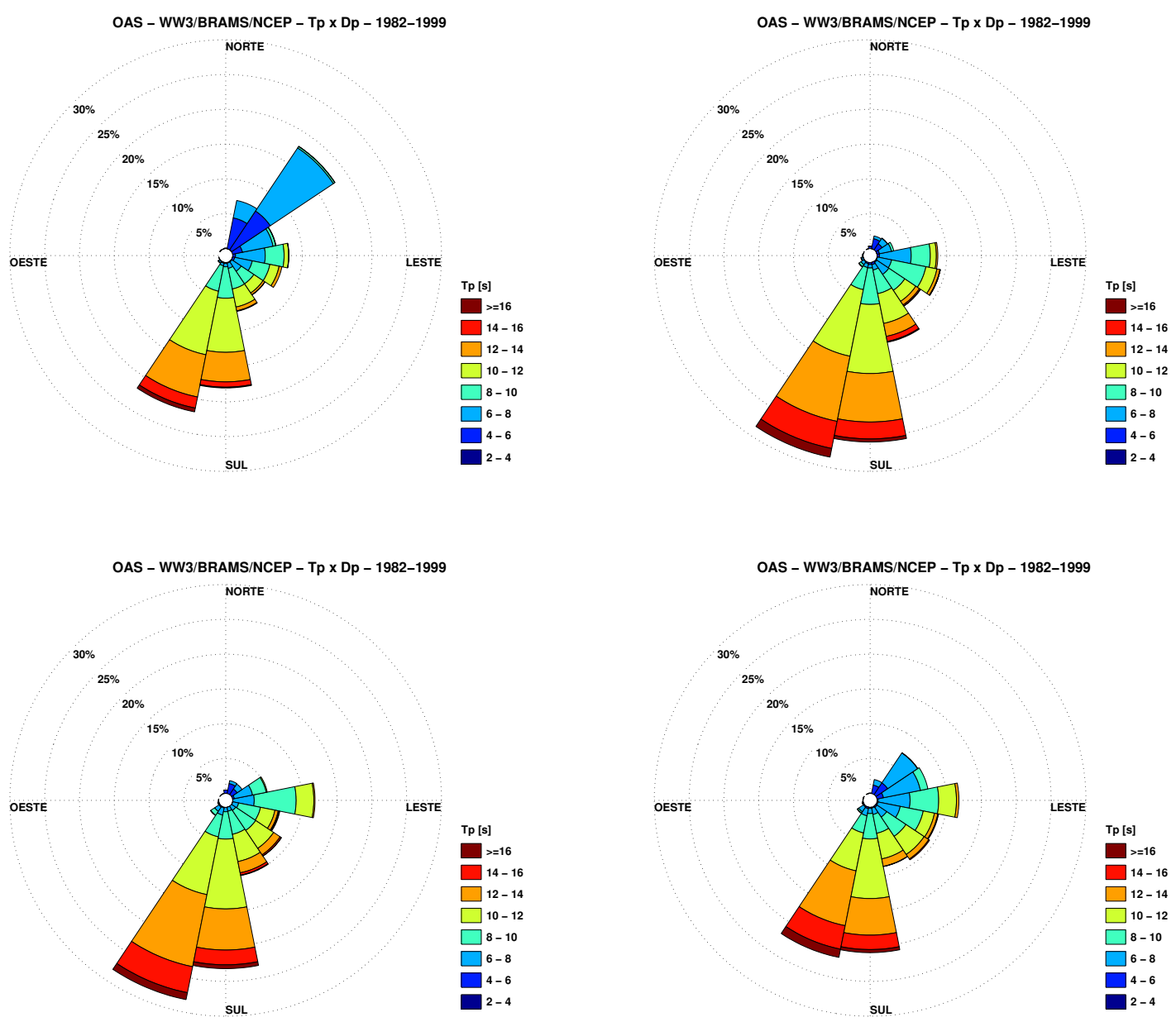

Figura 84 - Histogramas bivariados de Tp X Dp para verão (superior a esquerda), outono (superior a direita), inverno (inferior a esquerda) e primavera (inferior a direita) no ponto BSO. 
Século XX BRAMS/CCSM3
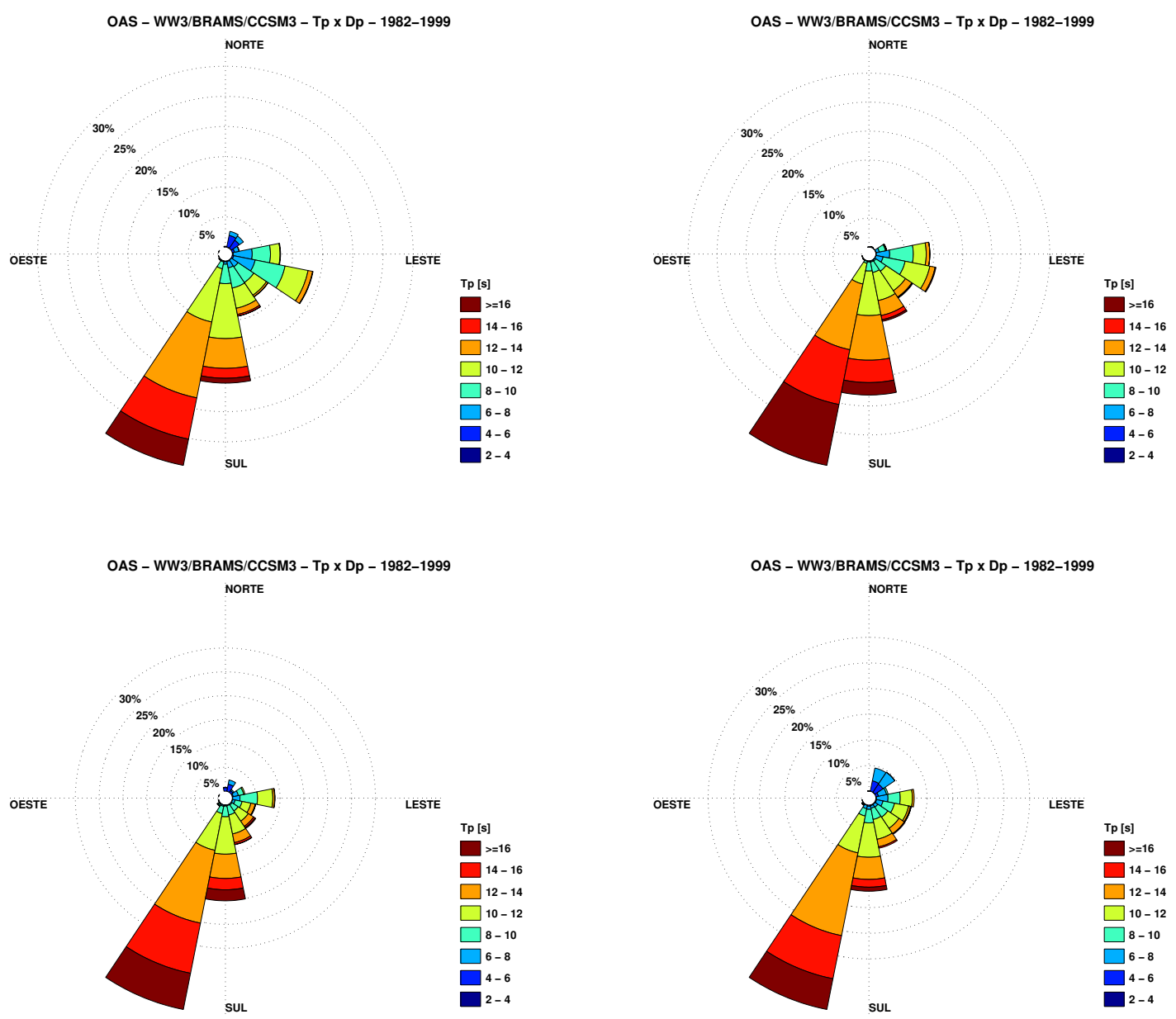

Figura 85 - Histogramas bivariados de Tp X Dp para verão (superior a esquerda), outono (superior a direita), inverno (inferior a esquerda) e primavera (inferior a direita) no ponto BSO. 
Século XXI BRAMS/RESA2
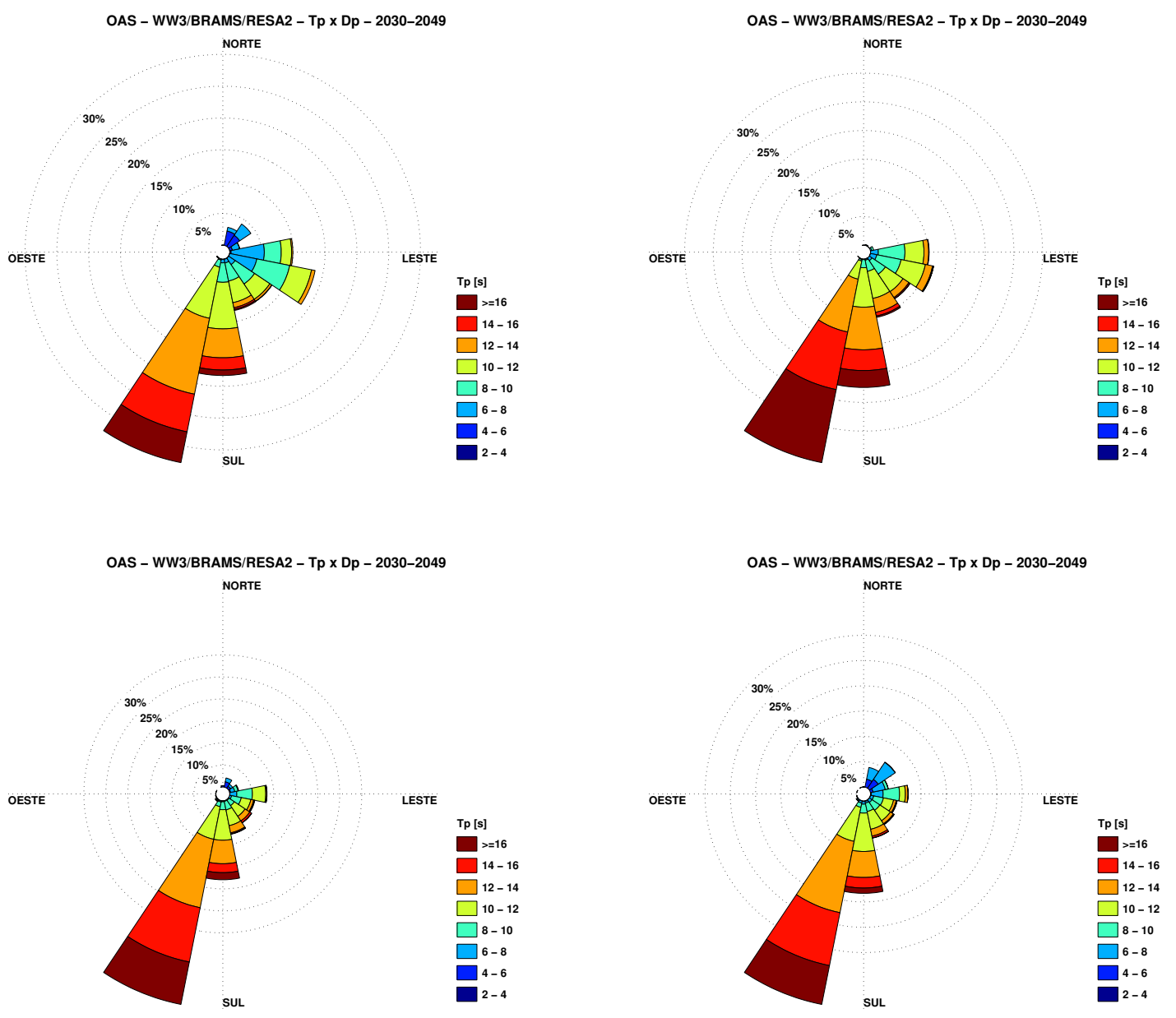

Figura 86 - Histogramas bivariados de Tp X Dp para verão (superior a esquerda), outono (superior a direita), inverno (inferior a esquerda) e primavera (inferior a direita) no ponto BSO. 
Século XXI BRAMS/RESB1
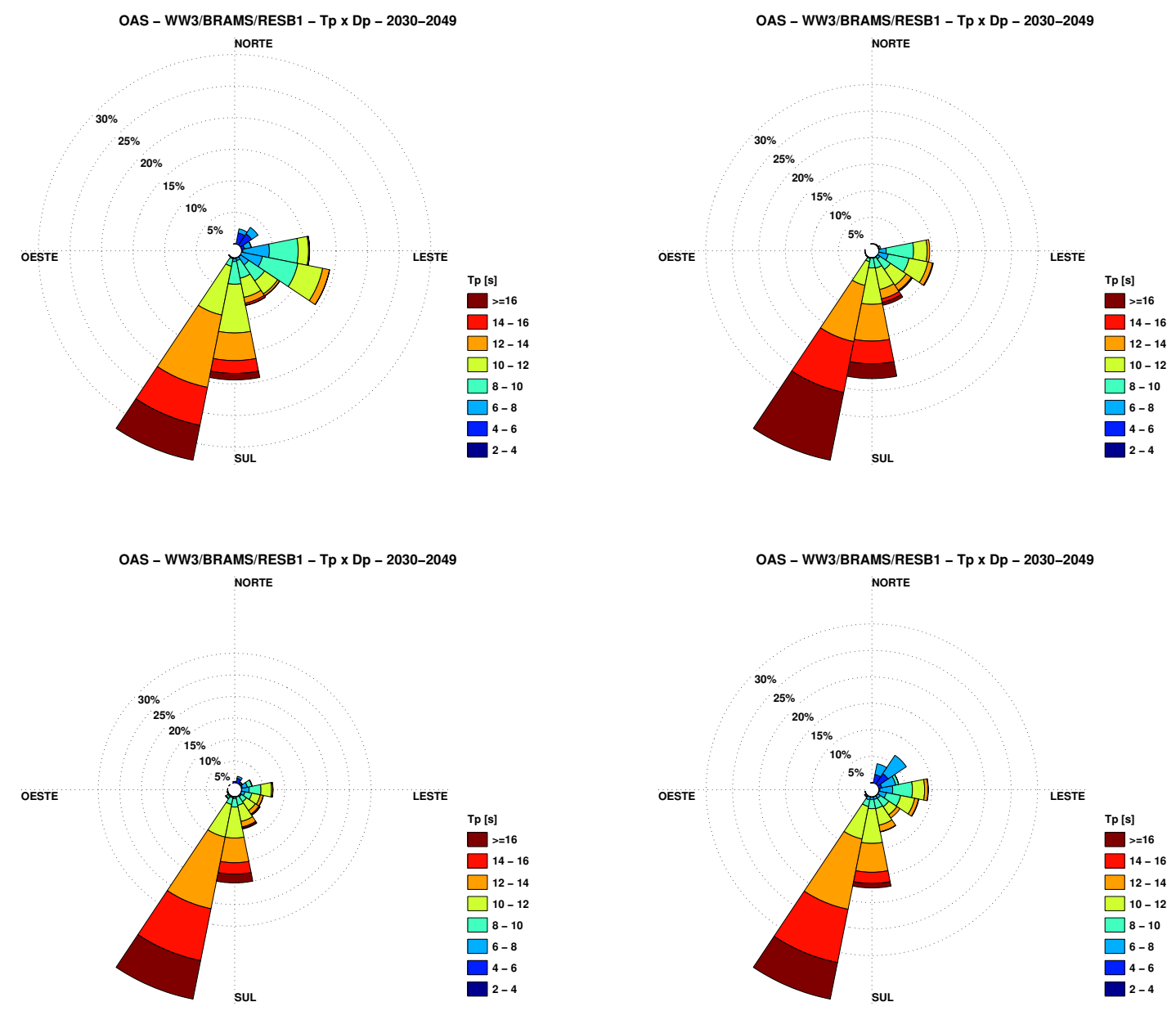

Figura 87 - Histogramas bivariados de Tp X Dp para verão (superior a esquerda), outono (superior a direita), inverno (inferior a esquerda) e primavera (inferior a direita) no ponto BSO. 
Anexo E - Anos Climatológicos dos Conjunos Simulados

\section{Ponto BC}

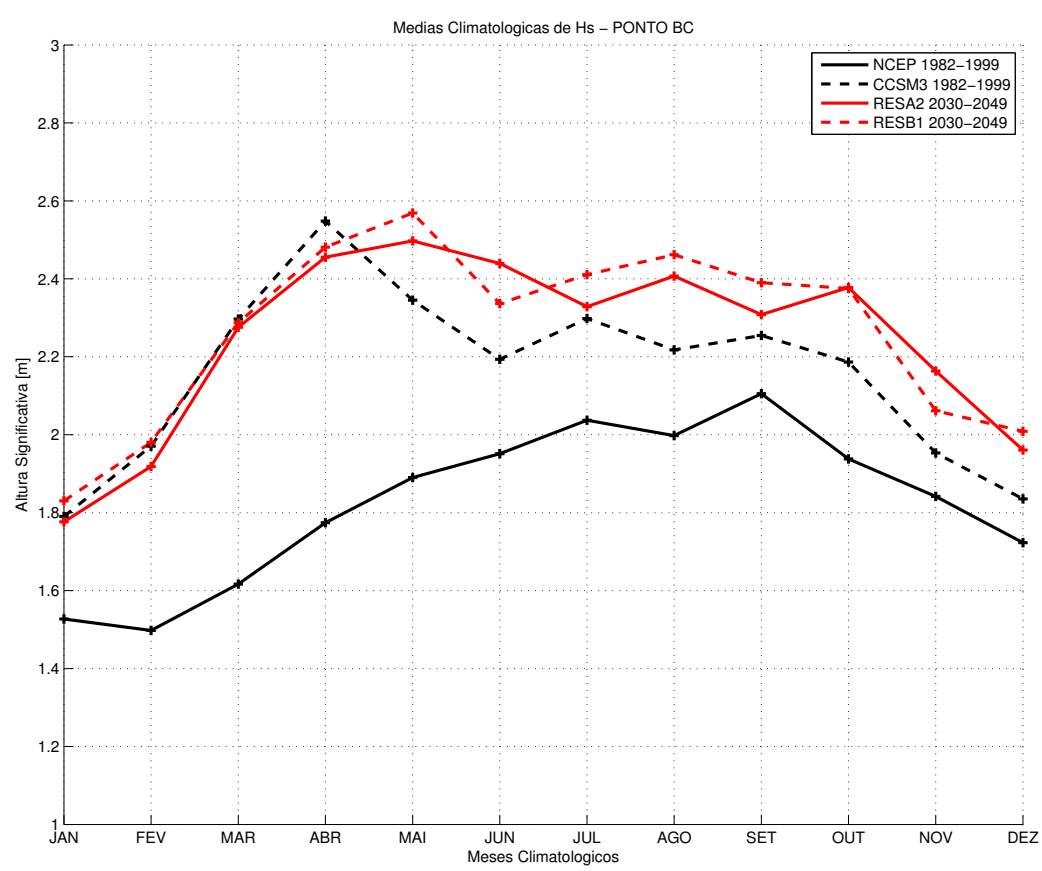

Figura 88 - Ano climatológico de altura significativa no ponto BC. 
Ponto BSO

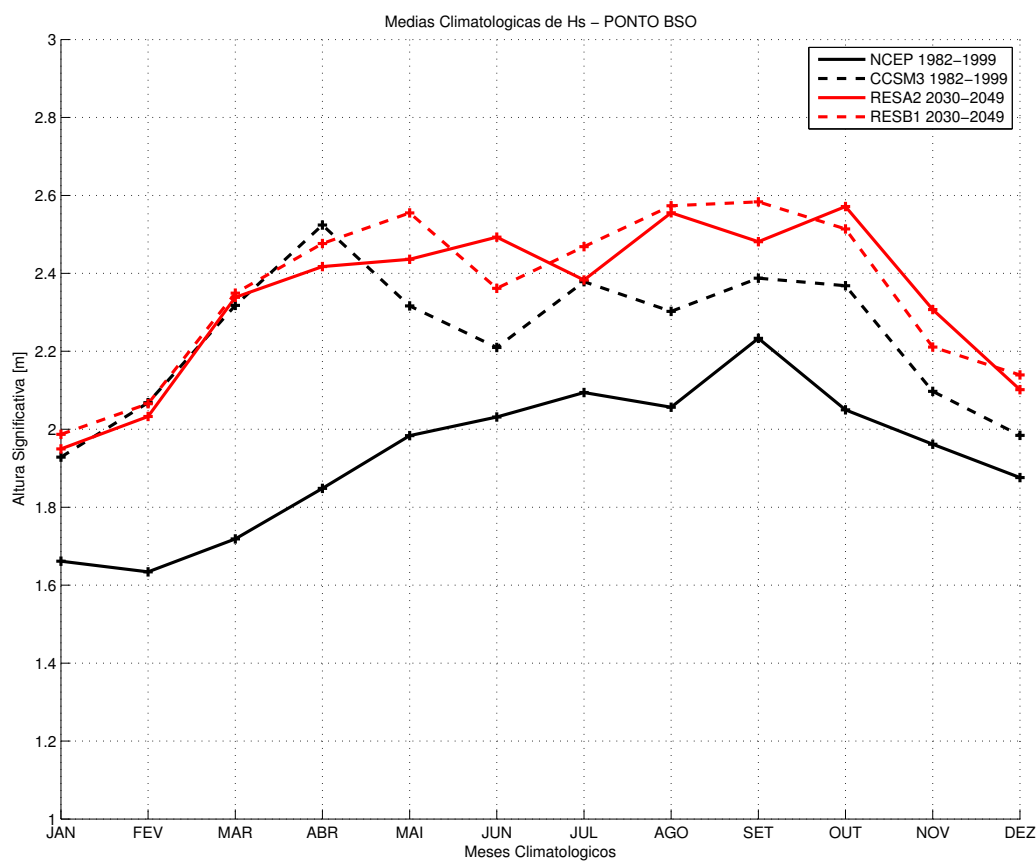

Figura 89 - Ano climatológico de altura significativa no ponto BSO. 